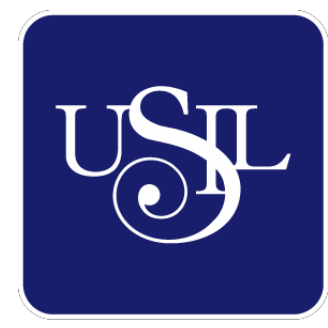

UNIVERSIDAD

SAN IGNACIO

DE LOYOLA

\title{
ESCUELA DE POSTGRADO \\ PLAN DE NEGOCIOS: SERVICIO TURÍSTICO DE AVENTURA EN LA CIUDAD DE PUNO
}

Tesis para optar el grado de:

ANGEL FERNANDO JARA BELTRAN

Maestro en Ciencias Empresariales con Mención en Gestión del Capital Humano

GIANFRANCO VICTOR ARANA ROJAS

Maestro en Ciencias Empresariales con Mención en Gestión Financiera

JANET ERIKA BUTRON BAZAN

Maestro en Ciencias Empresariales con Mención en Gestión de Operaciones

\section{RICHARD ANDRE MEDRANO CORNEJO}

Maestro en Ciencias Empresariales con Mención en Marketing y

Gestión Comercial

Asesor:

Edmundo Rafael Casavilca Maldonado

$$
\text { Lima - Perú }
$$

2018 
"PLAN DE NEGOCIOS: SERVICIO TURÍSTICOS DE AVENTURA EN LA CIUDAD DE PUNO” 
Dedicatoria

El presente plan de negocios está dedicado a Dios, quien ilumina nuestro camino, a nuestros padres y a todos quienes nos han apoyado durante todo este tiempo con su comprensión, experiencias y enseñanzas. 
Agradecimientos

A nuestros docentes quienes nos han guiado en cada momento para elaborar el presente proyecto.

A nuestros padres quienes están constantemente pendientes del desarrollo y camino de nuestras vidas.

A todos quienes nos han brindado su apoyo, sus experiencias personales y profesionales a cada momento. 


\section{Resumen Ejecutivo}

Capachica Aventure es una empresa dedicada exclusivamente al turismo de aventura siendo operadores directos los cuales van a interactuar principalmente con actividades consideradas extremas ya que dentro de ellas se cuenta con ciclismo, caminatas y paseo en moto acuática en el departamento de Puno (Playa Chifrón), la empresa busca proveerle a sus clientes experiencias únicas de contacto con el medio ambiente a través de los hermosos paisajes a recorrer en el circuito. Se cuentan con grandes ventajas a través de un servicio diferenciado y con precios mínimos accesibles en comparación a los que se ofrecen en el mercado ya que, en este caso serán los únicos operadores de este circuito.

La propuesta que contiene este plan de negocio es una respuesta a la necesidad de generar alternativas de diversión y beneficios económicos tanto para la empresa como para las comunidades de la región ya que, no es muy promocionada esta zona ni conocida. Los viajeros solo se enfocan en conocer el Lago Titicaca sin saber que existen otros lugares con paisajes naturales. Para la implementación de este proyecto se han identificado aspectos importantes para el desarrollo del mismo el cual este acorde con las políticas legales, económicas, ambientales y sociales. El estudio de mercado realizado permitió establecer la existencia de la oportunidad de negocio puesto que se observa que no se tiene una competencia directa que ofrezca este circuito.

La empresa será financiada por los accionistas en $43.54 \%$ y el 56,46\% será financiado a través de una institución financiera, por lo cual los socios estarán vinculados laboralmente con la empresa.

En cuanto a la estructura organizacional está conformada por siete empleados distribuidos por áreas. 
La oficina principal se encuentra ubicada en el Jr. Lima de la ciudad de Puno. Se estableció que es de gran importancia asignar gran parte de los recursos para la publicidad ya que, es un servicio innovador que deben conocer para poder explorarlo. El portal web mostrará cómo será el circuito y los horarios, permitirá realizar reservas y pagos por internet. Es de gran importancia mantener capacitado al personal ya que, será un servicio personalizado para cada cliente y orientado a que el cliente experimento nuevas experiencias y diversión.

De acuerdo con la evaluación financiera realizada se evidencia que la agencia Capachica Aventure, es económicamente viable ya que esta presenta un nivel adecuado de rentabilidad obteniendo s/ 450,000 de ventas anuales promedio, tomando en cuenta que el proyecto cuenta con la capacidad de satisfacer la rentabilidad mínima esperada por los inversionistas. 


\section{Executive Summary}

Capachica Aventure is a company dedicated exclusively to adventure tourism being direct operators which will interact mainly with activities considered extreme since within them there is cycling, hiking and jet skiing in the department of Puno (Playa Chifrón), the company seeks to provide its customers with unique experiences of contact with the environment through the beautiful landscapes to be covered in the circuit. There are great advantages through a differentiated service and with accessible minimum prices compared to those offered in the market since, in this case, they will be the only operators of this circuit.

The proposal that contains this business plan is a response to the need to generate alternatives of fun and economic benefits for both the company and the communities of the region since this area is not well known or known. Travelers only focus on knowing Lake Titicaca without knowing that there are other places with natural landscapes. For the implementation of this project, important aspects have been identified for its development, which is in accordance with legal, economic, environmental and social policies. The market study conducted established the existence of the business opportunity since it is observed that there is no direct competition offered by this circuit.

The company will be financed by shareholders at $43.54 \%$ and $56.46 \%$ will be financed through a financial institution, for which the partners will be linked to the company.

As for the organizational structure, it is made up of seven employees distributed by areas.

The main office is located in the Jr. Lima of the city of Puno. It was established that it is of great importance to allocate a large part of the resources for advertising since it is an innovative service that must be known in order to be able to explore it. The web portal will show 
what the circuit and schedules will be like, it will allow making reservations and payments online. It is of great importance to keep the staff trained, since it will be a personalized service for each client and aimed at the client experiencing new experiences and fun.

According to the financial evaluation carried out, it is evident that the Capachica Aventure agency is economically viable since it presents an adequate level of profitability obtaining s/ 450,000 average annual sales, taking into account that the project has the capacity to satisfy profitability minimum expected by investors. 
Índice

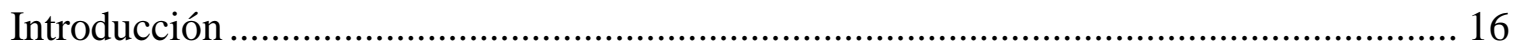

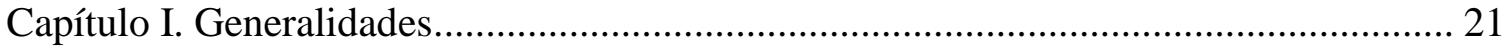

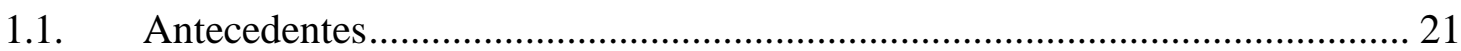

1.2. Determinación del Problema u Oportunidad .............................................. 22

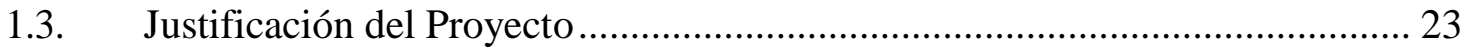

1.4. Objetivos Generales y Específicos ......................................................... 25

1.5. Alcances y Limitaciones de la Investigación .............................................. 26

Capítulo II: Estructura Económica del Sector ........................................................... 27

2.1 Descripción del Estado Actual de la Industria .............................................. 27

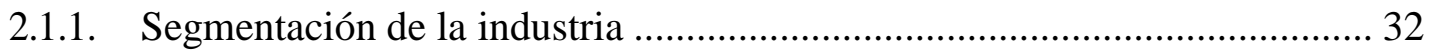

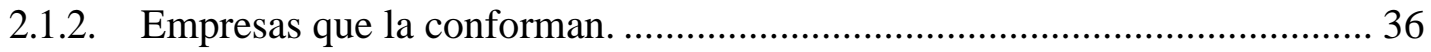

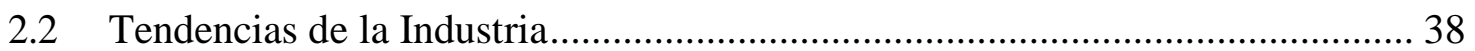

2.3 Análisis Estructural del Sector Industrial................................................. 40

2.4. Análisis de la Competencia .................................................................. 50

2.4.1. Empresas que ofrecen el mismo producto o servicio, indicando las semejanzas y diferencias que tienen con el proyecto de empresa................................... 50

2.4.2. Participación de mercado de cada uno de ellos ........................................ 51

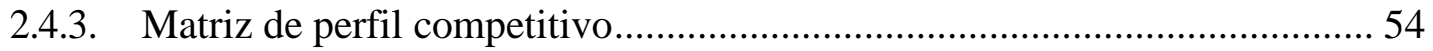

2.5. Análisis del Contexto Actual y Esperado ................................................56 
2.5.1. Análisis político-gubernamental.

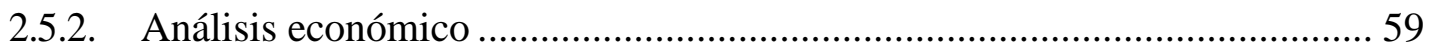

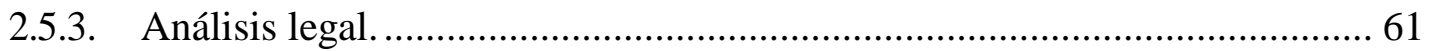

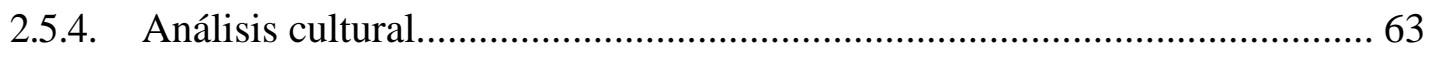

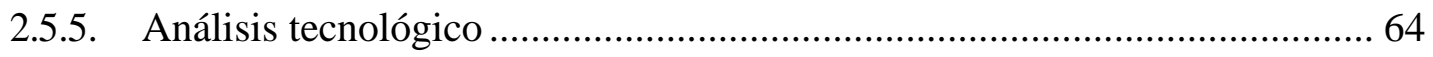

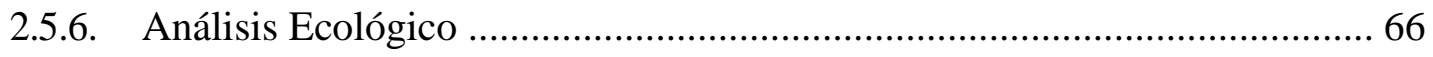

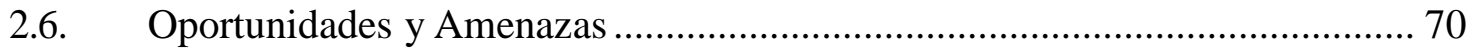

3.1. Descripción del Servicio o Producto .................................................. 73

3.2. Selección del Segmento de Mercado...................................................... 76

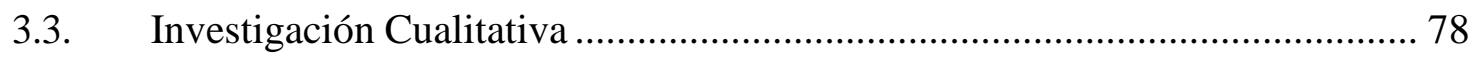

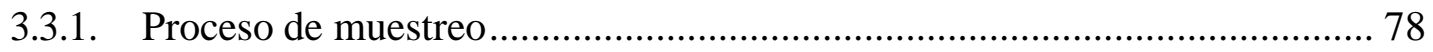

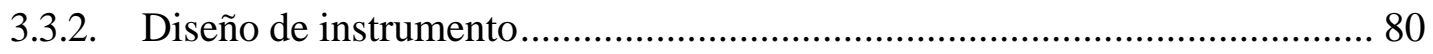

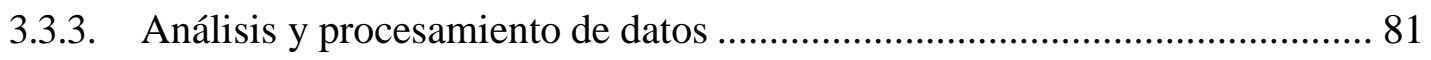

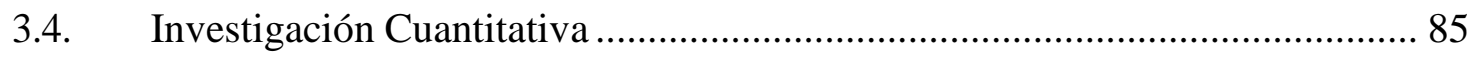

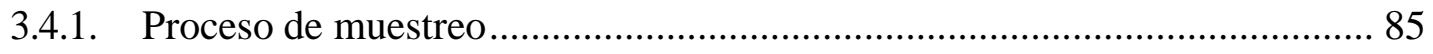

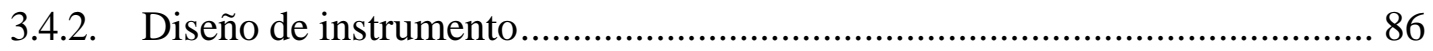

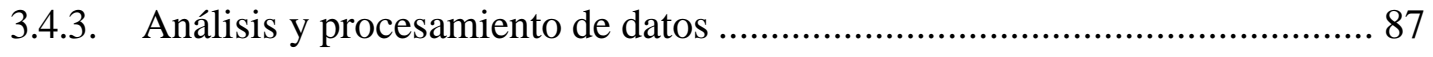

3.5. Conclusiones y Recomendaciones del Estudio Cualitativo y Cuantitativo ... 113

3.6. Perfil del Consumidor Tipo y sus Variantes ........................................... 114

Capítulo IV: Proyección del Mercado Objetivo ....................................................... 116 


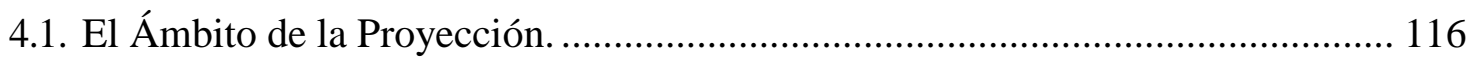

4.2. Selección del Método de Proyección..................................................................... 116

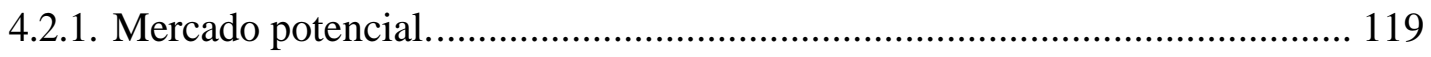

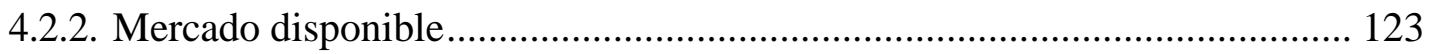

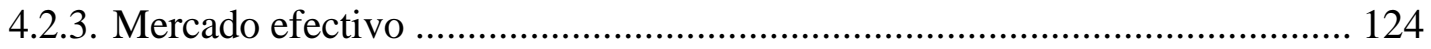

4.2.4. Mercado objetivo ……………………………….................................. 125

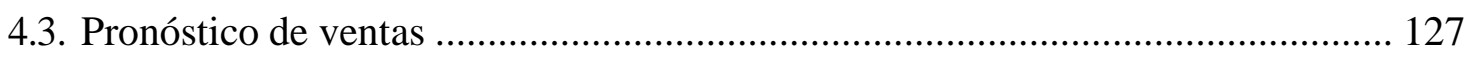

4.4. Aspectos Críticos que Impactan el Pronóstico de Ventas....................................... 127

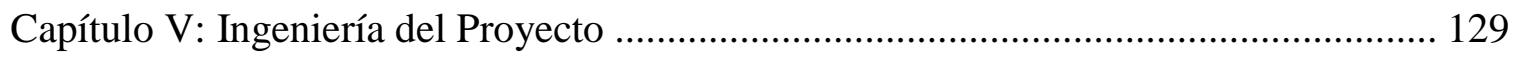

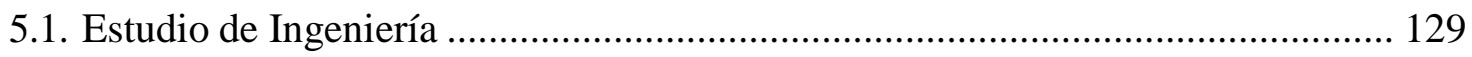

5.1.1. Modelamiento y selección de procesos productivos...................................... 129

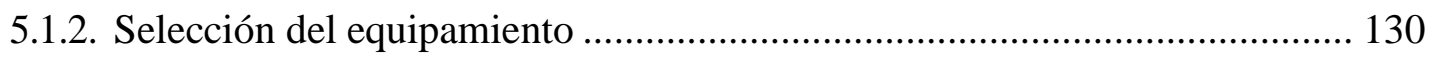

5.1.3. Lay out. 135

5.1.4. Distribución de equipos y maquinarias ............................................................ 136

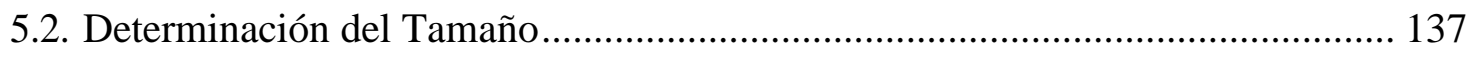

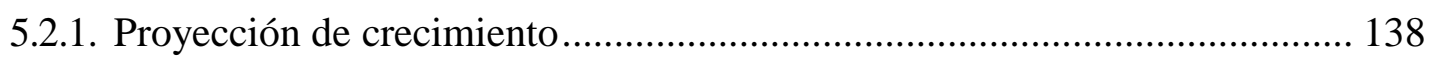

5.2.2. Recursos 138

5.2.3. Tecnología 139

5.2.4. Flexibilidad. 140

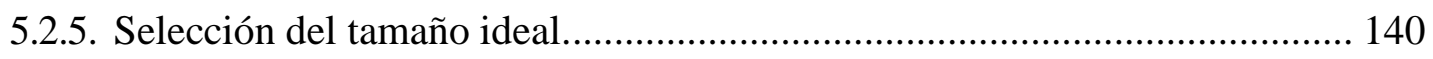


5.3. Estudio de Localización

5.3.1. Definición de factores locacionales

5.3.2. Consideraciones legales.

5.4. Determinación de la Localización Óptima

Capítulo VI: Aspectos Organizacionales

6.1. Caracterización de la Cultura Organizacional Deseada

6.1.1. Visión.

149

6.1.2. Misión.

149

6.1.3. Valores

150

6.2. Formulación de Estrategias del Negocio 151

6.3. Determinación de las Ventajas Competitivas Críticas

6.4. Diseño de la Estructura Organizacional Deseada 155

6.5. Diseño de los Perfiles de Puestos Clave 156

6.6. Remuneraciones, Compensaciones e Incentivos 165

6.7. Política de Recursos Humanos 169

7.1. Estrategias de Marketing

7.1.1. Estrategia de producto

7.1.2. Estrategia de precio

7.1.3. Estrategia de distribución. 183

7.1.4. Estrategia de promoción y publicidad. 185 
7.2. Estrategia de Ventas.

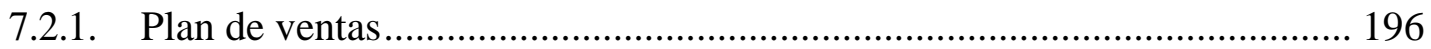

7.2.2. Políticas de servicios y garantías ........................................................... 197

Capítulo VIII: Planificación Financiera................................................................. 200

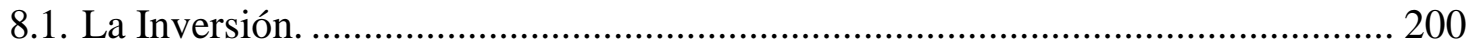

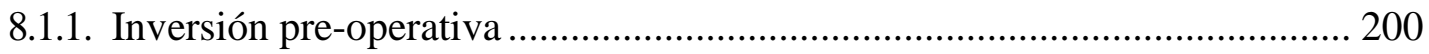

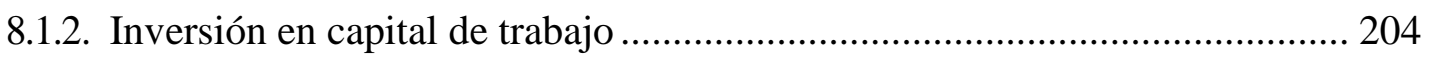

8.1.3. Costo del proyecto............................................................................. 207

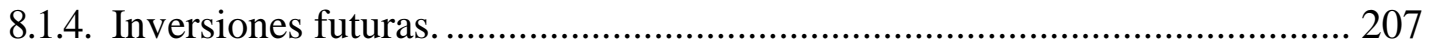

8.2. Financiamiento..................................................................................................................... 207

8.2.1. Endeudamiento y condiciones.............................................................. 207

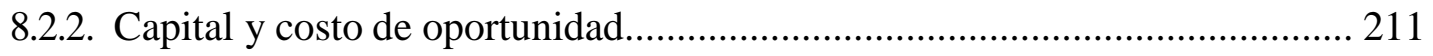

8.2.3. Costo de capital promedio ponderado.................................................... 214

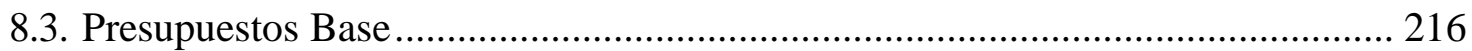

8.3.1. Presupuesto de ventas ................................................................................. 216

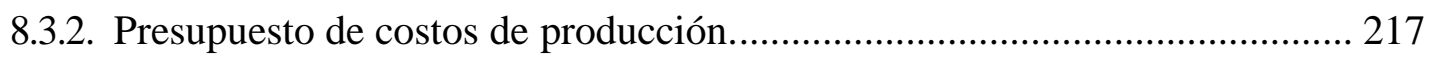

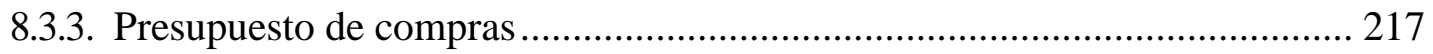

8.3.4. Presupuesto de costo de ventas. ................................................................ 218

8.3.5. Presupuesto de gastos administrativos..................................................... 222

8.3.6. Presupuesto de marketing y ventas ...................................................... 225 


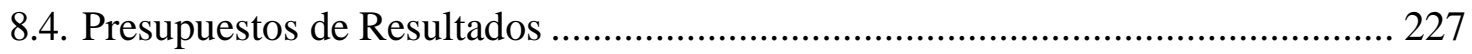

8.4.1. Estado de ganancias y pérdidas proyectado........................................... 227

8.4.2. Balance proyectado.......................................................................... 229

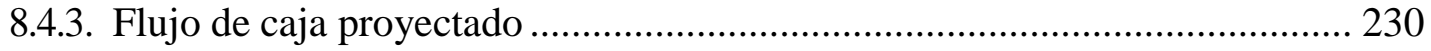

Capítulo IX: Evaluación Económico Financiera ....................................................... 233

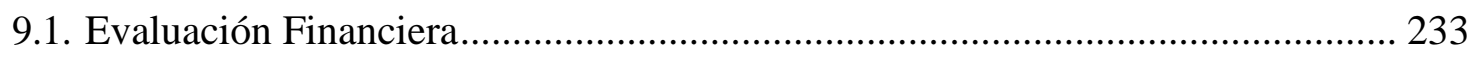

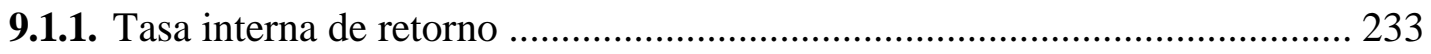

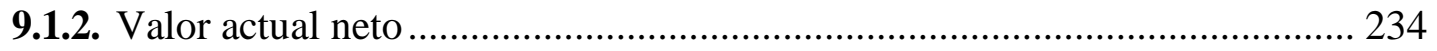

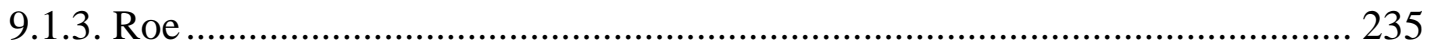

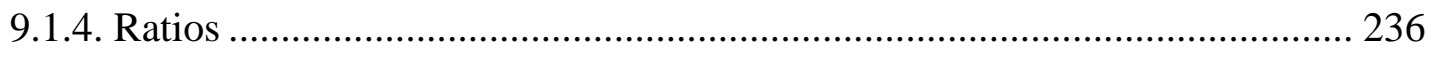

9.2. Análisis de Riesgo............................................................................................... 237

9.2.1. Análisis de punto de equilibrio. .................................................................... 237

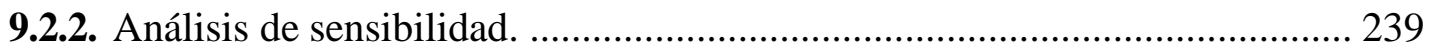

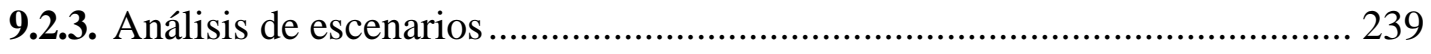

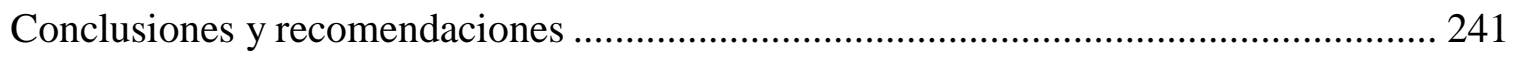

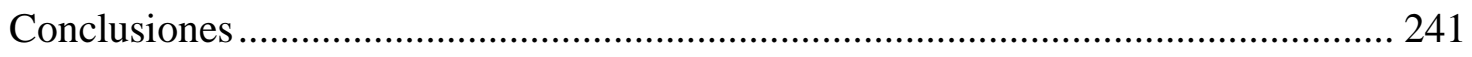

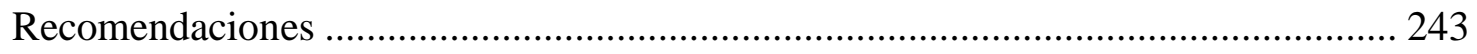

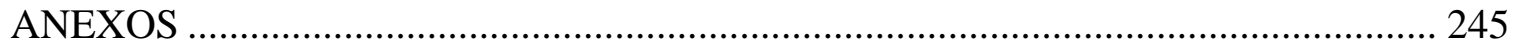

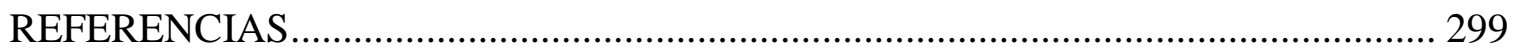




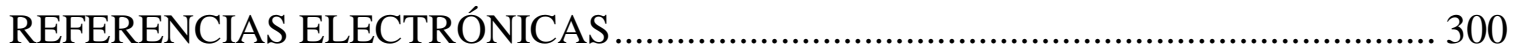




\section{Introducción}

Esta sinopsis será preámbulo para exponer el presente plan de negocios; el cual consiste en brindar servicios de turismo de aventura en el departamento de Puno. El proyecto será desarrollado en las playas del lago Titicaca en el departamento de Puno. Se enfocarábásicamente al habitante de la ciudad de Puno como a turistas nacionales que buscan realizar actividades de aventura y que gusten de apreciar de paisajes naturales. No se considerará agencias de viaje como mercado a analizar ya que, empresas del rubro trabajan bajo precios estables durante el año, lo cual no permitirá obtener una buena rentabilidad en fechas y meses de alta demanda. Se brindarán servicios de caminata o paseo en bicicleta, actividades complementarias pero necesarias para llegar al destino y el recorrido en el lago Titicaca en motos acuáticas.

El desarrollo del presente plan de negocios comprende los siguientes capítulos:

Capítulo I: Dentro de este capítulo observamos crecimiento del sector turismo a nivel mundial ha ido en aumento año tras año en un promedio $4 \%$ por año. Asimismo hay que destacar que el sector turismo representa un 10\% del producto bruto interno (PBI) mundial.

Respecto a la región de Puno, con importantes destinos turísticos, el arribo de turistas a la Reserva Nacional del Titicaca en los últimos cinco años ha crecido un promedio de $13 \%$.

La oportunidad para desarrollar turismo de aventura en el departamento de Puno radica en los paisajes naturales extensos, clima idóneo, poca oferta de servicios de aventura, y hay la posibilidad de desarrollar zonas poco visitadas.

Siendo el objetivo del presente proyecto realizar un plan de negocios para implementar una empresa de servicios de circuitos turísticos de aventura en las playas del Lago Titicaca en la región Puno. 
Cabe indicar algunas limitaciones que presenta el siguiente proyecto como la falta de información sobre los servicios de aventura, la informalidad de las empresas que realizan estos servicios, la poca predisposición de la población a ser encuestadas y el poco conocimiento de actividades de aventura en los pobladores de la región.

Capítulo II: Dentro del capítulo dos se determinó la clasificación del rubro turístico la cual es CIUU secundario: Actividades de agencias de viajes y organizadores de viajes y actividades de asistencia a turistas CIUU 6304. Así como los principales organismos que lo regulan.

Mediante la evaluación del perfil del turista se determinó el gasto promedio que es de S/.360 soles y la estadía entre 1 a 6 noches, siendo los lugares más visitados en Perú: Arequipa, Cusco, Puno, Iquitos y Lima.

La industria esta segmentada por distintas categorías de turismo ya sea de aventura, cultural, naturaleza, rural, urbano. Cada uno se vuelve más exigente al pasar de los años por la tecnología.

Se debe tener en consideración las fuerzas de Porter ya que, estas ayudan a analizar a los competidores, clientes, proveedores, por lo que se obtuvo un resultado total de tres y se llega a la conclusión de que la industria es atractiva y se pueden mejorar varios puntos a favor.

Dentro de las empresas que consideramos como competencia solo tres son las más conocidas ya que, en este rubro muchas de ellas son informales, se hizo una investigación mediante el número de turistas que ingresan a Perú, reporte de endeudamiento, pagina web de comentarios. Así como mediante la matriz de perfil competitivo se determinó cual era la agencia con mayor potencial por lo que se debe tomar en cuenta los valores para mejorar. En cuanto a los análisis culturales y ecológicos se tiene mucho cuidado ya que, el Lago es considerado una 
maravilla y estar al tanto del cuidado de la biodiversidad es un punto muy importante dentro de las políticas de la empresa.

Capítulo III: En el capítulo se describirá el servicio a brindar, se determina la segmentación de mercado y se procederá a realizar la investigación de mercados mediante técnicas de investigación cualitativas y cuantitativas.

Se define para el estudio cualitativo entrevistas a profundidad con expertos del sector y se realizan sesiones de grupo también llamados focus group para identificar usos, costumbres, actitudes y reacciones de posibles cliente hacia el proyecto.

Asimismo para el estudio cuantitativo se realiza encuestas en la zona de influencia, en este caso la ciudad de Puno ya que, es la ciudad donde hay una mayor cantidad de arribos tanto de turistas nacionales e internacionales y es la ciudad más poblada del departamento.

Finalmente con la información recabada se define el perfil de clientes deseado y se obtiene los datos necesarios para la proyección de la demanda.

Capítulo IV: De acuerdo a la estadística del mercado se proyectará una posible demanda para los servicios de turismo de aventura los cuales se completan con datos demográficos y arribo de turistas según información oficial del MINCETUR e INEI. Con ello se realizará un pronóstico de venta del proyecto que complementará la evaluación financiera.

Capítulo V: Dentro de la ingeniería del proyecto se busca determinar con exactitud cuál sería la localización óptima, cual va ser el inmobiliario que se requiere para realizar todo el circuito, motos acuáticas, bicicletas, tecnología como la Go pro, drones. El flujo de procesos, mediante la simbología ASME, inicia en el proceso de venta del circuito la cual se realiza en el centro de la ciudad aunque también hay la opción de hacerlo por página web o llamadas, proceso de traslado a la playa terminando en la misma plaza de armas. 
En cuanto a la evaluación de lay out se tomó en cuenta la ubicación de la oficina que estará ubicada en la calle principal de la Plaza de armas, y la playa que fue elegida por puntuación. Todos estos recursos son la principal preocupación de la empresa porque se debe contar con el personal capacitad, materia prima y tecnología.

Dentro de los factores de localización se tomó en cuenta las facilidades de acceso, energía eléctrica, abastecimiento de combustible, mercado, disponibilidad y confiabilidad de sistemas de apoyo, actitud de la comunidad. Así también las normas y leyes para la constitución de la empresa y los requisitos básicos.

Capítulo VI: En el presente capitulo damos a conocer la importancia de la estructura organizacional, su visión y misión teniendo como soporte los valores siendo a fin de cuentas la filosofía para la organización. Desde un punto de vista estratégico se formula las diversas estrategias a seguir como en la parte de la organización, marketing, finanzas e ingeniería, así también se describe las ventajas competitivas de la empresa frente a las ya existentes que prestan similar servicio. Cabe mencionar dentro de la estructura de la organización el organigrama delimitado por áreas y funciones de cada uno de nuestros puestos, esto según el perfil de puesto elaborado. Se plantean políticas que son las guías para tomar decisiones que nos ayuden a lograr el tipo de organización que se busca ser.

Capítulo VII: En el capítulo Se analizará las mejores estrategias de marketing para entrar en el mercado a competir con servicios tradicionales de paseos en lancha. Se enfocará el negocio brindar un servicios innovadores donde los beneficios percibidos por los clientes sean mayores a sus expectativas.

Se perfilará el servicio con diversas alternativas que ayudarán al cliente a percibir como principal atributo del servicio: "la diversión" y las "nuevas experiencias". 
Se realizará un análisis de precios de la competencia. Se tendrá diversas estrategias de acuerdo al tipo de cliente como promociones, precios especiales y descuentos.

Se define diversos canales de atención y distribución del servicio con el objetivo de diversificar las formas de llegar hacia los clientes.

La publicidad de boca en boca es uno de los principales medios que usará la empresa junto con una buena estrategia de medios a través de las redes sociales para poder generar la afluencia de personas deseada. Por último, se describe las garantías y políticas del servicio a brindar.

Capítulo VIII y IX: La planificación financiera es un proceso en virtud del cual se proyecta y se fijan las bases de las actividades financieras, con el objeto de minimizar el riesgo, aprovechar las oportunidades y los recursos.

El presente proyecto tiene por finalidad identificar todas las inversiones que se realicen para el funcionamiento del proyecto, el capital de trabajo necesario que se necesitará para funcionar, así como también mostrar el financiamiento del proyecto, el costo del accionista, el costo de oportunidad de invertir en dicho proyecto, desde un punto básicamente financiero, el cual tiene como objetivo cubrir las expectativas del inversionista en la rentabilidad como en su funcionamiento. 


\section{Capítulo I. Generalidades}

\subsection{Antecedentes}

En los últimos años, el crecimiento del sector turismo a nivel mundial ha ido en aumento año tras año desde el año 2009. Aproximadamente, el ritmo de crecimiento en estos años ha aumentado en un promedio del $4 \%$ por año, medido por las llegadas de turistas internacionales a los diversos países. Asimismo hay que destacar que el sector turismo representa un $10 \%$ del producto bruto interno (PBI) mundial, el 30\% de la exportación de servicios, genera un mercado de USD 1.5 trillones en la exportación mundial de servicios y 1 de cada 11 empleos pertenecen a este sector a nivel mundial (Organización Mundial del Turismo [OMT], 2016).

Las perspectivas según OMT (2016) indican que las llegadas de turistas internacionales podrían alcanzar un crecimiento entre $3.5 \%$ a 4,5\% a lo largo del presente año. Se espera superar para el presente año la cifra del año 2015 que llegó a 1,186 millones de arribos de turistas internacionales.

También hay que destacar que el segmento para turismo de aventura ha crecido enormemente llegando a representar al año 2015 un mercado total de USD 263 billones, solamente entre el año 2009 al 2012, este subsector ha crecido un 65\% según Adventure Travel Trade Association (2016).

Respecto al ámbito nacional el Producto Bruto Interno (PBI) del sector turismo ha contribuido con el PBI total en 6.9\% al año 2015. El ingreso por divisas representó un monto ascendente a USD 4,451 millones lo cual significó un crecimiento respecto al 2011 de 47,5\% al año 2015. La actividad de agencias de viaje representa el 3.2 \% del PBI turístico total al año 2015, siendo la actividad principal del sector el transportes de pasajeros que representa el $27 \%$ del total del PBI turístico. 
Según Henry Catacora Mayta, director regional de Comercio Exterior y Turismo de la región Puno, indicó que en la región Puno llegó a recibir 460 mil turistas a julio del año 2015, teniendo como principales destinos: (a) Islas de los Uros, Taquile y Amantani, (b) Templos coloniales de Juli y de la fertilidad, (c) Complejos arqueológicos de Sillustani y Pucará. Por otro lado, el arribo de turistas a la Reserva Nacional del Titicaca en los últimos cinco años ha crecido un promedio de $13 \%$ por año llegando a un total de arribos de 150624 personas entre nacionales y extranjeros (Ministerio de Comercio Exterior y Turismo [MINCETUR], 2017).

Según la Organización Mundial de Turismo ([OMT], (2016) el turismo consiste en los viajes y estancias que realizan personas en lugares distintos a su entorno habitual (al menos durante una noche y como máximo 365 días), por ocio, negocios u otros motivos. Si no se realiza pernoctación, se consideran excursionistas.

\subsection{Determinación del Problema u Oportunidad}

El Perú es actualmente el tercer país en Sudamérica con mayor potencial para desarrollar turismo de aventura. Según el informe Adventure Tourism Development Index ([ATDI], 2015) el Perú está mejor posicionado que Argentina y Brasil para desarrollar este mercado pese a que la imagen de dichos países es más fuerte que la peruana. Asimismo los deportes más realizados por los turistas en el Perú según la Comisión de Promoción del Perú para la Exportación y el Turismo ([PROMPERU], 2008) son el trekking, montañismo, canotaje y ciclismo. Siendo el perfil de los turistas en su mayoría solteros, mayores de 44 años, y originarios de Estados Unidos y España.

La región de Puno recibió unos 495 mil visitantes el año 2015 creciendo para el presente año entre enero y agosto un $26.7 \%$. Existe una oferta de hospedaje de 653 hospedajes y el 
promedio de estancia es de 1.07 días; (Comisión de Promoción del Perú para la Exportación y el Turismo [PROMPERU], 2016). Se desarrolla más un turismo cultural y vivencial.

Hay oportunidad para desarrollar turismo de aventura en el departamento de Puno ya que, cuenta con paisajes naturales extensos, clima idóneo durante casi todo el año, hay poca oferta de servicios de aventura, y hay la posibilidad de desarrollar zonas poco visitadas consiguiendo apoyo de las comunidades para la oferta y promoción de los servicios.

\subsection{Justificación del Proyecto}

Se contribuirá mediante técnicas de investigación la identificación de los gustos y preferencias de los turistas nacionales y locales respecto a servicios de aventura. Asimismo, el propósito final del plan de negocios será una posterior implementación del mismo y expansión de servicios en el departamento de Puno. Por tanto, se planteará diversas estrategias y alianzas para mantener y generar una buena afluencia de turistas nacionales.

El presente proyecto se realizará por las siguientes razones:

a. El crecimiento del sector turismo en los últimos años que pese al decrecimiento de otros rubros, ha mantenido una evolución favorable y constante.

b. A finales del año 2015 según la Cámara Nacional de Turismo ([CANATUR], 2015) el sector ha generado unos US\$ 3,500 millones de ingresos.

c. El turismo interno ha tenido un crecimiento del $9 \%$ representando por 41.3 millones de viajes y el turismo receptivo un $7 \%$. En promedio un turista nacional realiza viajes internos por 5 días y gasta unos 90 soles diarios durante su estancia (PROMPERU, 2015). 
d. Por último, el PBI per cápita del departamento de Puno es de S/ 6,093(Aurum

Consultoría y Mercado, 2016) lo cual da condiciones de tener un mercado adecuado y favorable para el proyecto.

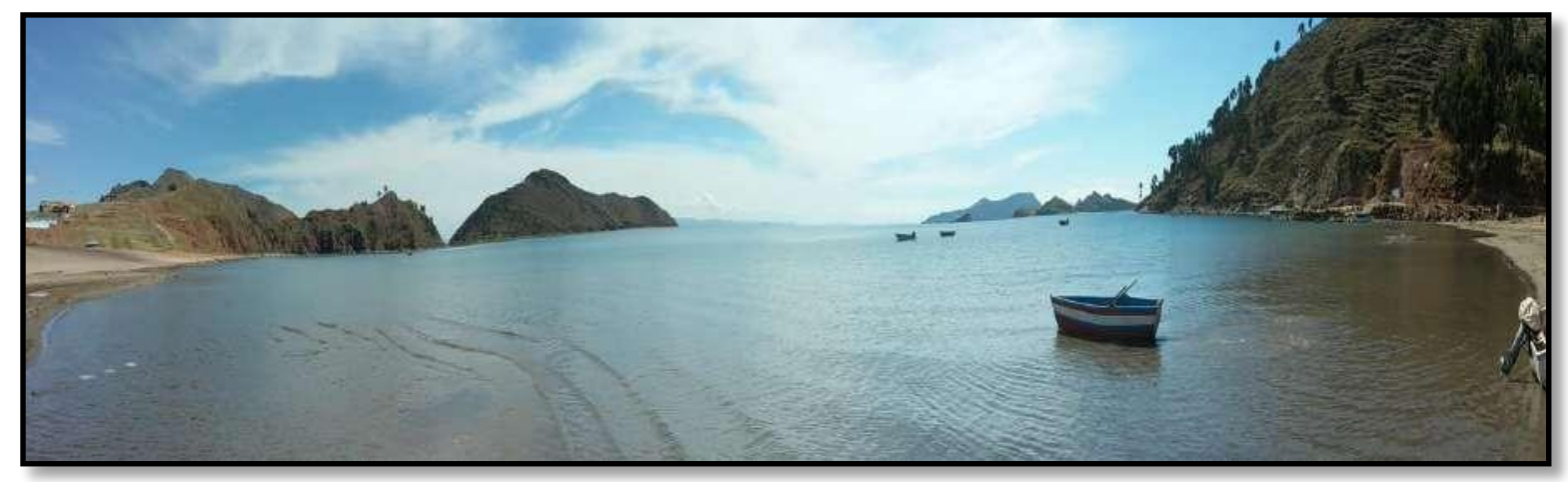

Figura 1. Paisaje playa Capachica donde se realizará el servicio de motos acuáticas.

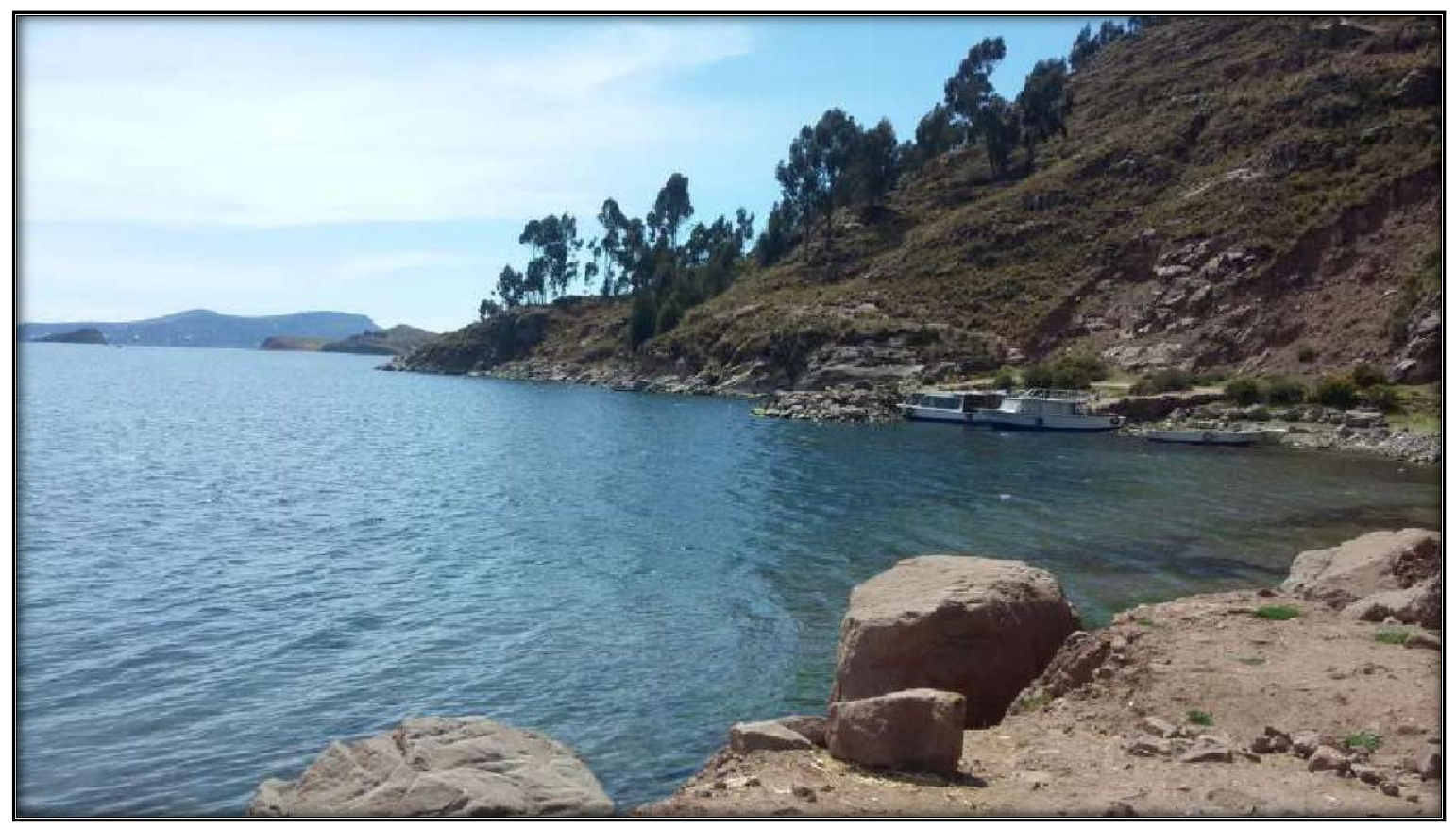

Figura 2. Servicios que se prestan en la actualidad. Lanchas tienen como ruta las Islas de Amantani. 


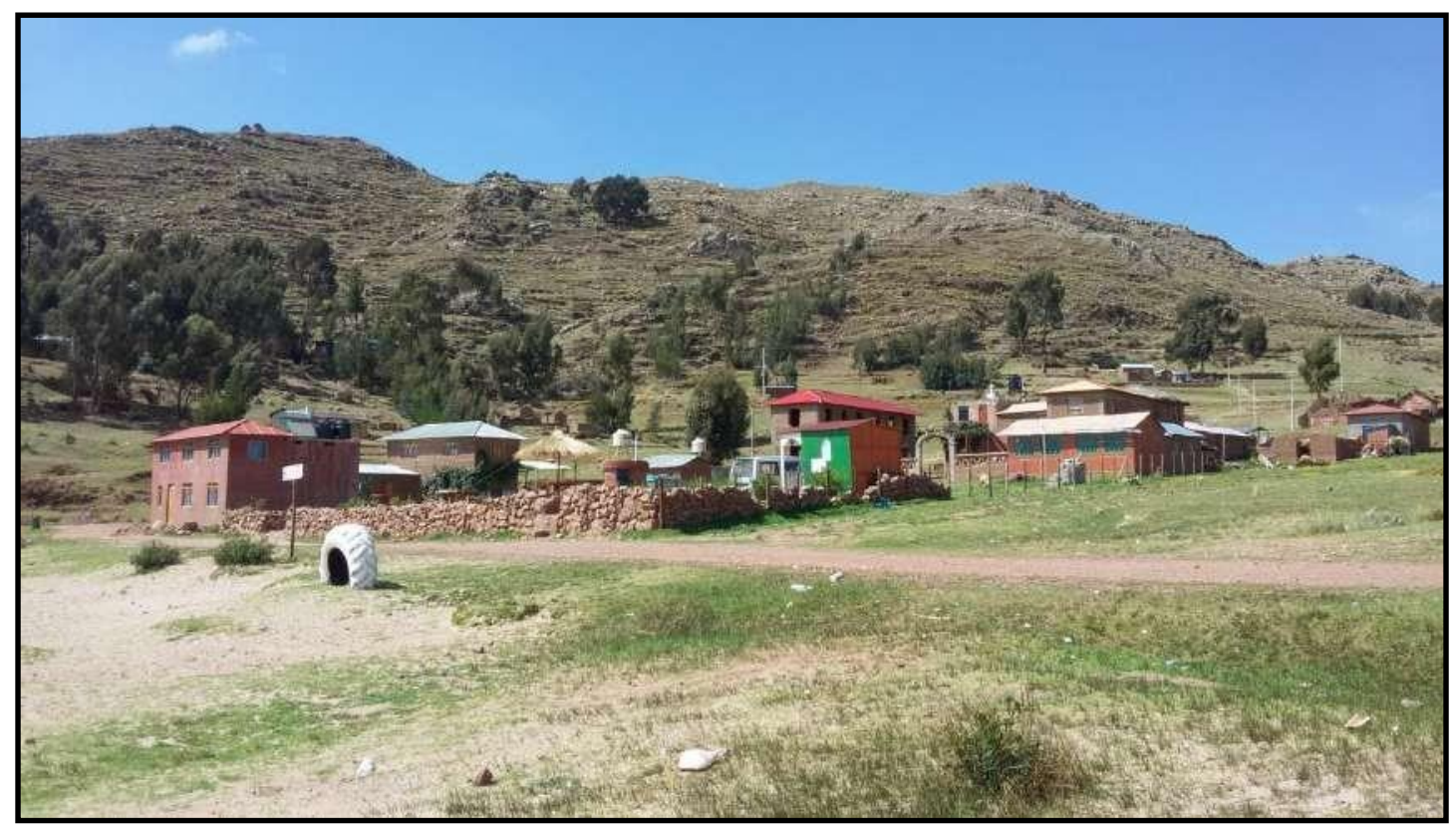

Figura 3. Servicios que se prestan en la actualidad. Hoteles y restaurantes.

\subsection{Objetivos Generales y Específicos}

Objetivo general:

Realizar un plan de negocios para implementar una empresa de servicios de circuitos turísticos de aventura en las playas del Lago Titicaca en la región Puno.

Objetivos Específicos:

a. Analizar la estructura y tendencias de la industria del turismo de aventura en la región Puno.

b. Analizar mediante un estudio de mercado las preferencias y gustos de los turistas nacionales y turistas locales que buscan servicios de circuitos de aventura.

c. Conocer los circuitos turísticos de aventura ofrecidos por la competencia directa en el sector turismo en la región Puno. 
d. Definir una estructura organizacional y operacional flexible orientada al proyecto.

e. Realizar un plan de marketing, conociendo gustos y preferencias de los turistas nacionales y locales.

g. Desarrollar el plan financiero del proyecto para determinar su viabilidad.

\subsection{Alcances y Limitaciones de la Investigación}

El proyecto tendrá un alcance regional en el departamento de Puno buscando a mediano plazo ser una de las principales empresas en desarrollar el turismo de aventura en dicha región. La zona donde se brinde el servicio se complementará con servicios brindados por las comunidades aledañas de modo que se generen sinergias y nuevas oportunidades de crecimiento.

Como principales limitaciones se tiene:

a. La falta de información sobre el subsector de servicios de aventura en el Perú. El poco tiempo de estancia del turista nacional limitara la cantidad de actividades a realizar en el paquete de viajes propuesto.

b. La informalidad laboral y empresarial no ayuda a determinar la verdadera capacidad de pago e ingresos de las ciudades de Puno y Juliaca.

c. El poco conocimiento de la población sobre actividades de aventura en el departamento de Puno. 


\section{Capítulo II: Estructura Económica del Sector}

\subsection{Descripción del Estado Actual de la Industria}

Según la clasificación internacional industrial uniforme (CIUU), el rubro al que corresponde la empresa es el siguiente.

a. CIUU principal: Actividades de transporte complementarias y auxiliares y actividades de agencias de viajes.

b. CIUU secundario: Actividades de agencias de viajes y organizadores de viajes y actividades de asistencia a turistas CIUU 6304.

Según Medlik \& Burkat (2013), el turismo puede definirse como el conjunto de las acciones que una persona lleva a cabo mientras viaja y pernocta en un sitio diferente al de su residencia habitual por un periodo de consecutivo que resulta inferior a un año. Hoy el turismo es una de las industrias más importantes a nivel mundial y promueve viajes de todo tipo: con fines de descanso, motivos culturales, interés social, negocios o simplemente ocio.

Los organismos internacionales que conforman la industria turística son los siguientes:

a. Organización Mundial del Turismo (OMT)

La OMT es el principal organismo en el campo de los viajes y turismo, que representa un foro mundial para cuestiones de política turística y una fuente práctica de conocimientos específicos.

b. Consejo Mundial de Viajes y Turismo (WTTC)

Es el foro mundial de líderes de negocios en viajes y turismo, incluyendo alojamiento, catering, entretenimiento, recreación, transporte y otros servicios afines. 


\section{c. Comunidad Andina - Rutas Turísticas Andinas}

Esta web permite promover el turismo regional, a través de la exhibición, difusión y eventualmente creación de "paquetes especiales", con el apoyo del sector privado, de los principales atractivos turísticos de cada uno de los países de la subregión.

MINCETUR ha desarrollado el Plan Estratégico Nacional de Turismo (PENTUR) 2008-

2018, como guía de planificación que orienta el desarrollo sostenible y competitivo de la actividad turística del Perú, para impulsar en el sector, la inversión pública e inversión privada en el corto, mediano y largo plazo. El mercado laboral nacional ofrece al sector turismo, disponibilidad de recursos humanos (mincetur.pe, 2012)

En los últimos años el turismo interno en el Perú ha mostrado un crecimiento anual llegando a un total de 39,8 millones.

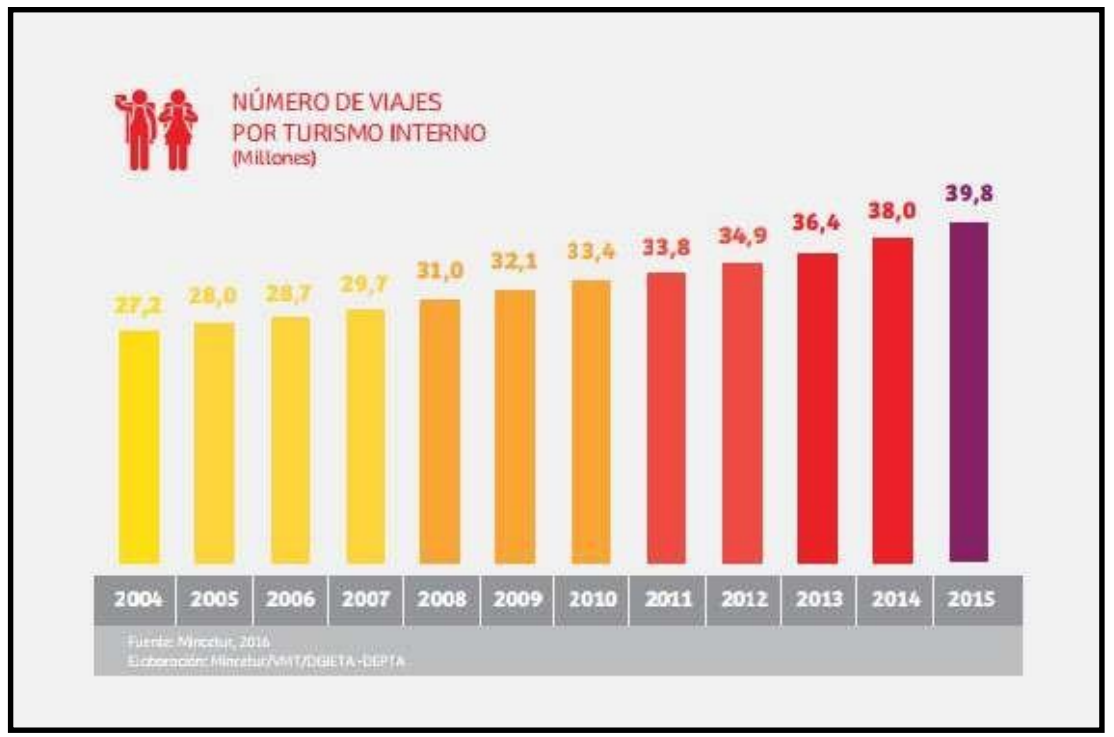

Figura 4. Número de viajes por turismo interno. Tomado de MINCETUR, 2016. Recuperado de http://ww2.mincetur.gob.pe/wp- 
Así también mostramos el perfil del turista nacional.

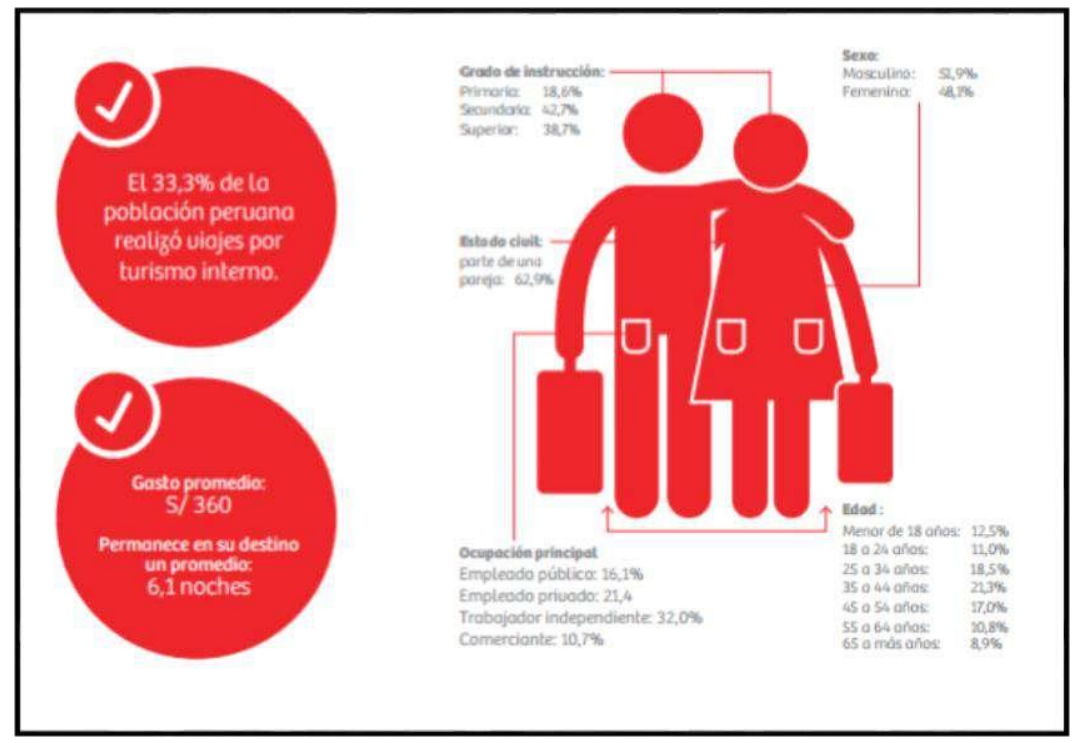

Figura 5. Perfil de turista nacional. Tomado de MINCETUR, 2016. Recuperado de http://ww2.mincetur.gob.pe/wpcontent/uploads/documentos/turismo/documentos/PENTUR/PENTUR_Final_JULIO2016.pdf

El turista interno realiza un gasto promedio de S/ 360 y su estadía aproximada en el destino tiene un promedio de 6,1 noches. Suelen pernoctar casa de familiares y/o amigos; utilizan en gran parte líneas de transporte terrestre interprovincial; y prefieren realizar un tour por cuenta propia.

El turismo de aventura tuvo un incremento del $72 \%$, considerando este un nicho de mercado por explotar a pesar de las turbulencias económicas y para los destinos supone además 
una fuente de ingresos por viajero superior a la de otras categorías, pero el rápido crecimiento representa a la vez una oportunidad y un peligro ya que se corre riesgos. (gestión.pe, 2016)

Los cinco lugares más turísticos de Perú:

a. Arequipa

Ubicada en el sur del país y reconocida por el del volcán Misti así como también llamada la "Ciudad Blanca" por las hermosas viviendas en sillar blanco, como casonas, templos y su hermoso monasterio de Santa Catalina. El hermoso centro histórico res reconocido como Patrimonio Cultural de la Humanidad. Rodeado por una preciosa campiña. También se puede visitar el famoso Valle del Colca y el Cañón del Colca.

Es un destino ideal para conocer un poco más de la Historia de esta hermosa ciudad así como las costumbres y platos típicos.

\section{b. Cusco - Machu Picchu}

La Capital Arqueológica de América"; es considerada como mayor atractivo turístico del Perú y el más turístico. Cusco fue la más grande ciudad del Imperio Inca. Hoy en día, Cusco conserva el mestizaje de la arquitectura Inca con la colonial española, lo que le da un carácter único en el mundo. El pueblo cusqueño es el único que aún conserva las costumbres y los mitos antiguos de la ciudad. Un lugar obligado para conocer es la mística y enigmática Machu Picchu, la ciudad sagrada de los Incas que los conquistadores españoles nunca conocieron y que fue dada a conocer a la cultura. Cusco como Machu Picchu son considerados Patrimonios de la Humanidad por la hermosa historia que deja para todos los peruanos y extranjeros que llegan a esta ciudad para conocer lo maravilloso de esta arquitectura. 


\section{c. Iquitos - Río Amazonas}

Esta es una ciudad que está ubicada en el norte del Perú, este es el lugar preferido para los que disfrutan de la naturaleza y biodiversidad así como para sentir el contacto con la naturaleza virgen de los bosques amazónicos. Desde esta ciudad se podrá navegar en el río Amazonas y empezar la aventura por la selva, normalmente con base en lodges ubicados en plena jungla, y los más audaces y aventureros pueden llegar hasta las Reservaciones y Parques Nacionales de fauna y flora, y conocer un poco a los aborígenes de la Amazonía.

\section{d. Lima}

La capital del Perú, una gran ciudad cosmopolita, con más de 7 millones de habitantes, considerada como la entrada al Perú. Podrá visitar su centro histórico con construcciones coloniales que se honran ser Patrimonio Cultural de la Humanidad; encontrara museos, algunos centros arqueológicos pre Hispánicos. Lo mejor de la gastronomía ya que ocupa uno de los primeros lugares en el mundo, además podrá disfrutar de una gran variedad de shows culturales, folklóricos, centros de diversión, casinos, juegos de todo tipo y centros artesanales. Lima en el verano es reconocido por las hermosas playas y balnearios ubicados al sur de la ciudad de Lima las cuales son perfectas para pasar unas vacaciones.

\section{e. Puno}

Puno está localizado en las alturas de los Andes Sur, a orillas del Titicaca, el lago navegable más alto del mundo habitado por los Uros y pueblos que guardan inalterables sus costumbres ancestrales, en las islas de Taquile y Amantani. Tierra del legendario pueblo Aimara, y la Cultura Tiahuanaco, muchas iglesias coloniales y joyas arquitectónicas. Es la capital folklórica del Perú, con una riqueza de más de 300 danzas autóctonas. Ofrece una excelente 
alternativa para el turismo arqueológico cultural, de culturas vivas y biodiversidad andina. Se recomienda combinar la visita a Puno con los destinos de Cusco y Arequipa.

Según MINCETUR las ventajas del turismo en el Perú constituyen una atractiva y potencial plaza de inversiones en el Sector Turismo, al ofrecer las siguientes condiciones favorables:

a. Incremento en la demanda de servicios turísticos que requieren de nuevas inversiones ante el aumento sostenido de llegadas internacionales de turistas.

b. Dinamismo en la Promoción del Perú como gran destino turístico en los más importantes mercados turísticos del mundo, aspecto que viene favoreciendo el incremento de las llegadas de turistas internacionales.

\subsection{Segmentación de la industria.}

"La diversidad de la demanda turística obliga a identificar segmentos de mercado, que se definen como subconjuntos de consumidores que responden a características similares entre sí” (Mochón, 2012).

La importancia de reconocerlos es esencial ya que se debe conoce a fondo el mercado para evaluar el consumo, a partir de ello, generar acciones y promover estrategias para así asegurar un porcentaje suficiente como para hacer viable el proyecto turístico.

La segmentación de la demanda turística se identifica por distintos criterios a evaluar, entre ellos, la motivación por la cual se realizara la visita. Empezando por este punto, se pueden identificar distintos mercados:

a. Turismo de aventura: actividad que implica realizar esfuerzos físicos de riesgo desafiando la geografía y naturaleza del lugar. 
b. Turismo cultural: actividad mediante la cual se desea conocer el valor histórico de las culturas, sitios arqueológicos, monumentos y arte de la zona visitada.

c. Turismo de naturaleza: actividad mediante la cual se tiene el deseo de conocer la diversidad de flora y fauna del lugar.

d. Turismo rural comunitario: actividad mediante la cual se desea participar de la vida cotidiana de las comunidades campesinas y nativas. Asimismo implican actividades de relajación, descanso y diversión.

e. Turismo urbano actividad mediante la cual se disfruta de realizar compras, paseos por la ciudad y visitas a museos locales.

El Perú es un destino gastronómico y cultural. También tiene claras potencialidades de desarrollo para el turismo de aventura, de naturaleza y el rural-comunitario, dado que hoy en día hay nuevas tendencias de actividades vivenciales esto es mundialmente ,cada vez se vuelve más exigente y promocionado (MINCETUR, 2013). 


\section{Tabla 1}

\section{Perfil de turista Tradicional vs Actual}

Turista tradicional

Consumido

Conocimiento básio de los sitios de viaje

Descanso, recreación

Busca playas y/o ciudades coloniales, regularmente ciudades grandes

Pocos viajes y de larga duración

Despreocupación de los sitios que visita

Consumista

Busca productos comunes, no le interesa innovación

Masivo

No realiza reservaciones, compra por si mismo
Turista actual

Multi-consumidor

Experimentado e informado

Elige su viaje pensando en sus actividades

Busca lugares diferentes

Hace más viajes y más cortos

Busca lugares no contaminados

Consume moderadamente

Busca productos a la medida con variedad de productos y actividades

Rechaza la masificación

Utiliza el Internet para comprar su viaje, genera blogs de viajes para compartir

Nota: Adaptado de Centros integrante planeados, por SECTUR, 2012. Recuperado de http://promperu.gob.pe/TurismoIN/Uploads/temp/Uploads_mercados_y_segmentos_seg mentos_1005_Publicacion-Perfil-del-Turista-de-Aventura.pdf 
Las actividades de los viajes de aventura pueden ser divididas en 4 segmentos:

Tabla 2

Actividades de Viaje

\begin{tabular}{llll}
\hline Naturaleza & Conocimiento & Marcas cuestionables & Descubrimiento \\
\hline $\begin{array}{l}\text { Este tipo de turismo está dirigido a gente } \\
\text { que le guste explorar los paisajes más } \\
\text { maravillosos que tiene el mundo. }\end{array}$ & $\begin{array}{l}\text { Este tipo de turismo está dirigido para } \\
\text { personas que deseen conocer más de la } \\
\text { cultura, costumbres de cada región }\end{array}$ & $\begin{array}{l}\text { Este tipo de turismo está dirigido a personas Este tipo de turismo es más que todo para } \\
\text { que les guste la adrenalina y las nuevas } \\
\text { experiencias }\end{array}$ & $\begin{array}{l}\text { poder investigar a fondo o también poder } \\
\text { conocer más de los safaris. }\end{array}$ \\
$\begin{array}{l}\text { Se pueden realizar en (canoa ,camping, } \\
\text { excursiones, escaladas, kayaking, ciclismo) }\end{array}$ & $\begin{array}{l}\text { Se pueden realizar mediante visitas a sitios } \\
\text { históricos, programas educacionales, } \\
\text { actividades culturales, tour de caminatas. }\end{array}$ & $\begin{array}{l}\text { Se pueden realizar como aventuras ( la } \\
\text { caza, esquí, buceo, vela, motos acuáticas) }\end{array}$ & Estas son expediciones ya sean de \\
investigación o también safaris & &
\end{tabular}

Según la OMT (2012), la hotelería es la rama del turismo que presta el servicio del alojamiento al turista. Este puede tener diversas clasificaciones, según el confort y el lugar donde se encuentren. Cada instalación hotelera tiene sus propias cualidades.

Según MINCETUR, 2017 los servicios turísticos se dividen en:

a. Hoteleros, conformado por:

1. Hoteles

2. Apart - Hoteles

3. Hostales

4. Resorts

5. Ecolodges

6. Albergues

7. Alojamiento Básico.

b. Transporte, compañías de transporte aquellas destinadas a trasladar o transportar viajeros de un punto a otro. Se clasifican en: 
1. Transporte aéreo: se encuentran las principales líneas aéreas comerciales.

2. Transporte terrestre: se consideran autobús, tren, particulares.

3. Transporte marítimo: se consideran barcos, yates, cruceros.

c. Operadores turísticos: Se encargan de realizar circuitos ya sea en un territorio nacional que se pueden ofrecer y vende a través de una agencia o directo al turista.

d. Agencias de viajes: Son empresas de bienes y servicios turísticos ya sea de alimentación alojamiento o transporte las cuales están disponibles para cualquier tipo de turista.

Las agencias de viajes se clasifican en tres grupos:

1. Mayoristas: Proyectan, elaboran y organizan toda clase de servicios y paquetes turísticos para venderlos a otras agencias no al público en general.

2. Minoristas: Comercializan los productos elaborados por las mayoristas o los suyos propios directamente al consumidor, no pueden ofrecer sus servicios a otras agencias.

3. Mayoristas-minoristas: Son empresas que cuentan con dos licencias, pueden elaborar y vender paquetes turísticos a otras empresas y a los turistas en general. (mincetur.pe, 2011)

\subsection{Empresas que la conforman.}

Dentro del sector turismo existen asociaciones las cuales agrupan a las diversas empresas del sector según su categoría a la cual pertenece. Actualmente están presentes las siguientes: 
a. Asociación Peruana de Agencias de Viajes y Turismo (APAVIT).

Afilia a las principales agencias de viaje de cada departamento de Perú asumiendo su representación gremial; y estimular la profesión del agente de viajes, buscando el perfeccionamiento y progreso.

b. Asociación Peruana de Albergues Turísticos Juveniles (APATJ).

Se encargan de afiliar, mantener la unión de los albergues turísticos de la zona.

c. Asociación Peruana de Hoteles, Restaurantes y Afines (AHORA).

Afilia a todas las empresas del sector y promueve el entendimiento permanente con entidades públicas y privadas y entes representativos de trabajadores y estudiante.

d. Asociación Peruana de Operadores de Turismo Receptivo e Interno (APOTUR).

Organización sin fines de lucro, desarrolla y mejor la oferta turística a fin de asegurar una mejor calidad de servicio que se ofrece a los clientes, apoya la participación de los miembros en ferias, congresos, fórum y encuentros de turismo.

e. Asociación Peruana de Turismo de Aventura y Ecoturismo (APTAE).

Difunde, fomenta y promociona el turismo de aventura y el ecoturismo en el país, alentando el desarrollo del Turismo Interno y Receptivo.

f. Asociación Peruana de Empresas Aéreas (APEA).

g. Cámara Nacional de Turismo (CANATUR).

Contribuye al desarrollo económico y social del país; fomenta el turismo interno y receptivo.

h. Asociación de Operadores de Turismo Receptivo del Perú (ASOTUR-PERÚ). 
Es una persona jurídica de derecho privado, representa a las agencias de viajes especializadas en la actividad del turismo receptivo, con la finalidad de promocionar, planificar y coordinar las actividades institucionales de los agentes de viajes tour operadores.

\subsection{Tendencias de la Industria.}

Según Stowell (2013) se han detectado cuatro tendencias que serían las principales entre los tour operadores de esta industria: cada vez se ofrecen más actividades "soft"; los viajes se personalizan; aumenta la demanda de grupos de distintas generaciones; y hay un mayor interés por vivir experiencias ecológicas y místicas.

Estas tendencias confirman que el mercado se está ampliando a nuevas capas de la sociedad. Sin embargo, "este rápido crecimiento representa a la vez una oportunidad y un peligro".

Según Stowell (2013) se considera como los activos principales del turismo de aventura los patrimonios naturales y culturales, de esta forma se puede mantener los negocios rentables con la creación y desarrollo de destinos prósperos, siempre y cuando siguiendo los lineamientos de un turismo sostenible.

Pero al mismo tiempo, añade, existen desafíos como el cambio climático, la degradación

medioambiental, la pérdida de hábitats y culturas, la pobreza ligada a estos fenómenos naturales que se están presentado.

La industria turística puede dar lo mejor de sí para combatir o prevenir estas cuestiones o, por negligencia, puede provocar incluso mayores daños. Hay muchos ejemplos de destinos que se han devaluado, algunos de los cuales nunca se llegarán a recuperar plenamente. 
Por eso, concluye, el turismo de aventura debe perseguir velar por la inclusión de las comunidades locales en los proyectos y garantizar que la sostenibilidad no sea un concepto vacío. (omt.pe, 2012)

La visión del turismo en el Perú hacia el siglo XXI es recibir 10 millones de turistas al año que ganan 2,000 dólares promedio en servicios consumidos dentro del país durante su estadía en los tres grandes circuitos turísticos del norte, centro y sur, logrando 20,000 millones de dólares como ingresos promedio al año por esta actividad. De esta forma, el Turismo finalmente considerado en el 2003 como actividad de exportación de servicios, es hoy una de las principales actividades económicas del país tanto en su contribución al PBI - que en el último año fue de $15 \%$ - como en la generación de empleos ya que cerca de diez millones de peruanos trabajan en Turismo en puestos de trabajo estables y bien remunerados. (MINCETUR, 2016).

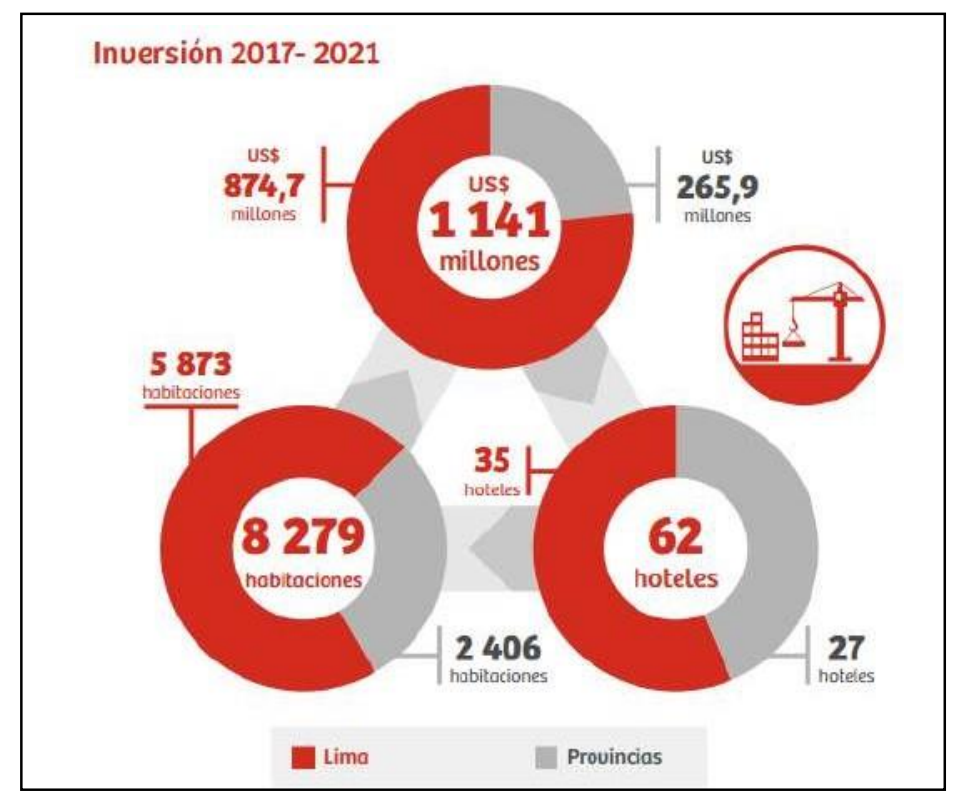

Figura 6. Inversión hotelera 2017. Tomado de MINCETUR, 2016. Recuperado de http://www.mincetur.gob.pe/set- 
regiones/(S(clm35s55jqaktu45zpyc2uf2))/Reportes/WebReportes/RptFiltro.aspx?StrCodGrupo= 01\&Nom Grupo=Establecimientos\%

\subsection{Análisis Estructural del Sector Industrial}

El modelo cinco fuerzas de Porter fue desarrollado originariamente como una forma de valorar el atractivo de diferentes industrias. Actualmente es un método que se aplica a todo tipo de empresas para proporcionar un punto de partida para el análisis estratégico (David, 2013).

Para el siguiente proyecto analizaremos el modelo de las cinco fuerzas de Porter ya que sirven para analizar la industria en este caso del turismo.

a. Poder de negociación de los consumidores.

El poder de los consumidores resulta ser de vital importancia para la supervivencia de cualquier empresa, en algunos casos se presiona reducir los precios cuando se negocia, así como es marcado por la diferenciación ya que los clientes prefieren productos de mayor calidad y si no es así el poder de negociación aumenta y exigen más.(David, 2013).

El cliente en el proyecto es el demandante de los circuitos turísticos el cual quede satisfecho dependiendo de sus preferencias, expectativas acerca del servicio. En la industria existen clientes que ya están acostumbrados a un servicio tradicional; sin embargo, dado al aumento del turismo nacional y tecnología, buscan constantemente nuevas alternativas, para optar por estas, los clientes evaluarán la calidad del servicio, la seguridad, la distancia y el precio a pagar por el servicio. Por lo tanto, está relacionado a la seguridad, precio, distancia y la 
calidad; que van de la mano de un servicio personalizado. Por esa razón se determina que el poder de los clientes es alto.

Tabla 3

Poder de Negociación de los Consumidores

\begin{tabular}{|c|c|c|c|c|c|c|}
\hline & 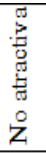 & 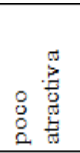 & $\begin{array}{l}\overrightarrow{\mathbb{E}} \\
\stackrel{\vec{E}}{\vec{J}} \\
\stackrel{\Xi}{=}\end{array}$ & 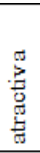 & 总莺 & \\
\hline Grupos de clientes concentrados & & & & & & \\
\hline compra en volumenes & & 2 & & & & \\
\hline Disponibilidad de sustitutos & & & & 3 & & \\
\hline Calidad en el servicio & & & & 3 & & \\
\hline EVALUACIÓN GENERAL DE LA FUERZA No atractivo & & & & & & Atractivo \\
\hline
\end{tabular}

Nota. Adaptado de Matriz de Atractividad, por A.A. Thonson M.A. Peteraf, J.E. Gamble y A.J. Strickland 2012, Administración Estratégica, p. 267. Copyright 2012 por The Mc Graw Hill Companies, Inc.

Poder de Negociación de los Consumidores

- Grupos de clientes concentrados -ALTO (4)

- Compra en volúmenes- MEDIO BAJO (2)

- Disponibilidad de sustitutos - MEDIO ALTO (3)

- Calidad en el servicio - MEDIO ALTO (3)

b. Poder de negociación de los proveedores.

El poder de los proveedores también recae en la industria, ya que los proveedores son un elemento muy importante en el proceso de posicionamiento de una empresa, ellos son los que ofrecen los elementos necesarios para que se ofrezca un buen servicio y va depender de la negociación para vender los productos, es decir mientras más proveedores será menor la capacidad de negociación (David, 2013). 
Para la industria el poder de negociación de los proveedores es bajo, ya que por ser una agencia de viajes no se dispone de proveedores estrictos que le ofrezcan materias primas, solo en el caso de la compra de la maquinaria. En estos últimos tiempos la tecnología ha ido en aumento por lo cual el servicio online es básico para poder negociar todo tipo de servicios adicionales como podrían ser los hoteles, traslados, etc.

Tabla 4

Poder de Negociación de los Proveedores

\begin{tabular}{|c|c|c|c|c|c|c|}
\hline & 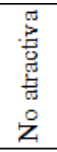 & 总 & 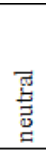 & 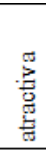 & 总 & \\
\hline Proveedores concentrados & & & 4 & & & \\
\hline Importancia de la industria para ellos & & 2 & & & & \\
\hline Costo de cambio & 1 & & & & & \\
\hline Amenaza de los proveedores de integracion adelante & 1 & & & & & \\
\hline Amenaza de la industria de integración hacia atrás & & & 3 & & & \\
\hline Contribucion de proveedores a la calidad o servicio & & & & 3 & & \\
\hline Contribucion de los costos por parte de los proveedores & & 2 & & & & \\
\hline EVALUACION GENERAL DE LA FUERZA No atractivo & & 2.25 & & & & Atractivo \\
\hline
\end{tabular}

Nota. Adaptado de Matriz de Atractividad, por A.A. Thonson M.A. Peteraf, J.E. Gamble y A.J. Strickland 2012, Administración Estratégica, p. 266. Copyright 2012 por The Mc Graw Hill Companies, Inc.

Poder de Negociación de los Proveedores

- Proveedores concentrados- ALTO (4)

- Importancia de la industria para ellos - MEDIO BAJO (2)

- Costo de cambio- BAJO (1)

- Amenaza de los proveedores de integración adelante - BAJO (1)

- Amenaza de la industria de integración hacia atrás - MEDIO ALTO (3)

- Contribución de proveedores a la calidad o servicio- MEDIO ALTO (3)

- Contribución de los costos por par te de los proveedores - MEDIO BAJO (2) 
c. Entrada potencial de nuevos competidores.

Existe la oportunidad que nuevas empresas ingresen a una industria, ya que es importante para medir la rentabilidad, depende también del número de barreras de entrada que existan. Estas barreras de entrada se definen como los factores que se deben superar por los nuevos entrantes para que así se pueda competir con éxito (David, 2013).

Existen dos factores importantes para determinar si existe esta amenaza y son las barreras de entrada existentes y la reacción que los entrantes pueden esperar de las empresas que ya compiten en el mercado. Dentro de las barreras obtenemos las siguientes:

\section{a. Economías de Escala}

Dado que no se necesitan grandes escalas de servicio para esta industria, no existen grandes requerimientos de economías de escala para poder competir, debido a la cantidad de empresas que ofrecen este servicio (agencias de viaje) y que ofrecen servicios tradicionales de circuitos turísticos.

\section{b. Requerimientos de Capital}

En la industria de turismo existen empresas físicas y online, por este motivo se puede deducir que las formales necesitan mucho más capital por lo que pagan impuestos, tienen local en el centro de la ciudad y pagan sueldos con planilla, por otro lado las empresas online no tienen este tipo de gastos ya que todo es por internet. Por lo que difiere uno del otro.

\section{c. Diferenciación de Productos}

En esta industria existen diversas alternativas de circuitos turísticos ya que tienen muchos lugares para poder visitar así como arman paquetes de circuitos nuevos con más atractivos para 
poder ser competitivos. Sin embargo, la diferenciación final no ha sido considerada como prioridad en este caso, por lo que no es considerada una barrera significativa para la industria.

\section{d. Acceso a Canales de Distribución}

Esta barrera podría ser considerara amenaza ya que los que quieran ingresar en esta industria, deben tomar en cuenta que son empresas nuevas que no cuenta de experiencia suficiente en el manejo de costos, negociación con proveedores, promociones y ofertas; por lo tanto para poder ingresar se necesita de una buena inversión ya sea para poder lanzar el servicio al mercado, así como para poder posicionarte y mantenerte vigente.

Dentro de las barreras de salida existentes tenemos:

\section{a. Activos especializados}

Dado que la maquinaria que se utilizara es difícil de negociar o vender a terceros, para este proyecto señala una barrera de salida difícil de afrontar.

b. Costos fijos de salida

Estos costos representarían una barrera de salida muy importante a considerar pero que no afectaría de manera significativa en vista de que, si el negocio llegara al declive en su ciclo de vida, se tendrían que incluir las indemnizaciones a los trabajadores, para el proyecto son nueve así como también la liquidación de los activos.

c. Restricciones sociales y gubernamentales

Esta barrera no indica una situación de mayor grado, en la que se tendrían que mitigar conflictos sociales ya sea por huelgas y legales con los municipios o trabajadores. 
Tabla 5

Nuevos Competidores - Barreras de Entrada

\begin{tabular}{|c|c|c|c|c|c|c|c|}
\hline & & 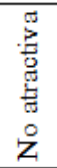 & 莺 & 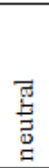 & 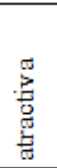 & 急莺 & \\
\hline Economias de escala & & & 1 & & & & \\
\hline Requerimiento de capital & & & & 4 & & & \\
\hline Diferenciación de productos & & & & & 4 & & \\
\hline Acceso a canales de distribución & & & & & 2 & & \\
\hline Acceso a proveedores & & & & 2 & & & \\
\hline Conocimiento de la industria & & & & & 3 & & \\
\hline EVALUACIÓN GENERAL DE LA FUERZA & No atractivo & & & & & & Atractivo \\
\hline
\end{tabular}

Nota. Adaptado de Matriz de Atractividad, por A.A. Thonson M.A. Peteraf, J.E. Gamble y A.J. Strickland 2012, Administración Estratégica, p. 267. Copyright 2012 por The Mc Graw Hill Companies, Inc.

Nuevos Competidores - Barreras de Entrada

- Economías de escala- BAJO (1)

- $\quad$ Requerimiento de capital- ALTO (4)

- Diferenciación de productos- ALTO (4)

- Acceso a canales de distribución- MEDIO BAJO (2)

- Acceso a proveedores- MEDIO BAJO (2)

- Conocimiento de la industria- MEDIO ALTO (3) 
Tabla 6

Nivel de Competitividad-Barreras de Salida

\begin{tabular}{|c|c|c|c|c|c|c|}
\hline & 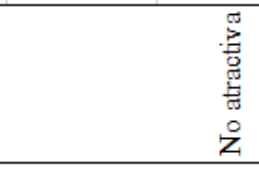 & 营 & 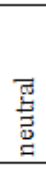 & 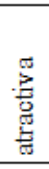 & 总惫 & \\
\hline Especialización de los activos & & & 4 & & & \\
\hline Relaciones estratégicas & & & & 3 & & \\
\hline Restricciones gubernamentales & & & 2 & & & \\
\hline Restricciones sociales & & 2 & & & & \\
\hline EVALUACIÓN GENERAL DE LA FUERZA & No atractivo & 2.75 & & & & Atractivo \\
\hline
\end{tabular}

Nota. Adaptado de Matriz de Atractividad, por A.A. Thonson M.A. Peteraf, J.E. Gamble y A.J. Strickland 2012, Administración Estratégica, p. 267. Copyright 2012 por The Mc Graw Hill Companies, Inc.

Nivel de Competitividad-Barreras de Salida

- Especialización de los activos- ALTO (4)

- Relaciones estratégicas- MEDIO ALTO (3)

- Restricciones gubernamentales- MEDIO BAJO (2)

- $\quad$ Restricciones sociales- MEDIO BAJO (2)

d. Desarrollo potencial de productos sustitutos.

La presencia en el mercado de los productos sustitutos ofrece un beneficio similar a los servicios de un mercado mediante un proceso distinto. Esto es una amenaza ya que puede alterar la oferta y la demanda más aun cuando los productos o servicios presentan precios bajos con buena calidad, pero siempre estar alerta ya que las preferencias de los consumidores pueden verse afectadas. (David, 2013). 
El proyecto se desarrolla dentro del ámbito de servicios turísticos, lo que significa que no está reservada solo para empresas sustitutas indirectas, sino también a todas aquellas que brinden circuitos turísticos ya sean paseos, caminatas, city tour. Esta industria está constituida por una variedad de negocios turísticos, por lo tanto, se debe tener en cuenta que cualquier circuito puede ser considerado como un sustituto directo o indirecto.

Tabla 7

Desarrollo Potencial de Productos Sustitutos

\begin{tabular}{|c|c|c|c|c|c|c|}
\hline & 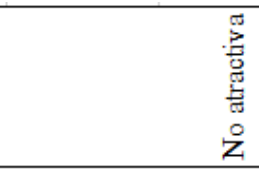 & 莺 & 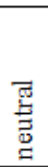 & 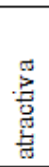 & 总 & \\
\hline Disponibilidad de sustitutos cercanos & & & 4 & & & \\
\hline Facilidades de pago & & & & 3 & & \\
\hline Agresividad de productos de sustitutos & & & 2 & & & \\
\hline Valor/precio del sustituto & & 2 & & & & \\
\hline EVALUACIÓN GENERAL DE LA FUERZA & No atractivo & 2.75 & & & & Atractivo \\
\hline
\end{tabular}

Nota. Adaptado de Matriz de Atractividad, por A.A. Thonson M.A. Peteraf, J.E. Gamble y A.J. Strickland 2012, Administración Estratégica, p. 267. Copyright 2012 por The Mc Graw Hill Companies, Inc.

\section{Desarrollo Potencial de Productos Sustitutos}

- $\quad$ Disponibilidad de sustitutos cercanos- ALTO (4)

- $\quad$ Facilidades de pago- MEDIO ALTO (3)

- Agresividad de productos sustitutos- MEDIO BAJO (2)

- Valor precio del sustituto- MEDIO BAJO (2) 
e. Rivalidad entre empresas competidoras.

Resulta ser una de las fuerzas más poderosas en este modelo, las estrategias de una empresa serán exitosas sólo si tiene una ventaja competitiva por sobre las estrategias de la competencia. Las empresas deben tomar medidas necesarias para que aseguren su posicionamiento en el mercado a costa de los rivales ya existentes (David, 2013).

La presencia de servicios de turismo ya sea por circuitos o paquetes es competentes entre sí.

La rivalidad existente entre empresas que prestan el servicio turístico; es bastante fuerte dado que la diferenciación del servicio es mínima, por lo que existen presentaciones con algún tipo de descuentos y ofertas (por cada 5 personas una liberada, 2 por 1 en city tour, etc.) que hacen que los servicios sean más atractivos y a un precio accesible, lo que no permite la fidelización a la marca.

Por lo antes señalado, y por tratarse de un servicio turístico de circuitos, el retorno de la inversión en estas barreras de salida sería Neutral.

Tabla 8

Rivalidad entre empresas competidoras

\begin{tabular}{|c|c|c|c|c|c|c|}
\hline & 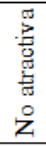 & 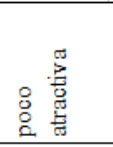 & 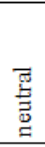 & 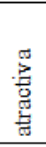 & 总 & \\
\hline Número de competidores con oferta similar & 1 & & & & & \\
\hline Crecimiento relativo de la industria & & & & 3 & & \\
\hline Liderazgo en costos & & 1 & & & & \\
\hline Caracteristicas del producto & & 1 & & & & \\
\hline Precios accesibles & & & 2 & & & \\
\hline Diversidad de competidores indirectos & & & & 3 & & \\
\hline EVALUACIÓN GENERAL DE LA FUERZA No atractivo & & 2.75 & & & & Atractivo \\
\hline
\end{tabular}

Nota. Adaptado de Matriz de Atractividad, por A.A. Thonson M.A. Peteraf, J.E. Gamble y A.J. Strickland 2012, Administración Estratégica, p. 267. Copyright 2012 por The Mc Graw Hill Companies, Inc. 


\section{Rivalidad entre empresas competidoras}

- Número de competidores con oferta similar- BAJO (1)

- Crecimiento relativo de la industria- MEDIO ALTO (3)

- $\quad$ Liderazgo en costos- BAJO (1)

- Características del producto- BAJO (1)

- $\quad$ Precios accesible-MEDIO BAJO (1)

- $\quad$ Diversidad de competidores indirectos- MEDIO ALTO (3)

En base al análisis elaborado del modelo de las cinco fuerzas de Porter se llega a la conclusión que esta industria es atractiva como se muestra en la siguiente tabla.

Tabla 9

Evaluación Global

\begin{tabular}{lr}
\hline Fuerza de Porter & Ponderación \\
\hline Barreras de entrada & 3 \\
Barreras de salida & 2.75 \\
Rivalidad entre competidores & 4 \\
Poder de negociacion con los clientes & 2.75 \\
Poder de negociacion de los proveedores & 2.75 \\
Amenaza de productos y servicios sustitutos & 2.75 \\
EVALUACIÓN GLOBAL & 3 \\
\hline
\end{tabular}

Nota. Adaptado de Matriz de Atractividad, por A.A. Thonson M.A. Peteraf, J.E. Gamble y A.J. Strickland 2012, Administración Estratégica, p. 267. Copyright 2012 por The Mc Graw Hill Companies, Inc. 


\subsection{Análisis de la Competencia}

En el 2012, Jiménez consideró que el análisis es cómo se comparan ambos negocios. Evaluando las fortalezas y debilidades de tu competidor, pueden empezar a formular cómo darle a tu empresa una ventaja. El análisis es parte del plan de marketing de la compañía y da un contexto para el crecimiento de los planes a futuro.

\subsection{Empresas que ofrecen el mismo producto o servicio, indicando las semejanzas y diferencias que tienen con el proyecto de empresa.}

Como empresas que conforman este mercado no se tiene una competencia directa ya que el servicio que se ofrecerá no está explotado aun en la ciudad de Puno.

Por lo cual se tomará en cuenta a la competencia indirecta, en este caso son las agencias de viaje que ofrecen servicio de lancha y canoas. Se toman a las 03 principales.

Sin embargo, dicha competencia indirecta podría a futuro ofrecer los mismos servicios. Por tanto, la estrategia que tendrá la empresa estará centrada en la innovación de los servicios brindados ofreciendo nuevas rutas de aventura dentro del lago Titicaca y alrededores. Con el fin de evitar que copien los circuitos turísticos.

Dentro de las diferencias ninguna de estas agencias tiene el capital necesario para poder invertir en la innovación para sus paquetes turísticos a la vez no cuentan con operadores que realicen este circuito por lo que la empresa sería la única en poder brindar el servicio. Las agencias de viaje se encargan de endosar este servicio en cambio como operador te encargas de realizar todo el circuito brindando la mejor experiencia. 
Tabla 10

Empresas que Ofrecen el Mismo Servicio - Análisis de la Competencia

\begin{tabular}{|c|c|c|c|}
\hline Empresa & Que hace & Que Producto & Precio \\
\hline Puno Travel AVT & $\begin{array}{l}\text { Es una reconocida agencia de viajes de } \\
\text { Puno. Brinda paquetes turisticos a las islas } \\
\text { del Lago Titicaca y viajes a Bolivia }\end{array}$ & $\begin{array}{l}\text { Puno e Islas flotantes } 2 \mathrm{~d} / 1 \mathrm{n} \text { Ciudad de } \\
\text { puno caminata y paseo. Tour isla Taquile }\end{array}$ & $\begin{array}{l}\text { El precio promedio por TOUR Simple es } \\
30 \$ \text { y un Tour completo es de } 50 \$\end{array}$ \\
\hline Sacred Lake & $\begin{array}{l}\text { Considerada una del as agencias con mayor } \\
\text { venta de servicios de kayak en la ciudad de } \\
\text { Puno, vende paquetes turisticos hacia las } \\
\text { islas del Lago Titicaca y brinda city tours. }\end{array}$ & $\begin{array}{l}\text { Ciudad de Puno con guiado turistico } 1 \mathrm{~d} \\
\text { Islas Flotantes Uros, Taquile, Amantani } \\
\text { 3d/2n Kallac en el lago } 1 \mathrm{~d}\end{array}$ & $\begin{array}{c}\text { El precio promedio por TOUR es de } 50 \\
\text { USD }\end{array}$ \\
\hline Jumbo Travel & $\begin{array}{l}\text { Es una reconocida agencia de viajes en } \\
\text { realizaentramos todo tipo de tours de } \\
\text { aventura ya sea en biciletasn, canoas, } \\
\text { paseo a caballo, etc } \\
\text { Vende }\end{array}$ & $\begin{array}{c}\text { Paseo por la ciudad } 2 \mathrm{~d} / 1 \mathrm{n} \text { Paseo por las } \\
\text { Islas } 1 \mathrm{~d}\end{array}$ & El precio por TOUR Puno $\$ 30$ por persona \\
\hline
\end{tabular}

\subsection{Participación de mercado de cada uno de ellos.}

Actualmente en la ciudad de Puno existen alrededor de 88 agencias de viaje según la Dirección Regional de Comercio Exterior y de Turismo de Puno (DICETUR - Puno, 2016). De las mismas sólo 69 empresas están declaran a la SUNAT y las restantes dejaron de declarar pero se mantienen en el mercado. Ello indica una informalidad en la industria del $20 \%$, asimismo la empresa legales no declaran la totalidad de sus trabajadores e ingresos.

Cabe señalar que no existen cifras oficiales sobre el tamaño de mercado turístico en Puno. Por tanto, se estimará según lo siguiente:

a. El ranking de agencias de viaje que realizan actividades al aire libre de la página Web Tripadvisor.com. Ello refleja sólo la calidad de atención a los pasajeros.

b. La determinación del tamaño de la empresa se basó en el reporte de endeudamiento de los representantes legales y las empresas. Se toma como referencia la suma de las 
mismas. Dichas cifras fueron extraídas de los reportes de crédito emitidos por la central de riesgos Infocorp.

c. El tamaño de mercado para el rubro se estimó de acuerdo al número de turistas nacionales que ingresaron al departamento de Puno. Se toma como ticket promedio de gasto por turista que realiza un paseo turístico. Se toma como precio promedio de S/70 dando como resultado un tamaño de mercado aproximado de S/36 millones al año 2015.

Tabla 11

Tamaño de Mercado - Agencias de Viaje en Puno

\begin{tabular}{cc}
\hline Arribo de visitantes nacionales a Puno & Tamaño de mercado turistico en Puno \\
& \\
\hline 216,452 & $15,151,640$ \\
254,384 & $17,806,880$ \\
305,696 & $21,398,720$ \\
344,437 & $24,110,590$ \\
377,825 & $26,447,750$ \\
418,864 & $29,320,480$ \\
426,656 & $29,865,920$ \\
416,471 & $29,152,970$ \\
419,481 & $29,363,670$ \\
504,930 & $35,345,100$ \\
516,342 & $36,143,940$ \\
\hline Nota: Arribo de turistas nacional basado en información de MINCETUR
\end{tabular}


Tabla 12

Ranking de Agencias de Viaje Según Tripadvisor y Nivel de Endeudamiento

\begin{tabular}{|c|c|c|c|c|c|c|}
\hline \multirow{2}{*}{ Empresa } & \multirow{2}{*}{$\begin{array}{c}\text { Ranking } \\
\text { Tripadvisor }\end{array}$} & \multirow{2}{*}{ Formalidad } & \multirow[b]{2}{*}{ RUC } & \multicolumn{3}{|c|}{ Deuda máxima ${ }^{2}$ euda empresa Endeudamiento } \\
\hline & & & & $\begin{array}{c}\text { representante } \\
\text { SBS }\end{array}$ & SRS & Thtal \\
\hline Jumbo Travel & 5 & Formal & 20447819482 & 14,600 & 956,270 & 970,870 \\
\hline Sacred Lake & 12 & Formal & 20406468331 & 312,780 & 40,352 & 353,132 \\
\hline Puno Travel AVT & 18 & Formal & 20406399185 & 257,608 & 0 & 257,608 \\
\hline \multirow[t]{2}{*}{ Magical Punotour } & 20 & Formal & 20601372437 & 97,944 & 0 & 97,944 \\
\hline & 9 & Formal & 20448467059 & 30,412 & 0 & 30,412 \\
\hline \multicolumn{7}{|l|}{ Agencia de Viaje } \\
\hline Andean Ways & 6 & Formal & 10444785026 & 20,000 & & 20,000 \\
\hline Geographic Expe & 3 & Formal & 20448708609 & 11,953 & 0 & 11,953 \\
\hline Suri Explorer & 7 & Formal & 20406473504 & 3,200 & 0 & 3,200 \\
\hline Inti Trail & 14 & Formal & 20601617821 & 2,297 & 0 & 2,297 \\
\hline Titicaca Travel P & 4 & Formal & 20448525270 & 1,500 & 0 & 1,500 \\
\hline La Raya Pass & 2 & Informal & - & & & 0 \\
\hline Puno Tours Servi & 8 & Formal & 20448459978 & 0 & 0 & 0 \\
\hline Titicaca Tour & 10 & Formal & 20542761092 & 0 & 0 & 0 \\
\hline Highland Adventu & 11 & Informal & - & & & 0 \\
\hline Boat Pub Fiesta d & 13 & Informal & - & & & 0 \\
\hline Kispus TraveL S & 15 & Formal & 20492094103 & 0 & 0 & 0 \\
\hline Quechuas Travel & 16 & Formal & 20527292973 & 0 & 0 & 0 \\
\hline Killary Peru Tour & 17 & Informal & - & & & 0 \\
\hline Royal Travel Age & 19 & Informal & - & & & 0 \\
\hline
\end{tabular}

Nota: Información basada en ranking Tripadvisor (actividades al aire libre - Puno) y Equifax - Infocorp nivel de

endeudamiento en el sistema financiero. Grado de informalidad top 20 es de $25 \%$.

Según el nivel de endeudamiento se toma como empresa de mayor tamaño: Jumbo

Travel, Sacred Lake y Puno Travel AVT. El nivel de ventas se toma de referencias bancarias y con ello se estimó la participación del mercado.

Tabla 13

Participación de Mercado - Agencias de Viajes en Puno

\begin{tabular}{ccc}
\hline Empresa & Ventas anuales & Participación \\
\hline Puno Travel AVT & $2,850,000$ & $8 \%$ \\
Sacred Lake & $1,036,623$ & $3 \%$ \\
Jumbo Travel & 756,211 & $2 \%$ \\
Demás empresas & $31,501,106$ & $87 \%$ \\
Total & $36,143,940$ & $100 \%$ \\
\hline
\end{tabular}


Finalmente, a nivel nacional se tiene que un $99 \%$ de las agencias de viaje y operadores en turismo son micro y pequeñas empresas, la mayoría de las agencias de viaje y operadores turísticos son micro y pequeñas empresas $(99,3 \%)$. El resto $(0,7 \%)$ son medianas y grandes

empresas. En general, estas agencias ofrecen servicios de viajes, organizan paquetes turísticos al público o a clientes comerciales, que comprenden transporte, alojamiento, comidas, visitas a museos, lugares históricos o culturales (mincetur.pe,2013)

\subsection{Matriz de perfil competitivo.}

En el 2011, Kepner consideró que es una herramienta analítica que identifica a los competidores más importantes de una empresa e informa sobre sus fortalezas y debilidades particulares. Los resultados de ellas dependen en parte de juicios subjetivos en la selección de factores, en la asignación de ponderaciones y en la determinación de clasificaciones, por ello debe usarse en forma cautelosa como ayuda en el proceso de la toma de decisiones.

Procedimiento para su desarrollo:

a. Se identifican los factores decisivos de éxito en la industria, así como los competidores más representativos del mercado.

b. Asignar una ponderación a cada factor de éxito con el objeto de indicar la importancia relativa de ese factor para el éxito de la industria.

$$
00=\sin \text { importancia }
$$$$
1.0=\text { muy importante }
$$

NOTA: La suma debe ser igual a 1.

c. Se asigna a cada uno de los competidores, así como también a la empresa que se está estudiando, debilidad o fortaleza de esa firma a cada factor clave de éxito. 


$$
\begin{array}{ll}
1=\text { Debilidad grave } & 3=\text { Fortaleza menor } \\
2=\text { Debilidad menor } & 4=\text { Fortaleza importante }
\end{array}
$$

d. Multiplicar la ponderación asignada a cada factor clave por la clasificación correspondiente otorgada a cada empresa.

e. Sumar la columna de resultados ponderados para cada empresa. El más alto indicará al competidor más amenazador y el menor al más débil (P.128).

Para poder puntuar y validar estos factores se tomó en cuenta la entrevista a profundidad de los expertos : En la entrevista a Carla Llerena se realizan preguntas sobre la calidad de los servicios brindados por empresas del rubro entre ellas las de servicio de aventura de las cuales las principales son las mencionadas en la matriz.

En la segunda entrevista realizada a William Bellido se realizaron preguntas base y él indica que Tripadvisor es una página confiable donde los turistas encuentran toda la información y calificación, habla también sobre la experiencia que tiene en cuanto a turismo de aventura, no especifica las empresas solo por nombre dio la evaluación según su criterio.

En la entrevista a Paola, que trabaja en agencia de viajes si pudo calificar a Jumbo Travel como principal competidor ya que es el más conocido, así como a lancha veloz.

Explica también formas de publicitar mediante la tecnología que se ofrece en el proyecto.

De acuerdo a la matriz se tomó en cuenta como principales puntos a investigar la calidad de servicio de la competencia ya que brindan servicios similares a los del proyecto y se necesita investigar para poder realizar mejoras.

En cuanto a la competitividad en la ciudad de Puno es muy frecuente la competencia por precios bajos, por lo cual se debe estar preparado. 
Servicio al cliente es donde más se enfocará el servicio ya que será personalizado.

Tecnología y experiencia al ser nuevo el servicio debe estar a la altura de las novedades y tendencias.

Tabla 14

Matriz de Perfil Competitivo

\begin{tabular}{|c|c|c|c|c|c|c|c|c|}
\hline \multirow{2}{*}{$\begin{array}{c}\text { FACTORES CLAVES DEL } \\
\text { ÉXITO }\end{array}$} & \multirow{2}{*}{\multicolumn{2}{|c|}{ PONDERACIÓN }} & \multicolumn{2}{|c|}{ JUMBO TRAVEL } & \multicolumn{2}{|c|}{ LANCHA VELOZ } & \multicolumn{2}{|c|}{ CANOTAJE PUNO } \\
\hline & & & Clasificació .. & $\begin{array}{l}\text { Resultado } \\
\text { ponderado }\end{array}$ & Jasificació .. & $\begin{array}{l}\text { Resultado } \\
\text { ponderado }\end{array}$ & Jasificació .. & $\begin{array}{l}\text { Resultado } \\
\text { ponderado }\end{array}$ \\
\hline Calidad del servicio & & 0.20 & 3 & 0.60 & 2 & 0.40 & 2 & 0.40 \\
\hline Competitividad & 0.20 & 0.02 & 1 & 0.20 & 4 & 0.80 & 1 & 0.20 \\
\hline Servicio al Cliente & & 0.40 & 2 & 0.80 & 1 & 0.40 & 4 & 1.60 \\
\hline Tecnologia & & 0.10 & 4 & 0.40 & 3 & 0.40 & 3 & 0.30 \\
\hline Experiencia & & 0.20 & 3 & 0.30 & 3 & 0.30 & 3 & 0.30 \\
\hline Total & & 1 & & 2.30 & & 2.20 & & 2.80 \\
\hline
\end{tabular}

Nota. Adaptado de Charles Kepner, 2011.

Por lo tanto Canotaje Puno (Inka Peak) es el competidor más amenazador para el mercado ya que ellos son reconocidos como la agencia mayorista de la ciudad, aunque ellos no tienen disponible el servicio que nosotros brindaremos, debemos tomar en cuenta los factores más importantes para poder superar la puntuación.

\subsection{Análisis del Contexto Actual y Esperado}

Según (David, 2013) Los cambios sociales, culturales, demográficos y ambientales tienen un fuerte impacto en casi todos los productos, servicios, mercados y clientes 


\subsection{Análisis político-gubernamental.}

El entorno político- gubernamental en el país se caracterizado en la última década por ser estable democrática y económicamente. Ello ha permitido al país lograr la firmar de más de 15 acuerdos comerciales como el Tratado de Libre Comercio (TLC) con Estados Unidos, China o Unión Europea. Asimismo, pese a los cambios de gobierno donde había periodos de cierta inestabilidad se ha llegado a tener una estabilidad macroeconómica en los diferentes cambios de gobierno.

Asimismo se destaca la inversión del Estado en ciertos programas como la "Marca Perú" la cual impulsó el sector turismo y gastronómico. Se dio una fuerte campaña por mejorar la marca país y se continúa trabajando en ello mediante la participación del Estado en ferias internacionales, designando embajadores de marca y fomentando la cultura peruana. Dicho apoyo ha generado una mayor afluencia de extranjeros al Perú, un mejor posicionamiento en el extranjero como país. (semanaeconomica.pe, 2016)

Programación y formulación de inversiones públicas Una adecuada identificación de Proyectos de Inversión Pública en el sector turismo ayudará fuertemente a la formulación de un portafolio acorde a las normas técnicas y principios del Sistema Nacional de inversión Pública (SNIP). En ese sentido, será importante trabajar y proponer, en coordinación con el Ministerio de Economía y Finanzas (MEF), lineamientos específicos para la formulación de proyectos y una guía metodológica para el sector turismo. Dichas intervenciones deberán tomar en cuenta el rol subsidiario del Estado en la provisión de bienes y servicios públicos, la corrección de externalidades o algunos costos de transacción. En el caso del sector turismo, se pueden tomar en cuenta: 
a. Intervenciones para el acceso a servicios turísticos; Intervenciones para la puesta en valor de atractivos turísticos.

b. Intervenciones para promover los negocios rurales vinculados a los circuitos turísticos.

c. Intervenciones para mejorar la señalética y la información de los atractivos turísticos.

d. Intervenciones para desarrollar innovación tecnológica en los servicios turísticos (asistencia técnica y capacitación), especialmente en PYMES; Intervenciones para apoyar la certificación turística.

e. Intervenciones para fortalecer la gestión y la administración de la atención, orientación y seguridad de los visitantes. Seis Estos son los criterios de la economía pública que recoge el SNIP en su marco conceptual y en la metodología de la evaluación social de proyectos. 19 A estas intervenciones se deben agregar ciertamente las inversiones públicas necesarias en servicios e infraestructura pública, especialmente en red vial y aérea, energía, agua, comunicaciones y seguridad. En cuanto a la programación, existe un importante esfuerzo de planeamiento en el PENTUR y en los planes regionales, incluyendo un trabajo coordinado con el sector privado que se debe resaltar. A partir de estos trabajos, será necesario reforzar que la programación de inversiones de mediano plano debe estar sostenida por un equipo técnico y una asignación presupuestal estables.

Los principales criterios de priorización pueden tomar en cuenta:

a. Proyectos del sector turismo en ejecución, cuyos niveles de avance presenten resultados satisfactorios;

b. Proyectos declarados viables con las mejores tasas de rentabilidad social; 
c. Proyectos en preparación que se encuentren en la fase final y estén enmarcados en el plan de desarrollo territorial. Por último, el planeamiento y la programación de inversiones deben apoyarse en una visión territorial más que sectorial. Difícilmente el Ministerio de Economía y Finanzas podrá entender la rentabilidad social de esas inversiones y de los recursos necesarios si no se presenta un esquema completo del circuito turístico y de los servicios e infraestructura básicos que se requieren

\subsection{Análisis económico.}

En los últimos años la economía peruana ha destacado por un crecimiento continuo durante más de 10 años. La tasa de crecimiento del PBI per cápita en la última década ha sido del 8.07\% siendo actualmente USD 6121.90 (2015) según estadísticas del Banco Mundial. Asimismo el crecimiento económico del país para el año 2016 está previsto en 3.5\%, el mismo que será impulsado por el sector minero con el inicio productivo de Cerro Verde (segunda etapa)

y Las Bambas; y la inversión en infraestructura como Gasoducto Sur Peruano o Línea dos Metro de Lima. Asimismo el consumo privado será más moderado que años anteriores teniendo una estimación de crecimiento de solo 3.5\%. Por otro lado, el reto para el Gobierno actual es el enfrentar una reducción de la recaudación tributaria que se estima para el 2016 en un 3\% del PBI (Semana Económica, 2016). 


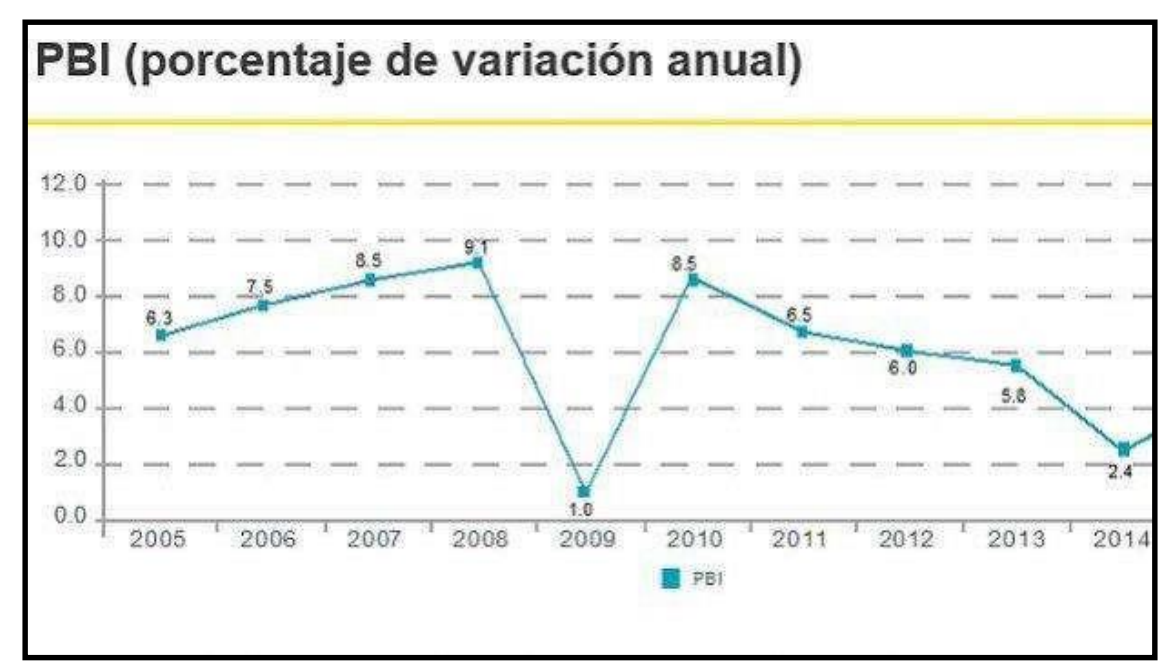

Figura 7. Variación porcentaje PBI 2005- 2014. Tomado de Diario El Comercio, 2015.Recuperado de http://cde.3.elcomercio.pe/ima/0/1/1/5/1/1151335/base_image.jpg

Según datos del (MINCETUR, 2015) el ingreso de divisas generado por el flujo de turistas extranjeros o receptivos ha crecido un 47.5\% entre el 2011 al 2015. Solo el flujo de divisas en el año 2015 fue de USD 4,151 millones. Ello gracias al aumento de la llegada de turistas que entre el 2011 al 2015 ha crecido en un 34.61\% llegando a una cifra de 3.5 millones de visitantes el 2015.

Tabla 15

Análisis de factores económicos

\begin{tabular}{llcc}
\hline \multicolumn{1}{c}{ Factor } & \multicolumn{1}{c}{ Análisis } & $\begin{array}{c}\text { Impacto en } \\
\text { proyecto }\end{array}$ & $\begin{array}{c}\text { Oportunidad / } \\
\text { Amenaza }\end{array}$ \\
\hline PBI & Ultima decada crecio $8.07 \%$ & Positivo & Oportunidad \\
Megaproyectos & $\begin{array}{l}\text { Inicio productivo Cerro Verde 2 etapa y Las Bambas } \\
\text { Gasoducto Sur Peruano y Línea 2 Metro de Lima }\end{array}$ & Positivo & Oportunidad \\
Consumo privado & Crecimiento privado moderado 3.5\% & Negativo & Amenaza \\
Ingreso divisas & Crecimiento en 47.5\% entre 2011 a 2015 & Positivo & Oportunidad \\
Turistas & Arribo turistas en 34.61\% & Positivo & Oportunidad \\
\hline
\end{tabular}




\section{Análisis legal.}

a. Ley que regula la actividad de las empresas especiales de servicios y de las cooperativas de trabajadores.

La presente Ley tiene por objeto regular la intermediación laboral del régimen laboral de la actividad privada, así como cautelar adecuadamente los derechos de los trabajadores.

La intermediación laboral sólo podrá prestarse por empresas de servicios constituidas como personas jurídicas de acuerdo a la Ley General de Sociedades o como Cooperativas conforme a la Ley General de Cooperativas, y tendrá como objeto exclusivo la prestación de servicios de intermediación laboral.

Asi como también se debe contar con un seguro de responsabilidad civil por el trayecto, otro seguro importante es uno de todo riesgo para las motos acuáticas.

b. Ley de Micro y Pequeña Empresa.

Es la ley más importante que ha expedido el Gobierno en el marco de las facultades legislativas delegadas por el Congreso mediante Ley No 29157. La nueva Ley MYPE, aprobada por Decreto Legislativo № 1086 (El Peruano: 28/06/08) es una ley integral que no sólo regula el aspecto laboral sino también los problemas administrativos, tributarios y de seguridad social que por más de 30 años se habían convertido en barreras burocráticas que impedían la formalización de este importante sector de la economía nacional, expresa el gremio empresarial.

c. La nueva Ley MYPE recoge la realidad de cada segmento empresarial, desde las empresas familiares, las micro hasta las pequeñas empresas, las que ahora tienen su propia regulación de acuerdo a sus características y a su propia realidad. La nueva ley será de aplicación permanente para la MYPE, en tanto cumplan con los requisitos establecidos. Este régimen 
especial no tendrá fecha de caducidad que contemplaba la Ley Nº 28015, limitación que constituía una barrera para la formalización empresarial y laboral de los microempresarios.

d. Ley $\mathrm{N}^{\circ} 28015$ de promoción y formalización de la micro y pequeña empresa (Promulgada el 3 de Julio del 2003)

La presente ley tiene por objeto la promoción de la competitividad, formalización y desarrollo de las micro y pequeñas empresas para incrementar el empleo sostenible, su productividad y rentabilidad, su contribución al Producto Bruto Interno, la ampliación del mercado interno y las exportaciones y su contribución a la recaudación tributaria. Definición de Micro y Pequeña Empresa La Micro y Pequeña Empresa es la unidad económica constituida por una persona natural o jurídica, bajo cualquier forma de organización o gestión empresarial contemplada en la legislación vigente, que tiene como objeto desarrollar actividades de extracción, transformación, producción, comercialización de bienes o prestación de servicios.

e. $\quad$ Ley General de Sociedades Ley $N^{\circ} 26887$.

La Sociedad Quienes constituyen la Sociedad convienen en aportar bienes o servicios para el ejercicio en común de actividades económicas. Aplicación de la Ley Toda sociedad debe adoptar alguna de las formas previstas en esta ley. Las sociedades sujetas a un régimen legal especial son reguladas supletoriamente por las disposiciones de la presente ley. La comunidad de bienes, en cualquiera de sus formas, se regula por las disposiciones pertinentes del Código Civil. Artículo 3.- Modalidades de Constitución La sociedad anónima se constituye simultáneamente en un solo acto por los socios fundadores o en forma sucesiva mediante oferta a terceros contenida en el programa de fundación otorgado por los fundadores. La sociedad colectiva, las sociedades en comandita, la sociedad comercial de responsabilidad limitada y las sociedades civiles sólo pueden constituirse simultáneamente en un solo acto. 
f. Ley N 28611 - Ley General del Medio Ambiente en Perú.

Mediante esta ley se reglamentan aspectos relacionados a la materia ambiental en el Perú. Asimismo; por un lado plantea a los ciudadanos una serie de derechos con relación al tema ambiental, en tanto que se debe garantizar un ambiente saludable, equilibrado y apropiado para el desarrollo de la vida; y por otro lado, deberes, en la medida en que todos estamos obligados a contribuir a una efectiva gestión ambiental y a proteger el ambiente.

Cabe mencionar que, uno de los objetivos de la mencionada Ley, es la regulación de los numerosos instrumentos que contribuyen a la gestión ambiental del país; y uno de los más significativos aportes es la consagración de la responsabilidad por daño ambiental.

Esta ley, nos informa sobre el Estándar de Calidad Ambiental (ECA), que es un indicador de la calidad ambiental, que mide la concentración de elementos, sustancias, parámetros físicos, químicos y biológicos que se encuentran presentes en el aire, agua o suelo, pero que no representan peligro para los seres humanos ni para el ambiente.

\subsection{Análisis cultural.}

Según el Ministerio de Cultura, 2012 en los lineamientos de políticas culturales afirma “cultura, en efecto, es un agente fundamental en la constitución de una sociedad con mejor calidad de vida, una sociedad más crítica de su historia y de sí misma”. Dicho ministerio tiene como objetivo principal destacar la importancia de la cultura y promover políticas y normativas para desarrollar eventos culturales. Si realizamos una mirada de frente a la cultura de nuestro país nos encontramos con datos alarmantes, queda como tarea fundamental a mencionado ministerio de realizar un trabajo arduo para cambiar esta situación.

El Perú se expresa en la diversidad de sus lenguas, siendo el idioma oficial el español, pero el quechua y aymara aún es una lengua viva en regiones del sur del país. Las fiestas 
religiosas son expresiones de creencias y de fe que también fueron influencias españolas. Las fiestas patronales siempre con temáticas ancestrales hacia la Madre Tierra. La gastronomía que hoy en día es una bandera de identidad nacional, dado esto por la diversidad culinaria de todas las regiones. No podemos dejar de mencionar la música y danzas de igual forma presenta diversidad en sus manifestaciones folclóricas.

El turismo cultural, de aventura, rural entre otros; y según estudios realizados por el gobierno del Perú indican que la tasa de satisfacción de los turistas respecto al Perú es de 94\%. Siendo en ese sentido el turismo la industria de rápido crecimiento con una tasa anual del $25 \%$ durante estos últimos cinco años. Ratificando esta información un estudio de Interval International indica que casi el $60 \%$ de peruanos optan por visitar destinos culturales siendo las más visitadas los departamentos de Cuzco (Machu Picchu), Arequipa (Cañón del Colca) y Puno (El Lago Titicaca) de esta forma potencializando la industria del turismo en esta parte sur del país. (gestión.pe, 2015)

\subsection{Análisis tecnológico.}

En lo que respecta al análisis tecnológico del negocio va a innovar el turismo de aventura en la ciudad de Puno con un nuevo modelo de diversión, que sería las motos acuáticas el activo principal el cual cuenta con todas las especificaciones técnicas y tecnológicas necesarias para su utilización, dando así a los turistas una nueva alternativa de diversión, distinguiéndonos de embarcaciones o botes con motor que actualmente se utilizan en la ciudad de Puno para el navego del lago, ampliando así, la gama de servicios que se le ofrece al turismo y con un enfoque más preciso al turista de aventura en el lago Titicaca. En el proyecto se busca utilizar al máximo la tecnología por lo cual se utilizará: 
a. Moto acuática.- Una moto acuática es un embarcación ligera, su forma de manejo es parecido al de una motocicleta convencional o tradicional, con un motor situado dentro de la misma máquina. La principal diferencia de una moto acuática con otra embarcación como un bote o una lancha con motor, es que la moto acuática no utiliza hélice sino que son propulsadas por una turbina la cual origina un chorro de agua en la parte trasera de la moto, la cual se extrae el agua debajo de la moto mediante una bomba que sale por una boquilla a la turbina.

b. Cámaras con tecnología Go pro H5 hero que son las ultimas del mercado.

El futuro de las Agencias Inteligentes:

¿De qué se trata esto? Pues estamos hablando de la incorporación cada vez más profunda y a mayores niveles de la inteligencia artificial, más específicamente, de los software diseñados especialmente para agencias de viajes. Los tiempos de ver a personas atrás de un mostrador, recomendando sitios basados en su experiencia humana parece que irán quedando atrás.

Puede sonar muy raro sin duda. Si había algo que pensamos que nunca sería reemplazado es el consejo de alguien como nosotros, un humano. Pero los últimos avances parecen predecir lo contrario. Actualmente se está trabajando en el desarrollo de software inteligentes, y en cierto modo, “emocionales". Es decir, capaces de conocer los gustos de las personas en base a sus características, elecciones en otras áreas, psicología, lugar donde vive, o historias de compras anteriores.

Todo esto tiene que ver con el grado de exposición que tiene nuestra vida privada en las redes. Cada vez que ingresamos un dato personal a la web, ya sea en un formulario o en una red social, estamos compartiendo una parte de nosotros. Los nuevos programas serían capaces de 
recolectar toda esa información y crear un "perfil de comprador"; de modo de poder establecer una recomendación perfecta y ajustada a cada individuo.

De ser así, lo más probable es que estas aplicaciones funcionen de modo sincronizado con Facebook, Twitter, LinkedIn y redes similares; ya que ellas son como formularios donde volcamos muchos de nuestros gustos personales. Como es de esperar, quedará abierto el debate sobre si esto es correcto o no, sobre cuánta información debería obtener Internet de nosotros. Pero esa discusión ya excede los propósitos meramente informativos de este artículo.

Reservas online:

Debemos esperar en el futuro ver a más y más agencias proveedoras de servicios de viajes adoptar modalidades de reservas on-line. Hace unos años, un pequeño grupo de agencias se habían aventurado a este terreno desconocido hasta entonces. Con programas algo rudimentarios, y aprendiendo a medida que funcionaban, fueron creando un mundo de negocios virtuales que terminó por sentar las bases del futuro de esta actividad (prontur.pe, 2011)

\subsection{Análisis Ecológico.}

El turismo es una industria que tiene que ir relacionado con los factores ambientales, económicos y sociales, en ese sentido el turismo tiene que buscar un desarrollo sostenible en las comunidades sin afectar ni alterar su flora y fauna del medio ambiente, como ente rector de la actividad turística, dentro de sus facultades esta gestionar políticas de gestión ambiental del sector turístico. Mencionado sector tiene como principio básico establecer un turismo racional y sostenible respetando y conservando el medio ambiente donde se desarrolla las actividades turísticas. 
Dentro de este sector de turismo no existe una dirección nacional responsable de asuntos ambientales. La Dirección Nacional de turismo, mediante la Dirección de Medio Ambiente y Sostenibilidad Turística tiene la responsabilidad de velar por la sostenibilidad socio-ambiental del turismo en el Perú.

Ésta dirección técnico-normativa, es responsable de proponer, evaluar y supervisar todas la normas nacionales en cuanto a política nacional de turismo sostenible en materia ambiental. (mincetur.pe, 2016)

Contaminación de la vida acuática del Lago

La eutrofización que se viene produciendo en los diferentes lagos y ríos del mundo es cada vez mayor. El Perú no escapa a esta situación que en la actualidad viene afectando a aguas marinas y continentales (lagos y ríos) y, en lo que a lagos se refiere, de manera general son los principales receptores de aguas contaminadas de origen doméstico e industrial, éstas últimas con presencia de sustancias tóxicas que afectan gravemente a la vida de los hidrosistemas. Problema que se torna preocupante considerando al Lago Titicaca como un ecosistema de vital importancia que sostiene de manera integral, a gran parte de la- población del altiplano peruano, ya que en él se encuentran importantes recursos acuáticos, y que son afectados por la contaminación.

Plan Director con el cual se sistematizaron los datos e información procedente de diferentes fuentes posibilitando su consulta e intercambio entre Perú y Bolivia y sirviendo como marco de referencia para el manejo del sistema basándose en:

- Enfocar las acciones hacia el uso sostenible de los recursos naturales con los recursos como elemento central. 
- Recuperar la integridad ecológica del sistema: proteger las especies en peligro de extinción, recuperar las poblaciones de peces y reducir el impacto de las actividades humanas en el sistema.

-Promover el desarrollo humano en las cuencas.

Organismos internacionales y proyectos preocupados

Hay que señalar que esta propuesta de actuaciones que se realiza en el marco del Programa de las naciones Unidas para el medio Ambiente (PNUMA) cuya finalidad es establecer coordinaciones con la Autoridad Binacional Autónoma del Sistema Hídrico del Lago Titicaca, Río Desaguadero, Lago Poopó, Salar de Coipasa, entidad que gestiona esta cuenca e integrarse en el Plan Director Global Binacional del Sistema Hídrico TDPS (El lago Titicaca (T), el río Desaguadero (D), el lago Poopó(P) y el lago Salar de Coipasa (S)) Esta autoridad depende funcional y políticamente de los Ministerios de Relaciones Exteriores de Perú y Bolivia.

Según el Instituto Nacional de Recursos Naturales (INRENA), (2015) Contaminación: Existe en el área una creciente presión sobre los recursos naturales, lo que ha llevado a niveles crecientes de degradación de los ecosistemas. De igual modo existe un número de problemas asociados a la regulación de los recursos hídricos para actividades económicas y los ecosistemas y en algunos casos deficiencias en el suministro de agua y servicios de saneamiento que afectan directamente la calidad del suministro de agua lo cual crea una amenaza potencial a la salud de la población. La erosión de los suelos y las descargas sin tratamiento de las ciudades, actividades agrícolas y minería también constituyen una amenaza.

Entre las zonas específicas de contaminación podemos mencionar:

- Áreas de expansión urbana de las ciudades de Juliaca (Perú) y Puno (Perú),El Alto (Bolivia), Oruro (Bolivia), Viacha (Bolivia), 
-Hay otras zonas de importante crecimiento turístico, como el caso de Copacabana (Bolivia), donde debido a la inexistencia de sistemas de saneamiento y depuración se está produciendo problemas sanitarios en las zonas de baño debido a la contaminación de las aguas. 


\subsection{Oportunidades y Amenazas.}

Tabla 16

Oportunidades y Amenazas del Entorno

\begin{tabular}{|c|c|c|c|}
\hline Contexto & Criterio & Oportunidad/Amenaza & Por que \\
\hline & TLC & Oportunidad & $\begin{array}{c}\text { Se convierte en oportunidad ya que genera estabilidad } \\
\text { e inversión }\end{array}$ \\
\hline \multicolumn{4}{|l|}{ Análisis Político } \\
\hline \multirow[t]{2}{*}{ Gubernamental } & Marca Perú & Oportunidad & $\begin{array}{l}\text { Se convierte en oportunidad ya que se posiciona } \\
\text { mejor el Perú en el mercado extranjero como } \\
\text { nacional }\end{array}$ \\
\hline & Huelgas & Amenaza & $\begin{array}{c}\text { Se convierte en amenaza ya que continuamente hay } \\
\text { huelgas que paran el turismo y generan molestias a } \\
\text { los turistas nacionales e internacionales }\end{array}$ \\
\hline \multirow[t]{3}{*}{ Análisis Económico } & PBI & Oportunidad & $\begin{array}{l}\text { Se considera una oportunidad ya que el crecimiento } \\
\text { económico beneficia al sector turismo }\end{array}$ \\
\hline & Flujo de divisas & Oportunidad & $\begin{array}{c}\text { Se considera una oportunidad ya que nos indica el } \\
\text { flujo de turistas al Perú }\end{array}$ \\
\hline & Impuestos & Amenaza & $\begin{array}{l}\text { Se convierte en amenaza ya que están en constante } \\
\text { aumento lo cual puede desequilibrar los presupuestos }\end{array}$ \\
\hline \multirow[t]{6}{*}{ Análisis Legal } & $\begin{array}{l}\text { Ley } \mathrm{N}^{\circ} 28611 \text { Ley general } \\
\text { del medio ambiente }\end{array}$ & Amenaza & $\begin{array}{l}\text { Se considera una amenaza ya que aumentan las } \\
\text { restricciones para acceder al Lago }\end{array}$ \\
\hline & $\begin{array}{l}\text { Ley } \mathrm{N}^{\circ} 26887 \text { Ley } \\
\text { generalde sociedades }\end{array}$ & Oportunidad & $\begin{array}{c}\text { Se considera una oportunidad ya que no todas las } \\
\text { empresas de turismo son legales }\end{array}$ \\
\hline & Seguro de responsabilidad & Oportunidad & $\begin{array}{l}\text { Se considera una oportunidad ya que se tiene un } \\
\text { respaldo para cualquier accidente }\end{array}$ \\
\hline & Seguro todo riesgo & Oportunidad & $\begin{array}{l}\text { Se considera una oportunidad ya que se debe } \\
\text { asegurar las motos acuaticas contra cualquier }\end{array}$ \\
\hline & Informalidad del sector & Amenaza & $\begin{array}{l}\text { Se considera amenaza ya que no se pagan impuestos } \\
\text { no se tiene ningún registro y son riesgosas }\end{array}$ \\
\hline & Diversidad de lenguas & Oportunidad & $\begin{array}{c}\text { Se considera una oportunidad ya que crece la } \\
\text { expectativa por conocer nuevas experiencias y la } \\
\text { cultura del país }\end{array}$ \\
\hline Análisis Cultural & Festividades & Oportunidad & $\begin{array}{c}\text { Se considera una oportunidad ya que incrementa el } \\
\text { Turismo Nacional }\end{array}$ \\
\hline Análisis Tecnológico & Innovación & Oportunidad & $\begin{array}{c}\text { Se considera una oportunidad ya que el mercado de } \\
\text { turismo debe innovar en los circuitos (Go pro, } \\
\text { Drones) }\end{array}$ \\
\hline \multirow{4}{*}{ Análisis Ecológico } & Gestión ambiental & Oportunidad & $\begin{array}{l}\text { Se considera una oportunidad ya que el gobierno se } \\
\text { preocupa y busca un desarrollo sostenible sin afectar }\end{array}$ \\
\hline & & & el ambiente \\
\hline & Contaminación & Amenaza & $\begin{array}{l}\text { Se considera una amenaza ya que con el paso del } \\
\text { tiempo puede ir en aumento y posible cierre }\end{array}$ \\
\hline & Permisos de la comunidad & Amenaza & $\begin{array}{l}\text { Se considera amenaza ya que no se sabe hasta } \\
\text { cuando se podra obtener el permiso y condiciones }\end{array}$ \\
\hline
\end{tabular}




\section{Capítulo III: Estudio de Mercado}

Según la Asociación Americana de Marketing ([AMA], 2014), la definición de estudio de mercado; es aquella que relaciona al cliente, el consumidor y al vendedor a través de la información para poder encontrar oportunidades y amenazas; generar, evaluar y afinar acciones de marketing; evaluar el desempeño de las ventas y comprender el proceso de compra. Por tanto la investigación de mercados permite diseñar un método para la recolección de la información y con ello poder analizar y comunicar sus resultados e implicaciones.

Por ello se realizó una investigación cualitativa y cuantitativa. Se tiene presente que el objeto principal en la investigación consistió en conocer la necesidad de un circuito turístico de aventura con alquiler de motos acuáticas en el departamento de Puno. Para ello se evaluó el nivel de aceptación o rechazo del proyecto, los factores de decisión que motiva a los potenciales clientes a realizar turismo de aventura y conocer lo medios preferidos para comunicar el proyecto ante una posible implementación. Se planteó objetivos generales y específicos que ayudo a definir las preguntas a realizar en la investigación. 


\section{Tabla 17}

\section{Objetivos Generales y Específicos de la Investigación Cuantitativa}

Objetivo General

\begin{tabular}{ll}
\hline & $\begin{array}{l}\text { Nivel de ingresos } \\
\text { Composición Familiar (\# miembros) } \\
\text { Acerca del Público }\end{array}$ \\
Objetivo estancia \\
\end{tabular}

Acerca de la decisión de Formas de obtener información ¿Cómo busca? compra de un circuito turístico

Duración del servicio

Rangos de precio

Motivaciones y frenos

Acerca de Playas del

Lago Titicaca

Ventajas de la zona; Percepción de Lago

Desventajas de la zona

Frecuencia de visita

Frecuencia uso servicio

Percepción del proyecto

Acerca del Proyecto

Percepción de la ubicación

Intención (de compra/recomendación)
Objetivos específicos

Ocupación (trabajo dependiente/independiente)

Tenencia de vehículo

Edades y género familia

Establecimientos de interés en la zona (restaurantes, grifos, hoteles, hospitales)

Medios donde encuentra información ¿Dónde busca?

Tiempo de viaje

Seguridad del servicio

Factores influyen visita al distrito

Conocimiento lugares turísticos y festividades

Actividades realizadas

Tiempo del servicio

Percepción de seguridad

Precio

Promociones esperadas (alternativas alimentación y hospedaje) 
Tabla 18

Objetivos Generales y Específicos de la investigación Cualitativa

\begin{tabular}{|c|c|c|}
\hline \multirow[t]{2}{*}{ Objetivo General } & \multicolumn{2}{|c|}{ Objetivos específicos } \\
\hline & Perspectiva de crecimiento & Interes de turista nacional o extranjero \\
\hline \multirow{3}{*}{ Acerca del sector } & Potencial turismo aventura en Perú & \\
\hline & Puno es propicio para turismo de aventura & \\
\hline & Oferta de circuitos de turismo de aventura & \\
\hline \multirow{4}{*}{$\begin{array}{l}\text { Acerca de la decisión de } \\
\text { compra de un circuito } \\
\text { turístico }\end{array}$} & Formas de obtener información ¿Cómo busca? & Medios donde encuentra información ¿Dónde busca? \\
\hline & Duración del servicio & Tiempo de viaje \\
\hline & Rangos de precio & Seguridad del servicio \\
\hline & Motivaciones y frenos & Factores influyen visita al distrito \\
\hline \multirow{5}{*}{$\begin{array}{l}\text { Acerca de Playas del } \\
\text { Lago Titicaca }\end{array}$} & Ventajas de la zona; Percepción de Lago & Conocimiento lugares turísticos y festividades \\
\hline & Desventajas de la zona & Actividades realizadas \\
\hline & Frecuencia de visita & \\
\hline & Frecuencia uso servicio & Tiempo del servicio \\
\hline & Percepción del proyecto & Percepción de seguridad \\
\hline \multirow[t]{3}{*}{ Acerca del Proyecto } & Percepción de la ubicación & Precio \\
\hline & Obstaculos para la ejecución del proyecto & Medios publicitarios \\
\hline & Intención (de compra/recomendación) & $\begin{array}{l}\text { Promociones esperadas (alternativas alimentación y } \\
\text { hospedaje) }\end{array}$ \\
\hline
\end{tabular}

\subsection{Descripción del Servicio o Producto}

El servicio se desarrollará en una de las playas del lago Titicaca. La playa a elegida es resultado de la investigación cualitativa donde se consultó cual es la playa con mejor acceso de transporte, mejor clima durante el año, y la de mayor afluencia por parte de los ciudadanos de Puno. La playa donde se desarrollará el proyecto es la playa Chifrón - Capachica, la cual es resultado de las sesiones de grupo y entrevistas realizadas.

El servicio será ofertado en la ciudad de Puno en dos zonas altamente transitadas por turistas nacionales como locales. Dichas zonas son: el puerto lacustre de la ciudad y la plaza de armas. En las zonas mencionadas se realizará la oferta al público general y turista nacional para realizar los paquetes diarios. Se brindará el itinerario del viaje, costos, información 
sobre los servicios adicionales al paquete básico y se detallará las medidas de seguridad a tener en cuenta durante la travesía.

Al cliente se le incluye el servicio de transporte de ida y vuelta (Puno- Playa Titicaca Puno) en cómodos minibuses. El viaje de la ciudad al punto de destino no demorará más de 45 minutos, en el trayecto se explicará de forma breve y concisa las acciones a realizar durante el viaje.

Una vez en destino se planteará al cliente dos alternativas: (a) bicicleta de montaña; (b) caminata. Cabe señalar que se llega a la playa caminando o en bicicleta, los pobladores locales no dejan entrar vehículos por la contaminación y polvo que generan. La opción de bicicleta de montaña tendrá un circuito más largo para llegar a la playa y de modo que el turista pueda apreciar el paisaje y experimentar el aire puro de la zona. Por otro lado, la opción de caminata será más corta y se recorrerá la campiña de la zona hasta llegar a un punto cercano a la playa. Las dos opciones tendrán una duración de 20 a 30 minutos guiados por un profesional donde se llegará a un punto cercano a la playa donde los dos grupos realizarán una actividad con ejercicios de relajación de estiramiento y anti stress.

En el punto de encuentro se dará una pequeña explicación de las costumbres de la zona, la flora y fauna que se puede encontrar en la zona. La duración de esta parte no será mayor a 20 minutos. 
Después el grupo se dirige hacia la playa donde habrá un reposo de 15 minutos para luego pasar a realizar el circuito de motos acuáticas.

Los turistas serán previamente equipados con un traje térmico y chaleco salvavidas antes de realizar el paseo en la moto acuática. Se realizará un periodo de prueba de 10 minutos antes de partir por el circuito. La asistencia en el manejo y uso de los equipos acuáticos estará a cargo por personal capacitado. La ruta está definida mediante boyas que guiaran al turista por el circuito que tendrá un tiempo de duración de 15 minutos a 20 minutos.

Durante el trayecto se realizará la filmación mediante un dron (caminata y bicicleta) y; la ruta acuática será filmada con una cámara Go Pro adherida a la moto acuática.

La filmación de los videos serán enviados vía redes sociales en 15 días hábiles después de la travesía.

Una vez terminado el circuito en moto acuática los turistas podrán pasear unos minutos antes de la partida para degustar de la comida típica de lugar. La comunidad local será quien ofrezca los servicios, productos o suvenir a los turistas.

El cliente tiene la opción de alojamiento en un hotel o realizar campamento en la playa del lago después de culminado el circuito. La empresa no interviene en la oferta del servicio ya que, lo ofrece la comuna local. 
La empresa entrega a todos los clientes equipos de seguridad y otros para cada parte del circuito. El servicio busca brindar adrenalina, velocidad, aventura y naturaleza a través de las actividades a realizar. Los mismos tendrán asistencia por parte de guías especializados y capacitados. El servicio durará en promedio tres a cinco horas durante las mañanas de martes a domingo y los que quieran quedarse en la zona la travesía tiene una duración total de un día.

\subsection{Selección del Segmento de Mercado}

Según Kotler \& Armstrong (2012), la segmentación de mercado puede tener diferentes variables, ya sea que se utilice una variable o una combinación de las mismas; estas son determinadas por el mercadólogo. Sin embargo, hay cuatro variables que son las más utilizadas:

a. Segmentación geográfica: consiste en subdividir el mercado en unidades geográficas

b. Segmentación demográfica: consiste en dividir el mercado en variables de edad, tamaño familiar, ingreso, ocupación, ciclo de vida, nacionalidad, etc.

c. Segmentación psicográfica: consiste en dividir al mercado según clase social, estilo de vida y personalidad

d. Segmentación conductual: consiste en dividir el mercado según sus conductas, estas pueden ser la frecuencia de uso, actitud hacia el servicio, beneficios buscados, etc.

Por otro lado, el estudio más empleado para la clasificación de estilos de vida es la planteada por Arellano (2016), quien separa seis estilos de vida en dos grupos: Moderno y Tradicionales. Dichos estilos de vida se encuentran presentes en todos los niveles socioeconómicos y no obedecen a un nivel de ingresos determinado sino hacia una forma de vida. 
El grupo de estilos de vida moderno son tres:

a. Sofisticados: Son personas que valoran la imagen personal, les interesa mantener un status social. En su mayoría son jóvenes. Cuentan con un ingreso mayor al promedio y son los más arriesgados a optar por nuevos servicios y tendencias. Género mixto

b. Formales: por lo general tienen cargos medios, valoran mucho su status, están orientados a sus familias. Optan por nuevas tendencias después de un tiempo.

c. Modernas: por lo general son mujeres. Buscan mantener bien sus familias y lograr retos sus retos personales. Suelen maquillarse, no les gusta el machismo, salen de compras y optan por productos que les faciliten las labores del hogar.

El grupo de estilos de vida tradicionales son los siguientes:

a. Progresistas: por lo general son hombres. Buscan el progreso continuo. Suelen ser empresarios, buscan siempre nuevas oportunidades. Estudian carreras cortas y los motiva a cambiar su situación actual.

b. Conservadores: por lo general mujeres muy tradicionales con fuertes influencias religiosas. Son amas de casa que visten lo básico, les gusta estar con sus hijos y ver telenovelas. Son las responsables de administrar la economía del hogar.

c. Austeros: de ambos géneros, no tienen muchos recursos económicos. No les gustan los cambios, no toman riesgos y prefieren una vida sin complicaciones.

Por tanto, la segmentación se realizó bajo las principales variables de segmentación y en la variable psicográfica se empleó los estilos de vida del Perú planteado por Arellano. Se tendrá dos tipos de público: turistas nacionales y ciudadanos locales de Puno. Según Tabla 19, se realizará la segmentación de mercado para el proyecto. 


\section{Tabla 19}

Segmentación de Mercado Para el Proyecto

\begin{tabular}{lll}
\hline Variables & Turista Nacional & Ciudadanos locales Puno \\
\hline $\begin{array}{l}\text { S. Geografica } \\
\text { S. Demografica }\end{array}$ & Peruanos o extranjeros & Puneños \\
- Edad & 14 a 59 años & 14 a 59 años \\
- Género & Masculino o femenino & Masculino o femenino \\
- Ciclo de vida & Solteros; casados con hijos; parejas no casadas & Solteros; casados con hijos; parejas no casadas \\
- NSE & A, B, C+. Ingresos familiares mayores a S/2,500 & A, B, C+. Ingresos familiares mayores a S/2,500 \\
- Estado civil & Indistinto & Indistinto \\
S. Psicografica & & \\
- Personalidad & Aventureros, emprendedores, innovadores, sociables, & Aventureros, emprendedores, innovadores, sociables, \\
estilo de vida & entusiastas & Sofisiastas \\
S. Conductual & Sofisticado, modernos, formales, progresistas & Fines de semana, vacaciones, feriados largos, \\
- Ocasiones & Vacaciones, por negocios, feriados largos & festividades locales
\end{tabular}

\subsection{Investigación Cualitativa}

Es la metodología de investigación exploratoria basada en la toma de pequeñas muestras, no es estructurada y tiene el propósito de brindar información y compresión de la situación del problema. Por lo general es un paso previo al desarrollo de una investigación más estructura como la cuantitativa (Benassini, 2014). Entre las metodologías existentes se tienen:
a. encuestas piloto
b. pruebas de productos
c. sesiones de grupo (focus group)
d. entrevistas a profundidad

\subsection{Proceso de muestreo.}

Se toma la técnica de muestreo no probabilístico por conveniencia para las sesiones de grupo y entrevistas a profundidad; la cual consiste seleccionar elementos convenientes que el entrevistador elige de acuerdo al perfil requerido. La mayoría de veces los seleccionados se 
encuentran en una misma área geográfica y horario. Es la técnica más económica y la que consume menor tiempo de reclutamiento. Este tipo de técnica es adecuada para estudios piloto y sesiones de grupo (Benassini, 2014)

Se diseña el proceso de muestreo de la siguiente manera: Tabla 20

Proceso del Diseño de Muestreo Para Sesiones de Grupo o Focus Group

\begin{tabular}{ll}
\hline Variables & Detalle \\
\hline Población meta & $\begin{array}{l}\text { Hombres o mujeres entre 14 a 59 años, estado civil } \\
\text { indistinto, que sean turistas nacionales y/o vivan en la ciudad } \\
\text { de Puno. }\end{array}$ \\
Marco de muestreo & $\begin{array}{l}\text { Pobladores y turistas que se encuentren en la plaza de armas, } \\
\text { centros comerciales y puerto lacustre de la ciudad de Puno }\end{array}$ \\
$\begin{array}{l}\text { Técnica e muestreo } \\
\text { Tamaño de la muestra }\end{array}$ & $\begin{array}{l}\text { Muestreo no probabilistico por conveniencia } \\
\text { Ocho personas por sesion de grupo. Cuatro sesiones en total } \\
\text { Se realizará en un fin de semana en la ciudad de Puno. Dos } \\
\text { sesiones se realizaran en la sala de conferencias de Casona } \\
\text { Realización }\end{array}$ \\
$\begin{array}{l}\text { Plaza Hotel, una en centro comercial Real Plaza Puno y } \\
\text { parques recreativos de la ciudad }\end{array}$ \\
\hline
\end{tabular}

Nota: Adaptado de "Investigación de Mercados" Quinta Edición, p. 333, por N. K. Malhotra, 2008, México, D.F. Mexico: Prentice Hall. Copyrigth 2008 por Pearson 
Tabla 21

Proceso del Diseño de Muestreo Para Entrevistas a Profundidad

Proceso del diseño de muestreo para Entrevistas a Profundidad

\begin{tabular}{ll}
\hline Variables & Detalle \\
\hline Población meta & $\begin{array}{l}\text { Género y edad indistinto, con experiencia de más de 5 años } \\
\text { en el sector turismo que sean Gerentes o Ejecutivos de venta } \\
\text { de Agencias de viaje u hoteles de la ciudad de Puno. }\end{array}$ \\
$\begin{array}{l}\text { Marco de muestreo } \\
\text { Técnica e muestreo }\end{array}$ & $\begin{array}{l}\text { Muestreo no probabilistico por conveniencia } \\
\text { Cuatro personas }\end{array}$ \\
Tamaño de la muestra & $\begin{array}{l}\text { Se realizará durante horario de trabajo entre 08:00 - 18:00 } \\
\text { hrs, en la ciudad de Puno o Arequipa }\end{array}$ \\
\hline $\begin{array}{l}\text { Nota: Adaptado de "Investigación de Mercados" Quinta Edición, p. 333, por N. K. } \\
\text { Malhotra, 2008, México, D.F. Mexico: Prentice Hall. Copyrigth 2008 por Pearson } \\
\text { Education }\end{array}$
\end{tabular}

Tabla 22

Procesos de Muestro Realizados

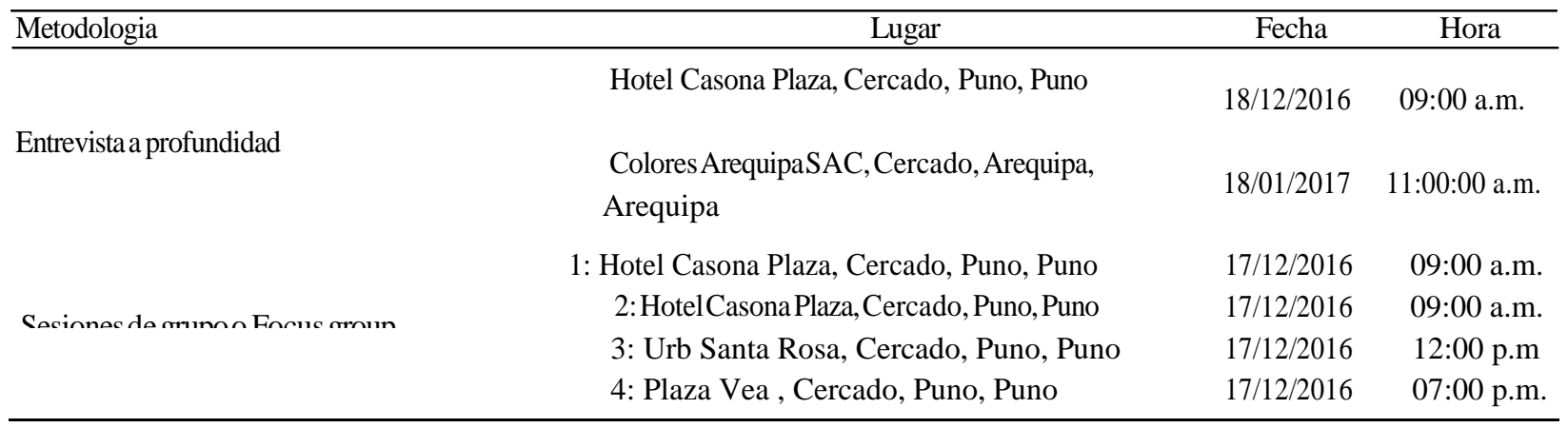

\subsection{Diseño de instrumento.}

Se propone un estudio de carácter exploratorio con la aplicación de la técnica de entrevistas grupales llamadas Focus Group y entrevistas a profundidad a expertos del sector turismo. Los estudios exploratorios tienen por objetivo proporcionar información y comprensión 
sobre un problema o situación. La muestra en reducida y no representativa, el análisis de los datos es cualitativo y otorgan resultados o hallazgos tentativos previos a una investigación concluyente (Benassini, 2014).

Dicha propuesta de investigación tiene como objetivo proporcionar a la empresa información valiosa de su público objetivo como conocer sus experiencias, saber que opinan del servicio, información de la competencia y entender de forma más clara el entorno donde se desenvuelve la empresa.

Para las dinámicas grupales se utilizó una guía de indagación (ver Anexo 2) para la dirección del proceso.

Para las entrevistas a profundidad se realizó mediante preguntas abiertas (ver Anexo 1) sobre el sector, la viabilidad del proyecto y movimiento del mercado.

\section{Análisis y procesamiento de datos.}

Para el proyecto a presentar se realizaron cuatro Focus Group en distintos lugares de la ciudad de Puno, con un número de participantes de ocho personas, entre 14 a 59 años, de ambos géneros, y la localización fue en Puno.

Asimismo se realizaron dos entrevistas a profundidad a expertos en el sector que laboran en agencias de viaje en la ciudad de Puno y Arequipa. Las entrevistas tuvieron una duración entre 15 a 20 minutos. 


\section{Resumen de los Focus Group:}

Los participantes son naturales de Puno y de otros lugares de Perú. Todos ellos coinciden que les gusta viajar y conocen ya muchos lugares de Puno, mayormente los lugares visitados por los turistas, siempre buscan nuevas experiencia, adrenalina y conocer lugares nuevos.

Consideran que el tiempo en transportarse es indispensable para realizar un circuito turístico, a estos se suma su presupuesto de viajes que oscila entre 100 a 300 soles dependiendo del circuito que les ofrezcan, puesto que un su mayoría para reducir gastos llevan su propio fiambre y de esta manera economizan más, esto también lo hacen porque en muchos lugares a visitar no hay servicio de restaurantes o alimentación.

Mencionados grupos busca sobre todo la seguridad aún más si van con sus familias, de esta forma garantizan pasarla bien y conocer más lugares.

La movilidad es un factor importante para ellos, saber a qué hora salen y a qué hora puede regresar. Esta información la reciben de los buses de los terminales donde toman los buses para hacer su viaje, así también prefieren viajar en grupos puesto que el gasto es compartido y les es más económico. Buscan una empresa segura para movilizarse y que les brinde la mayor información posible de esta forma se sienten más seguros.

Los lugares más conocidos en Puno son la Isla de los Uros, Amantaní, Taquile, Chucuito, July, Sillustani, etc, mayormente estos lugares son los más ofrecidos en los paquetes turísticos, no sabiendo que hay muchos lugares más hermosos que no son conocidos ni visitas por los turistas. 
Respecto a las playas que más conocen son Chiflón, Karina, Charcas y Suasi. Siendo la particularidad de estas playas su tranquilidad y limpieza. Generalmente van a las playas en verano en los meses de Diciembre a Marzo. En estos lugares buscan relajarse y prefieren la tranquilidad de estas playas. Estas playas son más frecuentadas en festividades como el día del estudiante, por viajes de promociones, viajes de estudios.

A pesar de todos los beneficios de estas playas la desventaja en que no tienen servicios como de restaurantes, alojamiento y peor aún no hay mucha movilidad.

Respecto al proyecto los grupos opinan que debería ejecutarse en las playas de Capachica porque ofrecen muchas más ventajas como: movilidad a toda hora, es lugar estratégico como eje comercial entre Juliaca y Puno, hay mayor afluencia de turistas casi todo el año.

Así también el servicio va a depender mucho del clima, del frío de como este el lago y el viento. La mejor temporada para aprovechar sería en los meses de Enero y Febrero, que son las fechas de la Fiesta de la Candelaria, en esos tiempos hay bastante gente.

Las peores fechas sería en épocas de helada que es de Mayo a Agosto, pero lo recomendable sería ofertarlo desde Lima puesto que los turistas ya vienen con un plan establecido en su visita a Puno.

Para promocionarlo en Puno los medios más usados sería la televisión, radio, cable. También tendría que promocionarse con agencias, los docentes de la universidad puesto que ellos mueven gentes de la universidad que no son pocos.

Respecto al pago por el servicio podría ser 100 soles si es como un tour, hasta cincuenta soles si es como promoción. Esto se tendría que canalizar con agencias, también puede ser los docentes de la universidad puesto que ellos mueven gentes de la universidad que no son pocos. 
La frecuencia de tomar estos servicios sería quincenal en la mayoría de los participantes, esto lo haría por tener nuevas experiencia y salir de lo rutinario que les ocasiona estrés.

Resumen de Entrevistas a profundidad:

Los entrevistados son profesionales con más de 10 años en el rubro radican en la ciudad de Arequipa y Puno.

Indicaron que hace 10 a 15 años el sector ha crecido a un ritmo de $10 \%$ anual, ha mejorado bastante la infraestructura del sector para garantizar el servicio de los paquetes turísticos que como agencia de viaje ofrecen. Un indicador o referente del sector es la cantidades visitantes que ingresan a la ciudad del Cusco. Falta un mayor apoyo de las autoridades para explotar otros circuitos. Lo más visitado en Puno es la isla de Los Uros, Amantani y Taquile. Lo más vendido es el turismo vivencial ya que, los turistas disfrutan de caminatas largas, cultura y el paisaje. En promedio una visita a Puno demora al turista entre 1 a 1.5 días.

El proyecto es atractivo para ofrecer solo demuestran preocupación por la logística que tendría el circuito y el apoyo de las autoridades para ofertar el circuito. Las dos mejores zonas de playa son Charcas y Chifrón. Las mismas no son promocionadas y hay más afluencia hacia Capacchica. La mejor formo para ellos de promocionar el servicios es a través de las redes sociales, páginas Web como "Tu que planes" o "Tripadvisor" pero sobretodo la publicidad boca a boca es la que mejor resultados tiene. El precio del circuito para turistas nacionales o extranjeros si se incluye el alojamiento puede estar entre USD 140 a USD 180 y para locales la media hora aconsejan que sea entre 40 a 50 soles. Asimismo las personas que consideran según la experiencia en el rubro, que gusta de realizar actividades al aire libre son para público local 8 de 10 personas y para un turista nacional 6.5 de 10 personas 


\subsection{Investigación Cuantitativa}

La investigación cuantitativa busca a partir de una muestra evaluar una población realizando inferencias y visualizar la existencia de una relación entre las variables recogidas de dicha muestra. (Ugalde y Balbastre, 2013; Ghauri y Gronhaug, 2010; Ragin, 1999a)

\subsubsection{Proceso de muestreo.}

Se toma la técnica de muestreo aleatorio simple, la cual permite que cualquier encuestado tenga la misma probabilidad de ser elegido. Cada elemento es independientemente elegido uno del otro (Benassini, 2014).

Según el INEI (2015), la cantidad de habitantes entre 14 a 59 años en el Perú es de 14, 732,593 siendo solo del departamento de Puno unos 658,679 habitantes. Asimismo la cantidad de turistas nacionales que llega a Puno fue de 516,342. Conociendo estos datos y asumiendo proporción del 50\%, un nivel de confianza del 95\% el tamaño de nuestra, y una población mayor a 100,000 se asume una población infinita para el cálculo del tamaño de la muestra:

Z: 1.96 (nivel de confianza al 95\%)

P: $50 \%$

Q: $50 \%$

E: $5 \%$

$\mathrm{n}=\left(\mathrm{Z}^{\wedge} 2 \mathrm{PQ}\right) / \mathrm{E}^{\wedge} 2=384$ encuestado

Por ende, se debe realizar la encuesta a 384 encuestas.

Esta metodología es de naturaleza descriptiva, concluyente de diseño transversal simple ya que, se extraerá una sola muestra de encuestados de la población meta y se obtiene información de esta una vez (Benassini, 2014). Se centrará en los aspectos observables y 
susceptibles de cuantificación, utiliza la estadística para el análisis de datos que nos permitirá examinar la información de manera concluyente a toda la población con ayuda del trabajo de campo que se realizará por medio de encuestas.

Se diseña el proceso de muestreo de la siguiente manera según tabla 23 para las encuestas:

Tabla 23

Proceso del Diseño de Muestreo Para Encuestas

\begin{tabular}{ll}
\hline Variables & Detalle \\
\hline Población meta & $\begin{array}{l}\text { Hombres o mujeres entre 14 a 59 años, estado civil } \\
\text { indistinto, que sean turistas nacionales y/o vivan en la ciudad } \\
\text { de Puno. }\end{array}$ \\
Marco de muestreo & $\begin{array}{l}\text { Pobladores y turistas que se encuentren en la plaza de armas, } \\
\text { centros comerciales y puerto lacustre de la ciudad de Puno }\end{array}$ \\
$\begin{array}{l}\text { Técnica e muestreo } \\
\text { Tamaño de la muestra }\end{array}$ & $\begin{array}{l}\text { Muestreo aleatorio simple } \\
384 \text { encuestados }\end{array}$ \\
Realización & $\begin{array}{l}\text { Se realizará durante un fin de semana en cuatro zonas de la } \\
\text { ciudad de Puno. Centro comercial Real Plaza Puno, Plaza de } \\
\text { armas de la ciudad, puerto lacustre y universidades de Puno. }\end{array}$
\end{tabular}

Nota: Adaptado de "Investigación de Mercados" Quinta Edición, p. 333, por N. K. Malhotra, 2008, México, D.F. Mexico: Prentice Hall. Copyrigth 2008 por Pearson Education

\subsection{Diseño de instrumento.}

Se utilizará las encuestas personales en calles comerciales de la ciudad de Puno, este tipo de encuestas tiene la ventaja de ser controlada y guiada por un encuestador, esto ayudará cuantificar los elementos de la investigación. 
En el cuestionario se utilizó preguntas en su mayoría con estructura cerradas de opción múltiple, simple y dicotómica (ver Anexo 3). El total de preguntas realizadas fueron 25.

\subsection{Análisis y procesamiento de datos.}

Para el análisis de los datos se usará tablas de frecuencia sobre cada una de las preguntas del cuestionario para visualizar las tendencias y nivel de aceptación del proyecto.

\section{Tabla 24}

Pregunta 1: Género

\begin{tabular}{lcc}
\hline Variables & Frecuencia & Porcentaje \\
\hline Masculino & 187 & 48.70 \\
Femenino & 197 & 51.30 \\
Total & 384 & 100.00 \\
\hline
\end{tabular}

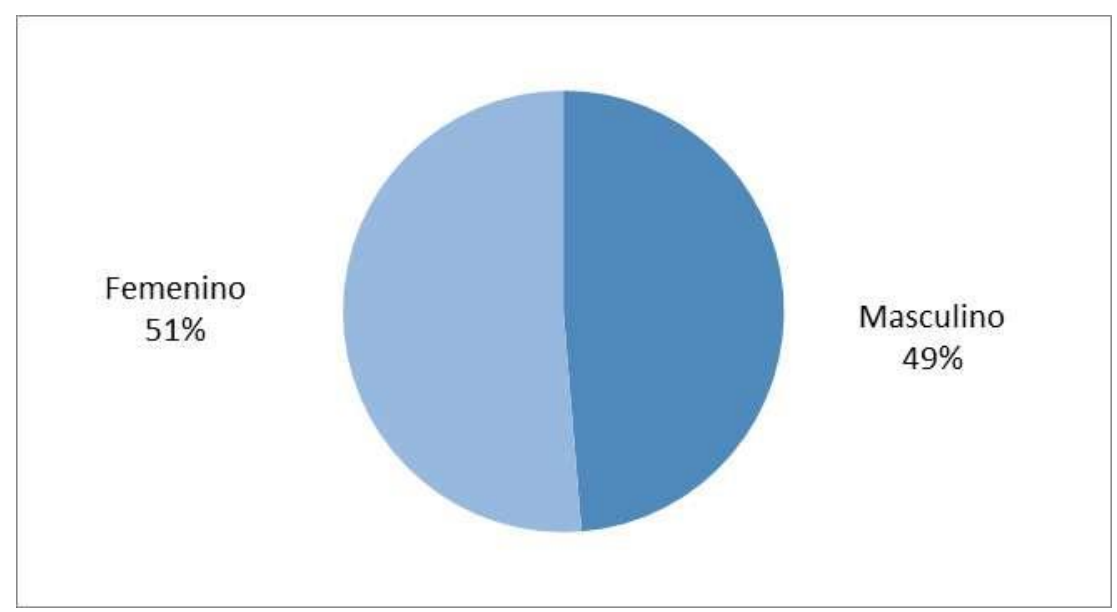

Figura 8. Género

El resultado obtenido nos indica que la mayor población encuestada es femenino, pese hacer la brecha muy estrecha $(2 \%)$ entre el género masculino. 
Tabla 25

Pregunta 2: Edad

\begin{tabular}{lcc}
\hline Variables & Frecuencia & Porcentaje \\
\hline Entre 14 a 29 años & 220 & 57.29 \\
Entre 30 a 44 años & 138 & 35.94 \\
Entre 45 a 59 años & 18 & 4.69 \\
Más de 59 años & 8 & 2.08 \\
Total & 384 & 100.00 \\
\hline
\end{tabular}

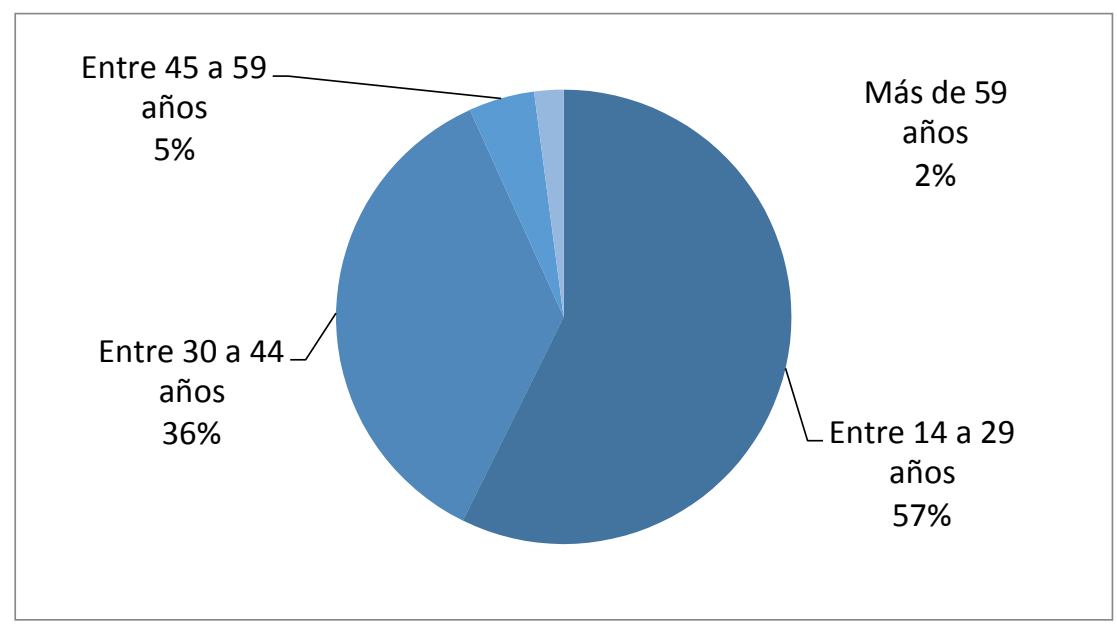

Figura 9. Edad

El resultado obtenido nos indica que la mayor población está entre 14 a 29 años (57\%) esto no permitirá orientar e impulsar nuestra campaña de publicidad hacia ese rango de edad e intentar obtener mayor impacto en este grupo.

Tabla 26 
Pregunta 3: Estado Civil

\begin{tabular}{lcc}
\hline Variables & Frecuencia & Porcentaje \\
\hline Soltero & 277 & 72.14 \\
Casado & 72 & 18.75 \\
Divorciado & 9 & 2.34 \\
Conviviente & 26 & 6.77 \\
Total & 384 & 100.00 \\
\hline
\end{tabular}

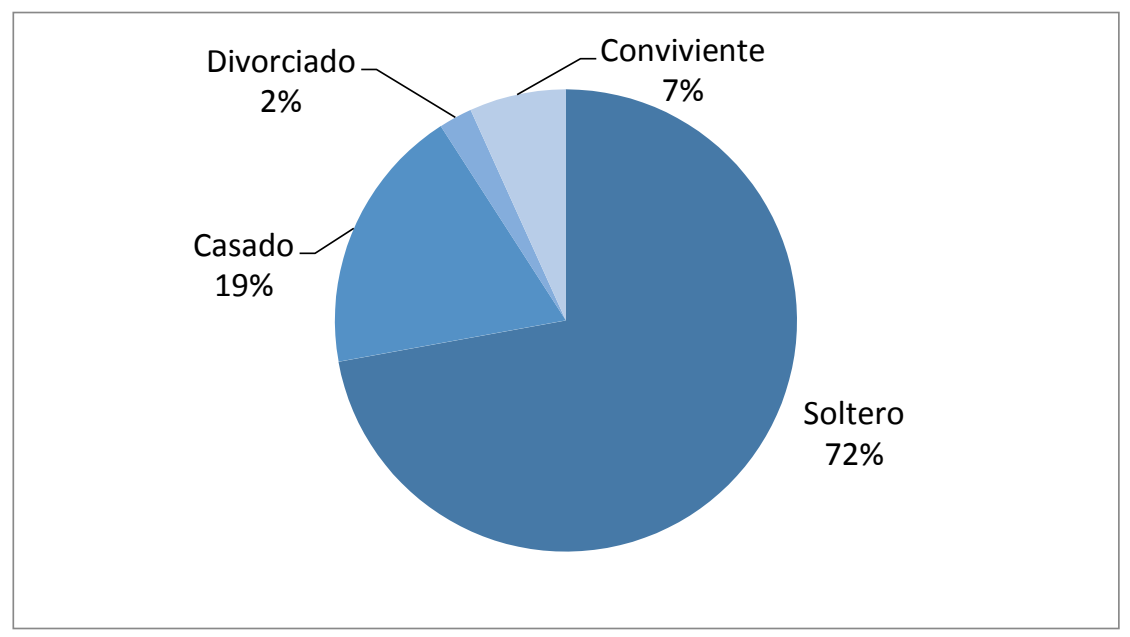

Figura 10. Estado Civil

El resultado obtenido nos indica que la mayor población está en los solteros (72.14\%) por lo tanto orientaremos el proyecto con alternativas atractivas en nuestro servicio para este grupo.

Tabla 27

Pregunta 4,5,6,7,8: NSE

\begin{tabular}{lcc}
\hline Variables & Frecuencia & Porcentaje \\
\hline NSE A & 26 & 6.77 \\
NSE B & 49 & 12.76 \\
NSE C & 110 & 28.65 \\
NSE D Y E & 199 & 51.82 \\
Total & 384 & 100 \\
\hline
\end{tabular}




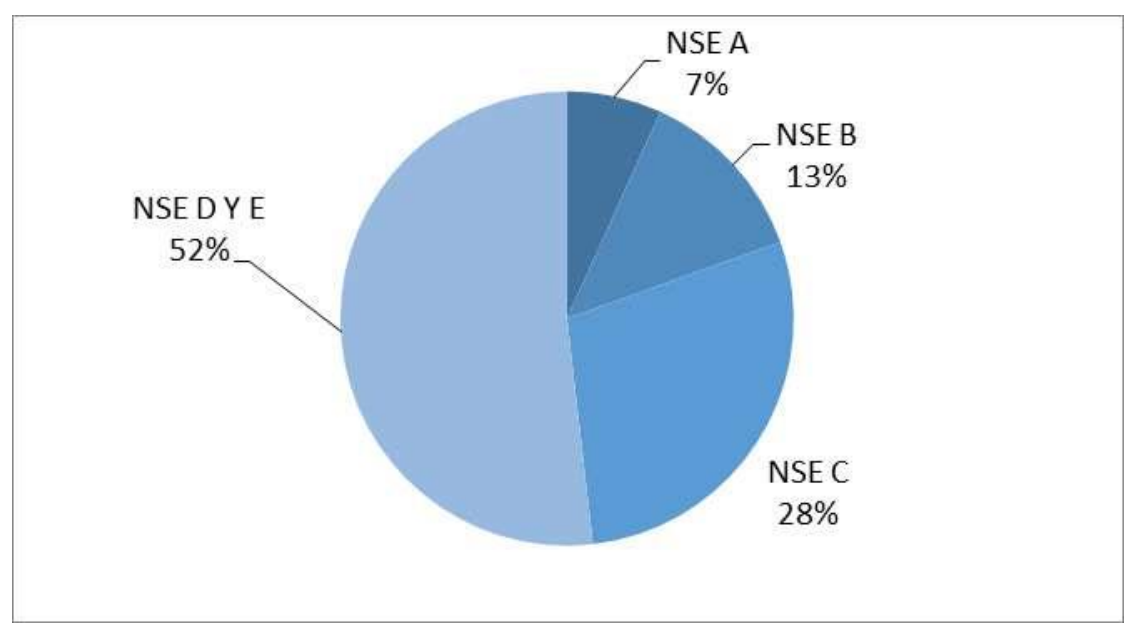

Figura 11. Nivel Socioeconómico

El resultado obtenido nos indica que el NSE D y E tiene el mayor porcentaje (51.82\%), siendo el $48.18 \%$ el NSE A,B y C, es a este sector donde orientaremos el proyecto.

Tabla 28

Pregunta 9 : ¿Ud. Vive en el departamento de Puno?

\begin{tabular}{lcc}
\hline Variables & Frecuencia & Porcentaje \\
\hline $\mathrm{Si}$ & 224 & 58.33 \\
No & 160 & 41.67 \\
Total & 384 & 100.00 \\
\hline
\end{tabular}




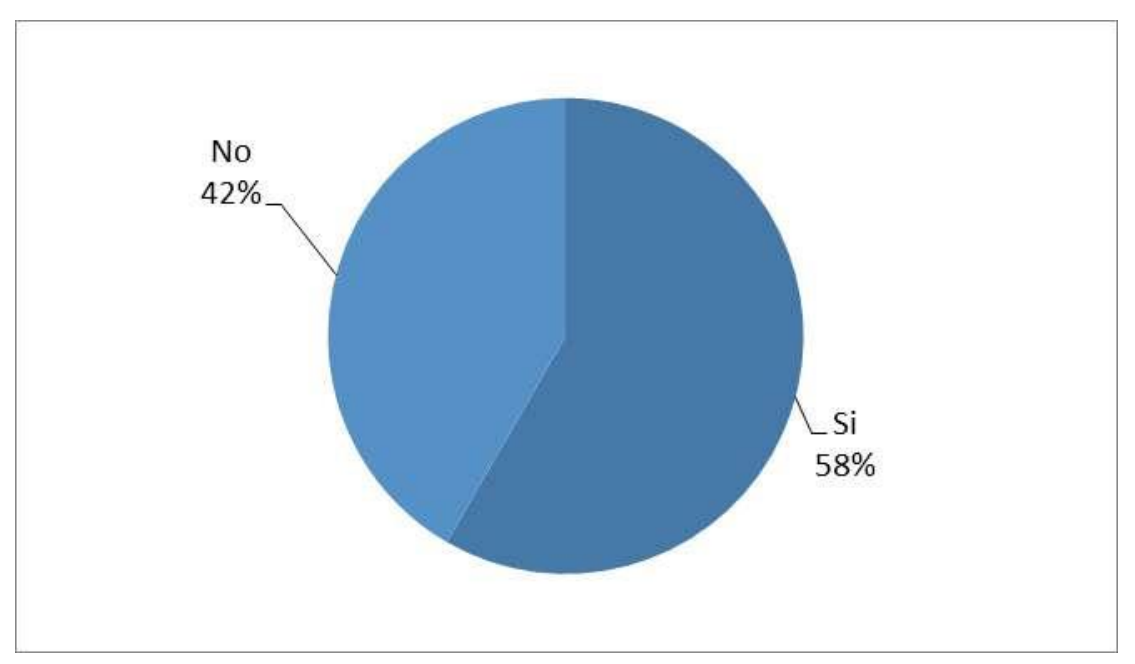

Figura 12. Vive en el departamento de Puno

El resultado obtenido muestra que la mayor población son de Puno (58.33\%), cabe indicar que mencionada encuesta se realizó en el centro y el puerto de dicha ciudad, puesto que en dichos lugares se tiene mayor afluencia de turistas locales y nacionales.

Tabla 29

Edad Mercado Local

\begin{tabular}{lcc}
\hline Variables & Frecuencia & Porcentaje \\
\hline Entre 14 a 29 años & 127 & 56.70 \\
Entre 30 a 44 años & 81 & 36.16 \\
Entre 45 a 59 años & 11 & 4.91 \\
Más de 59 años & 5 & 2.23 \\
Total & 224 & 100.00 \\
\hline
\end{tabular}




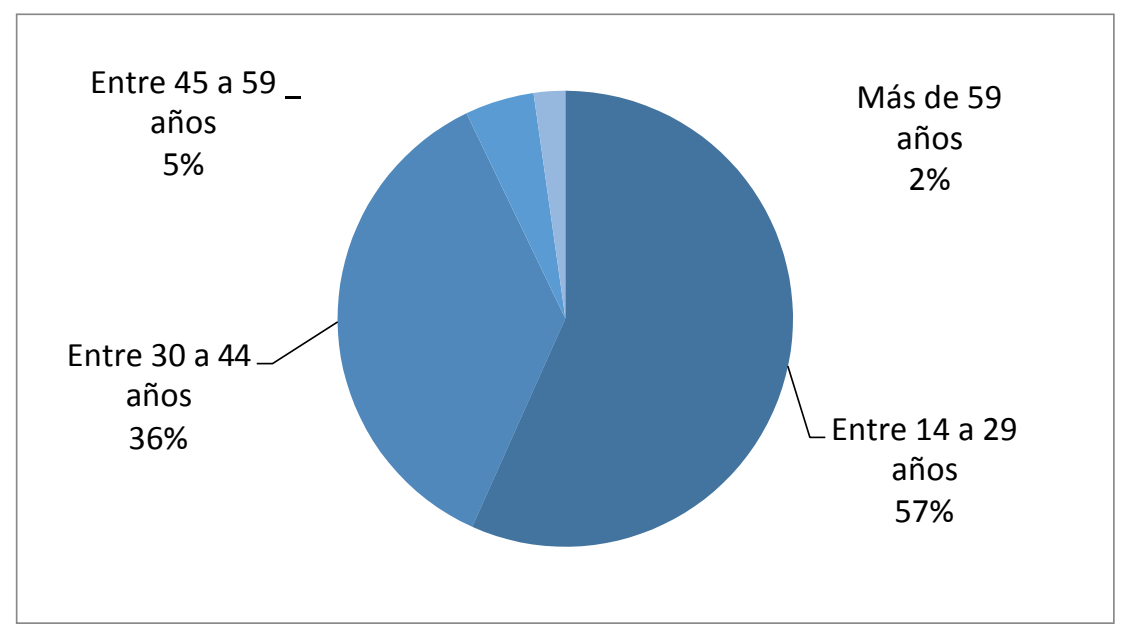

Figura 13. Edad del Mercado Local

El resultado obtenido muestra que el mayor rango de edad (14 a 29 años) tiene un $56.70 \%$, por lo tanto el proyecto orientará el mayor esfuerzo en los medios publicitarios en mencionado rango de edad.

Tabla 30

Edad Mercado Nacional

\begin{tabular}{lcc}
\hline Variables & Frecuencia & Porcentaje \\
\hline Entre 14 a 29 años & 93 & 58.13 \\
Entre 30 a 44 años & 57 & 35.63 \\
Entre 45 a 59 años & 7 & 4.38 \\
Más de 59 años & 3 & 1.88 \\
Total & 160 & 100.00 \\
\hline
\end{tabular}




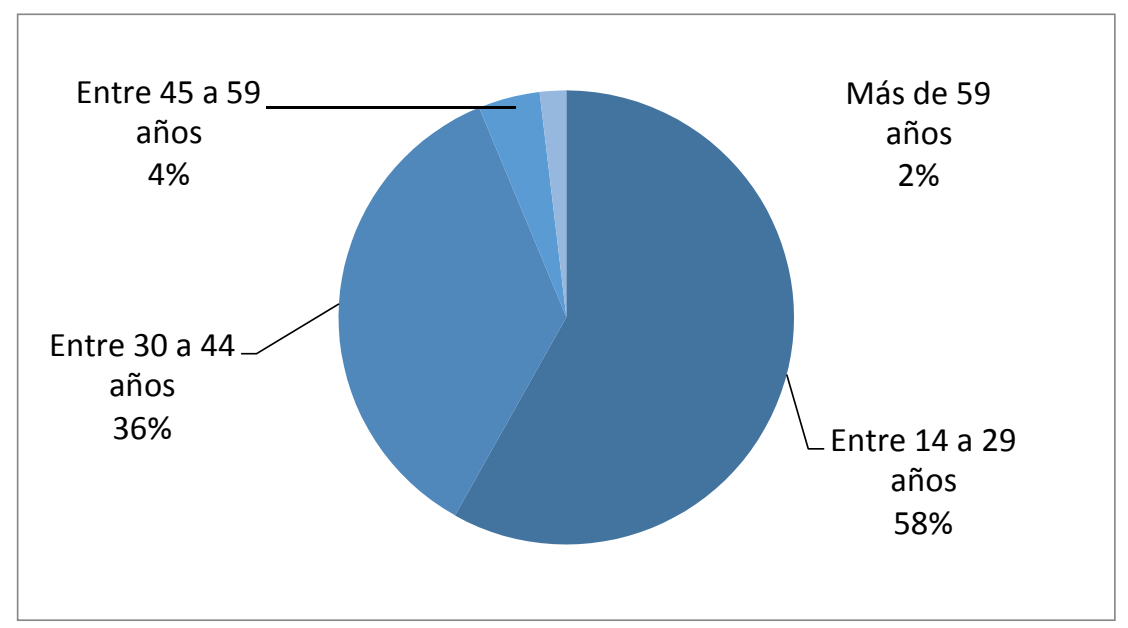

Figura 14. Edad del Mercado Nacional

El resultado obtenido muestra que el mayor rango de edad (14 a 29 años) tiene un 58\%, sin dejar de la lado el rango de edad (30 a 44 años) que representa un 36\%, considerando un porcentaje significativo para el proyecto.

Tabla 31

\begin{tabular}{lcc} 
NSE Mercado Local & & \\
\hline Variables & Frecuencia & Porcentaje \\
\hline NSE A & 9 & 4.02 \\
NSE B & 13 & 5.80 \\
NSE C & 57 & 25.45 \\
NSE D Y E & 145 & 64.73 \\
Total & 224 & 100.00 \\
\hline
\end{tabular}




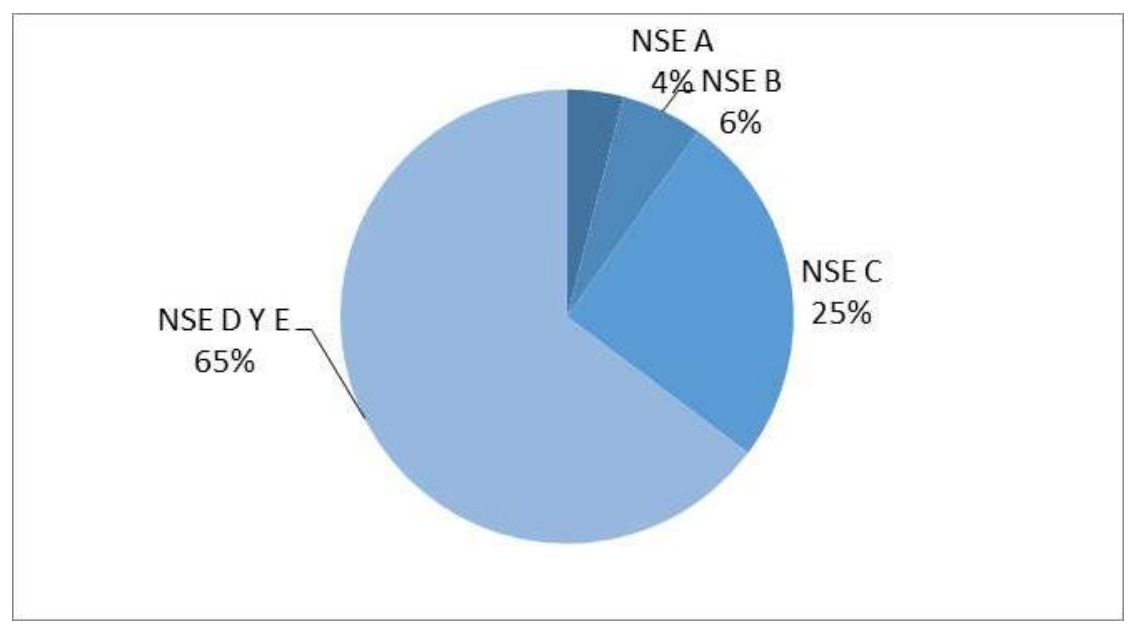

Figura 15. NSE Mercado Local

Se observa que el porcentaje del $64.73 \%$ corresponde al NSE D y E, sin dejar de lado el $35.27 \%$ del NSE A,B y C. el proyecto se enfocará en captar principalmente este último porcentaje.

Tabla 32

NSE Mercado Nacional

\begin{tabular}{lcc}
\hline Variables & Frecuencia & Porcentaje \\
\hline NSE A & 17 & 10.63 \\
NSE B & 36 & 22.50 \\
NSE C & 53 & 33.13 \\
NSE D Y E & 54 & 33.75 \\
Total & 160 & 100.00 \\
\hline
\end{tabular}




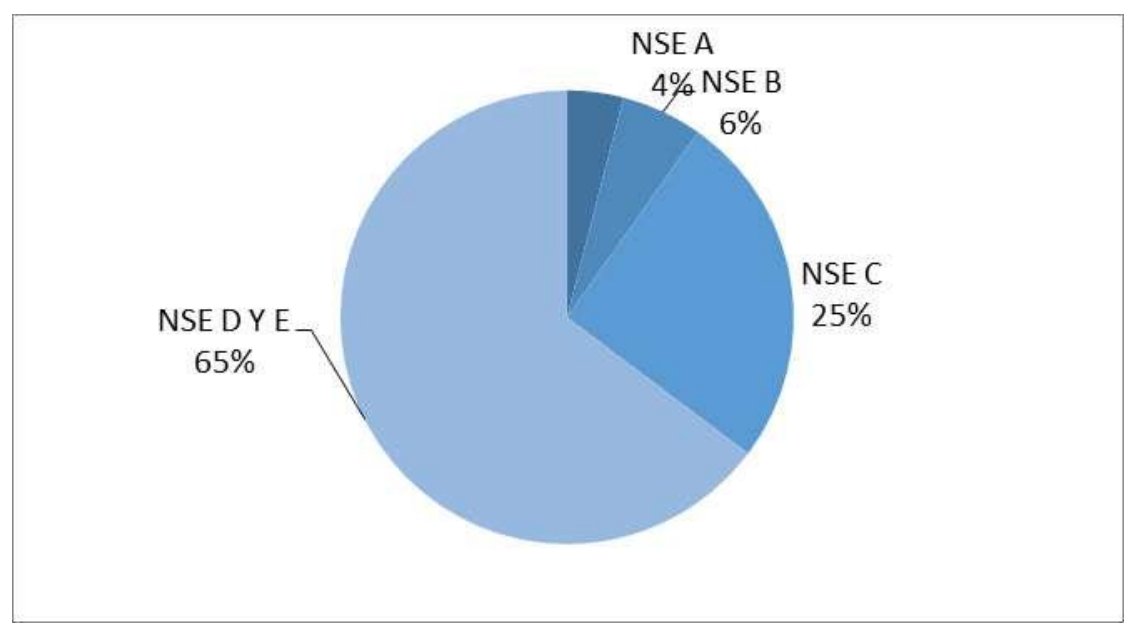

Figura 16. NSE Mercado Nacional

Se observa que el porcentaje del $66.26 \%$ corresponde al NSE A,B y C, porcentaje significativo para el desarrollo del proyecto.

Tabla 33

Pregunta 11 : ¿De que provincia proviene?

Procedencia Mercado Local

\begin{tabular}{|c|c|c|}
\hline Variables & Frecuencia & Porcentaje \\
\hline Puno (PUNO) & 72 & 45.28 \\
\hline San Roman (JULIACA) & 32 & 20.13 \\
\hline Chucuito (DESAGUADERO) & 11 & 6.92 \\
\hline Otros & 44 & 27.67 \\
\hline Total & 159 & 100 \\
\hline
\end{tabular}




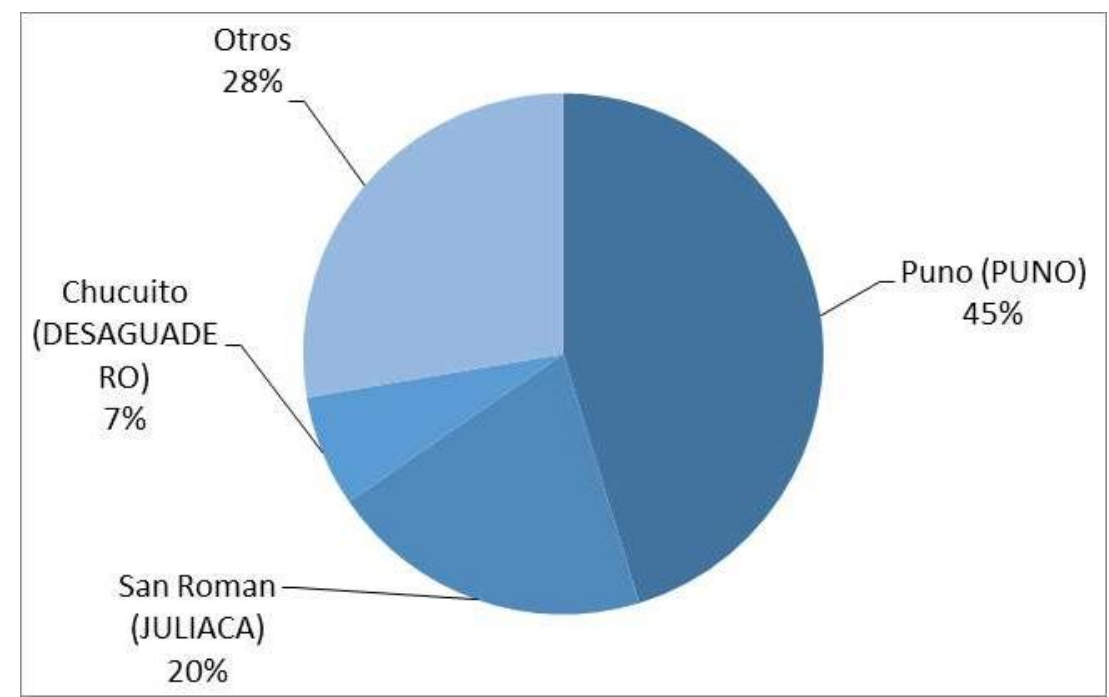

Figura 17. Procedencia del Mercado Local

De la mayoría de encuestados su procedencia es de Puno (45.28\%), esto permitirá al proyecto determinar su estrategia de marketing y ventas en este determinado grupo.

Tabla 34

Pregunta 12 : ¿De que departamento proviene?

Procedencia Mercado Nacional

\begin{tabular}{lcc}
\hline Variables & Frecuencia & Porcentaje \\
\hline Lima & 33 & 20.63 \\
Arequipa & 32 & 20.00 \\
Cusco & 20 & 12.50 \\
Otros & 75 & 46.88 \\
Total & 160 & 100.00 \\
\hline
\end{tabular}




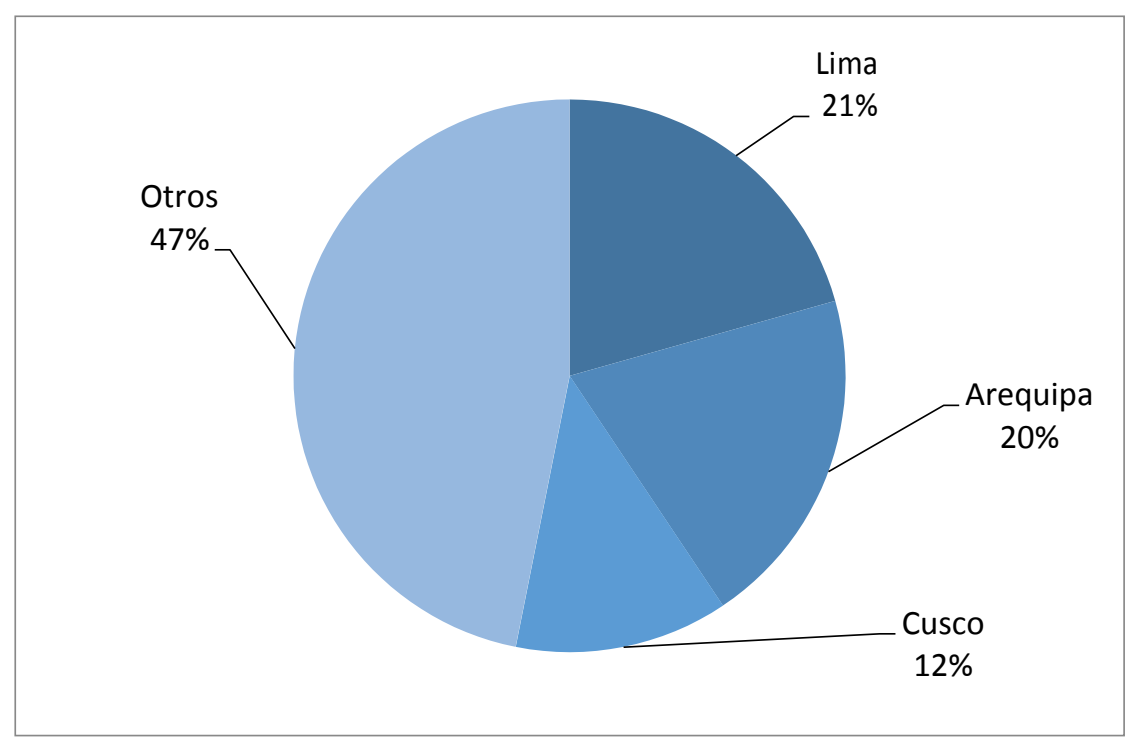

Figura 18. Procedencia del Mercado Nacional

La mayoría de encuestados proviene de Lima (21\%), Arequipa (20\%) y Cusco (12\%), por lo tanto el proyecto focalizará su estrategia de marketing y ventas a estos departamentos.

Tabla 35

Pregunta 13 : ¿Cuántos días permaneceras en la ciudad de Puno?

Permanencia Mercado Local

\begin{tabular}{lcc}
\hline Variables & Frecuencia & Porcentaje \\
\hline 01 DÍA & 25 & 11.16 \\
02 DÍAS & 23 & 10.27 \\
03 DÍAS & 31 & 13.84 \\
MAS DE 05 DÍAS & 145 & 64.73 \\
Total & 224 & 100.00 \\
\hline
\end{tabular}




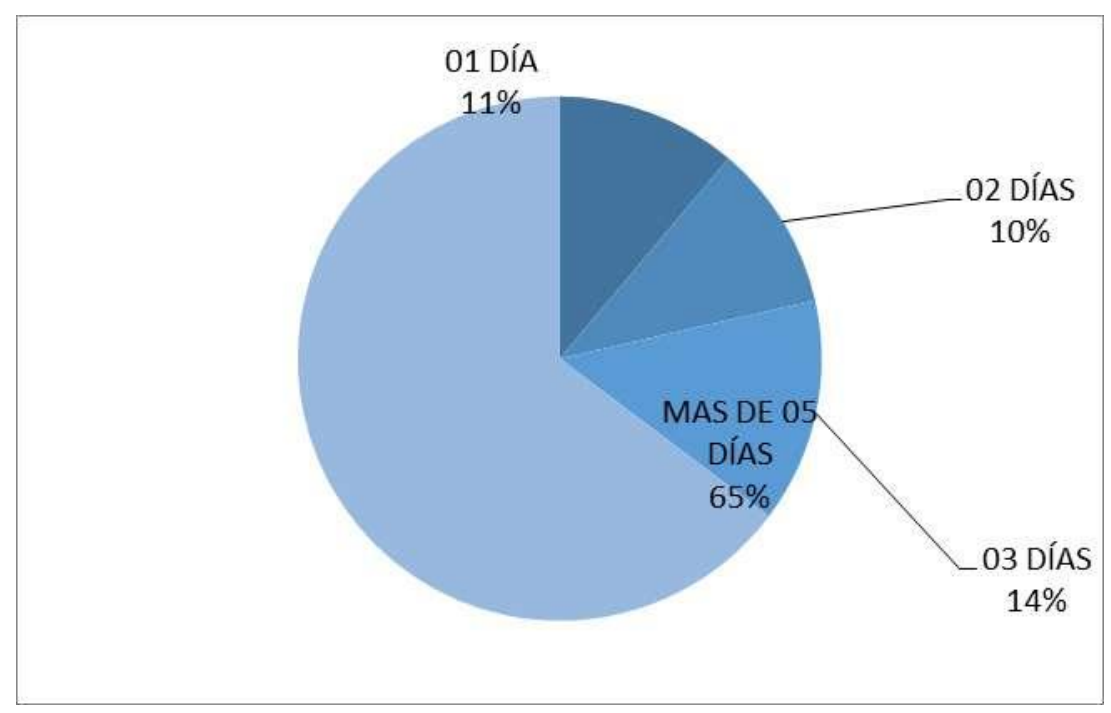

Figura 19. Permanencia del Mercado Local

La mayoría de encuestados pertenecientes al mercado Local (Puno) el 64.73\% permanece en Puno, por lo tanto se entiende que son pobladores del centro de Puno. Esto nos permitirá orientar el proyecto a esta población.

Tabla 36

Pregunta 13 : ¿Cuántos días permaneceras en la ciudad de Puno?

Permanencia Mercado Nacional

\begin{tabular}{lcc}
\hline Variables & Frecuencia & Porcentaje \\
\hline 01 DÍA & 28 & 17.50 \\
02 DÍAS & 26 & 16.25 \\
03 DÍAS & 45 & 28.13 \\
MAS DE 05 DÍAS & 61 & 38.13 \\
Total & 160 & 100.00 \\
\hline
\end{tabular}




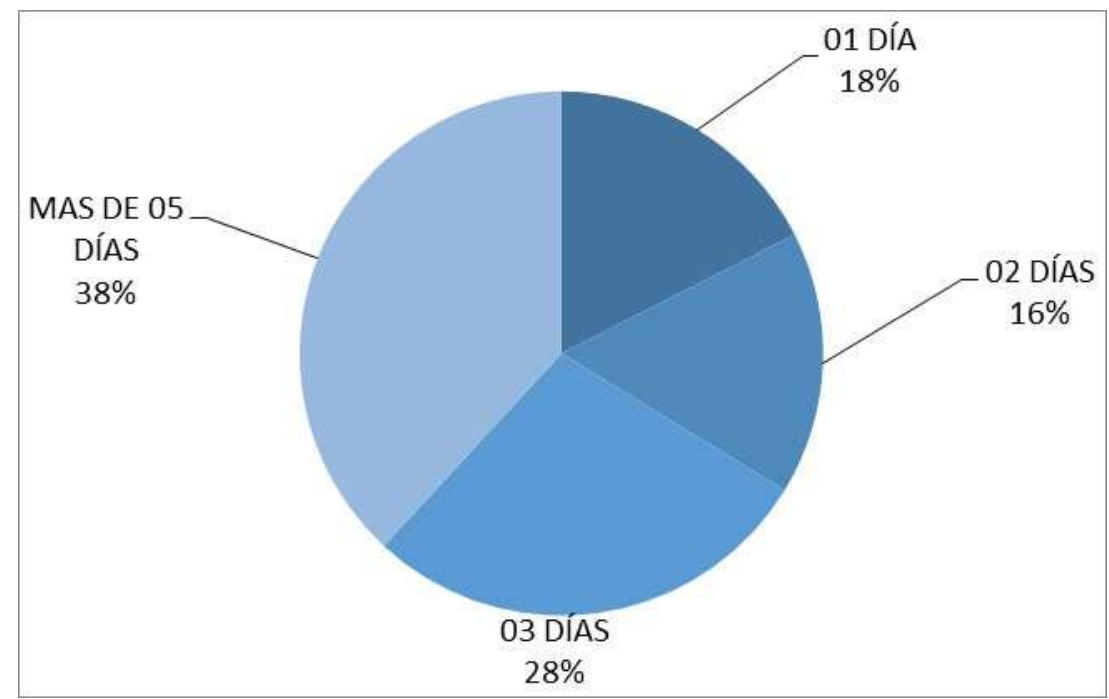

Figura 20. Pregunta 13: Permanencia del Mercado Nacional

Según las encuestas el turista nacional permanece más de cinco días representando un $38.13 \%$, también se estará considerando quienes permanecen de 02 a 03 días puesto que representa un $44.38 \%$.

Tabla 37

Pregunta 14: ¿Ha realizado alguna actividad de turismo de aventura? (Caminatas, ciclismo, Kayak, Descensos, Otros.)

\begin{tabular}{lcc}
\hline Variables & Frecuencia & Porcentaje \\
\hline $\mathrm{Si}$ & 262 & 68.23 \\
$\mathrm{No}$ & 122 & 31.77 \\
Total & 384 & 100.00 \\
\hline
\end{tabular}




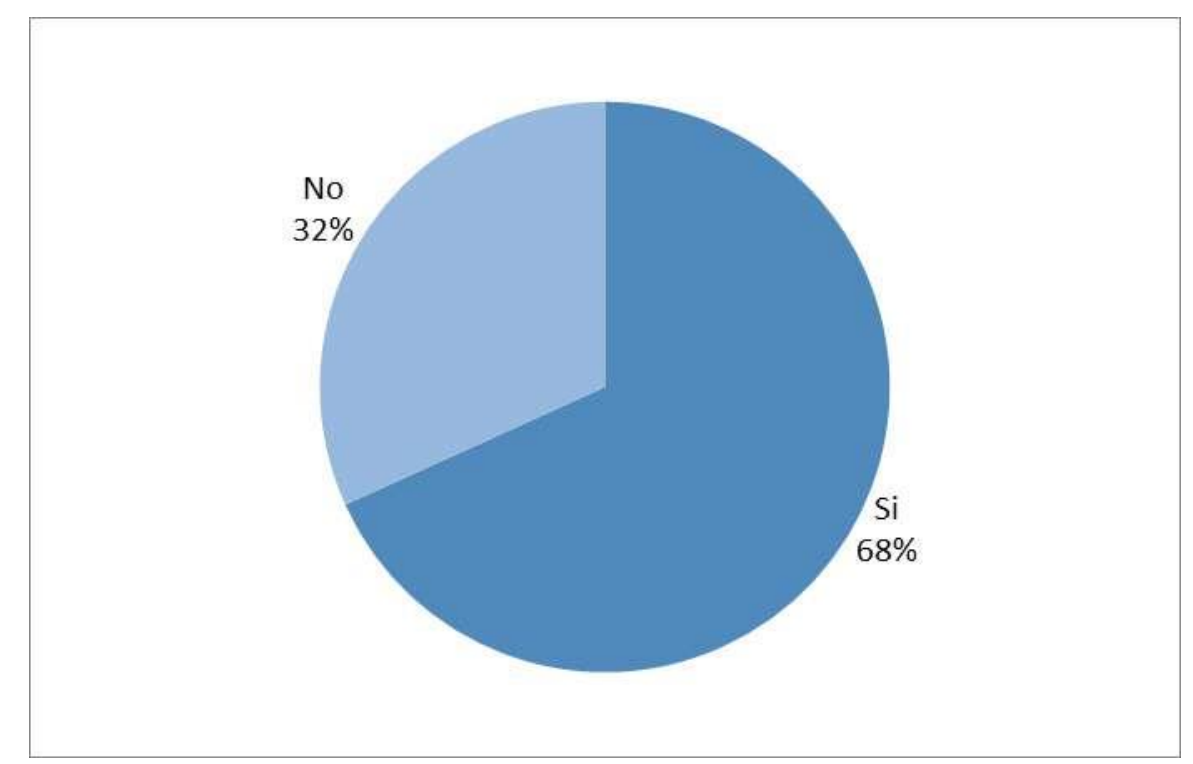

Figura 21. Pregunta 14: ¿Ha realizado alguna actividad de turismo de aventura? (Caminatas, ciclismo, Kayak, Descensos, Otros.)

Gran mayoría de los encuestados nos indican haber realizado alguna actividad de turismos de aventura siendo el $68.23 \%$, este porcentaje es muy importante para el proyecto planteado, puesto que nuestra actividad está directamente relacionada con turismo de aventura. 
Tabla 38

Pregunta 15: ¿Qué te motivó hacer turismo de aventura?

\begin{tabular}{|c|c|c|}
\hline Variables & Frecuencia & Porcentaje \\
\hline Adrenalina & 119 & 45.42 \\
\hline Nuevas Experiencias & 65 & 24.81 \\
\hline Diversión & 63 & 24.05 \\
\hline Reto & 15 & 5.73 \\
\hline Sub-total & 262 & 100.00 \\
\hline Sin respuesta & 122 & \\
\hline Total & 384 & \\
\hline
\end{tabular}

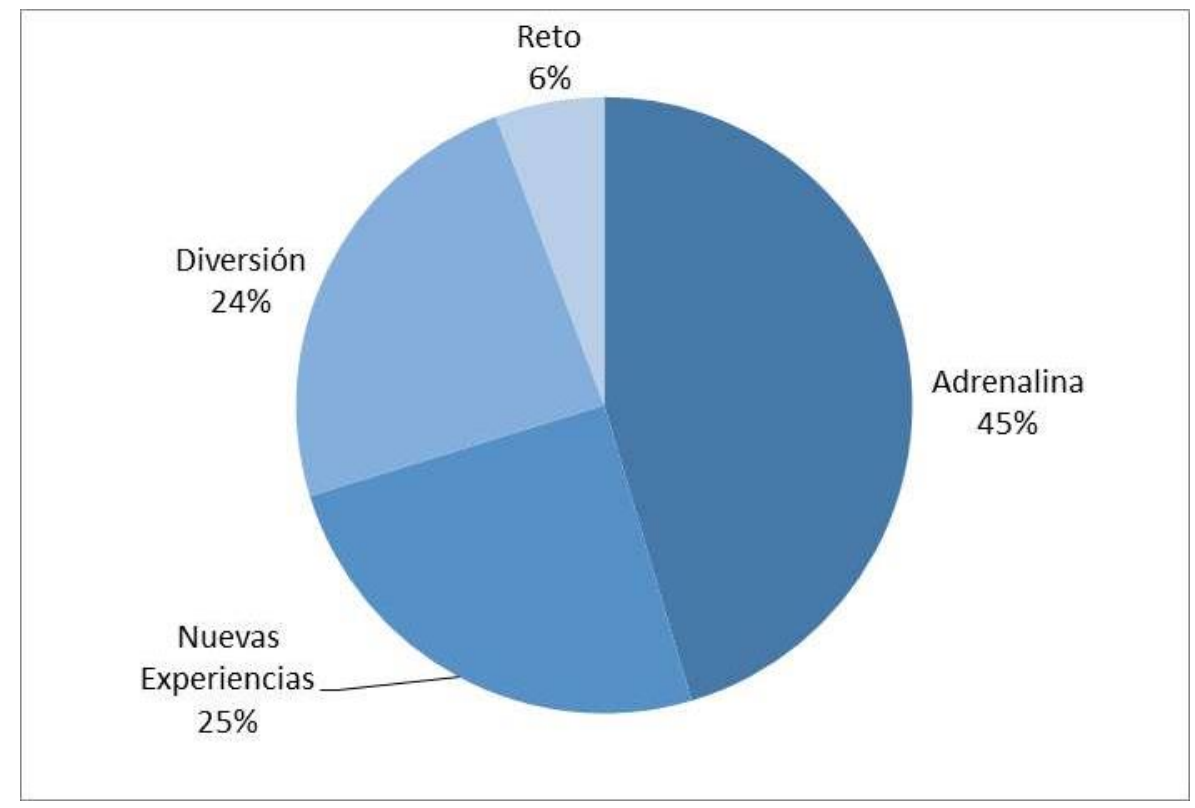

Figura 22. Pregunta 15: ¿Qué te motivo hacer turismo de aventura?

La mayoría de encuestados indicó que la motivación principal fue la adrenalina (45.42\%), esta información es relevante para el proyecto puesto que nuestra actividad ofrecerá principalmente esa variable. Cabe destacar que los encuestados también buscan experiencia nuevas y propiamente diversión $(48.86 \%)$. 
Tabla 39

Pregunta 16: ¿Dónde obtienes información sobre turismo de aventura?

\begin{tabular}{|c|c|c|}
\hline Variables & Frecuencia & Porcentaje \\
\hline Amigos & 82 & 31.30 \\
\hline Televisión & 19 & 7.25 \\
\hline Redes Sociales & 81 & 30.92 \\
\hline Agencia de Viajes & $=11$ & 4.20 \\
\hline Radio & $=49$ & 18.70 \\
\hline Paneles publicitarios & 20 & 7.63 \\
\hline Sub-total & 262 & 100.00 \\
\hline Sin respuesta & $=122$ & \\
\hline Total & 384 & \\
\hline
\end{tabular}

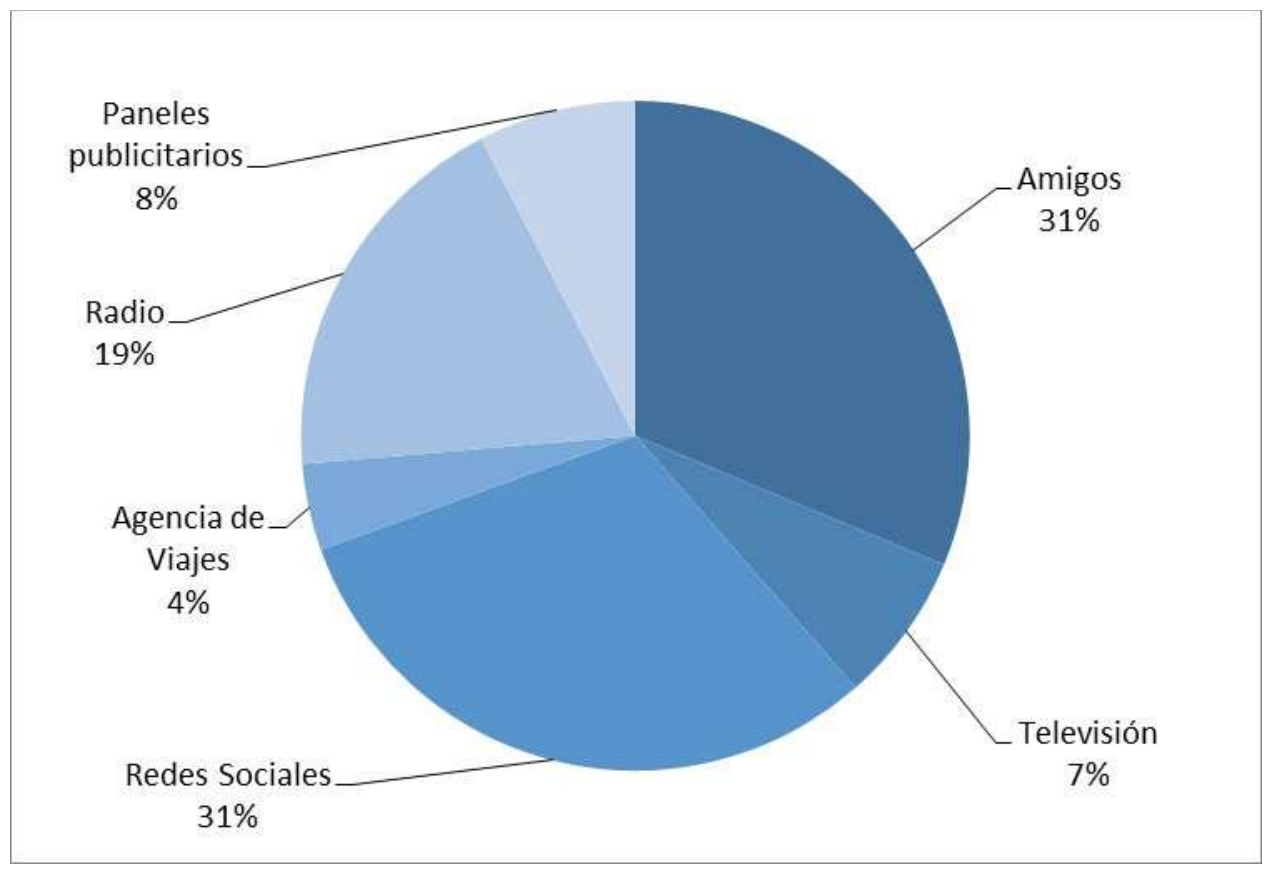

Figura 23. Pregunta 16: ¿Dónde obtienes información sobre turismo de aventura? 
La mayoría de encuestados obtiene información de turismo de aventura de sus amigos (30.31\%) y redes sociales (30.92\%). De esta información el proyecto tendrá que buscar mayor impacto en la recomendación de amigos y redes sociales.

Tabla 40

Pregunta 17: ¿Cuándo realizaste una actividad de turismo de aventura cuanto fue el gasto realizado?

\begin{tabular}{|c|c|c|}
\hline Variables & Frecuencia & Porcentaje \\
\hline Menos de S/100 & 87 & 33.21 \\
\hline$S / 101$ a $S / 200$ & 45 & 17.18 \\
\hline $\mathrm{S} / 201$ a $\mathrm{S} / 300$ & 96 & 36.64 \\
\hline $\mathrm{S} / 301$ a $\mathrm{S} / 400$ & 26 & 9.92 \\
\hline S/401 a más & 8 & 3.05 \\
\hline Sub-total & 262 & 100.00 \\
\hline Sin respuesta & 122 & \\
\hline Total & 384 & \\
\hline
\end{tabular}

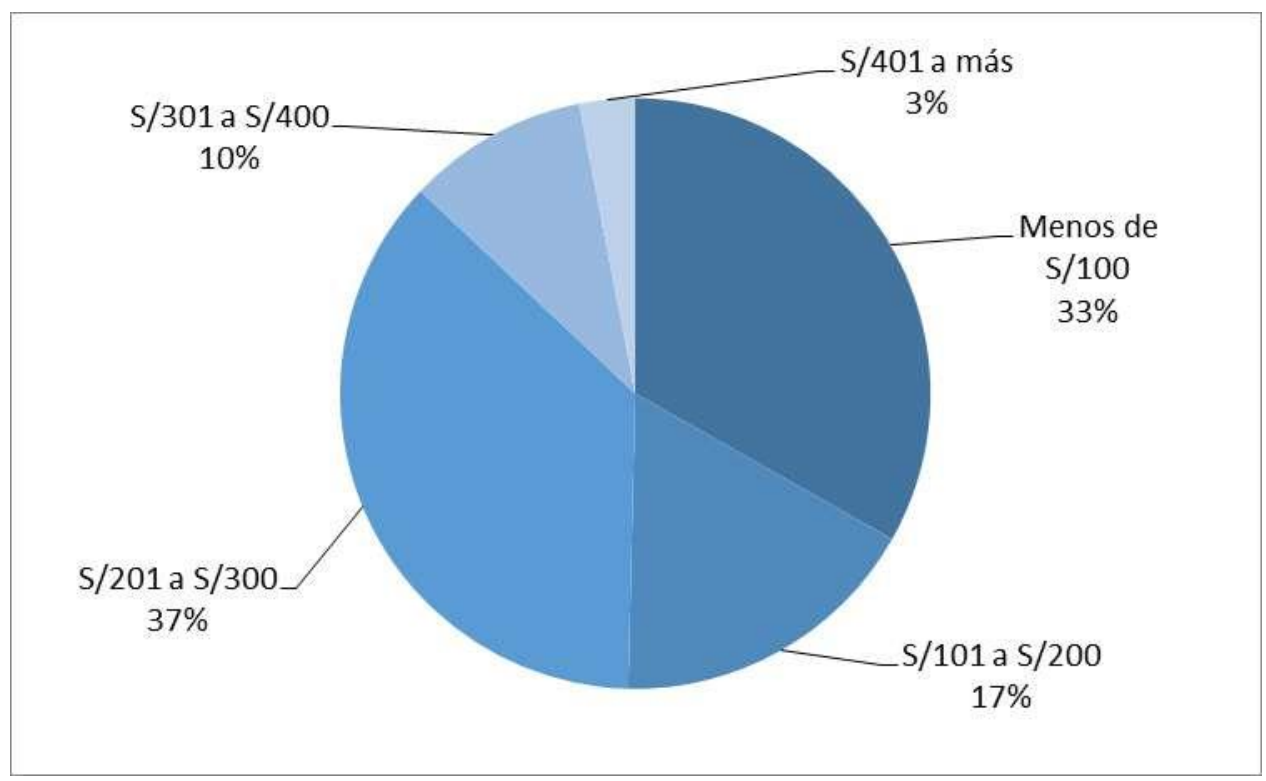

Figura 24. Pregunta 17: ¿Cuándo realizaste una actividad de turismo de aventura cuanto fue el gasto realizado? 
De la información de la encuesta el 36.64\% realizan un gasto de s/ 201.00 a s/ 300.00 y un $17.18 \%$ en el rango de s/101.00 a s/ 200.00 , estos porcentajes son importantes para los interés del proyecto, puesto que está dentro del rango del precio ofrecido en el proyecto.

Tabla 41

Pregunta 18: ¿Estás informado de las alternativas sobre turismo de aventura en Puno?

\begin{tabular}{|c|c|c|}
\hline Variables & Frecuencia & Porcentaje \\
\hline $\mathrm{Si}$ & 127 & 48.47 \\
\hline No & $=135$ & 51.53 \\
\hline Sub-total & 262 & 100.00 \\
\hline Sin respuesta & $=122$ & \\
\hline Total & 384 & \\
\hline
\end{tabular}

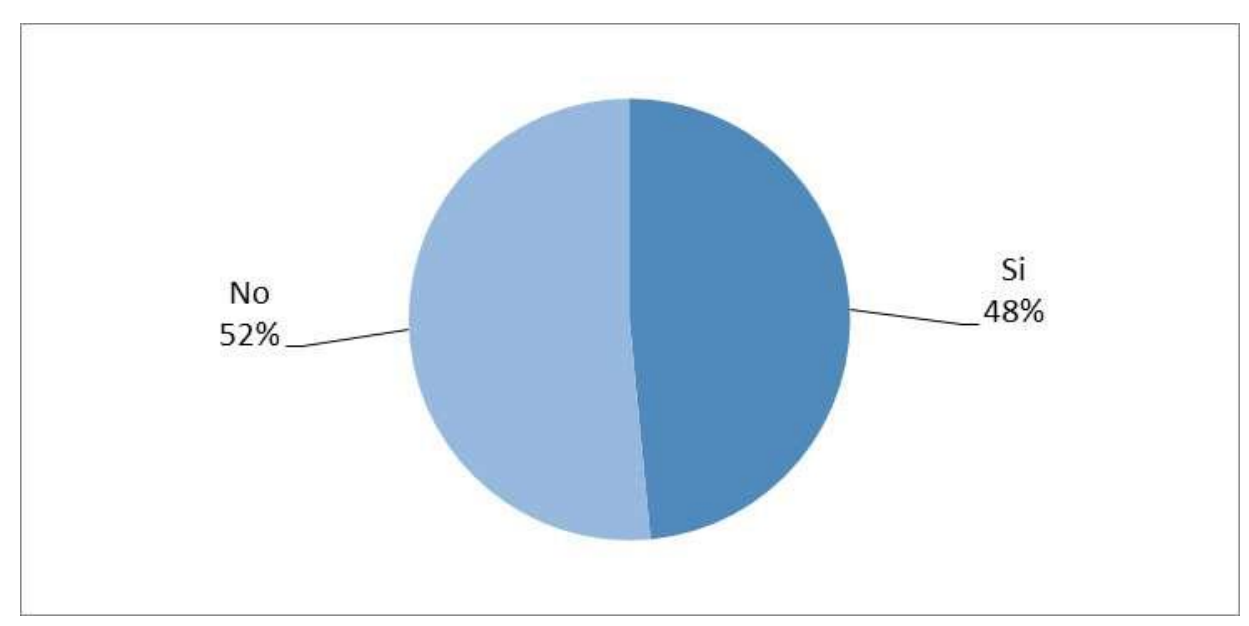

Figura 25. Pregunta 18: ¿Estás informado de las alternativas sobre turismo de aventura en Puno? 
La mayoría de los encuestados no está informado de las alternativa de turismo en Puno esto refleja un $51.53 \%$, dicha información es relevante para el proyecto porque encuentra un mercado que aún no conoce alternativas de turismo de aventura.

Tabla 42

Pregunta 19: Mencione a la agencia y/o empresa que conoces que realiza turismo de aventura en Puno

\begin{tabular}{lcc}
\hline Variables (moda) & Frecuencia & Porcentaje \\
\hline Municipio Sandia & 4 & 3.15 \\
Edgar Adventure's & 1 & 0.79 \\
Puno Travel AVT & 1 & 0.79 \\
Puno Adventures & 1 & 0.79 \\
Killary Peru & 1 & 0.79 \\
Inti Trail & 1 & 0.79 \\
NO RECUERDA & 118 & 92.91 \\
$\quad$ Sub-total & 127 & 100.00 \\
Sin respuesta & 257 & \\
Total & 384 & \\
\hline
\end{tabular}




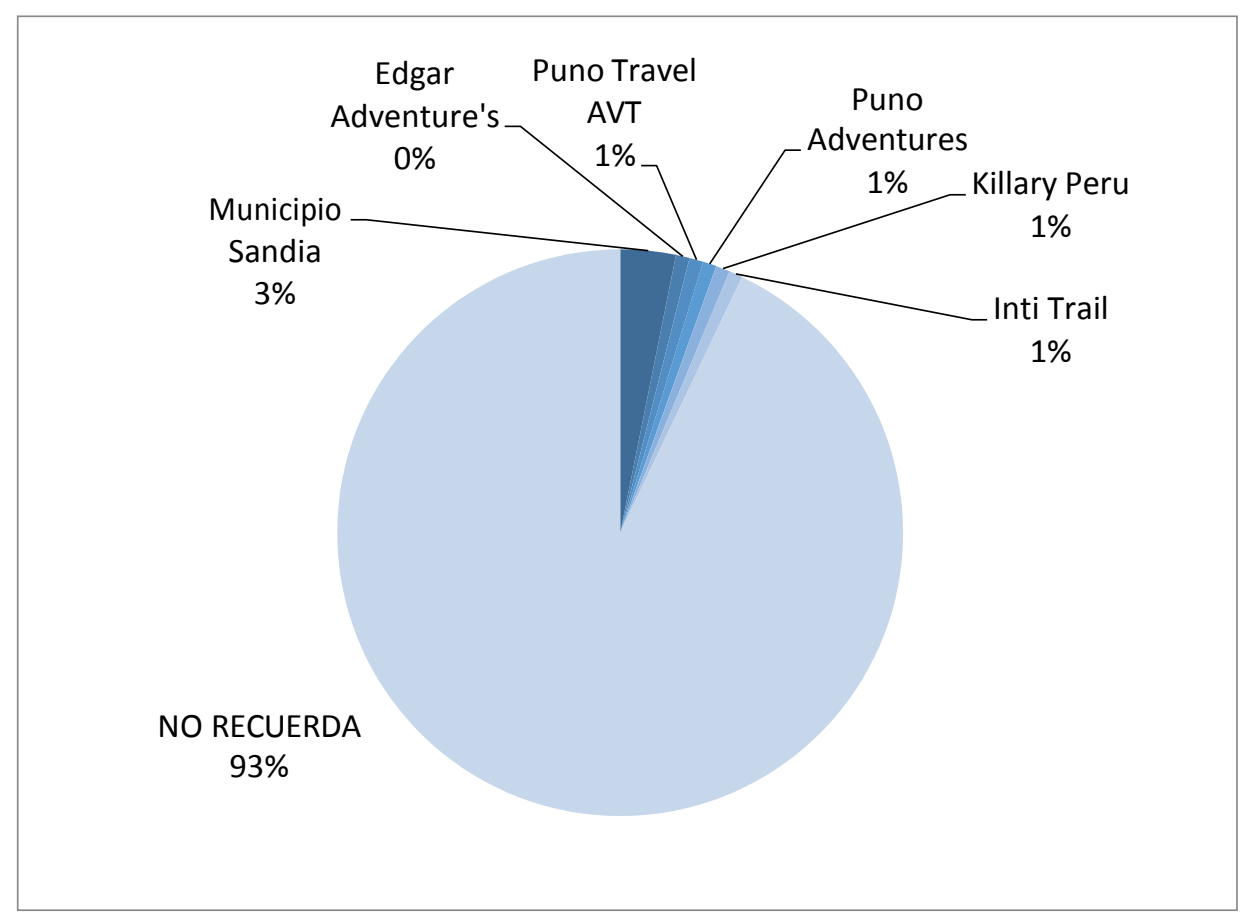

Figura 26. Pregunta 19: Mencione a la agencia y/o empresa que conoces que realiza turismo de aventura en Puno

La mayoría de encuestados no conoce agencias y/o empresas que realicen turismo de aventura (93\%), esta información es importante para el proyecto presentado puesto que permitirá tener presencia como operador turístico en la actividad que se realizará. 
Tabla 43

Pregunta 20: ¿Qué actividad de aventura realizaste?

\begin{tabular}{lcc}
\hline Variables & Frecuencia & Porcentaje \\
\hline Treeking & 47 & 37.01 \\
Ciclismo & 49 & 38.58 \\
Kayak & 22 & 17.32 \\
Moto Acuática & 0 & 0.00 \\
Cuatrimotos & 5 & 3.94 \\
Otros & 4 & 3.15 \\
$\quad$ Sub-total & 127 & 100.00 \\
Sin respuesta & 253 & \\
Total & 384 & \\
\hline
\end{tabular}

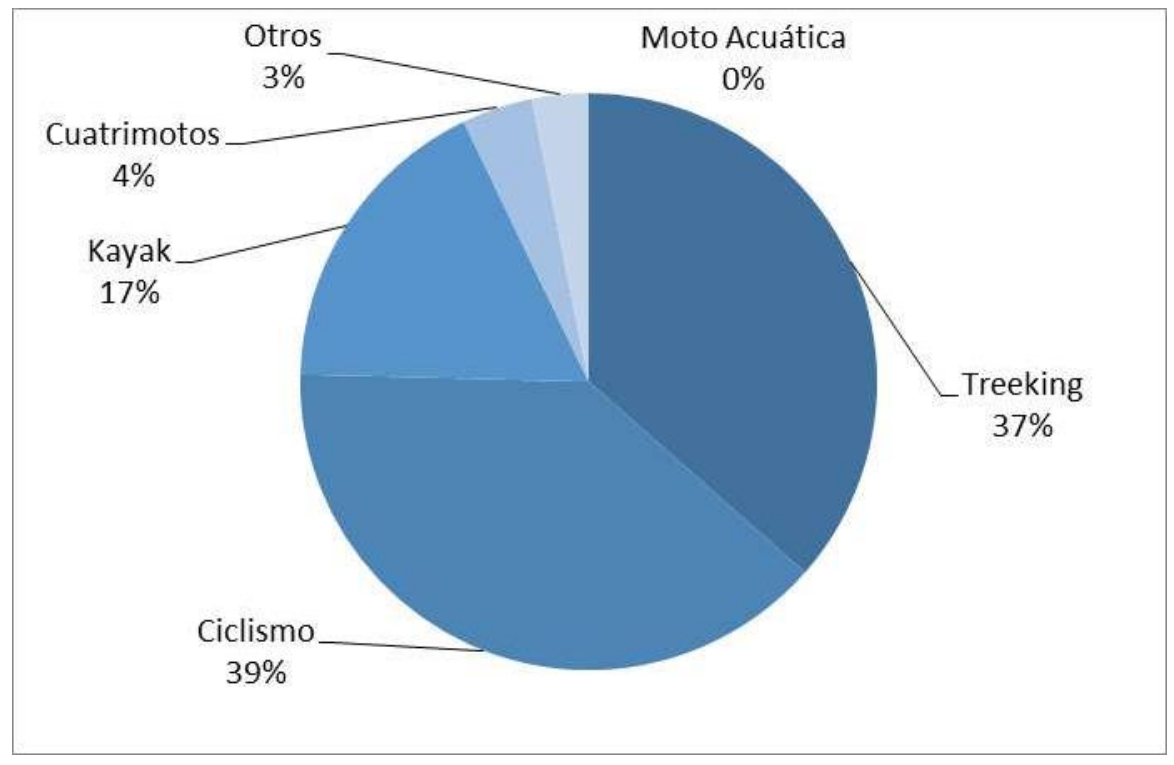

Figura 27. Pregunta 20: ¿Estás informado de las alternativas sobre turismo de aventura en Puno?

La mayoría de encuestados está informado de la actividad del ciclismo (38.89\%) seguido de treeking (36.51\%), de los encuestado ninguno (0\%) está informados del servicio del proyecto (motos acuáticas), esta información no es relevante puesto que es un servicio innovador. 
Tabla 44

Pregunta 21: ¿Te gustaría realizar un circuito de caminata, ciclismo y motos acuáticas en Capachica?

(a 40 min de Puno)

\begin{tabular}{|c|c|c|}
\hline Variables & Frecuencia & Porcentaje \\
\hline $\mathrm{Si}$ & 245 & 93.51 \\
\hline No & 17 & 6.49 \\
\hline Sub-total & 262 & 100.00 \\
\hline Sin respuesta & 122 & \\
\hline Total & 384 & \\
\hline
\end{tabular}

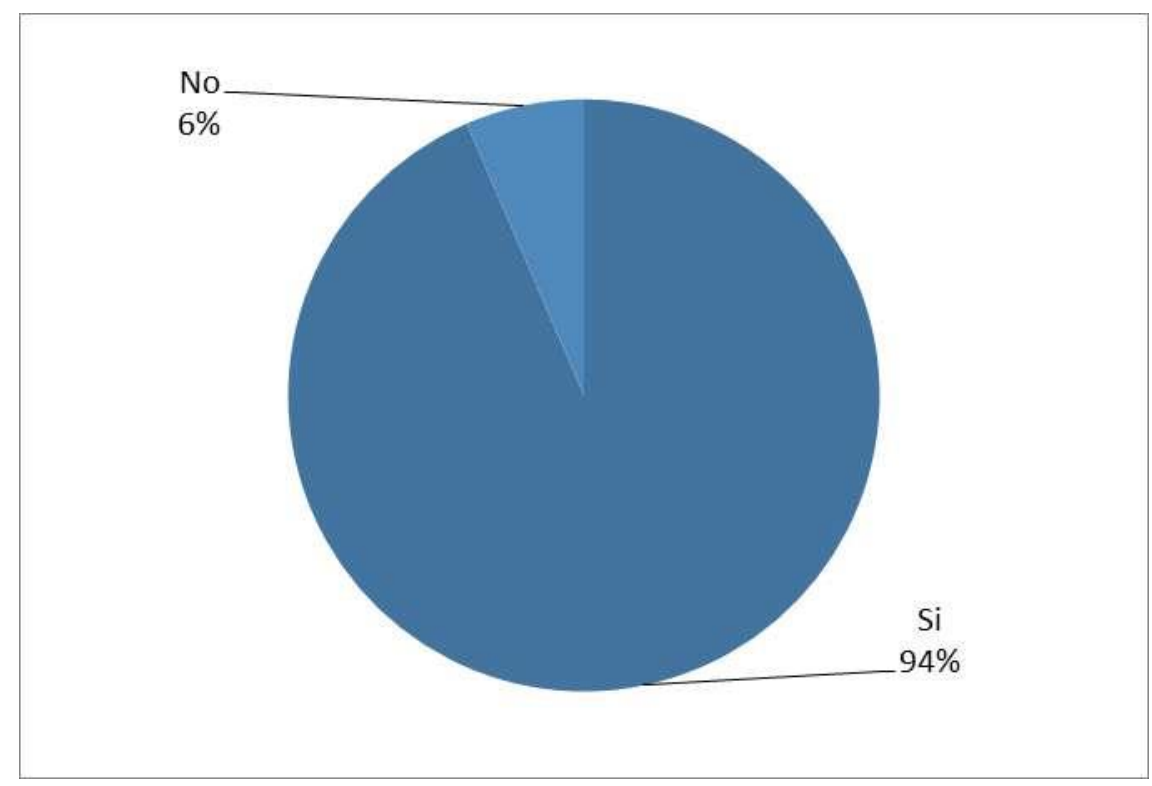

Figura 28. Pregunta 21: ¿Te gustaría realizar un circuito de caminata, ciclismo y motos acuáticas en Capachica?

A la mayoría de encuestados si le gustaría realizar el circuito planteado en Capachica $(93.51 \%)$ este es un indicador muy favorable para el proyecto planteado, puesto que la actividad y el servicio son nuevos tanto en equipos (motos acuáticas) como la ruta (Capachica). 
Tabla 45

Pregunta 22: ¿qué tiempo consideras adecuado que podría durar el circuito?

\begin{tabular}{|c|c|c|}
\hline Variables & Frecuencia & Porcentaje \\
\hline Hasta 01 hora & 74 & 30.20 \\
\hline De 01 hora a 02 horas & 158 & 64.49 \\
\hline Más de 02 horas & 13 & 5.31 \\
\hline Sub-total & 245 & 100.00 \\
\hline Sin respuesta & 139 & \\
\hline Total & 384 & \\
\hline
\end{tabular}

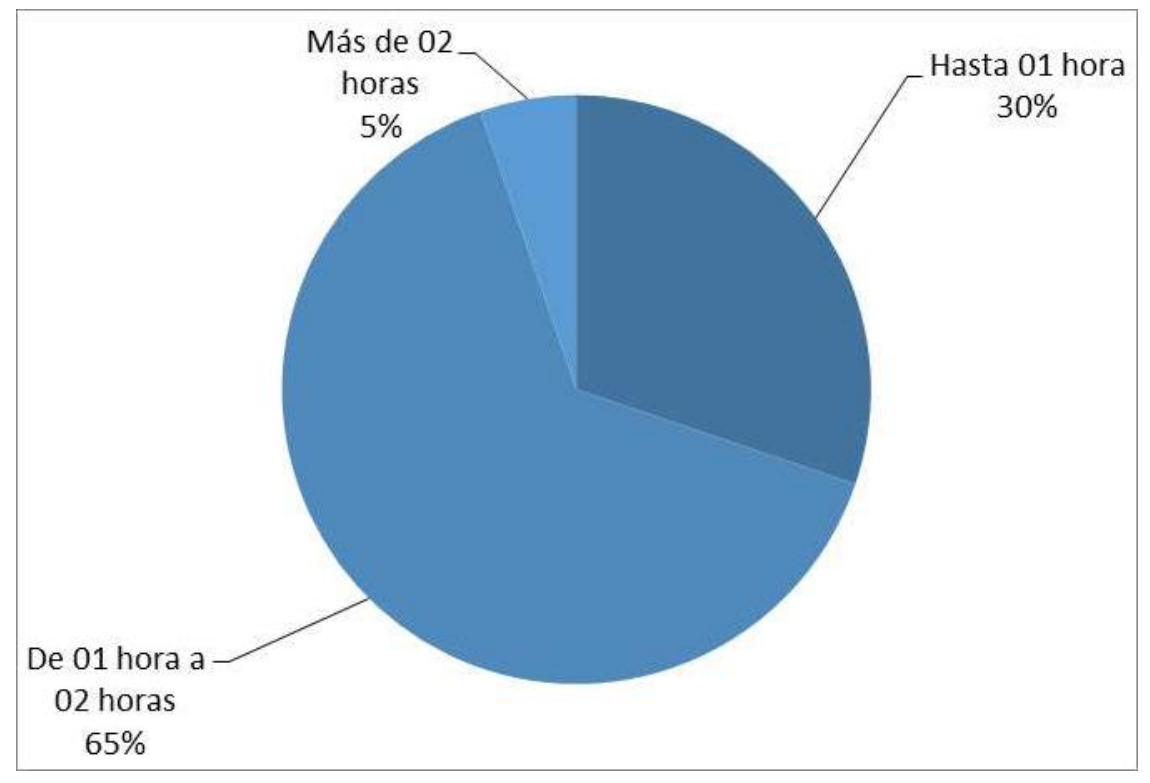

Figura 29. Pregunta 22: ¿qué tiempo consideras adecuado que podría durar el circuito?

A la mayoría de encuestados considera un tiempo apropiado del circuito de 01 hora a 02 horas $(64.49 \%)$, está información es beneficiosa para el proyecto puesto que es el tiempo estimado que dura la actividad planteada. 
Tabla 46

Pregunta 23: ¿Cuánto estarias dispuesto a pagar por el circuito descrito?

\begin{tabular}{lcc}
\hline Variables & Frecuencia & Porcentaje \\
\hline De S/100 a S/150 & 97 & 39.59 \\
De S/151 a S/200 & 117 & 47.76 \\
De S/201 a S/300 & 31 & 12.65 \\
$\quad$ Sub-total & 245 & 100.00 \\
Sin respuesta & - & \\
Total & & \\
\hline
\end{tabular}

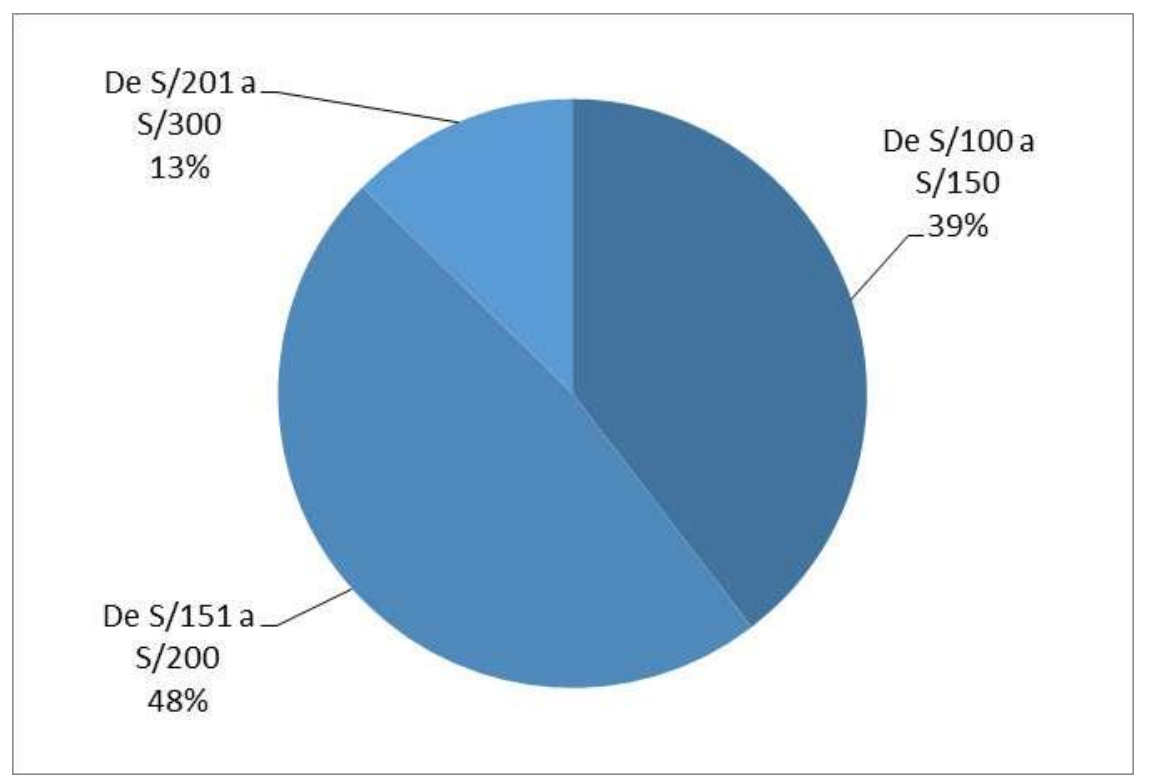

Figura 30. Pregunta 23: ¿Cuánto estarías dispuesto a pagar por el circuito descrito?

A la mayoría de encuestados estaría dispuesto a pagar entre s/ 151 y s/ 200 (47.76\%), considerando también un porcentaje importante de s/ 100 a s/ 150 (39.59\%), ambas porcentajes son beneficiosos para el proyecto puesto que está dentro del rango que se cobraría por el servicio planteado. 
Tabla 47

Pregunta 24: ¿Con qué frecuencia harías el circuito?

\begin{tabular}{|c|c|c|}
\hline Variables & Frecuencia & Porcentaje \\
\hline 01 vez al año & 177 & 72.24 \\
\hline 02 veces al año & 42 & 17.14 \\
\hline Mensual & 22 & 8.98 \\
\hline Quincenal & 4 & 1.63 \\
\hline Sub-total & 245 & 100.00 \\
\hline Sin respuesta & 139 & \\
\hline Total & 384 & \\
\hline
\end{tabular}

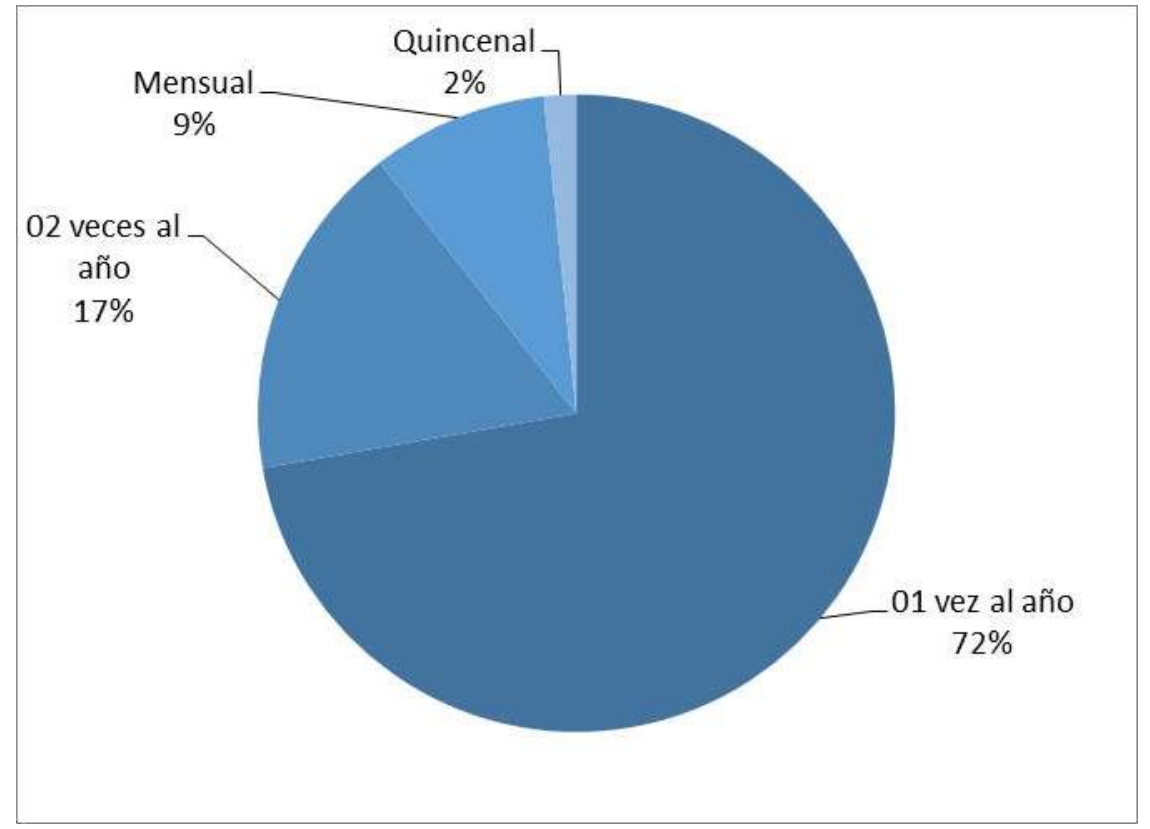

Figura 31. Pregunta 24: ¿Con qué frecuencia harías el circuito?

A la mayoría de encuestados realizaría la actividad 01 vez al año (72.24\%), sólo el 8.98\% realizaría la actividad mensualmente. De esta información el proyecto realizará promociones, alianzas estratégicas con instituciones de esta forma garantizar la mayor frecuencia del uso del servicio. 
Tabla 48

Pregunta 25: ¿qué servicios adicionales te gustaria encontrar en Capachica?

\begin{tabular}{|c|c|c|}
\hline Variables & Frecuencia & Porcentaje \\
\hline Hospedaje & 94 & 38.37 \\
\hline Minimarket & 25 & 10.20 \\
\hline Restaurante & 105 & 42.86 \\
\hline Tienda de Artesanias & $=19$ & 7.76 \\
\hline Otros & 2 & 0.82 \\
\hline Sub-total & 245 & 100.00 \\
\hline Sin respuesta & 139 & \\
\hline Total & 384 & \\
\hline
\end{tabular}

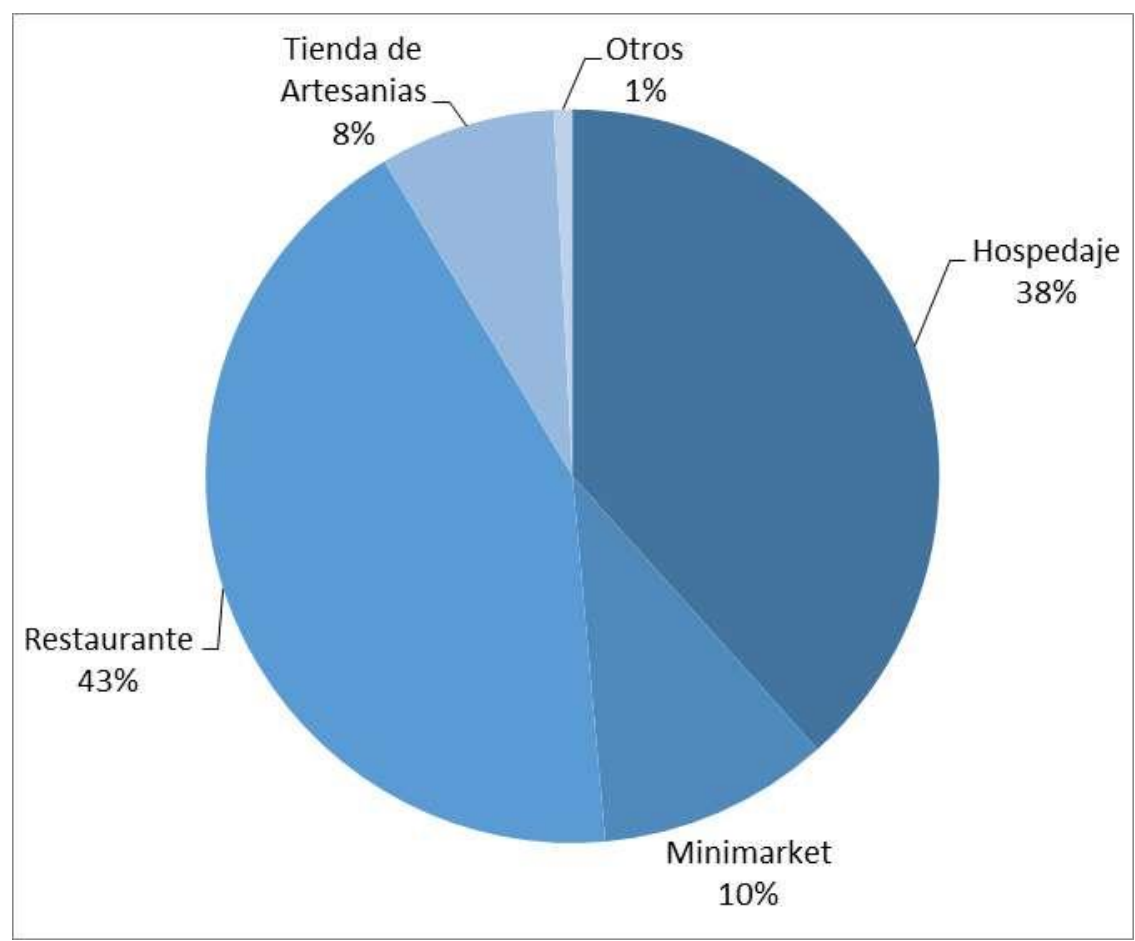

Figura 32. Pregunta 25: ¿qué servicios adicionales te gustaría encontrar en Capachica? 
A la mayoría de encuestados les gustaría encontrar el servicio de restaurante $42.86 \%$, esta información es relevante para el proyecto puesto que se llegará a un acuerdo con la comunidad de Capachica para brindar este servicio de esta forma buscar la sinergia con la comunidad.

\subsection{Conclusiones y Recomendaciones del Estudio Cualitativo y Cuantitativo}

a. Conclusiones del estudio cualitativo

Se ha identificado como público objetivo, tendrán un rango de edades entre 14 a 59 años, siendo indistinto el sexo.

Las motivaciones que tienen los turistas nacionales y turistas locales al decidirse realizar un servicio turístico son las nuevas experiencias, conocer lugares nuevos, salir de lo rutinario y en algunos casos la adrenalina. Según las entrevistas realizadas el precio ira de acuerdo a la calidad de servicios que se ofrezcan teniendo la oportunidad de discriminar mejor los precios.

Los lugares más frecuentados en tiempos y/o ratos libres son los ya conocidos por los turistas, la Isla de los Uros, Taquile, Amantani, Chucuito, July y Sillustani. Existen lugares más exóticos pero no son considerados en la ruta de las agencias de turismo. Una razón de ello es que no existe una adecuada infraestructura logística que atienda dichos lugares.

Las playas más conocidas y frecuentadas en Puno son: Chiflón, Karina, Charcas y Suasi, teniendo cada una de ellas sus particularidades desde ser tranquilas y limpias con hermosos paisajes. Las temporadas más frecuentadas son en los días festivos como el día del estudiante y en el verano que va desde Diciembre a Marzo.

Consideran el proyecto viable siempre y cuando se ejecute en Capachica, teniendo las condiciones de seguridad, movilidad y alimentación; así también como las condiciones del clima 
y precio, buscando un clima siempre apropiado. Respecto al precio prefieren un tour compartidos para economizar el servicio. Se tendrá que tomar en cuenta una negoción con las autoridades locales como recomendación hacia el proyecto ya que, las mismas podrían ser un obstáculo a la hora de la implementación y posterior funcionamiento.

b. Conclusiones del estudio cuantitativo

El rango de edades que optarían más por los servicios está en un rango de 14 a 59 años, siendo en su mayoría solteros y con grado universitario. Gran parte de nuestro público radicaría en la ciudad de Puno. Suelen gastar hasta S/200 en lugares turísticos de Puno. Una mayoría del $51 \%$ no está enterado de alternativas de turismo de aventura en la zona. Entre diferentes tipos de vehículos acuáticos para pasear en el lago un $49 \%$ prefieren una moto acuática. Una mayoría del 95\% si quisiera una propuesta de paseo en motos acuáticas en la que están dispuestos a viajar hasta 60 minutos de la ciudad. Por un paseo en moto acuática están dispuestos a pagar entre S/40 a S/60 solo por el servicio de alquiler de motos y realizar el paseo entre 15 minutos a media hora. El horario preferido esta entre 10:00am hasta 2:00 pm. Esperan que el servicio les brinde diversión y calidad de servicio. Por último un 77\% optaría por un servicio adicional de "camping" y "alimentación".

\subsection{Perfil del Consumidor Tipo y sus Variantes}

El perfil del consumidor ideal después de realizado el estudio de mercado es el siguiente: 
Tabla 49

\section{Perfil del Consumidor}

\begin{tabular}{ll}
\hline Variables & Mercado \\
\hline S. Geografica & $\begin{array}{l}\text { Ciudad de Puno } \\
\text { Género masculino y femenino, entre 14 a 59 años, siendo una } \\
\text { S. Demografica }\end{array}$ \\
mayoría en un rango 18 a 35 años \\
S. Psicografica & Aventureros , busquen calidad y economía \\
S. Conductual & Fines de semana, feriados largos y días particulares \\
\hline
\end{tabular}

Nota: Adaptado Kotler\&Armstrong (2012)

El cliente ideal tendrá una edad joven, de género indistinto y vive en la ciudad de Puno. Aprovecha los fines de semana, feriados largos y algunos días particulares en salir fuera de la ciudad en busca nuevas experiencias. Busca servicios de calidad que se ajusten a sus ingresos. Tiene una tendencia de buscar servicios que le ofrecen nuevas experiencias, adrenalina y deportes de aventura.

Sus posibles variantes irán de acuerdo a su rango de edad, siendo los más exigentes los que cuenten con mayores ingresos. Asimismo se puede tener clientes nacionales que solo llegan en temporadas festivas y buscarán servicios que les brinden todas las facilidades de comodidad, transporte y seguridad. 


\section{Capítulo IV: Proyección del Mercado Objetivo}

\subsection{El Ámbito de la Proyección.}

El ámbito de geográfico del proyecto abarca a los ciudadanos y visitantes de la ciudad de Puno. Los cuáles tienen que estar dentro de la Población Económicamente Activa (PEA) y en el rango de edades de 14 a 59 años.

\subsection{Selección del Método de Proyección.}

Se empleará el método de regresión lineal simple para la estimación de la demanda.

Dicho método consiste en llegar a una ecuación que permita proyectar la demanda futura del mercado. Se basa en una variable independiente y una dependiente, siendo la variable independiente la determinante a la hora de proyectar la demanda (Sweeney \& Camm, 2016)

Se proyecta el crecimiento anual de la población económicamente activa (PEA) del departamento de Puno y la cantidad de visitantes nacionales que llegan a Puno. De esta manera y con una base histórica se determinara el crecimiento de estas variables para los futuros 5 años del proyecto.

En las Tablas 50, 51 y 52 se visualiza la proyección de la PEA de Puno para los siguientes 05 años. 
Tabla 50

\begin{tabular}{ccc} 
Mercado local & \\
\hline \multirow{2}{*}{ Año } & $\begin{array}{c}\text { Población Departamento } \\
\text { Puno }\end{array}$ & $\begin{array}{c}\text { PEA Activa Departamento de } \\
\text { Puno }\end{array}$ \\
\hline 2005 & $1,293,843$ & 741,408 \\
2006 & $1,306,226$ & 742,376 \\
2007 & $1,317,911$ & 730,877 \\
2008 & $1,329,272$ & 739,169 \\
2009 & $1,340,684$ & 749,532 \\
2010 & $1,352,523$ & 772,555 \\
2011 & $1,364,752$ & 783,010 \\
2012 & $1,377,122$ & 783,615 \\
2013 & $1,389,684$ & 803,470 \\
2014 & $1,402,496$ & 817,412 \\
2015 & $1,415,608$ & 801,952 \\
\hline
\end{tabular}

Tabla 51

Estimación por ecuación de la demanda - Proyeccion PEA Activa Puno

\begin{tabular}{ccccc}
\hline Año & Periodo $(\mathrm{X})$ & Demanda $(\mathrm{Y})$ & $\mathrm{XY}$ & $\mathrm{X}^{\wedge} 2$ \\
\hline 2005 & 1 & 741,408 & 741,408 & 1 \\
2006 & 2 & 742,376 & $1,484,751$ & 4 \\
2007 & 3 & 730,877 & $2,192,631$ & 9 \\
2008 & 4 & 739,169 & $2,956,677$ & 16 \\
2009 & 5 & 749,532 & $3,747,659$ & 25 \\
2010 & 6 & 772,555 & $4,635,328$ & 36 \\
2011 & 7 & 783,010 & $5,481,071$ & 49 \\
2012 & 8 & 783,615 & $6,268,917$ & 64 \\
2013 & 9 & 803,470 & $7,231,228$ & 81 \\
\\
2014 & 10 & 817,412 & $8,174,121$ & 100 \\
\\
2015 & 11 & 801,952 & $8,821,476$ & 121 \\
\hline Suma total & 66 & $8,465,375$ & $51,735,266$ & 506 \\
Promedio & 6 & 769,580 & & \\
n & 11 & & & \\
\hline
\end{tabular}

$\begin{array}{lcc}\mathrm{a}= & 761,433 & \mathrm{~b}=\underline{\mathrm{n}\left(\sum \mathrm{xy}\right)-\left(\sum \mathrm{y}\right)\left(\sum \mathrm{x}\right)} \\ \mathrm{b}= & 1,358 & \mathrm{n}\left(\sum \mathrm{x}^{2}\right)-\left(\sum \mathrm{x}\right)^{2} \\ \mathrm{y}= & 672,345+1592 \mathrm{x} & \mathbf{v}=\mathbf{a}+\mathbf{h x}\end{array}$


Tabla 52

Estimación de Mercado local

\begin{tabular}{ccc} 
Año & Periodo & $\begin{array}{c}\text { Proyeccion PEA Activa } \\
\text { Puno }\end{array}$ \\
\hline 2017 & 13 & 693,041 \\
2018 & 14 & 694,633 \\
2019 & 15 & 696,225 \\
2020 & 16 & 697,817 \\
2021 & 17 & 699,409 \\
\hline
\end{tabular}

En las Tablas 54,55, y 56 se visualiza la proyección de los visitantes a Puno para los siguientes 05 años.

Tabla 53

Mercado nacional

\begin{tabular}{ccc}
\hline Año & $\begin{array}{c}\text { Arribo de visitantes } \\
\text { nacionales a Puno }\end{array}$ & $\begin{array}{c}\text { Mercado Público } \\
\text { nacional }\end{array}$ \\
\hline 2005 & 216,452 & 216,452 \\
2006 & 254,384 & 254,384 \\
2007 & 305,696 & 305,696 \\
2008 & 344,437 & 344,437 \\
2009 & 377,825 & 377,825 \\
2010 & 418,864 & 418,864 \\
2011 & 426,656 & 426,656 \\
2012 & 416,471 & 416,471 \\
2013 & 419,481 & 419,481 \\
2014 & 504,930 & 504,930 \\
2015 & 516,342 & 516,342 \\
\hline
\end{tabular}


Tabla 54

Estimación por ecuación de la demanda - Proyecccion Arribo de visitantes nacionales a Puno

\begin{tabular}{|c|c|c|c|c|}
\hline Año & Periodo (X) & Demanda (Y) & $\mathrm{XY}$ & $\mathrm{X}^{\wedge} 2$ \\
\hline 2005 & 1 & 216,452 & 216,452 & 1 \\
\hline 2006 & 2 & 254,384 & 508,768 & 4 \\
\hline 2007 & 3 & 305,696 & 917,088 & 9 \\
\hline 2008 & 4 & 344,437 & $1,377,748$ & 16 \\
\hline 2009 & 5 & 377,825 & $1,889,125$ & 25 \\
\hline 2010 & 6 & 418,864 & $2,513,184$ & 36 \\
\hline 2011 & 7 & 426,656 & $2,986,592$ & 49 \\
\hline 2012 & 8 & 416,471 & $3,331,768$ & 64 \\
\hline 2013 & 9 & 419,481 & $3,775,329$ & 81 \\
\hline 2014 & 10 & 504,930 & $5,049,300$ & 100 \\
\hline 2015 & 11 & 516,342 & $5,679,762$ & 121 \\
\hline Suma total & 66 & $4,201,538$ & $28,245,116$ & 506 \\
\hline Promedio & 6 & 381,958 & & \\
\hline $\mathrm{n}$ & 11 & & & \\
\hline & & \multicolumn{3}{|c|}{$a=\bar{y}-b(\bar{x})$} \\
\hline$a=$ & 348,995 & \multicolumn{3}{|c|}{$\mathrm{b}=\underline{\mathrm{n}\left(\sum \mathrm{xy}\right)-\left(\sum \mathrm{y}\right)\left(\sum \mathrm{x}\right)}$} \\
\hline $\begin{array}{l}\mathrm{b}= \\
\mathrm{y}=\end{array}$ & 5,494 & \multicolumn{3}{|c|}{$\mathrm{n}\left(\sum \mathrm{x}^{2}\right)-\left(\sum \mathrm{x}\right)^{2}$} \\
\hline$y=$ & $348,995+5494 x$ & \multicolumn{3}{|c|}{$y=a+b x$} \\
\hline
\end{tabular}

Tabla 55

Estimación de Mercado nacional

\begin{tabular}{ccc}
\hline Año & Periodo & $\begin{array}{c}\text { Proyecccion Arribo de } \\
\text { visitantes nacionales a } \\
\text { Puno }\end{array}$ \\
\hline 2017 & 13 & 420,417 \\
2018 & 14 & 425,911 \\
2019 & 15 & 431,405 \\
2020 & 16 & 436,899 \\
2021 & 17 & 442,393 \\
\hline
\end{tabular}

\subsubsection{Mercado potencial.}

Según Kotler \& Keller (2012), el mercado potencial es aquel donde hay un grupo con capacidad de adquirir un producto o servicio y que están interesados en la oferta del mercado.

Se tiene dos tipos de clientes; un cliente local originario de Puno y un cliente nacional que lo conforman turistas nacionales. 
Para la determinación del mercado potencial se tiene dos tipos de público:

La población del departamento de Puno perteneciente a la PEA, en un rango de edad entre 14 a 59 años, que provienen de las 03 regiones más pobladas del departamento y sean pertenecientes a los niveles socioeconómicos A, B y C. Dicho público se denominará público local.

Por otro lado, se tiene al público determinado por los visitantes nacionales que recibe Puno cada año, los cuales están entre 14 a 59 años, perteneciendo a los niveles socioeconómicos A,B y C, y que provengan de los 03 departamentos que más viajes realizan a Puno al año. Dicho público se denominará público nacional.

Se determina el público local en base a la PEA activa del departamento de Puno Proyectada como base para determinar el potencial. Y se utiliza los datos recogidos en la investigación de mercados para determinar las demás el mercado potencial del público local. Respecto a las regiones más pobladas se toma como referencia la encuesta y los datos del INEI determinando que las regiones más pobladas del departamento son las regiones de Puno, Chucuito y San Román tal como se muestra en la Tabla 57. Por último se realiza un ajuste de acuerdo al juicio de expertos recogido en la entrevistas de profundidad que indica que un $80 \%$ de las publico local gusta de realizar actividades al aire libre. 
Tabla 56

Población entre 14 a 59 años de las regiones de Puno 2015

\begin{tabular}{|c|c|c|c|}
\hline Regiones de Puno & $14-59$ & $\%$ & Ciudad más representativa \\
\hline Puno & 152,937 & $18.11 \%$ & Puno \\
\hline Azángaro & 74,458 & $8.82 \%$ & \\
\hline Carabaya & 53,503 & $6.33 \%$ & \\
\hline Chucuito & 88,568 & $10.49 \%$ & Desagüadero \\
\hline El Collao & 50,417 & $5.97 \%$ & \\
\hline Huancané & 34,367 & $4.07 \%$ & \\
\hline Lampa & 30,433 & $3.60 \%$ & \\
\hline Melgar & 42,534 & $5.04 \%$ & \\
\hline Moho & 12,957 & $1.53 \%$ & \\
\hline San Antonio de Putina & 48,561 & $5.75 \%$ & \\
\hline San Román & 187,026 & $22.14 \%$ & Juliaca \\
\hline Sandia & 41,574 & $4.92 \%$ & \\
\hline Yunguyo & 27,232 & $3.22 \%$ & \\
\hline Total & 844,567 & $100.00 \%$ & \\
\hline
\end{tabular}

De este modo se determina el mercado potencial del público local tal como se muestra en la

Tabla 57.

Tabla 57

\begin{tabular}{|c|c|c|c|c|c|c|}
\hline \multirow[b]{2}{*}{ Año } & \multirow[b]{2}{*}{$\begin{array}{c}\text { PEA Activa de Puno } \\
\text { Proyectada }\end{array}$} & \multirow{2}{*}{$\begin{array}{c}\text { Edad de publico } \\
\text { entre } 14 \text { a } 59 \text { años } \\
\text { P2 } \\
\text { (según encuesta) }\end{array}$} & \multirow{2}{*}{$\begin{array}{c}\text { NSE A,B,C } \\
\text { P4,P5,P6,P7,P8 } \\
\text { (según encuesta) }\end{array}$} & \multicolumn{3}{|c|}{ Procedencia Mercado Local } \\
\hline & & & & $\begin{array}{c}\text { - P11 } \\
\text { Puno-Chucuito-San Roman } \\
\text { (según encuesta) }\end{array}$ & $\begin{array}{l}\text { Actividades al aire libre } 80 \% \\
\text { Según juicio de expertos }\end{array}$ & Mercado Potencial(a) \\
\hline 2017 & 693,041 & $97.77 \%$ & $33.93 \%$ & $74.11 \%$ & $80.00 \%$ & 136,306 \\
\hline 2018 & 694,633 & $97.77 \%$ & $33.93 \%$ & $74.11 \%$ & $80.00 \%$ & 136,619 \\
\hline 2019 & 696,225 & $97.77 \%$ & $33.93 \%$ & $74.11 \%$ & $80.00 \%$ & 136,932 \\
\hline 2020 & 697,817 & $97.77 \%$ & $33.93 \%$ & $74.11 \%$ & $80.00 \%$ & 137,245 \\
\hline 2021 & 699,409 & $97.77 \%$ & $33.93 \%$ & $74.11 \%$ & $80.00 \%$ & 137,559 \\
\hline
\end{tabular}

Se determina el público nacional de acuerdo al total de visitantes a Puno Proyectada como base para determinar el potencial, cifra se obtiene de MINCETUR. Se utiliza los datos recogidos en la investigación de mercados para determinar el mercado potencial del público nacional. Respecto a los departamento de donde proviene los visitantes se toma como referencia la encuesta y los datos del MINCETUR determinando que las regiones de procedencia de los visitantes nacionales se concentran en Lima, Arequipa y Cusco tal como se muestra en la Figura 33. Por último se realiza un ajuste de acuerdo al juicio de expertos recogido en la entrevistas de 
profundidad que indica que un $65 \%$ de las publico nacional gusta de realizar actividades al aire libre.

\begin{tabular}{|c|c|c|c|}
\hline \multicolumn{4}{|c|}{$\begin{array}{l}\text { Región de Procedencia de los huespedes Nacionales, } \\
\qquad 2016^{*}\end{array}$} \\
\hline Región & Número & Part. \% & Part. \% \\
\hline Lim a metropo & 95.995 & $28,0 \%$ & $14,2 \%$ \\
\hline Arequipa & 92.537 & $27,0 \%$ & $13,7 \%$ \\
\hline Cusco & 62.547 & $18,2 \%$ & $9,3 \%$ \\
\hline Lima provinciz & 25.532 & $7,4 \%$ & $3,8 \%$ \\
\hline Tacna & 19.833 & $5,8 \%$ & $2,9 \%$ \\
\hline Moquegua & 11.661 & $3,4 \%$ & $1,7 \%$ \\
\hline Madre de Dio. & 5.963 & $1,7 \%$ & $0,9 \%$ \\
\hline Otros & 28.985 & $8,4 \%$ & $4,3 \%$ \\
\hline Total & 343.053 & $100,0 \%$ & \\
\hline Puno & 332.463 & & $49,2 \%$ \\
\hline Total & 675.516 & & $100,0 \%$ \\
\hline \multicolumn{4}{|c|}{$\begin{array}{l}\text { - Sin considerar la misma región } \\
\text { Fuente: Mincetur }\end{array}$} \\
\hline
\end{tabular}

Figura 33. Región de Procedencia de los huéspedes Nacionales 2016. . Tomado de

PeruCamaras, 2016. Recuperado de http://www.perucam.com/perucam_new/file/Infsem/Edición\%20N%20238-Reporte\%20Regional\%20Sur.xlsx

De este modo se determina el mercado potencial del público nacional tal como se muestra en la Tabla 58.

Tabla 58

\begin{tabular}{|c|c|c|c|c|c|c|}
\hline Año & $\begin{array}{c}\text { Visitantes nacionales a Puno } \\
\text { Proyectado }\end{array}$ & $\begin{array}{c}\text { Edad de visitantes } \\
\text { entre } 14 \text { a } 59 \text { años } \\
\text { P22 } \\
\text { (según encuesta) }\end{array}$ & $\begin{array}{c}\text { NSF. A R C } \\
\text { P4,P5,P6,P7,P8 } \\
\text { (seorín encuesta) }\end{array}$ & $\begin{array}{l}\text { Procedencia Mercado } \\
\text { Nacional - P12 } \\
\text { Lima - Arequipa -Cusco } \\
\text { (según encuesta) }\end{array}$ & $\begin{array}{l}\text { Actividades al aire libre } 65 \% \\
\text { Según juicio de expertos }\end{array}$ & Mercado Potencial (b) \\
\hline 2017 & 420,417 & $98.13 \%$ & $68.13 \%$ & $53.13 \%$ & $65.00 \%$ & 97,067 \\
\hline 2018 & 425,911 & $98.13 \%$ & $68.13 \%$ & $53.13 \%$ & $65.00 \%$ & 98,336 \\
\hline 2019 & 431,405 & $98.13 \%$ & $68.13 \%$ & $53.13 \%$ & $65.00 \%$ & 99,604 \\
\hline 2020 & 436,899 & $98.13 \%$ & $68.13 \%$ & $53.13 \%$ & $65.00 \%$ & 100,873 \\
\hline 2021 & 442,393 & $98.13 \%$ & $68.13 \%$ & $53.13 \%$ & $65.00 \%$ & 102,141 \\
\hline
\end{tabular}

Una vez hallado el mercado potencial de cada público (local y nacional) se tiene un total de 236,537 personas como mercado potencial promedio total en los próximos cinco años. 
Tabla 59

Determinación del mercado potencial

\begin{tabular}{cccc}
\hline Año & $\begin{array}{c}\text { Mercado potencial - Público } \\
\text { local (a) }\end{array}$ & $\begin{array}{c}\text { Mercado potencial - } \\
\text { Público nacional (b) }\end{array}$ & $\begin{array}{c}\text { Mercado potencial total } \\
\text { (a+b) }\end{array}$ \\
\hline 2017 & 136,306 & 97,067 & 233,374 \\
2018 & 136,619 & 98,336 & 234,955 \\
2019 & 136,932 & 99,604 & 236,537 \\
2020 & 137,245 & 100,873 & 238,118 \\
2021 & 137,559 & 102,141 & 239,700 \\
\hline
\end{tabular}

\subsubsection{Mercado disponible.}

El mercado disponible es aquel grupo de consumidores con capacidad de acceso, ingresos e interés suficiente en adquirir un determinado producto o servicio del mercado (Kotler y Keller, 2012).

Dado que se presenta un servicio nuevo en el mercado se considera como mercado disponible, las personas que han realizado alguna vez una actividad de aventura.

El servicio se enfoca en contar con clientes que busquen realizar nuevas actividades y que en las mismas predomine la adrenalina.

Tabla 60 


\begin{tabular}{cccc}
\hline$\Delta \tilde{\mathbf{n}} \boldsymbol{}$ & $\begin{array}{c}\text { Mercado potencial total } \\
\text { proyectado }\end{array}$ & $\begin{array}{c}\text { ¿Ha realizado alguna } \\
\text { actividad de turismo de } \\
\text { aventura? } \\
\text { P14 }\end{array}$ & Merradn disnnihle \\
\hline 2017 & 233,374 & $68.23 \%$ & 159,231 \\
2018 & 234,955 & $68.23 \%$ & 160,310 \\
2019 & 236,537 & $68.23 \%$ & 161,389 \\
2020 & 238,118 & $68.23 \%$ & 162,468 \\
2021 & 239,700 & $68.23 \%$ & 163,547 \\
\hline
\end{tabular}

\subsubsection{Mercado efectivo.}

El mercado meta u efectivo es aquel grupo de consumidores calificado que una empresa decide atender para la oferta de sus productos o servicios. (Kotler y Keller, 2012)

En base al mercado disponible total se determina el mercado efectivo de acuerdo a la siguiente pregunta:

P21: ¿Te gustaría realizar un circuito de caminatas, ciclismo y motos acuáticas en Capachica? (a cuarenta minutos de Puno)

P24: ¿Con que frecuencia harías el circuito ofrecido? (se realiza un promedio ponderado)

La frecuencia del uso dará un indicio de cuántas veces al año el nicho de mercado usaría el servicio. De este modo se visualiza en la Tabla 61 que el promedio de uso del servicio será de 0.68 veces al año.

Tabla 61 


\begin{tabular}{lccccc} 
Variables & $\begin{array}{c}\text { Entrevistados } \\
\text { (a) }\end{array}$ & $\begin{array}{c}\text { Porcentaje } \\
\text { (b) }\end{array}$ & $\begin{array}{c}\text { Frecuencia de } \\
\text { uso anual } \\
\text { (c) }\end{array}$ & $\begin{array}{c}\text { Uso Anual } \\
\text { (a) } *(\mathrm{c}\end{array}$ & $\begin{array}{c}\text { Ponderado } \\
\text { (b)*[(a)*(c) }]\end{array}$ \\
\hline Z al año & 177 & $72.24 \%$ & 1 & 177 & 128 \\
ces al año & 42 & $17.14 \%$ & 2 & 84 & 14 \\
cual & 22 & $8.99 \%$ & 12 & 264 & 24 \\
& 4 & $1.63 \%$ & 24 & 96 & 2 \\
& 245 & $100.00 \%$ & & 621 & 168 \\
\hline
\end{tabular}

Promedio de veces al año:

Total Ponderado/Total $\quad 0.68$ veces

Entrevistados

Obtenido el dato de frecuencia se halla el mercado efectivo total en personas atendidas por año y número de servicios realizados por año.

Tabla 62

\begin{tabular}{|c|c|c|c|c|c|}
\hline Año & $\begin{array}{c}\text { Mercado disponible total } \\
\text { proyectado }\end{array}$ & $\begin{array}{c}\text { ¿Te gustaría realizar un } \\
\text { circuito de caminatas, } \\
\text { ciclismo y motos acuáticas } \\
\text { en Capachica? } \\
\text { P21 }\end{array}$ & $\begin{array}{c}\text { Mercado Efectivo } \\
\text { (en personas) }\end{array}$ & $\begin{array}{c}\text { Promedio de veces al año que } \\
\text { usarían el servicio } \\
\text { P24 }\end{array}$ & $\begin{array}{c}\text { Mercado Efectivo } \\
\text { (en servicios ha realizar) }\end{array}$ \\
\hline 2017 & 159,231 & $93.51 \%$ & 148,897 & 0.68 & 101,816 \\
\hline 2018 & 160,310 & $93.51 \%$ & 149,906 & 0.68 & 102,506 \\
\hline 2019 & 161,389 & $93.51 \%$ & 150,915 & 0.68 & 103,196 \\
\hline 2020 & 162,468 & $93.51 \%$ & 151,924 & 0.68 & 103,886 \\
\hline 2021 & 163,547 & $93.51 \%$ & 152,933 & 0.68 & 104,576 \\
\hline
\end{tabular}

\subsubsection{Mercado objetivo.}

El mercado penetrado u objetivo es aquel conjunto de consumidores que compra el producto o servicio ofertado de una empresa (Kotler y Keller, 2012).

De acuerdo a los indicios de crecimiento del sector turismo en el Perú, al crecimiento en el PBI per capita, la participación de mercado de la competencia y los factores internos y/o 
extorno vistos. Se determina que el mercado meta a lograr en un primer año será de un $2 \%$ del mercado efectivo. Ello sustentado en que el promedio de recordación de las empresa no es más de $1.18 \%$ (ver Tabla 42 - Pregunta 19) y que los esfuerzo de marketing a realizar permitirán llegar a dicha participación el primer año.

Asimismo se considera que el crecimiento por año será de $6.48 \%$. Ello sustentado en el promedio de crecimiento sector turismo a nivel mundial, al crecimiento sector a nivel nacional, crecimiento del turismo interno y crecimiento del PBI per cápita en los últimos 05 años.

Tabla 63

Determinacion del crecimiento anual

\begin{tabular}{lc}
\hline \multicolumn{1}{c}{ Variables } \\
(últimos 05 años) & Porcentaje \\
\hline Crecimiento sector turismo a nivel mundial & $3.00 \%$ \\
Crecimiento sector turismo a nivel nacional & $8.00 \%$ \\
Crecimiento turismo interno & $9.00 \%$ \\
Crecimiento del PBI per cápita & $5.90 \%$ \\
Promedio total & $6.48 \%$ \\
\hline
\end{tabular}

Se tiene claro una participación de mercado a llegar de $2 \%$ llegando hasta $2.5 \%$.

Asimismo el crecimiento en ventas será de $6.48 \%$ por año y está acorde al crecimiento del sector.

Tabla 64

\begin{tabular}{|c|c|c|c|c|c|}
\hline Año & $\begin{array}{l}\text { Mercado Efectivo } \\
\text { (en personas) }\end{array}$ & $\begin{array}{l}\text { Participación de } \\
\text { mercado a alcanzar }\end{array}$ & Crecimiento empresa & $\begin{array}{l}\text { Mercado Objetivo } \\
\text { (en personas) }\end{array}$ & $\begin{array}{c}\text { Mercado Objetivo } \\
\text { (en servicios por año - } \\
0.68 \text { ) } \\
\end{array}$ \\
\hline 2017 & 148,897 & $2.00 \%$ & & 2978 & 2036 \\
\hline 2018 & 149,906 & $2.12 \%$ & $6.48 \%$ & 3171 & 2168 \\
\hline 2019 & 150,915 & $2.24 \%$ & $6.48 \%$ & 3376 & 2309 \\
\hline 2020 & 151,924 & $2.37 \%$ & $6.48 \%$ & 3595 & 2458 \\
\hline 2021 & 152,933 & $2.50 \%$ & $6.48 \%$ & 3827 & 2617 \\
\hline
\end{tabular}




\subsection{Pronóstico de ventas}

Con lo determinado en el mercado objetivo, el proyecto tendrá un grupo diario al día y se llegará un rango entre 9 a 13 personas diarias el primer año. Se asume un precio de s/ 201 por el servicio con lo cual se proyectan las ventas.

Tabla 65

Proyección ventas

\begin{tabular}{ccc} 
Año & $\begin{array}{c}\text { Clientes atendidos por año } \\
\text { (Mercado Objetivo) }\end{array}$ & $\begin{array}{c}\text { Ventas aproximadas por año } \\
\text { (Precio promedio S/201) }\end{array}$ \\
\hline 2017 & 2,036 & 409,299 \\
2018 & 2,168 & 435,801 \\
2019 & 2,309 & 464,019 \\
2020 & 2,458 & 494,064 \\
2021 & 2,617 & 526,055 \\
\hline
\end{tabular}

\subsection{Aspectos Críticos que Impactan el Pronóstico de Ventas}

Los aspectos que más críticos que impactan el pronóstico de ventas son los relacionados al clima ya que, ante un fenómeno climático inestable perjudica las ventas ya sea por lluvia, tormentas eléctricas, heladas, granizo, etc. Sin embargo, hay otros factores que impactan los ingresos, los cuáles fueron sustentos en las entrevistas a profundidad y sesiones de grupo realizadas:

a. El clima es una variable importante ya que, las personas pueden desanimarse de realizar el servicio debido a factores climáticos. Asimismo afecta las operaciones de la empresa, ya sea porque no permite brindar un servicio adecuado al esperado por el cliente o porque los fenómenos climáticos pueden poner en riesgo la vida de los clientes.

b. Problemas con las comunidades aledañas impedirían brindar el servicio por situaciones de huelga o protesta. 
c. Una propuesta similar en el mercado puede disminuir nuestras ventas ya que, los clientes son muy susceptible al precio del servicio.

d. Un mal control de los equipos, no contar con seguros vigentes y una mala acción de los empleados puede afectar la imagen de la empresa. Por ello, los empleados estarán bien capacitados para poder actuar en cualquier situación y evitar clientes descontentos. 


\section{Capítulo V: Ingeniería del Proyecto}

\subsection{Estudio de Ingeniería}

Según Sapag (2011) se entiende por ingeniería de proyecto, la etapa dentro de la formulación de un proyecto de inversión donde se definen todos los recursos necesarios para llevar a cabo el proyecto para lograr un óptimo desarrollo se busca mantener un equilibrio entre costos, calidad, satisfacción de los clientes, tecnología y tiempo.

\subsubsection{Modelamiento y selección de procesos productivos.}

La cadena de valor es un proceso que grafica y permite describir las actividades de una organización para generar valor al cliente final y a la misma empresa. Cada empresa es un conjunto de distintas actividades como diseñar, producir, llevar al mercado, entregar, etc. Todas esas actividades pueden representarse en la cadena de valor (Porter, 2012).

El proyecto necesita entregar un servicio de calidad el cual debe cumplir con requerimientos y necesidades de los clientes por lo que se ha diseñado la siguiente cadena de valor, seguida por los siguientes puntos:

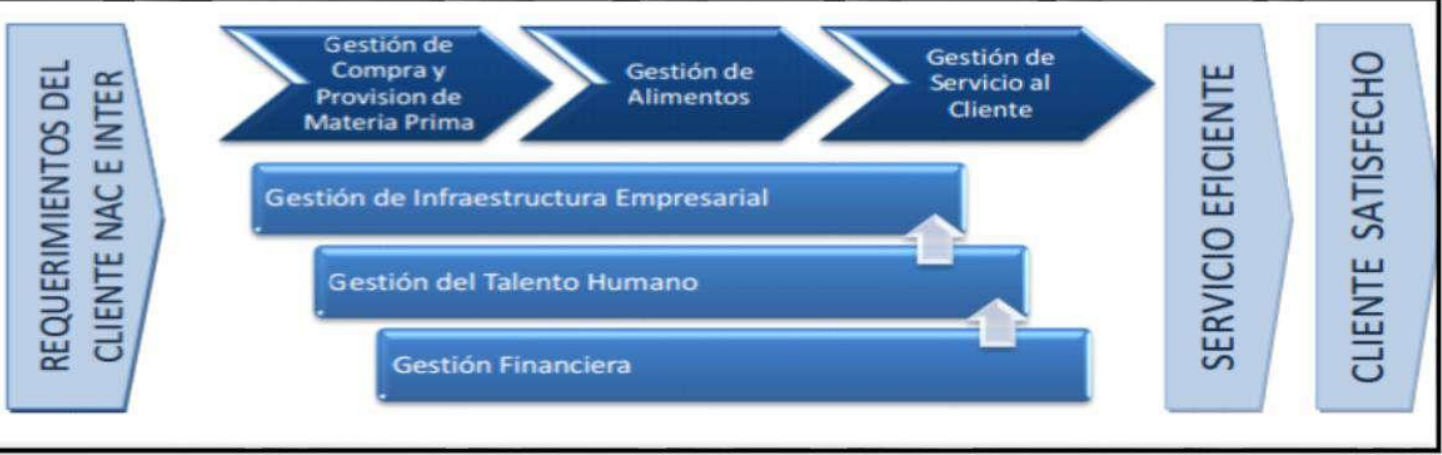

Figura 34. Actividades de la cadena de valor. Adaptado de la estrategia competitiva, 2015. p. 215, por Michael Porter, 2015, México. Segunda edición. Patria. 
Infraestructura de la empresa. Se cuenta con dos locales ubicados en la plaza central y otro en la playa de Chifrón.

Dentro de la industria se puede encontrar personal capacitado y con experiencia en el rubro.

Todas las empresas turísticas ahora emplean medios electrónicos para agilizar procedimientos.

Es de suma importancia la cartera de clientes con la cual se empezará a trabajar.

Las operaciones no se planean hay gran improvisación para realizar diferentes estrategias de ventas.

Excelente atención y precios bajos que la competencia no tiene hasta la fecha.

\subsubsection{Selección del equipamiento.}

El procedimiento del circuito constará de lo siguiente:

Tabla 66

Inversión de Equipos para el Servicio

\begin{tabular}{|c|c|c|c|c|}
\hline Item & cantidad & costo unitario & $\begin{array}{c}\text { costo total sin } \\
\text { IGV }\end{array}$ & $\begin{array}{c}\text { costo total } \\
\text { incluido IGV }\end{array}$ \\
\hline bicicleta montaña con suspensión delantera & a 10 & 5,599 & 47,449 & 55,990 \\
\hline go pro & 8 & 1,799 & 12,197 & 14,392 \\
\hline dron & 1 & 6,599 & 5,592 & 6,599 \\
\hline equipo de seguridad & 8 & 200 & 1,356 & 1,600 \\
\hline chaleco salvavida & 8 & 299 & 2,028 & 2,393 \\
\hline guantes & 10 & 33 & 280 & 330 \\
\hline motos acuaticas Seadoo Gti $90 \mathrm{HP}$ & 8 & 28,586 & 193,800 & 228,684 \\
\hline total & & & 262,702 & 309,988 \\
\hline
\end{tabular}

Tabla 67 


\begin{tabular}{lcccc}
\hline & cantidad costo unitario & costototarsitI & costo total \\
Item & & & IGV & incluido IGV \\
\hline Mueble de recepción & 2 & 300 & 508 & 600 \\
Sillas de madera tornillo & 12 & 50 & 508 & 600 \\
Computadora marca toshiba & 2 & 1,750 & 2,966 & 3,500 \\
Juego de sillones de cuero & 1 & 1,800 & 1,525 & 1,800 \\
Impresora multifuncional epson & 1 & 600 & 508 & 600 \\
Escritorio de madera tornillo & 2 & 800 & 1,356 & 1,600 \\
Teléfono marca Samsung & 2 & 215 & 364 & 430 \\
Televisor 43" marca samsung & 1 & 1,650 & 1,398 & 1,650 \\
Útiles de escritorio(papel, lapiceros) & 2 & 215 & 364 & 430 \\
Total & & & 9,500 & 11,210 \\
\hline
\end{tabular}

Los flujos del proceso son los siguientes:

a. Flujo de operaciones

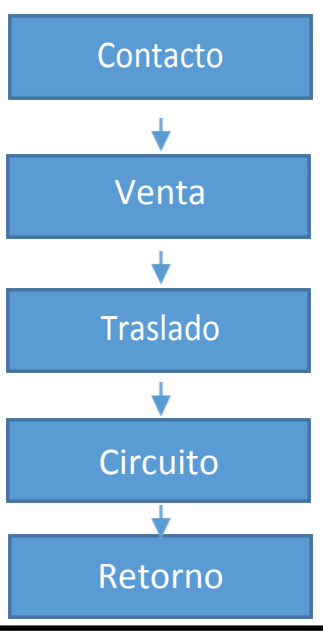

Figura 35. Flujo de operaciones. 


\section{b. Flujo de procesos}

Según Sapag (2013) considera que los diagramas de flujo se utilizan para describir y mejorar el proceso de transformación en las empresas. Para mejorar la efectividad o la eficiencia de los procesos productivos, pueden cambiarse algunos o todos los siguientes elementos del proceso. Existen dos simbologías American Society of Mechanical Engineers (ASME) que se utiliza para diagramación administrativa y American National Standard Institute (ANSI) se utiliza esta se simbología para el procedimiento electrónico de datos con el fin de representar flujos de información.

Para el proyecto se utilizará la simbología ASME ya que se son flujos de procesos.

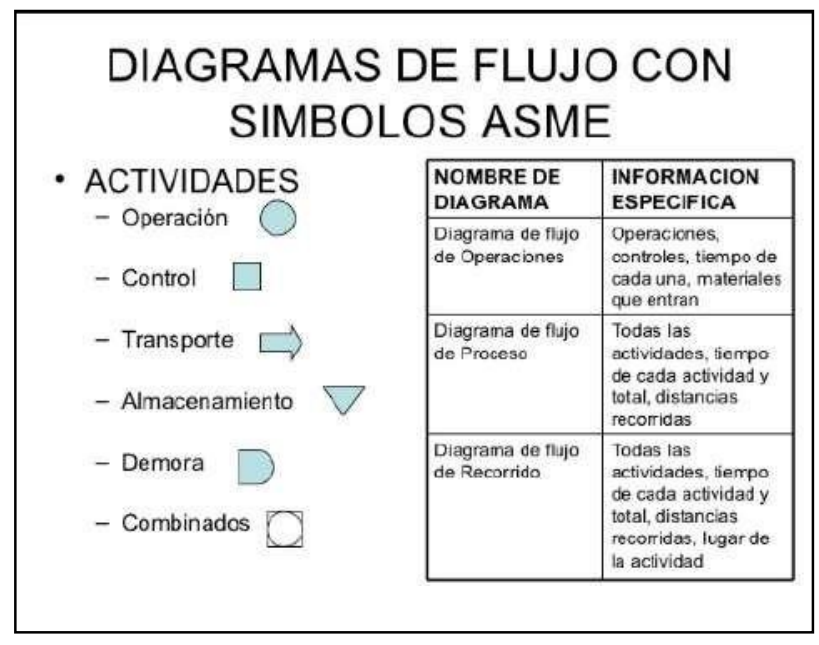

Figura 36. Diagramas de flujo con símbolos ASME. 
c. Proceso de venta del circuito

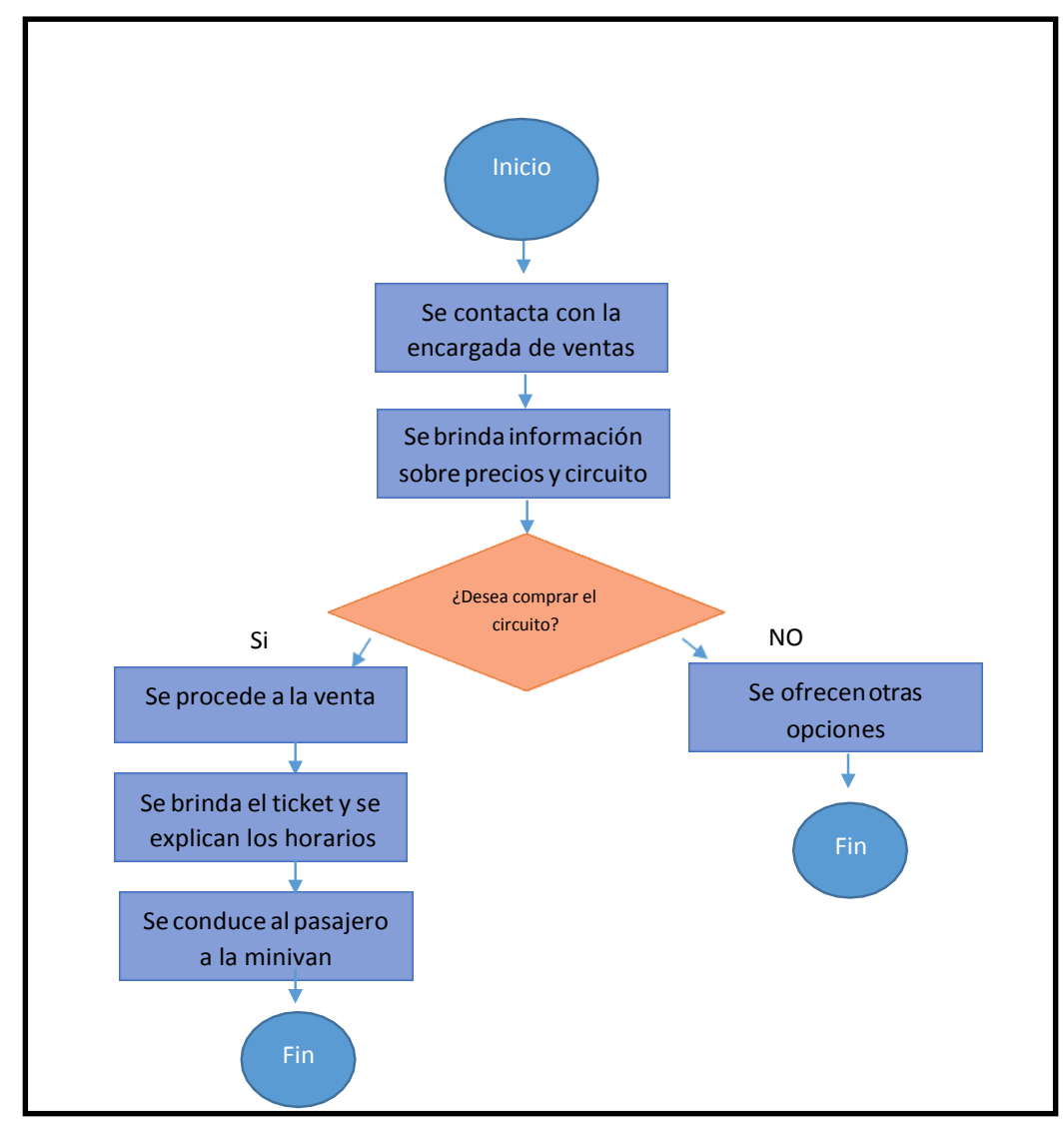

Figura 37. Proceso de ventas del circuito.

d. Proceso de traslado a la playa 


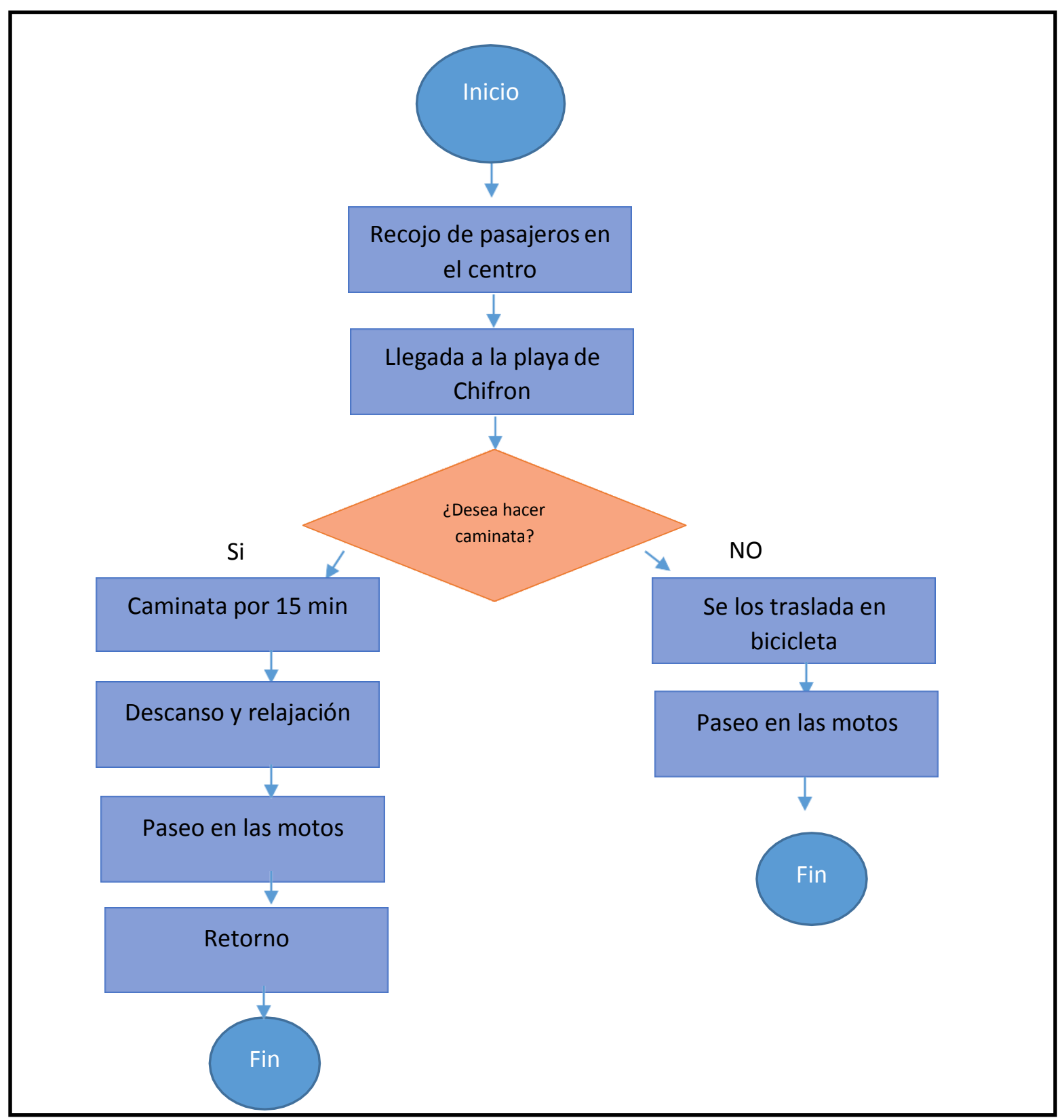

Figura 38. Proceso de traslado a la playa. 


\subsubsection{Lay out.}

Muestra la distribución de las distintas áreas del predio donde se ubicará la planta, incluye los diferentes equipos, espacios para circulación y mantenimiento para montaje, mostrados a escalas reales (Sapag, 2012).

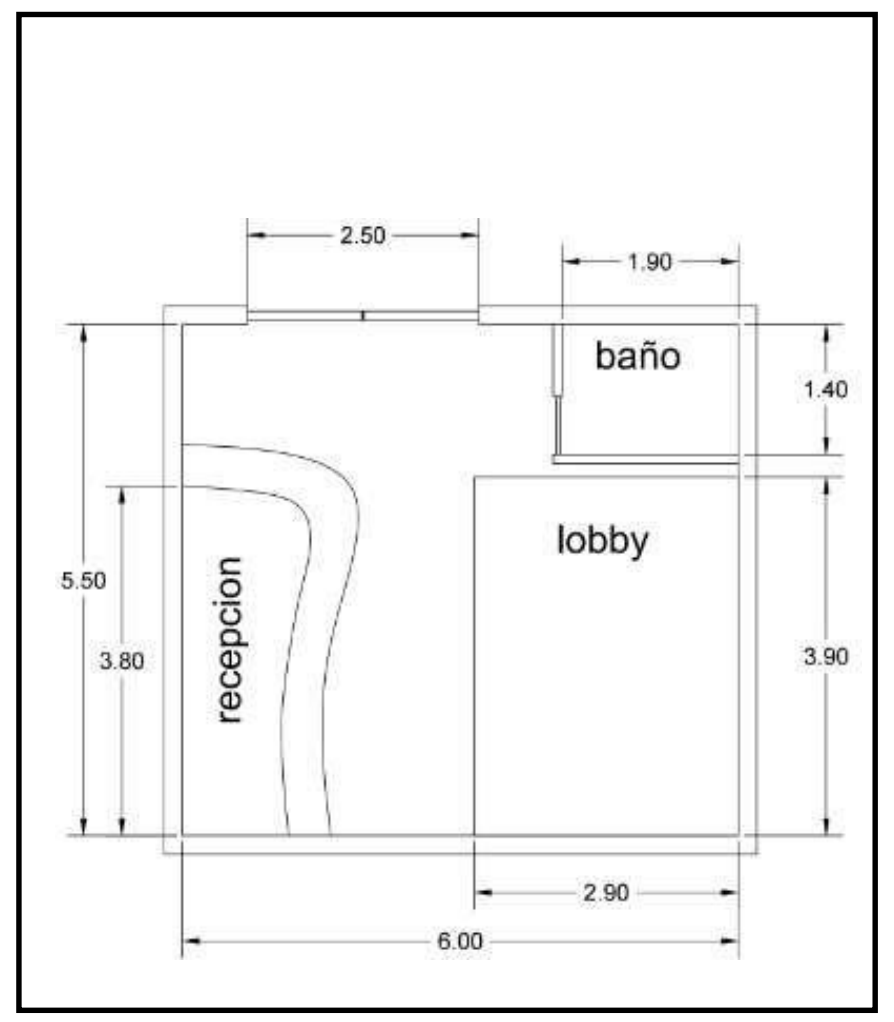

Figura 39. Plano de la oficina principal. 


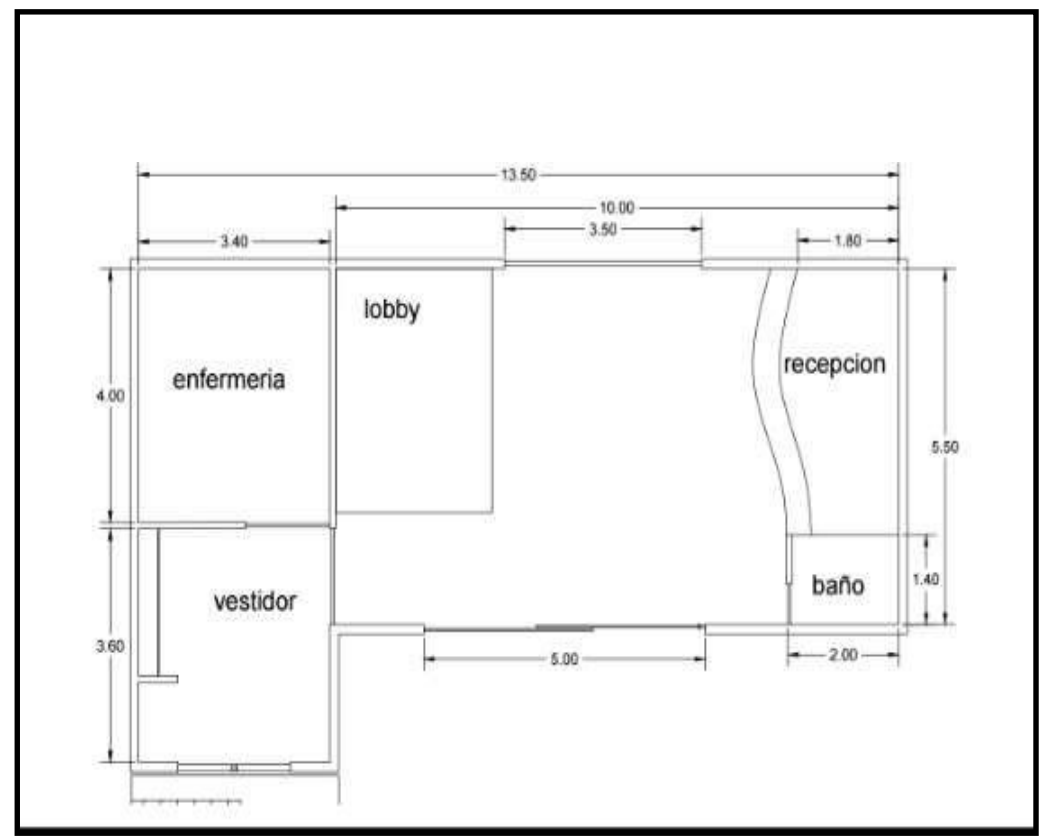

Figura 40. Plano del local ubicado en la playa.

\subsubsection{Distribución de equipos y maquinarias.}

Se establece la siguiente distribución de maquinaria requerida para la elaboración del circuito:

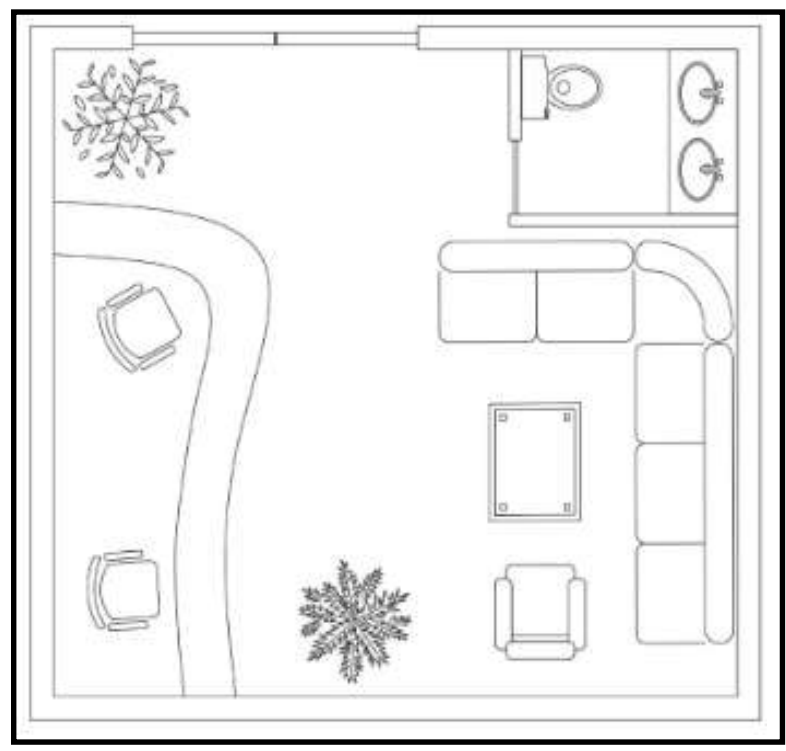

Figura 41. Plano del mobiliario en la oficina principal. 


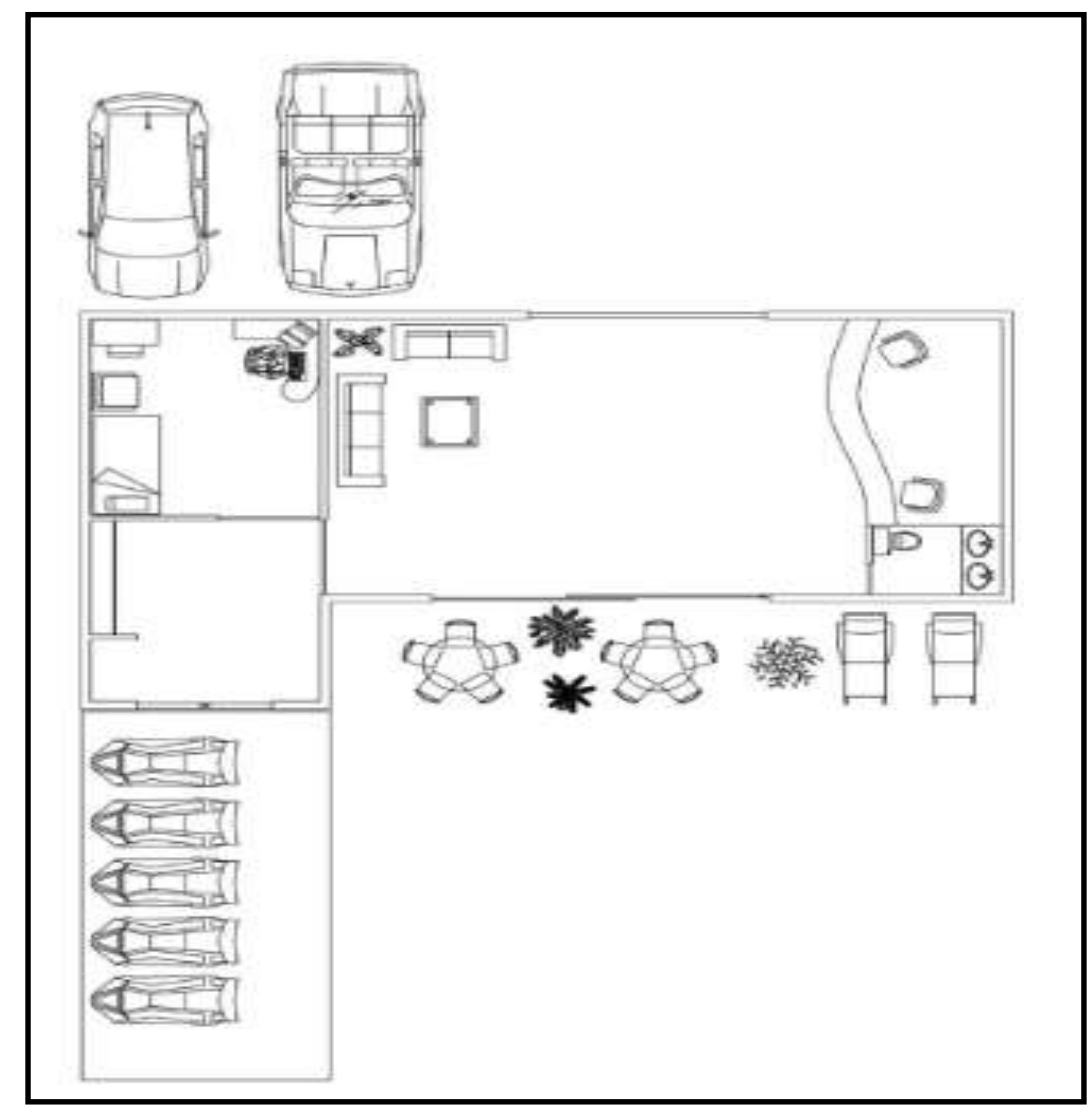

Figura 42. Plano de los equipos en el local de la playa.

\subsection{Determinación del Tamaño}

Según Sapag (2012) se considera que la importancia al definir el tamaño que tendrá el proyecto se manifiesta principalmente en su incidencia sobre el nivel de las inversiones y los costos que se calculen y, por tanto, sobre la estimación de la rentabilidad que podría generar su implementación. De igual manera, la decisión que se tome respecto del tamaño determinará el nivel de operación que posteriormente explicará la estimación de los ingresos por venta.

El tamaño está en base al conocimiento, determinación de la maquinaria necesaria y la planificación para iniciar en el año 2017. 
La capacidad de atención se define por la cantidad de personas diarias que se atenderán por día. En los cinco años proyectados se llegará a una atención de 17 personas diarias como máximo. Para ello, solo se empleará una unidad Sprinter con capacidad de 21 personas, lo que posibilita que en meses de alta demanda se pueda llevar hasta un máximo de 19 personas. En cuanto al requerimiento de equipos solo se requerirá 10 bicicletas y ocho motos acuáticas. Para el servicio de motos acuáticas se tendrá hasta tres turnos de 20 minutos a fin de no saturar el circuito en el lago mientras una parte de los excursionistas aprovechan la playa para descansar y sacar fotografías. La capacidad de equipamiento en los 5 años solo será utilizada a un $89 \%$ en cuanto al transporte y un $100 \%$ en cuanto a motos, biclicletas y equipos de seguridad.

\subsubsection{Proyección de crecimiento.}

El crecimiento se vendrá dando respectivamente a la proyección de ventas la cual será el promedio de crecimiento del 2.81\% para los siguientes años.

\subsubsection{Recursos.}

Los recursos son todos aquellos que se necesitan para que la empresa pueda lograr sus objetivos, se consideran como principales a los recursos humanos y financieros ya que dependerá de estos el logro de los objetivos esperados por el proyecto Sapag (2012). 
Tabla 68

Recursos Necesarios Para el Proyecto

\begin{tabular}{|c|c|}
\hline \multicolumn{2}{|l|}{ Recursos } \\
\hline Humanos & Trabajadores ( administrador, enfermera, guía) \\
\hline financieros & $\begin{array}{l}\text { Capital propio, aporte socios } \\
\text { oficina, materias }\end{array}$ \\
\hline materiales & primas \\
\hline tecnológicos & adquisición de tecnología \\
\hline
\end{tabular}

\subsubsection{Tecnología.}

Según Sapag (2012) es el conjunto de conocimientos técnicos, científicamente ordenados, que permiten diseñar y crear bienes, servicios que facilitan la adaptación al medio ambiente y la satisfacción de las necesidades esenciales y los deseos de la humanidad.

En el proyecto que se realizará, la tecnología es el punto que estará a favor ya que hoy en día las otras agencias de viaje no realizan los circuitos turísticos utilizando este gran recurso.

Para cada tramo del circuito se utilizará lo moderno y novedoso, como por ejemplo: en el primer tramo que es el de la caminata, se utilizara un dron el cual estará encargado de la filmación de todo el recorrido volando por los aires y a la vez tomando diversas fotografías; en el segundo tramo que es el de la bicicletas, se pondrá unas cámaras Go pro Hero 5 especiales para poder filmar los momentos más divertidos y capturando momentos.

En el tercer tramo se utilizará la cámara incluida en los cascos para poder filmar todo el recorrido que se hará en el Lago. 
Así se hace un uso muy productivo de la tecnología que hoy en día va en aumento para beneficio de los empresarios que desean darle un valor agregado a sus servicios ya tradicionales y poder competir en el mercado.

\subsubsection{Flexibilidad.}

Según Sapag (2012) la distribución flexible consta de tres etapas las cuales son:
a. Reunir información
b. $\quad$ Crear un plano de bloques
c. Diseñar una distribución detallada

La capacidad instalada está en función de cómo crece el mercado.

Si el crecimiento fuera positivo tendríamos el plan A (Aumento de capital para futuras compras de aumento de maquinaria).

Si el crecimiento fuera negativo tendríamos el plan B (Disminución y optimización de los recursos).

\subsubsection{Selección del tamaño ideal.}

La determinación del tamaño está relacionada con las variables del proyecto: demanda, disponibilidad de insumos, localización y plan estratégico comercial de desarrollo futuro de la empresa. La cantidad demandada proyectada a futuro es quizá el factor condicionante más importante del tamaño, así no esté en función al crecimiento del mercado, ya que el nivel óptimo de operación no siempre será el que maximice las ventas.

El tamaño óptimo depende de la economía de escala del proyecto, dependiendo de la creciente de la industria, ya que deberá optarse por definir un tamaño inicial lo suficientemente grande como para que pueda responder a futuro a ese crecimiento. El segundo caso hace 
necesario que, además de evaluarse la importancia de implementar el proyecto por etapas, deba plantear cuándo debe hacerse la ampliación (Sapag, 2012).

\subsection{Estudio de Localización}

La localización tiene efecto sobre la tecnología utilizada, tanto por las restricciones físicas que importa como la variación de los costos de operación y capital de las alternativas tecnológicas de cada ubicación posible, esto incrementará con el análisis que se realice para el estudio de prefactibilidad. Una localización puede ser óptima en el presente con las condiciones vigentes, pero esto no quiere decir que en el futuro lo sea (Sapag, 2012).

Se cuentan con alternativas en función de las fuerzas locacionales que servirán como elementos para la evaluación. Una clasificación más concentrada debería incluir por lo menos los siguientes factores globales:

- Medios y costos de transporte

- Disponibilidad y costo de mano de obra

- Cercanía de las fuentes de abastecimiento

- Cercanía del mercado

- Costo y disponibilidad de terrenos

- Topografía de suelos

- Estructura impositiva y legal

- Disponibilidad de agua, energía y otros suministros

- Comunicaciones

- Posibilidad de desprenderse de desechos 
Para el proyecto se definieron como puntos básicos la accesibilidad, seguridad, mano de obra, clima y estructura legal, ya que es importante los permisos de la municipalidad de la ciudad de Puno para el circuito de motos acuáticas.

\subsubsection{Definición de factores locacionales.}

Son los factores que influyen en la decisión de la localización de un proyecto. En forma global se pueden resumir:

a. Facilidades de acceso: el presente proyecto contará con dos puntos: (1) en el centro de Puno en el Jirón Lima, oficina donde se realizarán las ventas del circuito se eligió esta ubicación porque es un lugar transitable por los turistas nacionales, extranjeros y locales de Puno. (2) el local donde se desarrollará el proyecto es en Capachica zona ubicada a 40 minutos de Puno con vías asfaltadas y de rápido acceso.

b. Energía eléctrica: se considera un factor importante porque el servicio brindado requiere de uso de equipos como computadoras, post, internet, etc.

c. Combustibles: se considera un factor porque los equipos (motos acuáticas) requieren abastecer de combustible, así como el vehículo de transporte donde se llevará a los turistas hacia la playa de Capachica.

d. Mercado: la oficina principal se encuentra en una zona comercial donde se ubican los bancos, tiendas comerciales, agencias de viajes, etc.

e. Disponibilidad y confiabilidad de los sistemas de apoyo: cercanía a las agencia de viajes, porque con ellos se tendrá una alianza estratégica para la captación de los turistas. 
f. Actitud de la comunidad: factor importante ya que para tener la aceptación de la comunidad de Capachica, se les brindará la tercerización de los servicios como alimentación y alojamiento en sus comunidades.

Los factores localizaciones buscan maximizar la rentabilidad, aumentando el ingreso y disminuyendo el costo, además busca evaluar los aspectos técnicos, legales, sociales que permitan tomar decisiones dinámicas y que se puedan establecer a largo plazo (Sapag, 2013).

\subsubsection{Consideraciones legales.}

En esta sección, se indicarán las acciones que se realizarán a la hora de crear una empresa junto a sus correspondientes trámites.

Se tendrá que considerar la siguientes leyes y reglamentos respecto al sector de turismo:

a. Ley General de Turismo (Ley 29408, 17.09.2009): Contiene el marco legal para el desarrollo y la regulación de la actividad turística, los principios básicos de la actividad turística y los objetivos de la política estatal, declarando al MINCETUR como el ente rector a nivel nacional competente en materia turística.

b. Reglamento de la Ley General de Turismo (Aprobado mediante Decreto Supremo $\mathrm{N}^{\circ}$ 003-2010- MINCETUR del 16.01.2010).

c. Modifican (R.M. No 155-2001-ITINCI/DM) relativas a las actividades que operan los Prestadores de Servicios Turísticos (Resolución Ministerial No 224-2005MINCETUR-DM, 27.07.05)

d. Se adecúan Normas Reglamentarias relativas al Comité Consultivo de Turismo, D.S No 002-2008-MINCETUR. 
Referente a las agencias de viajes la siguiente normatividad:

a. Reglamento de Agencias de Viajes y Turismo - Decreto Supremo Nº 004-2016MINCETUR- Reglamento que establece las disposiciones administrativas para la adecuada prestación del servicio de las agencias de viaje y turismo que opera en el país y para su supervisión; asimismo, establece el procedimiento para su inscripción en el Directorio Nacional de Prestadores de Servicios Turísticos Calificados y las funciones de los Órganos Competentes en dicha materia. Establece la clasificación como: Minorista, Mayorista y Operador de Turismo.

Referente a la reglamentación del turismo de aventura:

a. Reglamento de Seguridad para la Prestación del Servicio Turístico de Aventura Decreto Supremo Nº 005-2016-MINCETUR- Reglamento que establece las disposiciones administrativas para la seguridad en la prestación del servicio de turismo de aventura, a través de las agencias de viaje y turismo debidamente autorizadas por el órgano competente.

\subsubsection{1. identificación del marco legal.}

La actividad empresarial y los proyectos que de ella se derivan se encuentran incorporados a un determinado ordenamiento jurídico que regula el marco legal en el cual los agentes económicos se desenvolverán (Sapag, 2012).

Para el siguiente proyecto se deben tramitar las licencias municipales de funcionamiento la cual es otorgada por la municipalidad de Puno, así como las debidas conversaciones con la junta de asamblea de la población de Chifrón, la acreditación formal de un negocio ya sea con defensa civil y MINCETUR que regula a los establecimientos turísticos. 


\subsubsection{2. ordenamiento jurídico de la empresa.}

El ordenamiento jurídico de la organización social, expresado mayoritariamente en la constitución política de cada país, preceptúa normas que condicionan la estructura operacional de los proyectos, y que obligan al evaluador a buscar la optimización de la inversión dentro de restricciones legales que a veces atentan contra la sola maximización de la rentabilidad.

Para dar cumplimiento al ordenamiento jurídico se realizará los siguientes procedimientos:

a. Elaboración de la minuta: Es la declaración de voluntad de constituir una empresa. La minuta debe ser firmada por un abogado, no ocurriendo los mimos con el acta de constitución.

Pasos a seguir para la elaboración de la minuta:

1. Precisar la actividad económica y los estatutos.

2. Señalar el capital con el que se creará la empresa.

3. Acompañar con documentos personales.

Duración: en el caso de minuta, el plazo puede ser 5 días.

b. Constitución de la empresa SAC

1. Es la alternativa ideal para empresas familiares.

2. El número de accionistas no puede ser menor de dos y como máximo tendrá 20 accionistas.

3. Se impone el derecho de adquisición preferente por los socios, salvo que el estatuto disponga lo contrario. 
4. Se constituye por los fundadores al momento de otorgarse la escritura pública que contiene el pacto social y el estatuto, en cuyo caso suscriben íntegramente las acciones.

5. El Capital Social está representado por acciones nominativas y se conforma con los aportes (en bienes y/o en efectivo) de los socios, quienes no responden personalmente por las deudas sociales.

6. Es una persona jurídica de Responsabilidad Limitada.

7. No puede inscribir sus acciones en el Registro Público del Mercado de Valores.

8. Predomina el elemento personal, dentro de un esquema de sociedad de capitales.

c. Denominación: La denominación adoptada debe incluir la indicación: "Sociedad Anónima Cerrada" o estar acompañada de su abreviatura "S.A.C.".

d. Órganos de la empresa

1. junta general de accionistas

1. Es el órgano supremo de la sociedad. Está integrada por el total de socios que conforman la empresa.

2. Gerente es la persona en quien recae la representación legal y de gestión de la sociedad. El Gerente convoca a la junta de accionistas.

3. Sub-gerente reemplaza al Gerente en caso de ausencia.

4. Directorio el nombramiento de un Directorio por la Junta es facultativo (no es obligatorio).

e. Registro Indecopi

f. Inspecciones Técnicas de defensa civil 
La Inspección Técnica de Seguridad de Defensa Civil [ITSDC], es la revisión de condiciones de seguridad que tiene una edificación, recinto o instalación de un lugar donde se trabaje ya sea público o privado.

Las ITSDC se encuentran reguladas por el decreto Supremo Nº13 2000 modificaciones aprobadas mediante el Decreto Nulo 2003- PCM.

En el caso de las oficinas de hasta $100 \mathrm{~m} 2$ como es el proyecto solo se observarán las condiciones de seguridad. El costo del trámite es de 150 soles.

\subsection{Determinación de la Localización Óptima}

Para poder evaluar la localización optima tomaremos el método cualitativo por puntos el cual consiste en definir cuáles serán los factores determinantes de la localización, a los cuales se deberá asignar valores con peso, esto ira variando dependiendo de la importancia. El peso, suma igual a uno, será básico el criterio y la experiencia del calificador (Sapag, 2012).

En el proyecto se compara dos localizaciones para lo cual se asigna una calificación a cada factor de 0 a 10. La suma permitirá elegir cual será la localización óptima, en este caso por factores como accesibilidad a la zona y clima se eligió la playa de Chifrón. 
Tabla 69

Método Cualitativo por Puntos

\begin{tabular}{|c|c|c|c|c|c|c|}
\hline \multirow[b]{2}{*}{ Factores } & \multicolumn{3}{|c|}{ Playa Charcas } & \multicolumn{3}{|c|}{ Playa Chifron } \\
\hline & Peso & Escala & Calificación & Peso & Escala & Calificación \\
\hline Accesibilidad & 0.3 & 5 & 1.5 & 0.3 & 4 & 1.2 \\
\hline Seguridad & 0.14 & 3 & 0.42 & 0.14 & 4 & 0.56 \\
\hline Clima & 0.1 & 2 & 0.2 & 0.1 & 3 & 0.3 \\
\hline Grifos & 0.16 & 2 & 0.32 & 0.16 & 3 & 0.48 \\
\hline Permisos locales & 0.3 & 4 & 1.2 & 0.3 & 5 & 1.5 \\
\hline \multirow[t]{2}{*}{ TOTAL } & 1 & & 3.64 & 1 & & 4.04 \\
\hline & \multicolumn{5}{|c|}{ Escala } & \\
\hline \multirow[t]{2}{*}{ Leyenda } & 1 & 2 & 3 & 4 & 5 & \\
\hline & nulo & bajo & moderado & fuerte & muy fuerte & \\
\hline
\end{tabular}




\section{Capítulo VI: Aspectos Organizacionales}

\subsection{Caracterización de la Cultura Organizacional Deseada}

Todo negocio está dirigido por sus acciones y enfoques, esto es influenciado por la cultura que tiene cada empresa, es así que la cultura toma la importancia al poder pensar que es como el ADN de toda empresa. (Thompson, 2012, p. 383).

Dentro de las organizaciones no basta con realizar cambios en la estructura, en los procedimientos, funciones, manuales, etc. Se debe llegar a la raíz que es la cultura y de esta manera se asegura un cambio real en la organización.

\subsubsection{Visión.}

“La visión estratégica defines las aspiraciones de los directivos para la empresa mediante una panorámica del "lugar a donde vamos" y razones convincentes por las cuales es sensato para el negocio". (Thompson, 2012, p. 22).

Tabla 70

Concepto de Visión

\begin{tabular}{ll}
\hline & \multicolumn{1}{c}{ Visión } \\
\hline ¿A dónde vamos? & Proponer el mejor circuito de turismo \\
¿Por qué? & Se brindará aventura y diversión inolvidable a los turistas \\
¿Qué buscamos ser? & La mejor alternativa de turismo de aventura \\
\hline
\end{tabular}

"Ser el mejor circuito de turismo brindando aventura y diversión inolvidable a los turistas".

\subsubsection{Misión.}

"Una declaración de misión describe el propósito y el negocio actual de la empresa: quienes somos, qué hacemos y por qué estamos aquí”. (Thompson, 2012, p. 26). 


\section{Tabla 71}

Concepto de Misión

\begin{tabular}{ll}
\hline & \multicolumn{1}{c}{ Misión } \\
\hline ¿Quienes somos? & Una empresa de servicio turístico \\
¿Qué buscamos? & Satisfacer las necesidades de diversión de aventura los turistas \\
¿Qué hacemos? & Brindar circuitos de aventura \\
¿Por qué lo hacemos? & Para dar una experiencia inolvidable a los turitas \\
¿Por qué estamos aquí? & Para satisfacer las espectativas de aventura y diversión de los \\
\hline
\end{tabular}

"Somos una empresa de servicios turísticos que brinda circuitos de aventura a los turístas para satisfacer las espectativas de aventura y diversión haciendola una experiencia inolvidable".

\subsubsection{Valores.}

“Los valores de una compañía son las creencia, características y normas conductuales que la administración determinó que debe guiar el cumplimiento de visión y misión”. (Thompson, 2012, p. 27).

Los valores se muestran y son el soporte de la cultura, son la filosofía que se manifiesta en la forma de servir y pensar de la organización.

a. cultura de innovación.

Mantener un servicio de acuerdo a las tendencias modernas del mercado turístico de aventura, innovando nuevo equipos y nuevos servicios tecnológicos, para garantizar la competitividad de innovación en tecnológica y de servicio. 
b. $\quad$ cultura de calidad.

Tener el mejor servicio mediante una mejora continua, de esta forma lograr eficiencia y eficacia en cada momento, de esta forma tener excelencia en el servicio, beneficio y satisfacción en cada cliente.

c. trabajo en equipo.

Para garantizar la calidad del servicio y la atención a los clientes todos los miembros del equipo de colaboración deben tener claro en objetivo único que perseguimos y queremos alcanzar todos, esto mediante ayuda, colaboración, enseñanzas, etc.

d. compromiso en el servicio.

Los procedimientos a seguir en el servicio no solo estarán escritos en un manual, sino por el contrario tendrá un alto compromiso personal, dada en la comunicación, iniciativa y creatividad en la relación con el cliente.

\subsection{Formulación de Estrategias del Negocio}

En el sector de turismo se encuentra un segmentación respecto a los servicios brindados, en este sentido el presente proyecto está orientado a los servicios de turismo de aventura, es así que la estretegía definida para el proyecto es la de enfoque puesto que atenderemos a un mercado especifico que son los turistas locales y nacionales, de esta forma la diferenciación será en el trato al personal y la innovación en los equipos que se usarán para dar el servicio.

El proyecto estará orientado a brindar un servicio de circuito de aventura con las siguientes características:

a) Novedosos circuitos de aventuras, la realización de los circuitos será en rutas nunca antes exploradas. 
b) La novedad de las motos acuáticas en los que se realizará los servicios de aventura.

c) El uso de la tecnología como camaras Go pro y drones para grabar cada momento del circuito.

d) La seguridad que se brindará durante la realización del circuito.

Tabla 72

Formulación de la Estratégica del Negocio

\begin{tabular}{|c|c|c|}
\hline \multicolumn{2}{|c|}{ Formulación } & Estrategía del negocio \\
\hline & Equipos & $\begin{array}{l}\text { Adquisión de equipos (motos acuáticas) de ultima generación con } \\
\text { proveedores especializados en su rubro }\end{array}$ \\
\hline \multirow[t]{4}{*}{ Ingeniería } & Tecnología & $\begin{array}{l}\text { Adquisición de accesorios innovadores para los circuitos turísticos } \\
\text { (camaras go pro y drones) }\end{array}$ \\
\hline & Procesos & $\begin{array}{l}\text { Procesos definidos desde la atención al cliente hasta la culminación } \\
\text { del servicio }\end{array}$ \\
\hline & Ubicación & Oficina de atención amploia y acogedora en el centro de Puno \\
\hline & Personal & $\begin{array}{l}\text { Personal con experiencia en el rubro de acuerdo al perfil de la } \\
\text { empresa }\end{array}$ \\
\hline \multirow[t]{4}{*}{ Organización } & Beneficios de ley & $\begin{array}{l}\text { Personal en planillas con todos los beneficios de ley (vacaciones, } \\
\text { gratificaciones y compensación de tiempos de servicios) }\end{array}$ \\
\hline & Políticas & Políticas que hacen sinergia entre los colaboradores y laempresa \\
\hline & Alianzas estratégicas & $\begin{array}{l}\text { Viculos con las agencias de viajes, hoteles e instituciones publicas y } \\
\text { privadas }\end{array}$ \\
\hline & Circuito & $\begin{array}{l}\text { Rutas nuevas de aventura con un circuito de caminata o bicicletas y } \\
\text { motos acuáticas }\end{array}$ \\
\hline \multirow{3}{*}{ Marketing } & Equipos Innovadores & $\begin{array}{l}\text { Circuito en las motos acuticas y el uso de camaras go pro y dornes } \\
\text { para grabar cada momento de la aventura }\end{array}$ \\
\hline & Publicidad & $\begin{array}{l}\text { Publicidad: en las avenidad más concurridas de Puno, en los } \\
\text { medios de comunicación más escuchados y en eventos realizados } \\
\text { respecto al turismos }\end{array}$ \\
\hline & Financiamiento & $\begin{array}{l}\text { Financiamiento con el banco que ofresca la más atractiva tasa de } \\
\text { interes con facilidades de medios de pago }\end{array}$ \\
\hline \multirow[t]{2}{*}{ Finanzas } & Ingresos & $\begin{array}{l}\text { Con la estratégia de marketing nos garantiza tener las ventas } \\
\text { proyectadas, pese a ubicarnos en esenariospesimistas }\end{array}$ \\
\hline & Gastos & $\begin{array}{l}\text { Los gastos serán controlados diariamente, todos estos } \\
\text { supervisados por el administrador, llevandose un control } \\
\text { documentario e informático }\end{array}$ \\
\hline
\end{tabular}




\subsection{Determinación de las Ventajas Competitivas Críticas}

El presente proyecto se aplica la matriz VRIO, herramienta desarrollada por Jay B. Barney, esta matriz indica 4 condiciones que deben cumplirse para que una empresa pueda establecer sus ventajas competitivas que sean sostenibles en el tiempo.

Definición.

a. Valioso.

¿Me permite aprovechar oportunidades o enfrentar amenazas?

b. Raro.

¿Cuántos competidores cuentan con el mismo recurso o capacidad?

c. Imitable.

¿Es costoso adquirir o desarrollar el mismo recurso para tus competidores que no lo tienen?

d. Organización.

¿Tienes tus políticas y procesos organizados para apoyar la explotación de este recurso valioso, raro y difícil de imitar? 
Tabla 73

Sistema de Competitividad de la Matriz VRIO

\begin{tabular}{|c|c|c|c|c|c|}
\hline $\begin{array}{l}\text { RECURSOS / CAPACIDAD } \\
\text { RECURSOS FISICOS } \\
\end{array}$ & Valioso & Raro & Inimitable & Organización & IMPLICANCIA COMPETITIVA \\
\hline Oficina instalado en el centro de la ciudad & SI & NO & NO & SI & VENTAJA COMPETITIVA TEMPORAL \\
\hline Rutas nueva e innovadoras de turismo & SI & SI & NO & SI & POSIBLE VENTAJA COMPETITIVA SOSTENIB \\
\hline \multicolumn{6}{|l|}{ RECURSOS TECNOLOGICOS } \\
\hline Motos acuáticas & SI & SI & SI & SI & VENTAJA COMPETITIVA SOSTENIBLE \\
\hline Bicletas con motor & SI & SI & NO & SI & POSIBLE VENTAJA COMPETITIVA SOSTENIB \\
\hline Camaras gopro & SI & SI & SI & SI & VENTAJA COMPETITIVA SOSTENIBLE \\
\hline Diseño de sitio Web & SI & NO & NO & SI & VENTAJA COMPETITIVA TEMPORAL \\
\hline drones & SI & SI & NO & SI & POSIBLE VENTAJA COMPETITIVA SOSTENIB \\
\hline \multicolumn{6}{|l|}{ RECURSOS HUMANOS } \\
\hline Personal con experiencia & SI & NO & NO & SI & VENTAJA COMPETITIVA TEMPORAL \\
\hline Personal capacitado y comprometido & SI & SI & SI & SI & VENTAJA COMPETITIVA SOSTENIBLE \\
\hline Calidad de servicio - trato amable y cordial & SI & SI & SI & SI & VENTAJA COMPETITIVA SOSTENIBLE \\
\hline \multicolumn{6}{|l|}{ RECURSOS ORGANIZACIONALES } \\
\hline Empresa formalizada & SI & SI & NO & SI & POSIBLE VENTAJA COMPETITIVA SOSTENIB \\
\hline Estructura organizativa & SI & NO & SI & SI & POSIBLE VENTAJA COMPETITIVA SOSTENIB \\
\hline Promociones y Ofertas con instituciones & SI & SI & SI & SI & VENTAJA COMPETITIVA SOSTENIBLE \\
\hline Alianza estrategica con agencias de turismo & SI & NO & NO & SI & VENTAJA COMPETITIVA TEMPORAL \\
\hline
\end{tabular}

Análisis de la matriz VRIO:

a. Valioso

La nueva alternativa de circuitos de turismo de aventura con rutas novedosas y no tradicionales por el turismo ya existente.

Los servicios con motos acuáticas, equipos y tecnología de punta como las cámaras Go pro y drone, así como la atención del personal y la estrategia de publicidad de la empresa

b. Raro.

Las rutas por donde se desarrollará el circuito y las actividades a realizar en cada etapa del circuito. 
Las motos acuáticas, la tecnología a usar en el recorrido de todo el circuito con la grabación mediante cámaras Go pro y drone durante cada actividad del circuito, así como el trato amable y promociones a los turistas.

c. Inimitable.

Por la inversión a realizar de los equipos del circuito como las motos acuáticas, las cámaras Go pro, y las promociones con instituciones y a turistas.

d. Organización.

La capacidad profesional de los colaboradores, así como la formalización de la empresa permiten que tener una estructura, políticas y principios que cumplirá cada colaborador de la empresa, así también el asesoramiento profesional como son la parte legal y contable.

\subsection{Diseño de la Estructura Organizacional Deseada}

Toda empresa se organiza de acuerdo a las actividades que realiza, a esto se llamaría departamentalización de funciones, puesto que todos quieren algo útil que la empresa ofrece. En ese sentido lo más lógico es agrupar en departamentos dichas actividades. (Koontz, 2013, p.164)

La empresa cuenta con una estructura organizacional según funciones que van a llevar a cabo cada puesto, la correcta estructura nos permitirá mantener un orden y control en el servicio que se va a brindar, esto con el fin de alcanzar los objetivos propuestos por la empresa. 


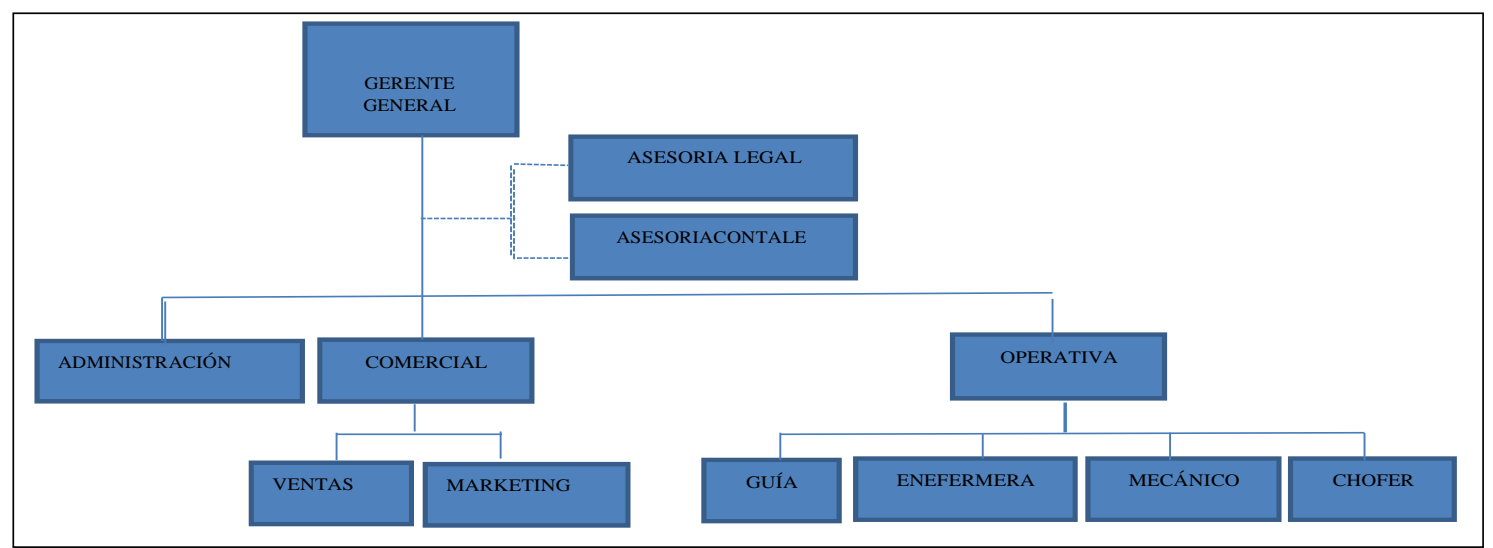

Figura 43. Organigrama de la empresa

\subsection{Diseño de los Perfiles de Puestos Clave}

La descripción del análisis de puesto es el producto más importante, la descripción textual del puesto explica todo lo referente a su labor, es decir lo que en realidad hace el trabajador respecto a cómo realiza sus funciones, cuales son las condiciones donde ejecuta su labor. Esta información permitirá identificar y redactar las especificaciones del puesto, listando los conocimientos, habilidades y capacidades que requiere el trabajo para ser desarrollada satisfactoriamente. (Dessler, 2015, p. 67).

Se desarrollará los puestos que conforman la estructura organizacional según sus responsabilidades y habilidades que cumplirán dentro de la empresa:
1. Administrador
2. Vendedor
3. Marketing
4. Guía
5. Enfermera
6. Mantenimiento

7. Chofer 


\section{Tabla 74}

\section{Perfil de Puesto Administrador}

\begin{tabular}{l}
\hline \multicolumn{1}{c}{ Descripción } \\
\hline Nombre del puesto \\
Nivel de salario recomendado \\
Categoría del puesto \\
División \\
Departamente \\
A quién supervisa \\
A quién reporta \\
Lugar
\end{tabular}

Administrador de agencia de turismo
s/ $1,000.00$ a s/ $1,500.00$
Empleado
Educación superior
Administración
Área comercial y área operativa
Gerente general
Puno

Este puesto es responsable de la planeación, organización, control y supervisión de las actividades que se desarrollan dentro de la agencia y los servicios brindados, así también será

Resumen responsable de dar seguimiento a los procedimientos establecidos, asegurándose que se cumplan los objetivos de la agencia y del servicio.

Responsabilidades económicas

Este puesto es responsable de la revisión y análisis de los resultados financieros y operacionales mensuales, comparándolos contra el presupuesto actual y con los del año anterior.

Responsabilidades de supervisión Directas al área comercial y área operativa

$\begin{array}{ll}\text { Conocimiento yexperiencias } & \begin{array}{l}\text { 1. Experiencia relacionada con el trabajo } \\ \text { necesarias }\end{array} \\ \text { Estudios formales o equivalentes } & \begin{array}{l}\text { dedicados a servicio de circuitos turísticos } \\ \text { 1. Títo Profesional en Administración }\end{array} \\ & \begin{array}{l}\text { 2. Estudios de inglés avanzado } \\ \text { 1. Negociación }\end{array} \\ \text { Habilidades } & \begin{array}{l}\text { 2. Comunicación } \\ \text { 3. Trabajo en Equipo }\end{array} \\ \text { Otro } & \text { 4. Liderazgo } \\ \text { Viajes para la supervisión del servicio }\end{array}$

1. Es responsable de la administración diaria de la agencia

2. Asegurar la efectiva comunicación del personal dela agencia

3. Asegurar el cumplimiento de la calidad del servicio

4. Atender las quejas de los clientes y dar solución hasta la completa satisfacción

5. Supervisar el cumplimiento de los estándares de la agencia de turismo

6. Es responsable de mantener las relaciones internas y externas adecuadas, en beneficio de la agencia

Principales responsabilidades

7. Realizar informes semanales sobre los servicios brindados, teniendo un control estadístico de los indicadores de los circuitos brindados

8. Elaborar planes estratégicos, sugerencia y/o recomendaciones, presupuestos, planes de trabajo

9. Coordinar con las asesorías externas las respectivas, presentaciones y cumplimiento de pagos de impuestos, tasas y otros

10. Gestionar con las áreas correspondientes el cumplimiento de las metas y estrategia establecidas para el cumplimiento de los objetivos de la empresa

Nota. Adaptado de "Administración de Recursos Humanos" por G. Dessler, 2015, Descripción de Puesto, p. 67.Editorial Pearson Educación México. 


\section{Tabla 75}

\section{Perfil de Puesto Vendedor}

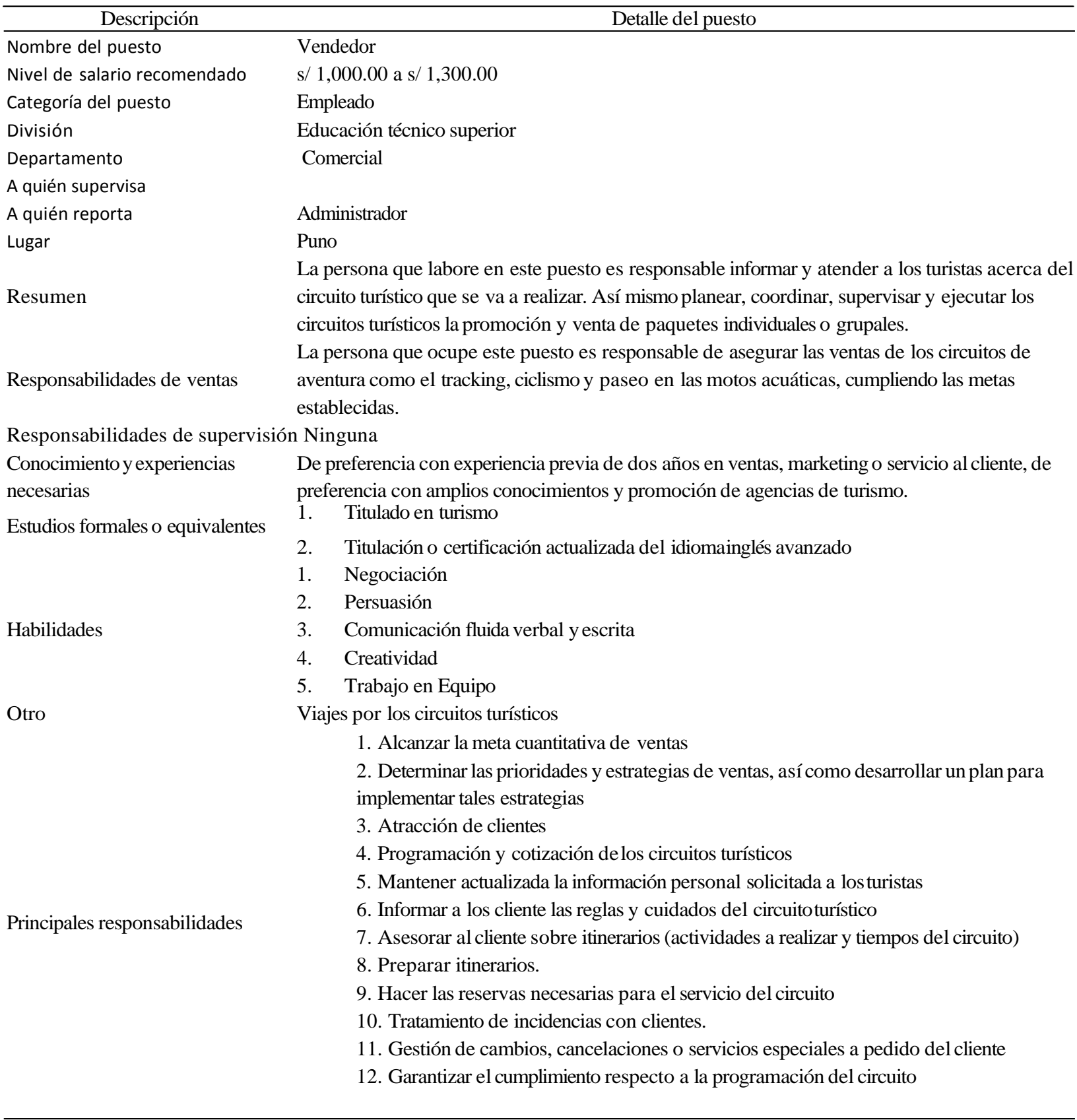

Nota. Adaptado de “Administración de Recursos Humanos” por G. Dessler, 2015, Descripción de Puesto, p. 67.Editorial Pearson Educación México. 
Tabla 76

\section{Perfil de Guía de Turismo}

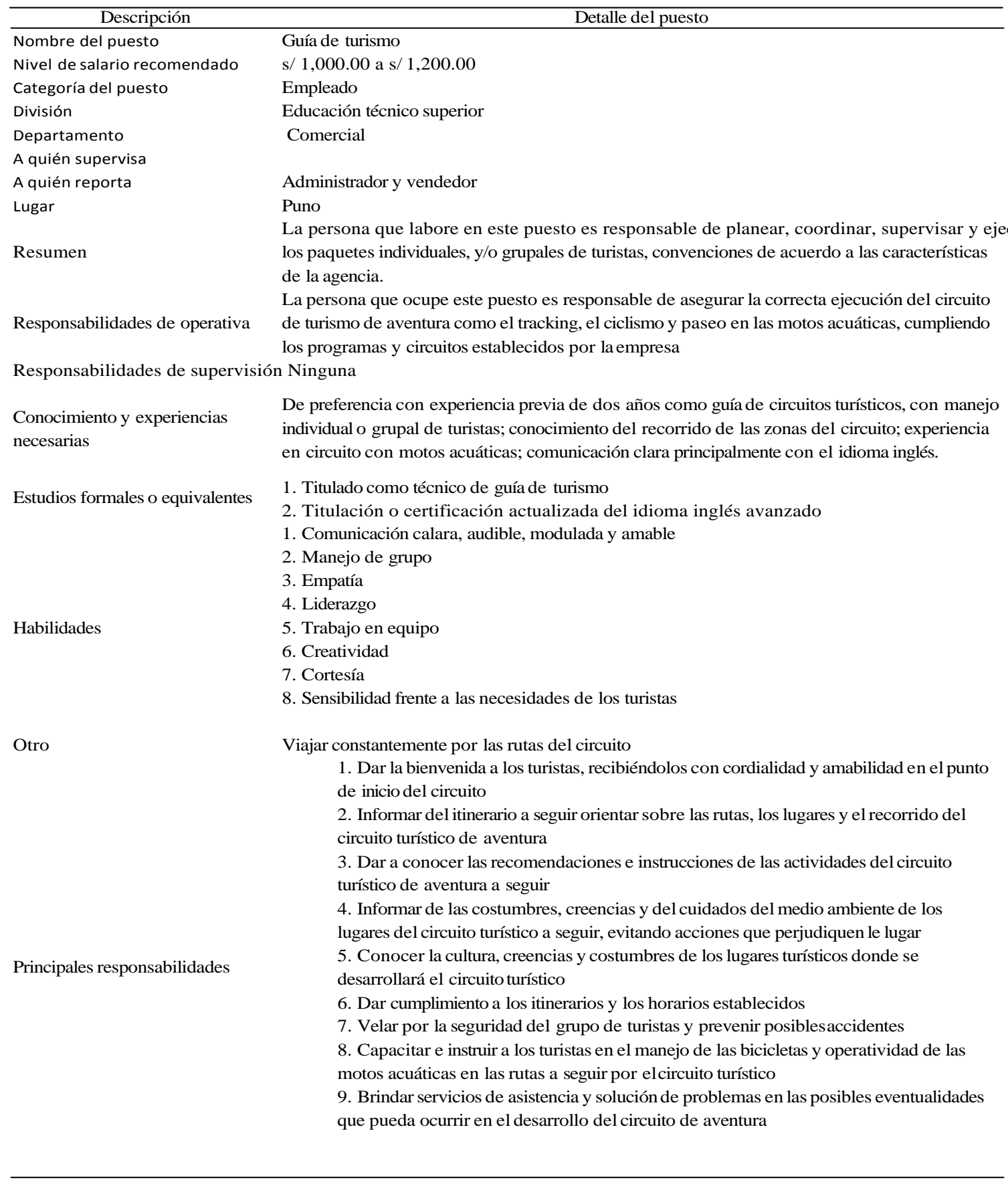

Nota. Adaptado de "Administración de Recursos Humanos” por G. Dessler, 2015, Descripción de Puesto, p. 67.Editorial Pearson Educación México. 
Tabla 77

Perfil de Enfermera Técnica

\begin{tabular}{ll}
\hline \multicolumn{1}{c}{ Descripción } & \multicolumn{1}{c}{ Detalle del puesto } \\
\hline Nombre del puesto & Enfermera técnica \\
Nivel de salario recomendado & s/ 850.00 a s/ 900.00 \\
Categoría del puesto & Empleado \\
División & Educación técnico superior \\
Departamento & Operativo \\
A quién supervisa & Administrador y guía \\
A quién reporta & Puno \\
Lugar & La persona que labore en este puesto es responsable brindar atenciones a los turistas en caso \\
Resumen & que se presente problemas de salud en la realización del circuito turístico. \\
& La persona que ocupe este puesto es responsable de la salud e integridad de los turistas dentro \\
Responsabilidades de salubridad & del circuito brindado.
\end{tabular}

Responsabilidades de supervisión Ninguna

Conocimiento y experiencias necesarias

Estudios formales o equivalentes

Habilidades

Otro

Principales responsabilidades
De preferencia con experiencia previa de dos años como enfermera técnica en atención, en hospitales o centros de salud.

1. Titulado como técnico en enfermería

2. Titulación o certificación actualizada del idioma inglés avanzado

3. Certificado de charlas de seguridad y primeros auxilios

1. Trato amable

2. Comunicación

3. Empatía

4. Trabajo en equipo

5. Cortesía

6. Sensibilidad frente a las necesidades de los turistas

Viajar constantemente por las rutas del circuito

1. Brindar breves charlas de seguridad respecto al uso de los equipos que se usaran en el circuito turistico

2. Usar responsablemente los equipos y medicamentos en caso de bridar servicios de primeros auxilio a los turistas

3. Auxiliar a los turistas en forma rápida y responsable en caso de sufrir algún accidente (caídas, heridas, cortes) dentro del circuito turístico

4. Asistir a los turistas en caso de emergencia identificando las molestias por males de altura, mareos, descompensaciones u otros.

5. Llevar a un centro de salud si el turista lorequiere

6. Tomar registro de datos de los turistas, accidentes y/o atenciones brindadas dentro del circuito turístico

7. Reportar diariamente las eventualidades y incidencias y/o accidentes que ocurran en dentro del circuito turistico de aventura

Nota. Adaptado de "Administración de Recursos Humanos" por G. Dessler, 2015, Descripción de Puesto, p. 67.Editorial Pearson Educación México. 


\section{Tabla 78}

\section{Perfil de Técnico de Mantenimiento}

\begin{tabular}{|c|c|}
\hline Descripción & Detalle del puesto \\
\hline Nombre del puesto & Técnico de mantenimiento \\
\hline Nivel de salario recomendado & $\mathrm{s} / 900.00 \mathrm{a} \mathrm{s} / 1,000.00$ \\
\hline Categoría del puesto & Empleado \\
\hline División & Educación técnico superior \\
\hline Departamento & Operativo \\
\hline \multicolumn{2}{|l|}{ A quién supervisa } \\
\hline A quién reporta & Administrador \\
\hline Lugar & Puno \\
\hline Resumen & $\begin{array}{l}\text { La persona que labore en este puesto es responsable del mantenimiento preventivo y correctivo } \\
\text { de las motos acuáticas con frecuencia diaria, con la finalidad de que los equipos se encuentren } \\
\text { operativas y en condiciones de uso. }\end{array}$ \\
\hline $\begin{array}{l}\text { Responsabilidades de } \\
\text { mantenimiento }\end{array}$ & $\begin{array}{l}\text { Este puesto es responsable del mantenimiento diario a las motos acuáticas que se harán usadas } \\
\text { en el circuito de aventura }\end{array}$ \\
\hline \multicolumn{2}{|c|}{ Responsabilidades de supervisión Ninguna } \\
\hline $\begin{array}{l}\text { Conocimiento y experiencias } \\
\text { necesarias }\end{array}$ & $\begin{array}{l}\text { De preferencia con experiencia previa de dos años en servicios de mantenimiento preventivo y } \\
\text { correctivo de unidades automotrices y eléctricas }\end{array}$ \\
\hline Estudios formales o equivalentes & $\begin{array}{l}\text { 1. Titulado como técnico en mantenimiento } \\
\text { 1. Responsabilidad } \\
\text { 2. Trabajo en equipo }\end{array}$ \\
\hline Habilidades & $\begin{array}{l}\text { 3. Disciplina } \\
\text { 4. Iniciativa }\end{array}$ \\
\hline Otro & Viajar constantemente por las rutas del circuito \\
\hline Principales responsabilidades & $\begin{array}{l}\text { 1. Realizar el mantenimiento preventivo y correctivo a las motos acuáticas } \\
\text { 2. Revisar minuciosa y diariamente las motos acuáticas después del circuito recorrido } \\
\text { 3. Detectar el tipo de reparación que serequiere } \\
\text { 4. Identificar las fallas mecánicos - eléctricos de las motos acuáticas } \\
\text { 5. Remitir un informe diario sobre la situación yestado de las motos acuáticas } \\
\text { 6. Remitir solicitudes de compra del caso de algún accesorio y/o repuesto de las motos } \\
\text { acuáticas }\end{array}$ \\
\hline
\end{tabular}

Nota. Adaptado de "Administración de Recursos Humanos” por G. Dessler, 2015, Descripción de Puesto, p. 67.Editorial Pearson Educación México. 


\section{Tabla 79}

\section{Perfil de Puesto Marketing}

\begin{tabular}{ll}
\hline \multicolumn{1}{c}{ Descripción } & \multicolumn{1}{c}{ Detalle del puesto } \\
\hline $\begin{array}{l}\text { Nombre del puesto } \\
\text { Nivel de salario recomendado }\end{array}$ & Asistente de marketing \\
Categoría del puesto & Empleado a s/ 1,000.00 \\
División & Educación técnico superior \\
Departamento & Comercial \\
A quién supervisa & Administrador \\
A quién reporta & Puno \\
Lugar & La persona que labore en este puesto es responsable elaborar un plan de marketing a mediano y \\
& largo plazo, dicho plan debe incluir las estrategias para fortalecer nuestros servicios en todas las \\
Resumen & área de la empresa. \\
& La persona que ocupe este puesto es responsable de promocionar los servicios que ofrece la \\
empresa ya sea por diversos medios y/o plataformas de internet, cumpliendo las metas
\end{tabular}

Responsabilidades de supervisión Ninguna

Conocimiento y experiencias necesarias

Estudios formales o equivalentes

Habilidades

Otro

Principales responsabilidades
De preferencia con experiencia previa de dos años en elaboración de estrategia de marketing preferentemente en empresas de servicio turísticos.

1. Técnico Titulado en Marketing

2. Titulación o certificación actualizada del idioma inglésavanzado

1. Comunicación: Comunicación fluida verbal y escrita

2. Creatividad

3. Innovación

4. Dinamismo

5. Trabajo en Equipo

Viajar constantemente por las rutas del circuito

1. Analizar el mercado definiendo y ubicando a losclientes potenciales

2. Implementar estrategia de marketing por internet

3. Realizar promociones de ventas de nuestros circuito turístico de aventura

4. Mantener una base de datos actualizada de nuestros clientes locales y nacionales

5. Remitir mail de promociones, novedades de nuestro circuito turístico

6. Administrar las plataformas de internet usadas por la empresa comoFacebook

7. Actualizar la información de las fotos, rutas, circuitos y comentarios de nuestros clientes

8. Gestionar promociones de nuestro circuito turístico con instituciones, colegio, universidades, empresas y otras instituciones locales

\section{Nota. Adaptado de "Administración de Recursos Humanos" por G. Dessler, 2015, Descripción de}

\section{Puesto, p. 67.Editorial Pearson Educación México.}




\section{Tabla 80}

\section{Perfil de Puesto Conductor}

\begin{tabular}{ll}
\hline \multicolumn{1}{c}{ Descripción } & \multicolumn{1}{c}{ Detalle del puesto } \\
\hline Nombre del puesto & Conductor \\
Nivel de salario recomendado & s/ 900.00 a s/ 1,000.00 \\
$\begin{array}{l}\text { Categoría del puesto } \\
\text { División }\end{array}$ & Empleado \\
Departamento & Educación técnico superior \\
A quién supervisa & Operativa \\
A quién reporta & Administrador \\
Lugar & Puno \\
& La persona que labore en este puesto es responsable de transportar a los turistas desde las \\
Resumen & oficinas principales en el centro de Puno hacía el lugar del circuito turístico en los horarios \\
& establecidos por la empresa. \\
La persona que ocupe este puesto es responsable del transporte de los turistas de acuerdo a las \\
Responsabilidades de transporte
\end{tabular}

Responsabilidades de supervisión Ninguna

Conocimiento y experiencias necesarias

Estudios formales o equivalentes

Habilidades

Otro

Principales responsabilidades
De preferencia con experiencia previa de dos años en transporte de turistas, conocimiento de las rutas donde se desarrollará el circuito de aventura.

1. Con licencia mínima de A II

2. Certificados con conocimientos de mecánica

1. Responsabilidad

2. Puntualidad

3. Trabajo en Equipo

Disponibilidad para trabajar en eventuales jornadas extraordinarias.

1. Transportar a los turistas en horarios y rutas establecidas por la empresa

2. Cumplir con la leyes de tránsito, siéndose responsable por las sanciones que se presente por el incumpliendo de dichas leyes

3. Verificar el correcto funcionamiento de las unidades de transporte asegurando su buen funcionamiento, de ocurrir algunos desperfectos informar a quien corresponda 4. Reportar diariamente a la administración las hojas de rutas desarrolladas según el formato establecido por la empresa

5. Mantener elcuidado y la limpieza de la unidad entregada a su cargo

6. Apoyar en el recorrido de la ruta del circuito turístico con el manejo de drones

Nota. Adaptado de “Administración de Recursos Humanos" por G. Dessler, 2015, Descripción de Puesto, p. 67.Editorial Pearson Educación México. 


\subsubsection{Asesoría legal.}

Será encargada a un estudio legal teniendo como principales funciones:

a) Representar a la empresa ante instituciones como la SUNAT, SUNAFIL, Registros Públicos, Municipalidades, etc.

b) Elaboración de documentos legales para contestaciones de notificaciones de las diversas instituciones

c) Revisión de contratos que la empresa pueda celebrar ante otras instituciones

d) Brindar asesoramiento legal frente a las situaciones que se puedan presentar

\subsubsection{Asesoría contable.}

La contabilidad será encargada a un estudio contable teniendo como principales funciones:

a) Realizar la presentación, declaración y pago de impuestos mensuales ante la SUNAT

b) Presentación de los balances anuales

c) Elaboración de planillas de los empleados

d) Realizar la presentación, declaración y pago de impuestos de materia laboral en la PLAME

e) Realizar la elaboración de liquidaciones de beneficios sociales de presentarse el caso

f) Control de los documentos correspondientes a la declaración de impuestos (facturas, boletas de ventas, notas de créditos, etc.).

g) Brindar asesoramiento contable frente a las situaciones que se puedan presentar 


\subsection{Remuneraciones, Compensaciones e Incentivos}

En el 2015, Dessler considera la remuneración una forma de retribución destinada al personal, por el empleo que realizan. Así también se distingue dos componentes como son el pago directo que son propiamente salarios, comisiones, etc. y los pagos indirectos refiriéndose a los pago de a cargo del empleador. Hoy por hoy la mayoría de las empresas aún tiene establecido el pago de remuneraciones en función al tiempo (por horas y días) teniendo como segunda opción el pago de remuneración en base al desempeño relacionada con su producción.

La empresa tendrá un sistema de remuneración, compensaciones e incentivos de acuerdo al área y funciones que cada colaborador, según su perfil de puesto, realice; dicho sistema de compensaciones estará bajo el marco legal del Decreto Legislativo $\mathrm{N}^{\circ} 728$, Ley de Productividad y Competitividad Laboral la misma que regula la actividad laboral de las empresas privadas.

Según un informe del diario Correo, el Ministerio de Trabajo y Promoción del Empleo [MTPE], elaboró un listado con los ingresos máximos y mínimos que obtienen los profesionales y técnicos del país. (diariocorreo.pe, 2016)

Realizando el respectivo análisis del mercado laboral, tal como señala el perfil de puesto de los empleados y según los estudios superiores (universitario y/o técnicos) requeridos, es así que los ingresos brutos detallados para el presente proyecto se ubican dentro del rango y por mínima diferencia del ingreso promedio, tal como se muestra en la tabla $\mathrm{N}^{\mathrm{o}} 52$ (carrera universitaria) y tabla $\mathrm{N}^{\circ} 53$ (carrera técnica). 


\title{
Tablas 81
}

\section{Mínimos y Máximos de los Ingresos Brutos Promedio de los Jóvenes Egresados Entre}

\author{
el 2010 y 2011, Según Familia de Carrera universitaria
}

\begin{tabular}{ccc}
\hline Familiade carrera universitaria(1) & IngresoPromedio(2) & Rango (3) \\
\hline Administración de Servicios Turísticos,Hoteleríay Gastronomía & s/1,663 & De s/900 a s/2,800 \\
\hline
\end{tabular}

\section{Nota:}

Se considera jóvenes a los trabajadores de 18 a29 años

Se excluyen a los jóvenes con remuneraciones mayores al percentil 98 según familia de carreras

Se considera solo a los trabajadores con jornada laboral complenta

Se considera solo a las familias de carreras con 25 caso a más

1. Lasdenominacionesycódigocorrespondenalasfamilias decarreras delatabla№34delAnexo №34delAnexo № 2 del T-Registro de la Planilla Electrónica

2. Considera la remuneración bruta promedio antes de los descuentos de ley, ordenada de manera descendente

3. Los mínimos y máximos corresponden a los percentiles 10 y 90 de los ingresos brutos redondeados a las centenas

Fuente: MTPE - OGETIC - OE - Planilla Electrónica PLAME Abril 2014-Marzo 2015 / T-Registro al 01 de Junio de 2015. Información al 64\% de los trabajadores del sector privado

Elavoración: Ministerio de Trabajo y Promoción del Empleo

\section{Tablas 82}

Mínimos y Máximos de los Ingresos Brutos Promedio de los Jóvenes Egresados Entre el 2010 y 2011, Según Familia de Carrera Técnica

\begin{tabular}{lcc}
\hline \multicolumn{1}{c}{ Familiadecarrerauniversitaria(1) } & IngresoPromedio(2) & Rango (3) \\
\hline Técnico en Administraciónde Servicios Turísticos, Hotelería y Gatronomía & $\mathrm{s} / 1,450$ & De s/800 a s/2,400 \\
Técnicoen Turísmo & $\mathrm{s} / 1,204$ & Des $/ 800 \mathrm{a}$ s $/ 1,700$ \\
TécnicoenEnfermería & $\mathrm{s} / 1,014$ & Des $/ 800 \mathrm{a} / 1,300$ \\
TécnicoenMarketing & $\mathrm{s} / 1,746$ & Des $/ 900 \mathrm{a} / 3,000$ \\
TécnicoenMécanica & $\mathrm{s} / 1,680$ & Des $/ 900 \mathrm{as} / 2,700$ \\
\hline
\end{tabular}

Nota:

Se considera jóvenes a los trabajadores de 18 a29 años

Se excluyen a los jóvenes con remuneraciones mayores al percentil 98 según familia de carreras

Se considera solo a los trabajadores con jornada laboral complenta

Se considera solo a las familias de carreras con 25 caso a más

1. Las denominaciones y código corresponden a las familias de carreras de la tabla № 34 del Anexo № 34 del Anexo № 2 del T-Registro de la Planilla Electrónica

2. Considera la remuneración bruta promedio antes de los descuentos de ley, ordenada de manera descendente

3. Los mínimos y máximos corresponden a los percentiles 10 y 90 de los ingresos brutos redondeados a las centenas

Fuente: MTPE - OGETIC - OE - Planilla Electrónica PLAME Abril 2014-Marzo 2015 / T-Registro al 01 de Junio de 2015. Información al 64\% de los trabajadores del sector privado

Elavoración: Ministerio de Trabajo y Promoción del Empleo 
En base a este informe se han estructurado las remuneraciones del personal de la empresa, más no se considera el rango de edad en los perfiles de puestos, entendiéndose a la remuneración como una forma de pago por la contraprestación del servicio o labor dada.

\section{a. Remuneración.}

\section{Remuneración Fija:}

Son los conceptos remunerativos pactados entre el empleado y empleador, tales como ingreso bruto, asignación familiar.

\section{b. Aportes.}

El empleador es el responsable de declarar y pagar los aportes mensuales, en base a los ingresos obtenidos por los colaboradores, para nuestro caso se establece dos de los aportes exigidos por ley:

\section{I. essalud.}

La empresa es responsables de pagar los aportes de ESSALUD que corresponde al 9\% del total de sus ingresos por cada uno de los colaboradores, cabe mencionar que dichos aportes son obligación del empleador por cumplir.

\section{II. seguro complementario de trabajo de riesgo (sctr).}

La empresa en responsable del aporte de SCTR, cuyo seguro cobertura contra accidentes de trabajo y enfermedades profesionales a nuestros colaboradores. Dicho seguro ampara en totalidad a los trabajadores que desarrollen actividades de riesgo ya sean temporales o permanentes.

\section{c. Beneficios sociales.}

I. compensación por tiempos de servicios.

Según Decreto Supremo 001-97-TR se establece para el depósito: 
- Laborar más de cuatro horas diarias

- El pago equivale a dos depósitos semestrales que comprende los periodos de Noviembre a Abril y Mayo a Octubre.

- Los depósitos semestrales se realizan como fecha última el 15 de Mayo y 15 de Noviembre

- La base de cálculo corresponde a la remuneración percibida al 30 de Noviembre o 30 de Abril más 1/6 de la última gratificación percibida.

\section{II. vacaciones.}

Según el Decreto Legislativo $N^{\circ} 713$, tienen derecho al goce vacacional:

- Laborar más de cuatro horas diarias

- Tienen record vacacional quienes hayan laborado un año efectivo de la fecha de ingreso

- El descanso físico comprenderá de 30 días calendario

- La oportunidad del descanso será previo acuerdo entre el colaborador y el empleador, a falta de acuerdo el empleador señalará la fecha de descanso.

- El descanso mínimo a gozar por periodo vacacional es de siete días

\section{III. gratificación.}

Según Ley $\mathrm{N}^{\circ} 27735$ para las gratificaciones legales se establece:

- Corresponde dos gratificaciones por Fiestas Patrias y Navidad

- Las gratificaciones equivalen a una remuneración semestral, correspondientes a los periodos de Enero a Junio y de Julio a Diciembre

- La oportunidad de pago será a más tardar el 15 de Julio y 15 de Diciembre 
De igual forma presentamos la estructura de costos de las remuneraciones y beneficios sociales:

Tabla 83

Cuadro de Remuneraciones y Beneficios de los Trabajadores

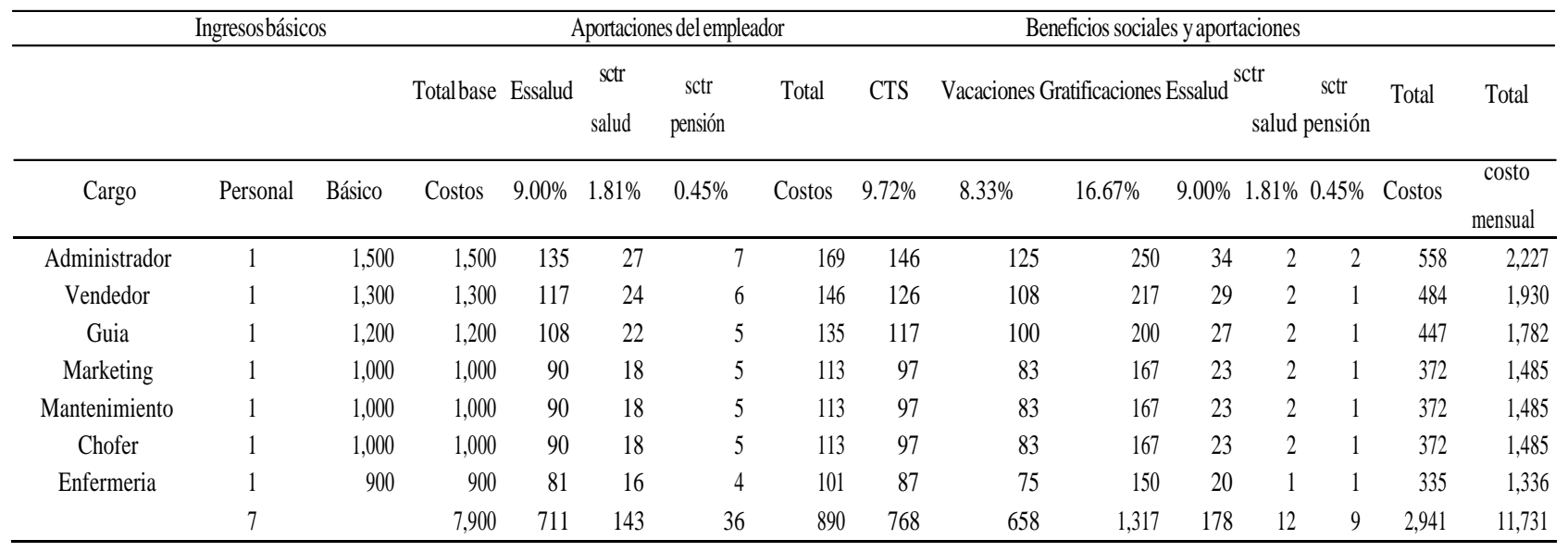

\subsection{Política de Recursos Humanos}

En el 2013, Koontz consideró a que las políticas se deben poner en práctica para llegar a la esencia de lo que queremos lograr en cada procedimiento de la empresa, sirven como guía al momento de tomar una decisión final. La discrecionalidad es la esencia de la política, de esta forma se entiende a la política como declaraciones que guían las reflexiones para la toma de decisiones.

Las políticas y procedimientos dan la guía cotidiana que los empleados necesitan para realizar su trabajo de una forma consistente con los planes y las metas de la compañía. Las políticas establecen directrices generales sobre la forma en que los empleados deberían proceder. (Dessler, 2015, p. 28)

Las políticas de recursos humanos de la empresa se orientan a brindar la calidad de servicio del circuito turístico, siendo las políticas: 


\section{a. Crecimiento profesional.}

Todos los puesto de la empresa están relacionados íntegramente con los clientes que son los turistas, en ese sentido el crecimiento profesional en parte integra de la empresa; es por esto que estamos convencidos que un empleado capacitado tiene amplia motivación para brindar un mejor servicio.

\section{b. Remuneraciones.}

Las remuneraciones de la empresa son equitativas y motivadoras, cada nivel de remuneración es justa y apropiada de acuerdo al área y funciones que realicen cada uno de los puestos. Así mismo la puntualidad del cumplimiento de nuestras obligaciones con los empleados es un factor importante para su motivación.

\section{c. Seguridad y salud en el trabajo.}

Tenemos un compromiso de seguridad y salud para con los empleados, cualquier lesión o enfermedad ocurrido en plena acción de sus funciones se asumen como responsabilidad, por esto el esfuerzo en cumplir rigurosamente todas las normas de seguridad y salud en el trabajo. La prevención y disminución de riesgos es importante en cada uno de los servicios.

\section{d. Equilibrio de vida privada y vida laboral.}

Los lazos entre la empresa y la comunidad tiene que estar fuertemente relacionadas, es por eso que la empresa incentiva a los colaboradores a tener presencia en la comunidad ya se ha con participación profesional o actividades culturales. Buscamos tener un equilibrio entre la vida privada (creencias, costumbres, religión) de los empleados con su vida laboral que se desarrolla en la empresa que es parte de la comunidad. 


\section{e. Organización de recursos humanos.}

Los empleados están presentes en cada proceso y momento del flujo de los servicios, en ese sentido, las herramientas y sistemas están condicionados para asegurar un trato justo de los empleados. Somos conscientes la adecuada gestión del recurso humano garantiza el bienestar propiamente de los empleados y por ende de la organización. 


\section{Capítulo VII: Plan de Marketing}

\subsection{Estrategias de Marketing}

Dentro de las estrategias genéricas de Porter, la empresa optará por un estrategia de enfoque, la cual consiste en atender un nicho de mercado determinado para seguir un liderazgo por diferenciación o en costos. (Kotler y Keller, 2012).

La empresa se enfocará en un nicho de personas que busca la aventura sea casual, por adrenalina o deportiva. Se dará un servicio diferenciado a través de la atención de los colaboradores, los equipos utilizados y los componentes adicionales en la postventa. Los colaboradores destacarán por una atención personalizada y amigable. Los equipos son nuevos y siguen un adecuado mantenimiento que garantice al $100 \%$ el uso del equipo. Asimismo, como componentes adicionales (postventa) será la entregado mediante la edición del video, lo grabado durante toda la travesía con drones y cámaras especializadas Go pro.

Las alianzas estratégicas son aquellas donde intervienen dos o más partes para generar objetivos que permiten beneficiar a las partes.

Es por ello que se contará con alianzas de servicio donde los clientes podrán pagar con cualquier tipo de medio de pago. Convenios con Visa y Martercard facilitará el proceso de compra. Por otro lado se realizarán alianzas promocionales que permitirán incrementar la afluencia de turistas a los servicios brindados. Dichas alianzas se realizarán con hoteles y agencias de viaje de la ciudad de Puno.

Asimismo, según el ciclo de vida del producto la empresa se encuentra en una fase introductoria. Por tanto, la estrategia a usar será ser pionero en el mercado y brindar un servicio de aventura completo mediante un diseño de ruta innovador. 
Para alcanzar los objetivos y seguir con la estrategia general de la empresa, se optará por las siguientes acciones a corto plazo:

- Participar en ferias regionales de promoción del turismo desarrolladas por entidades municipales y provinciales de Puno. Se pretende dar a conocer a la empresa, contactar clientes y difundir la propuesta de servicio de aventura.

- Establecer alianzas con los principales hoteles de la ciudad con el fin de que puedan referirnos clientes o turistas al circuito turístico. Se otorgaría incentivos a los recepcionistas de los hoteles para poder generar sinergias.

- Buscar reunir a las principales agencias de turismo de Puno para realizar una preventa de nuestros servicios a una tarifa diferenciada. Ello les permitiría discriminar precios sobre los servicios ofrecidos y con ello rentabilizarían la alianza estratégica con la empresa.

- Buscar que medios locales publiciten los innovadores servicios mediante un publirreportaje. Con el fin de optimizar nuestro plan de medios para llegar a más personas.

Para concretar los objetivos a corto plazo la empresa optara por mantener alianzas estratégicas con agencias de viajes, hoteles, municipalidades, etc. Para el éxito del plan de marketing se buscará maximizar el marketing digital, las relaciones públicas y la publicidad boca a boca de los clientes.

Se tendrá una inversión inicial para construir la imagen corporativa de la empresa que será de la siguiente manera: 
Tabla 84

Inversión Inicial - Imagen y Marketing

Detalle

Costo

Banner $1.40 \times 2.00 \mathrm{~m}(02)$

S/. $\quad 78.00$

Pagina Web

(pagina Web + dominio y correos)

S/. $\quad 800.00$

Participacion de eventos y/o activaciones

S/. $\quad 5,000.00$

Folleteria

(5 millares de tripticos en A4)

S/. $\quad 500.00$

\subsubsection{Estrategia de producto.}

Según la clasificación de los productos de acuerdo a su durabilidad y tangibilidad, los servicios son aquellos productos que se caracterizan por ser intangibles, inseparables de sus proveedores, perecederos y tienden a exigir un mayor nivel exigencia en la calidad (Kotler y Keller, 2012).

Por tanto, los servicios ofrecidos por la empresa son actividades de aventura en el lago Titicaca; los cuáles comprenderán tres tipos de actividades de aventura: caminata, bicicleta de montaña y moto acuática.

Un logotipo o símbolo señala de forma clara el servicio brindado, asimismo funciona como un sello, sencillo y versátil, que comunica calidad y confianza. (Kotler y Keller, 2012)

La empresa contará con un logo que transmitirá a los clientes el lugar donde se desarrollan las actividades. Tendrá tonalidades azules ya que, la actividad principal se realiza en 
el lago Titicaca. Contará con la forma de una bahía que simula las playas de Capachica y su contraste con el lago. El nombre de la empresa lo conforman dos palabras que representan el nombre de la zona "Capachica" y la palabra "aventure" se pone en idioma inglés ya que, al pronunciar guarda mejor fonética que la palabra en idioma español.

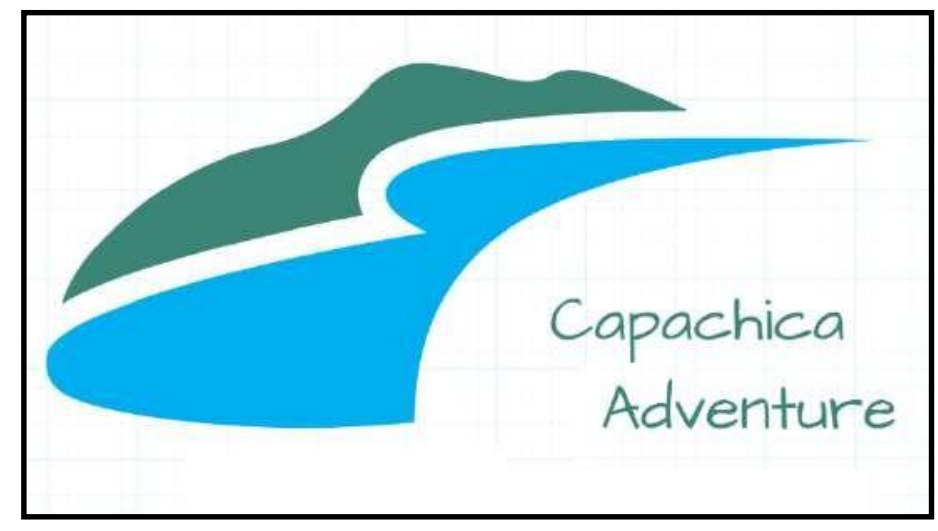

Figura 44. Logo de la empresa

El logo de la empresa estará presente en la folletería, en el transporte, en los implementos de seguridad, en el uniforme de los empleados, en los equipos, etc. Ello con el fin de guardar uniformidad y garantía de servicio.

La estrategia servicio-utilidades es aquella en la relaciona a los clientes, a los empleados y las utilidades de la empresa. La misma consiste en cinco eslabones: calidad interna del servicio, empleados satisfechos y productivos, mayor valor del servicio, clientes satisfechos, utilidades y crecimiento saludables. La correcta sinergia de los eslabones genera satisfacción del cliente y retribución de utilidades para la empresa (Kotler \& Armstrong, 2012).

Por tanto, se definen los siguientes eslabones que estarán presentes en el servicio:

a. Calidad interna del servicio: se capacitará constantemente al empleado, se mantendrá un adecuado ambiente de trabajo, y se explicará el impacto de brindar un buen servicio para la empresa 
b. Empleados satisfechos y productivos: se tendrá un ambiente y cultura organizacional orientada a la aventura, se otorgaran beneficios no dinerarios a los empleados más productivos. Todo ello con el fin de mantener a un trabajador leal y satisfecho.

c. Mayor valor al servicio: se tendrá un política de mejorar constantemente los procesos, de modo que la eficacia en el servicio permite una mayor generación de valor para el cliente.

d. Clientes satisfechos: se dará un trato cordial y amable en cada proceso del servicio, los empleados podrán anticiparse a los requerimientos del cliente para generar que los mismos recomienden y vuelvan a usar los servicios

e. Utilidades y crecimiento saludables: al cuidar los aspectos anteriores, generar una fuerte recomendación boca a boca, permite a la empresa generar buenas utilidades y garantizar un crecimiento constante.

Para la oferta del servicio se consideran tres niveles de producto, los cuales adicionan un mayor valor para el cliente con cada nivel. En un primer nivel se define lo que el consumidor busca de un servicio. En el segundo nivel, se desarrollan características, el nivel de calidad y nombre de la marca. Por último, en el tercer nivel serán los servicios y beneficios adicionales que se brindan al cliente. (Kotler \& Armstrong, 2012)

El servicio tendrá los siguientes niveles de producto de acuerdo a la Figura 45, rescatando lo que representará valor para el cliente. 


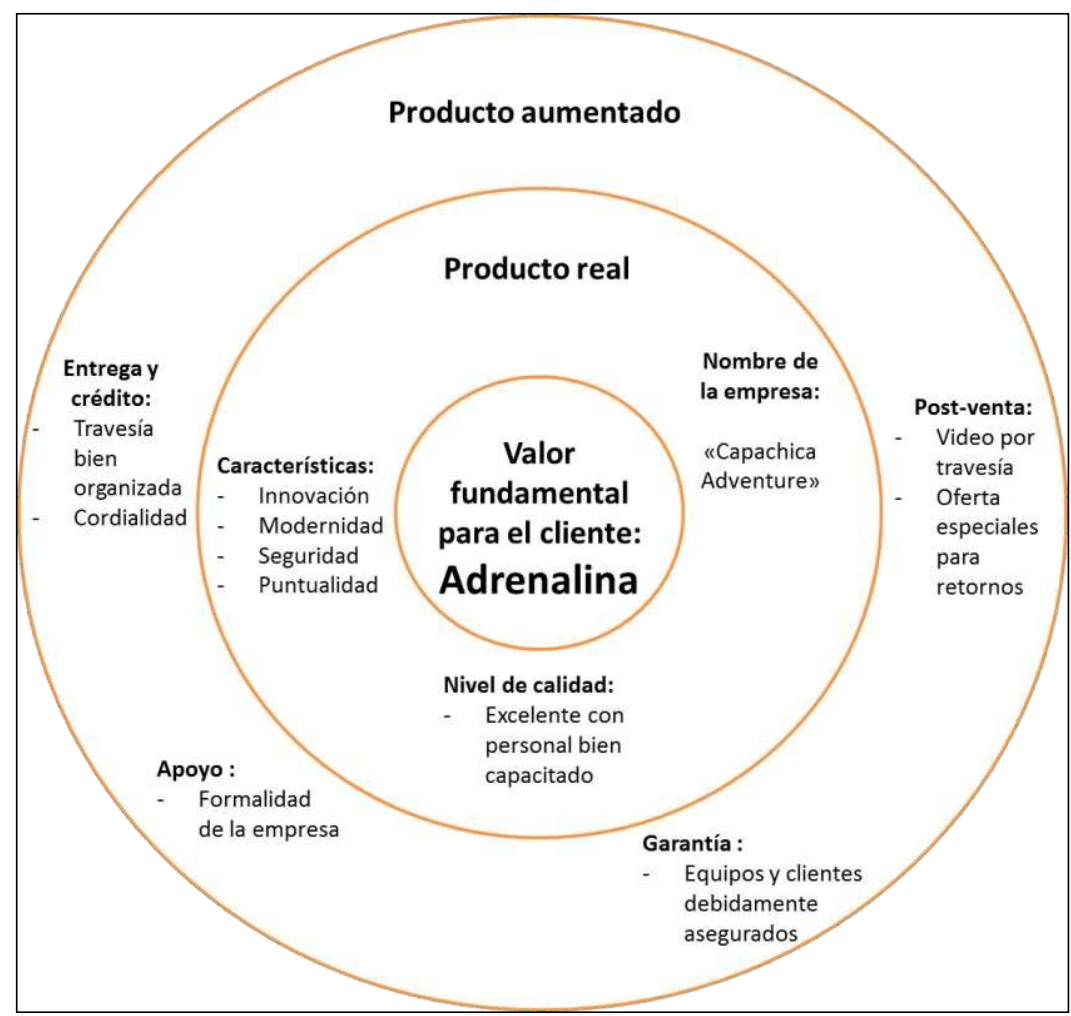

Figura 45. Niveles de producto. Tomado de Dirección de marketing, p.326, por P. Kotler y K. Keller, 2012, México. Decimocuarta edición. Pearson educación 2012.

Según la encuesta realizada lo que más buscarán los clientes con el servicio brindado será “Adrenalina". A partir de ello, el producto real tendrá características del servicio como la innovación, modernidad, seguridad, diversión y puntualidad. Asegurados por un nivel de calidad muy bueno gracias al personal capacitado. El servicio no tendrá una marca en particular sino se trabajará bajo el nombre de la empresa que garantizará el servicio. El producto aumentado está conformado por la formalidad de la empresa, contar con equipos y clientes debidamente asegurados, tener una travesía bien organizada y el envío de un video editado del trayecto que recordará la experiencia y adrenalina vivida. 


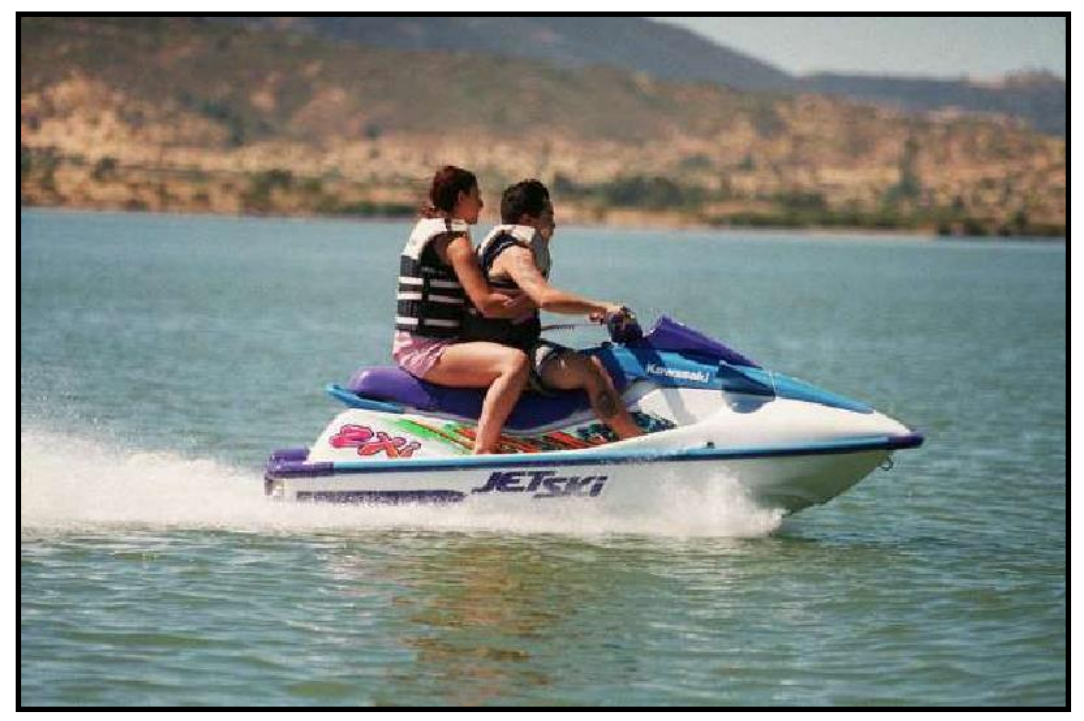

Figura 46. Foto referencial de servicio moto acuática. Tomado de Diario La Tercera.

Recuperado de http://static.diario.latercera.com/201101/1167875.jpg

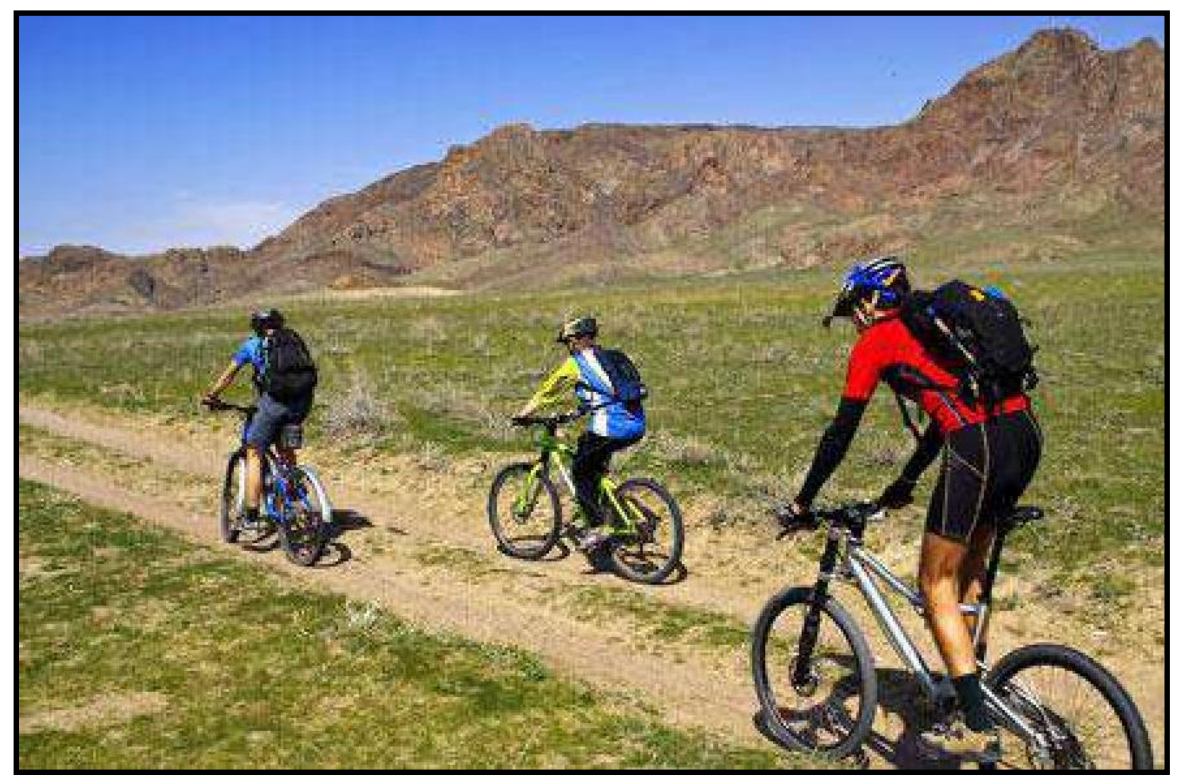

Figura 47. Foto referencial de bicicleta de montaña . Tomado de TeamExtreme.

Recuperado de http://www.teamxtreme.es/media/activities/2/main.jpg 


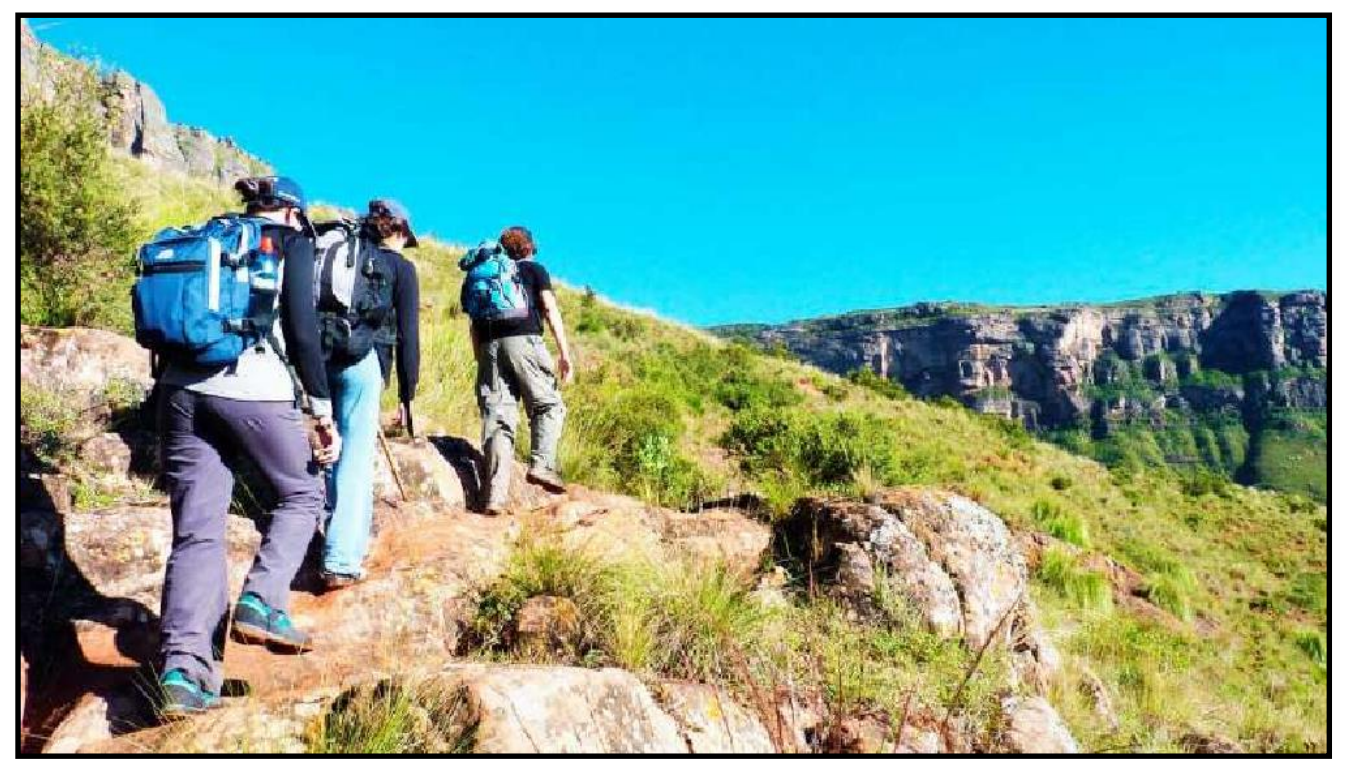

Figura 48. Foto referencial de Trekking . Tomado de DeAventura.pe. Recuperado de http://www.deaventura.pe/blog/wp-content/uploads/2016/06/Trekking.jpg

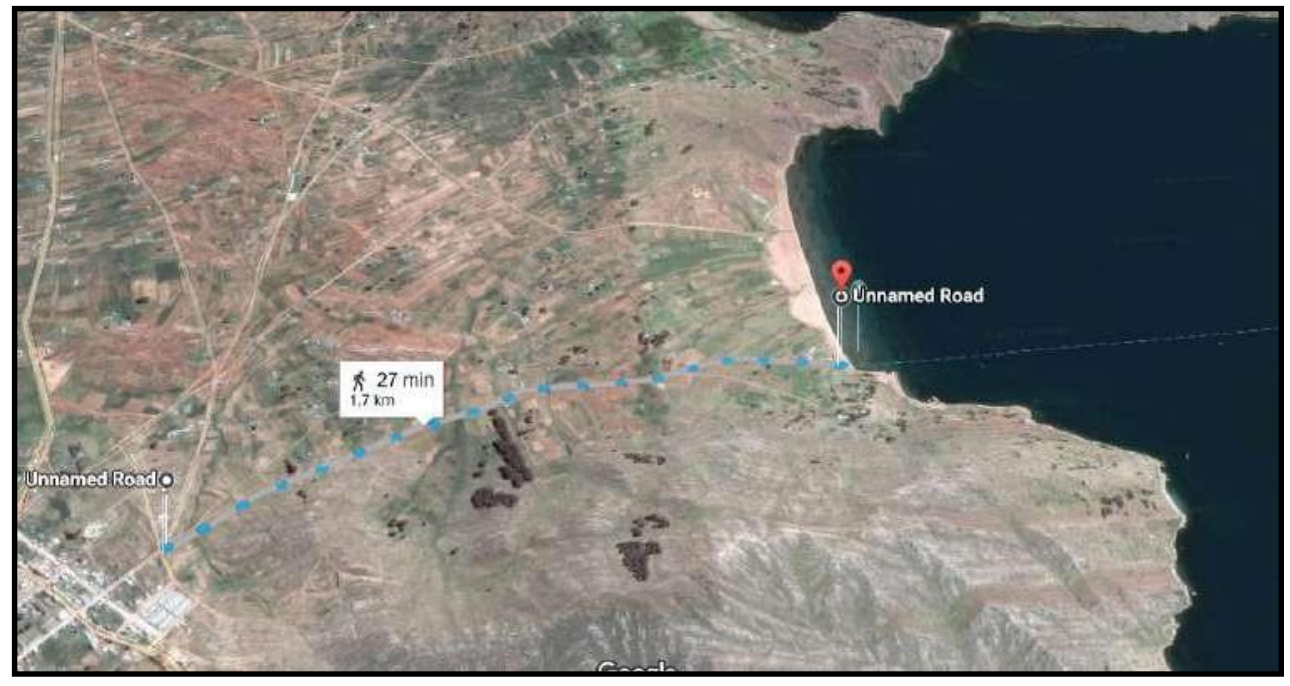

Figura 49. Foto Ruta Trekking . Tomado de Google Maps. Recuperado de

https://www.google.com.pe/maps/dir/-15.6413244,-69.8282498/-15.6376283,-69.813778/@_ $\underline{15.656198,-69.8204402,2330 \mathrm{a}, 35 \mathrm{y}, 5.8 \mathrm{~h}, 44.58 \mathrm{t} / \mathrm{data}=! 3 \mathrm{~m} 1 ! 1 \mathrm{e} 3 ! 4 \mathrm{~m} 2 ! 4 \mathrm{~m} 1 ! 5 \mathrm{i} 1}$ 


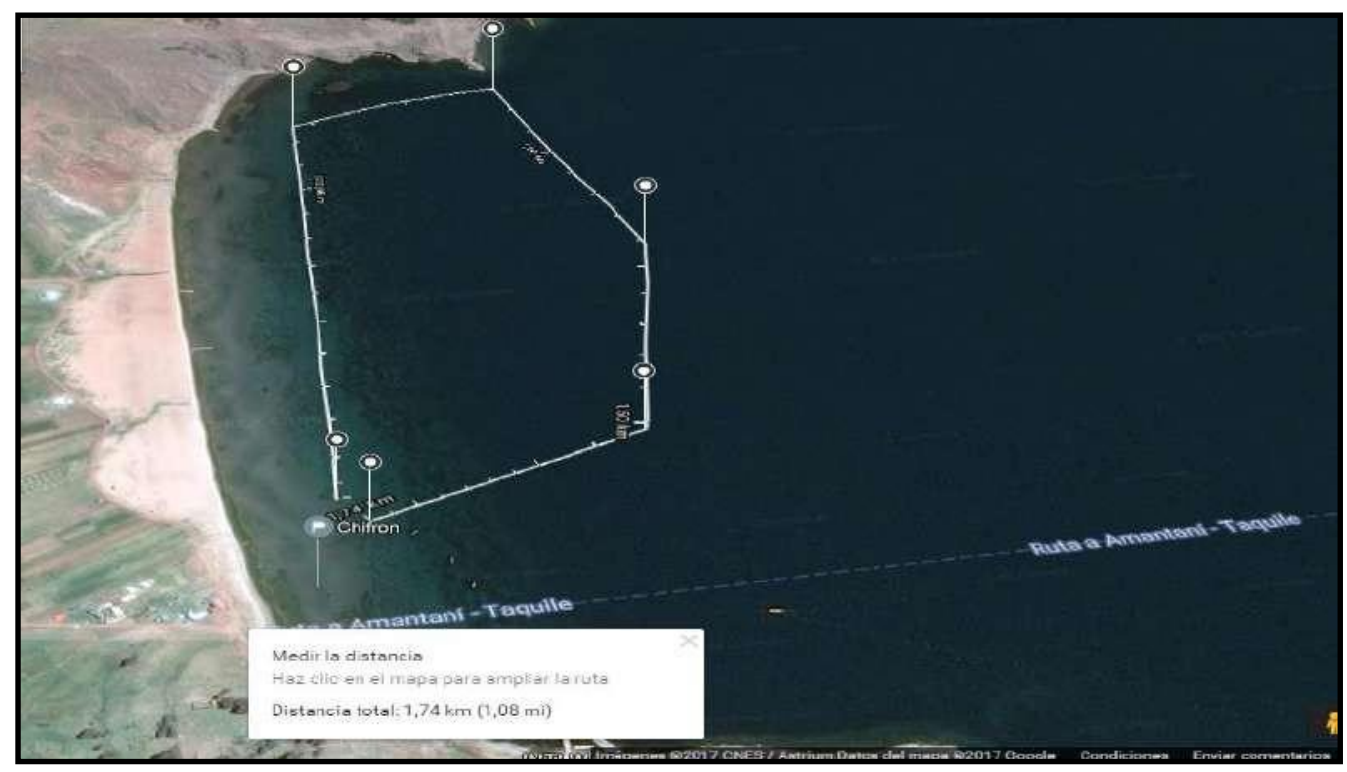

Figura 50. Foto Ruta Moto Acuática. Tomado de Google Maps. Recuperado de https://www.google.com.pe/maps/@-15.6431134,-

$\underline{69.8133503,883 \mathrm{a}, 35 \mathrm{y}, 9.75 \mathrm{~h}, 45.1 \mathrm{t} / \mathrm{data}=! 3 \mathrm{~m} 1 ! 1 \mathrm{e} 3}$

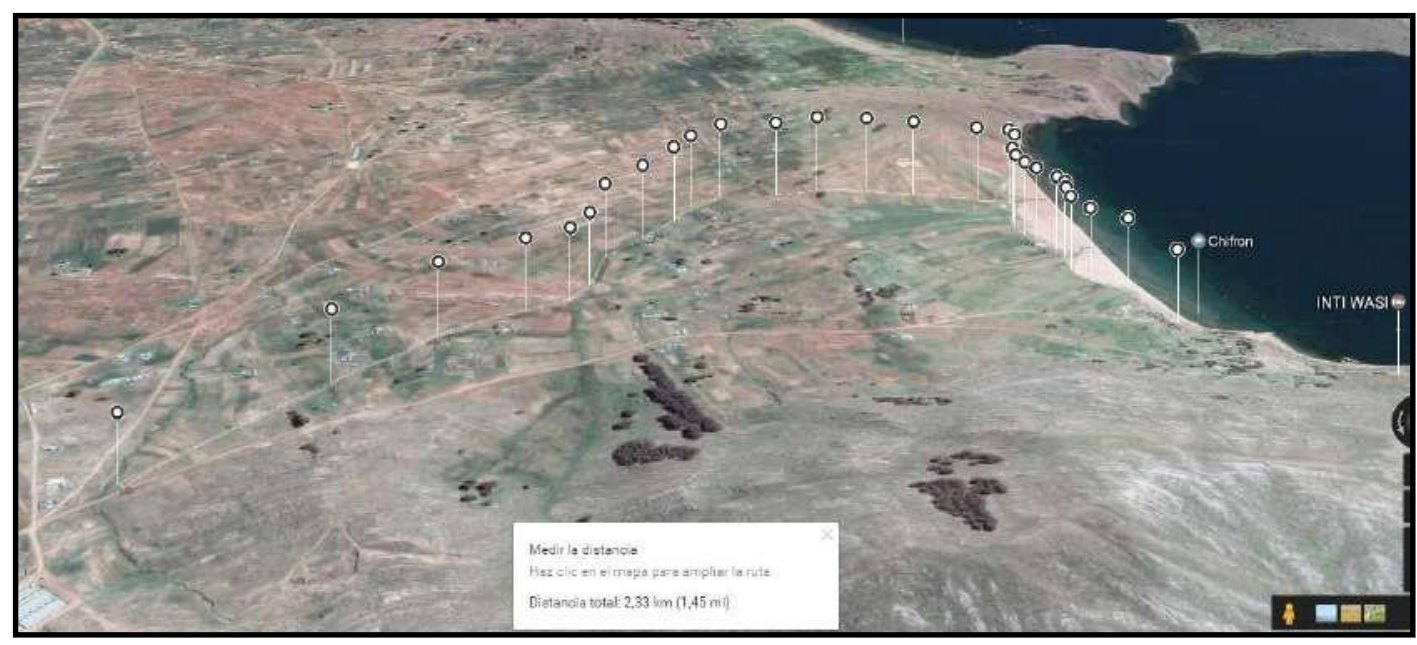

Figura 51. Foto Ruta Bicicleta Montaña. Tomado de Google Maps. Recuperado de https://www.google.com.pe/maps/@-15.651317,-

$\underline{69.8224309,746 \mathrm{a}, 35 \mathrm{y}, 5.01 \mathrm{~h}, 62.35 \mathrm{t} / \mathrm{data}=! 3 \mathrm{~m} 1 ! 1 \mathrm{e} 3}$ 


\subsubsection{Estrategia de precio.}

La fijación de los precios de un producto o servicio tiene tres consideraciones: los costos determinan el límite inferior del precio; los precios de competidores y sustitos dan un punto de referencia; y el límite superior los dan los clientes de acuerdo a la evaluación de las características únicas del producto o servicio. (Kotler \& Keller, 2012)

La empresa empleará diversas técnicas de fijación de precios para lo cual se considerarán los canales, la competencia y la percepción de valor del cliente.

El valor percibido por un cliente tiene varios factores como imagen, garantía de calidad, servicios al cliente y otras de menor exigencia. Por ello la fijación de precios basados en el valor percibido tendrá como principal objetivo medir la percepción del cliente respecto al valor que promete la empresa a través de sus servicios o productos. (Kotler \& Keller, 2012)

Por ello, según la encuesta realizada el gasto por viaje a lugares turísticos en Puno esta entre S/201 a S/300 representado por un 37\% de los encuestados que realizaron actividades de aventura. Asimismo consideran que el tiempo adecuado de duración del servicio está entre 01 a 02 horas y en su mayoría estarían dispuestos a pagar entre S/151 a S/200. Asimismo la frecuencia con que haría el servicio sería en un $72.24 \%$ una vez al año. Dando un total de servicios anuales proyectados un total 2790 el primer año.

La fijación de precios con base en la competencia recoge los precios de los contendores del mercado para que la empresa base, en gran medida, el precio final a sus clientes (Kotler \& Keller, 2012)

Por otro lado, se tiene como competencia las empresas que brindan el traslado en lancha hacia las islas del lago Titicaca. En cuanto a turismo de aventura se brindan ofertas individuales 
de kayac, bicicleta de montaña, cuatrimoto, paseo a caballo, todas ellas a un precio promedio que incluye el traslado interno de la ciudad al lugar donde se realizan las actividades.

Tabla 85

Rango de valor de venta de la Competencia

\begin{tabular}{lc}
\hline Competencia & Rango precios \\
\hline Lancha & S/. 20 a S/. 35 \\
Kayac & USD 15 a USD 59 \\
Bicicleta de montaña & USD 15 a USD 59 \\
Caminata & USD 15 a USD 59 \\
\hline
\end{tabular}

Nota: precios referenciales de diversas empresas locales y agencias de turismo

La fijación del valor de venta diferenciada se realiza para responder a los diversos segmentos de clientes, diferencias de producto, ubicación, etc. Dando lugar a una discriminación del valor de venta para ajustar de acuerdo a los factores y tipo de cliente. (Kotler \& Keller, 2012).

La empresa contará con dos canales uno directo y otro indirecto. El canal directo está determinado por aquel que se realiza en el punto de venta de la empresa y por su fuerza de ventas. En el canal indirecto se tendrá a los hoteles y agencias de viajes, los cuáles solicitan una tarifa plana durante un año para que puedan discriminar valor de venta con sus propios clientes y ganar una diferencia por el servicio.

Asimismo se otorgará un valor de venta diferenciado por tipo de cliente. Se tendrán dos: público en general, que serán ciudadanos locales y turistas nacionales.

Al tener estas condiciones del mercado se optará por una estrategia orientada al mercado. Sin embargo, se seguirá en conjunto de estrategias combinadas: 
a. Fijación de valor de venta basada en valor percibido, se toma en cuenta los datos arrojados en la investigación cuantitativa de la cual se concluye que el cliente estaría dispuesto a pagar hasta S/200 por el circuito ofrecido. Se establece un valor de venta máximo de todo el servicio de hasta S/ 300 según el rango de gasto realizado por personas que algunas vez realizaron actividades de aventura

b. Fijación de valor de venta basado en la competencia, se tomará en cuenta los servicios similares al proyecto como base para la determinación del valor de venta. Se estimaría un valor de venta inicial de S/ 201 ya que, por un solo servicio de aventura el mercado llega cobrar hasta USD 59 que sería un monto de S/197.

c. Fijación de valor de venta diferenciada, de la cual se toma dos casos:

i. Fijación del valor de venta por canal, se tiene que un canal directo habrá un valor de venta fijo de S/201; mientras que para el canal indirecto se tendrá un valor de venta fijo establecido de forma anual por S/186, dando solo un margen de S/15 por servicio referido.

ii. Fijación de valor de venta por segmento de consumidor, se tendrá un valor de venta de S/ 201

\subsubsection{Estrategia de distribución.}

"Los canales de marketing son un conjunto de organizaciones interdependientes que participa del proceso de poner a disposición de los consumidores un bien o un servicio para sus uso o adquisición”. (Kotler \& Keller, p 415)

Los niveles de canal identifican la longitud de intermediarios que tendrá un canal. Los canales de venta que tendrá la empresa serán directos e indirectos. Los canales directos serán los 
que la empresa realice sin intermediarios. Los canales indirectos usaran intermediarios para llegar los compradores finales.

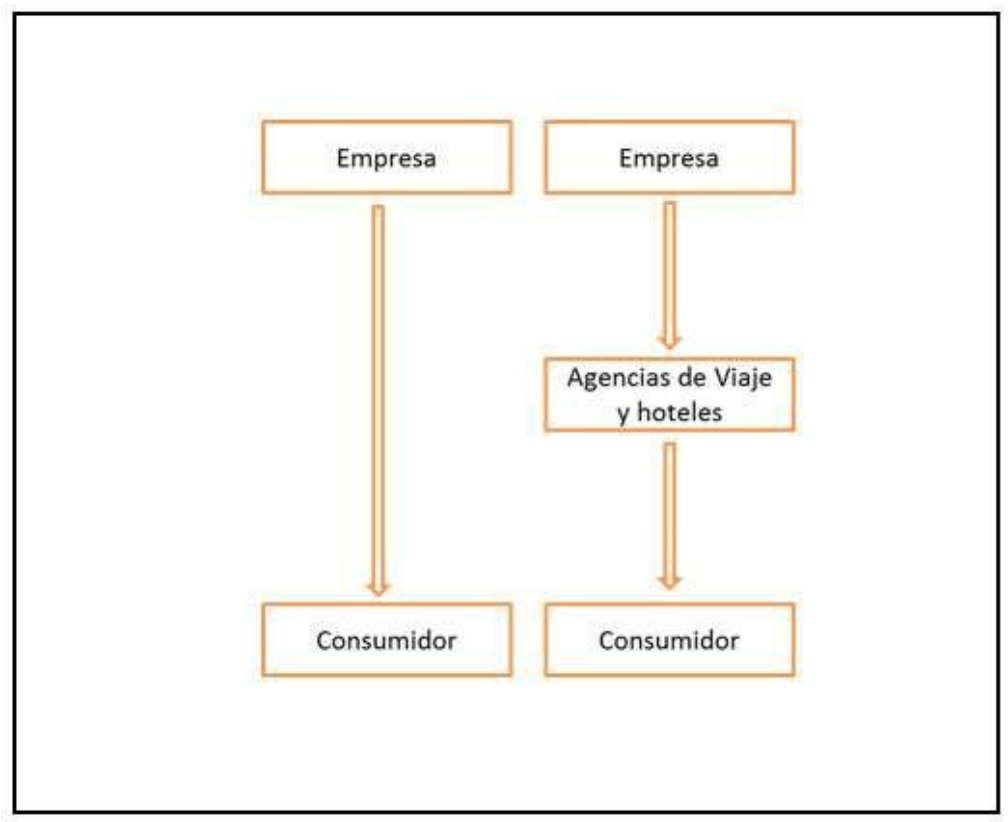

Figura 52. Canles de marketing de bienes de consumo. Adaptado de Dirección de marketing, p.420, por P. Kotler y K. Keller, 2012, México. Decimocuarta edición. Pearson educación 2012.

El canal directo será a través de los puntos de ventas de la empresa, la captación de clientes mediante las redes sociales y las visitas realizadas por el gerente de la empresa a instituciones como colegio, universidades, y/o empresas. Este canal solo usará personal propio para concretar las ventas.

El canal indirecto lo conformaran hoteles y agencia de viaje de Puno. Tanto hoteles como agencias tendrán como objetivo incrementar la afluencia de clientes y por ello contará con un valor de venta diferenciado. Con ello se llegará a más segmentos de clientes como turistas nacionales y extranjeros en épocas de alta demanda. Cabe señalar que tanto hoteles como agencias de viaje serán aliados estratégicos de la empresa pero no se enfocarán esfuerzos para este canal. 
La elección de las empresas hoteles de este canal será de una forma de distribución selectiva de acuerdo al tamaño, capacidad de atención y reputación en redes sociales como Tripadvisor.

Tabla 86

Ranking Hoteles según Opinión de Viajeros

\begin{tabular}{lr}
\hline \multicolumn{1}{c}{ Hoteles } & Ranking \\
\hline Titilaka & 1 \\
Tierra Viva Puno Plaza Hotel & 2 \\
Suites Antonio's & 3 \\
Mirador de Titikaka & 4 \\
Sonesta Posadas del Inca Lak & 5 \\
Hotel Hacienda Plaza de Arma & 6 \\
Libertador Lago Titicaca & 7 \\
Taypikala Lago & 8 \\
Cantuta Inn & 9 \\
Casa Andina Private Collectio & 10 \\
\hline
\end{tabular}

Nota: adaptado de Tripadvisor.com (2017)

Por otro lado, la elección de agencias de viaje se realizará mediante una distribución intensiva, la cual consiste en tener una mayor cantidad de puntos de venta. En este caso se tratará de abarcar la mayor cantidad de agencias de viaje de las ciudades de Puno y Juliaca.

\subsubsection{Estrategia de promoción y publicidad.}

Los medios son usados por las empresas para informar, persuadir y posicionarse en la mente del consumidor. Los mismos contribuyen a una mayor lealtad de los cliente al establecer un dialogo constante con el consumidor. Asimismo contribuye al Brand equity, promueva mayores ventas e incluso puede afectar el valor de las acciones de una empresa. (Kotler y Keller, 2012) 
Se realizará la siguiente mezcla de comunicaciones de marketing:

a. Publicidad: Se promocionará la empresa a través de folletos, paneles móviles, medios electrónicos como página Web y radios locales. Ello debido a que la encuesta realizada nos indica que un $57.23 \%$ de los encuestados obtiene información de circuitos de aventura a través de redes sociales, radio y paneles publicitarios.

b. Promoción de ventas: se realizará promociones comerciales mediante publicidad en fechas festivas de la ciudad de Puno. La mejor alternativa será vallas móviles en el mes de febrero por la festividad de la Virgen de la Candelaria.

c. Eventos y experiencias: se participará en el patrocinio o participación de eventos deportivos acuáticos a realizarse en el departamento de Puno. Asimismo se buscará patrocinar dentro de la festividad de la Virgen de la Candelaria que se realiza los meses de enero y febrero.

d. Relaciones públicas y publicity: se realizara convenios institucionales con centros educativos, empresas privadas y públicas para que obtengan descuentos especiales.

e. Marketing directo: todo aquel que consulte por la Web o se acerque a las oficinas de la empresa, se les pedirá un correo electrónico. Con ello se realizarán campañas de mailing y conseguir que tanto interesados como clientes estén informados de las ofertas.

f. Marketing interactivo: Se realizarán campañas digitales mediante redes sociales con el objetivo de generar mayor interacción con los consumidores y posicionar a la empresa en dicho medio. Se reforzará constantemente durante el proyecto ya que, un $30.92 \%$ de los encuestados obtiene información de turismo de aventura a traves de estos canales. 
g. Marketing de boca a boca: se buscará que el cliente refiera a la empresa a su círculo de amistades. Se logrará brindando un servicio de calidad, eficaz y puntual. Este el que más reforzará la empresa ya que, según el estudio realizado un $31.30 \%$ obtiene información sobre un servicio de turismo de aventura a través de amigos.

h. Ventas personales: las ventas personales se darán en el punto de venta y zonas cercanas a la oficina de la empresa. El personal tendrá que cumplir un determinado número de horas en campo. Asimismo el área comercial se encargará de realizar visitas personales a diversas instituciones y generar mayores canales de venta.

El plan de medios se realizará en dos etapas; una de lanzamiento y otra de mantenimiento. Se usarán tres medios para la publicidad: radio, redes sociales y buscadores, y vallas publicitarias.

Para la elección de los medios se toma en cuenta información interna de la Compañía Peruana de estudios de mercados y opinión pública S.A. (CPI) a través de su herramienta IBOPE media para medios de radiofusión y datos de COMSCORE para la elección de los medios digitales.

En el caso de los medios de radiodifusión a utilizar se eligieron dos: Radio Pachamama y Radio Onda Azul. Los mismos son radios locales con buena acogida en público joven y adulto. Si bien radios como RPP o Nueva Q cuenta con mayor audiencia por hora; invertir en dichos medios tiene un costo mucho más elevado que las radios locales. Por ello, y dado que gran parte del público objetivo será local, la empresa se enfocará en medios locales.

En cuánto a medios digitales se toman Google sites y Facebook por contar con una mayor cantidad de visitantes únicos, para los cuales se usaran diversos formatos para llegar mejor al público objetivo. 


\begin{tabular}{|c|c|c|c|}
\hline \multicolumn{4}{|c|}{ C.P.I. AUDIENCIA RADIAL DE EMISORAS EN PRINCIPALES CIUDADES } \\
\hline Periodo & \multicolumn{3}{|l|}{ '201602 } \\
\hline Ciudad & \multicolumn{3}{|l|}{ Juliaca-puno } \\
\hline Lugar de audiencia & \multicolumn{3}{|l|}{ Hogares/Fuera del Hogar } \\
\hline Bloques de dias & \multicolumn{3}{|l|}{ Lunes a Sabado/Domingo } \\
\hline Horas & \multicolumn{3}{|l|}{$06-2 \mathrm{OH}$} \\
\hline Nivel & \multirow{2}{*}{\multicolumn{3}{|c|}{ Alto - Medio/Bajo Superior - Bajo Inferior - Marginal }} \\
\hline Grupo objetivo & & & \\
\hline Universo & \multicolumn{3}{|l|}{228.30} \\
\hline Rnk & Emisora & Rating & Miles \\
\hline & AUDIENCLA PROMEDIO PORHORA & 15.4 & 35.05 \\
\hline & 1) R.P.P. [FMAM] & 1.9 & 4.43 \\
\hline & 2 NUEVA Q FM[FM] & 1.8 & 4.01 \\
\hline & 3 PACHAMAMA [AM] & 1.2 & 2.78 \\
\hline & 4 ONDAAZUL [FMAM] & 1.2 & 2.78 \\
\hline & 5 SOL DELOS ANDES [FMAM! & 1.1 & 2.49 \\
\hline & 3 MODA [FM] & 1.0 & 2.34 \\
\hline & 7 RITMO ROMANTICA [FM] & 0.8 & 1.94 \\
\hline & 3 LA KARIBEÑA [FM] & 0.7 & 1.62 \\
\hline & LA INOLVIDABLE[FM] & 0.6 & 1.40 \\
\hline 10 & D LAZONA [FM] & 0.6 & 1.28 \\
\hline & 1 JULLACA [FMAM] & 0.5 & 1.10 \\
\hline 12 & 2. EXITOSA [FM] & 0.5 & 1.09 \\
\hline 13 & 3 PANAMERICANA[FM] & 0.4 & 0.98 \\
\hline 14 & 4 STUDIO 92 [FM] & 0.3 & 0.64 \\
\hline 15 & 6 LA PODEROSA [FM] & 0.3 & 0.60 \\
\hline 18 & ONDA CERO [FM] & 0.2 & 0.58 \\
\hline 17 & 7 FELICIDAD [FM] & 0.2 & 0.37 \\
\hline 18 & RED ANDINA [AM] & 0.0 & 0.08 . \\
\hline 19 & OTRAS EMISORAS [FM] & 1.3. & 2.98 \\
\hline 20 & OTRAS EMISORAS [AM] & 0.3 & 0.70 \\
\hline 21 & 1 NO RECUERDA & 0.4 & 0.95 \\
\hline
\end{tabular}

Figura 53. Niveles de audiencia y radioescuchas según CPI Perú en Juliaca y Puno. 


\begin{tabular}{|c|c|c|c|c|c|c|c|c|c|c|c|c|c|}
\hline \multirow[t]{4}{*}{$\square$} & \multicolumn{2}{|c|}{ cOMSCORE. } & \multicolumn{2}{|c|}{$\begin{array}{l}\text { Zona geográfica : } \\
\text { Universo: } \\
\text { Período: } \\
\text { Objetivo: } \\
\text { Medios : } \\
\text { Fecha : }\end{array}$} & \multicolumn{9}{|c|}{$\begin{array}{l}\text { Perú } \\
\text { Home and Work } \\
\text { Mayo de } 2016 \\
\text { Personas: } 18+ \\
\text { Top } 100 \text { Properties [Sin dup.] } \\
\text { 04/07/2016 }\end{array}$} \\
\hline & & Medios & $\begin{array}{c}\text { Total } \\
\text { visitantes } \\
\text { únicos }(000)\end{array}$ & $\begin{array}{l}\% \text { de } \\
\text { alcance }\end{array}$ & $\begin{array}{c}\% \\
\text { composición } \\
\text { visitantes } \\
\text { únicos }\end{array}$ & $\begin{array}{c}\text { Índice de } \\
\text { composición } \\
\text { VU }\end{array}$ & $\begin{array}{l}\text { Indice de } \\
\text { composición } \\
\text { PV }\end{array}$ & $\begin{array}{l}\text { Promedio de } \\
\text { visitantes } \\
\text { diarios }(000)\end{array}$ & $\begin{array}{l}\text { Total } \\
\text { minutos } \\
\text { (MM) }\end{array}$ & $\begin{array}{c}\text { Total } \\
\text { páginas } \\
\text { vistas (MM) }\end{array}$ & $\begin{array}{l}\text { Total visitas } \\
\qquad(000)\end{array}$ & $\begin{array}{l}\text { Promedio de } \\
\text { minutos por } \\
\text { visita }\end{array}$ & $\begin{array}{l}\text { Promedio de } \\
\text { visitas por } \\
\text { visitante }\end{array}$ \\
\hline & & $\begin{array}{l}\text { Total Internet: Persons: } \\
18+\end{array}$ & 6,826 & 100.0 & 93.7 & 100 & 100 & 3,700 & 6,441 & 6,783 & 279,189 & 23.1 & 40.9 \\
\hline & & Top 100 Properties & & & & & & & & & & & \\
\hline 1 & {$[\mathrm{P}]$} & Google Sites & 6,431 & 94.2 & 93.7 & 100 & 100 & 2,340 & 2,223 & 1,890 & 178,535 & 12.5 & 27.8 \\
\hline 2 & {$[\mathrm{P}]$} & Facebook & 5,476 & 80.2 & 93.3 & 100 & 99 & 1,380 & 1,369 & 1,408 & 91,462 & 15.0 & 16.7 \\
\hline 3 & {$[\mathrm{P}](\mathrm{U})$} & Microsot Sites & 4,861 & 71.2 & 94.6 & 101 & 100 & 1,905 & 568 & 292 & 88,986 & 6.4 & 18.3 \\
\hline 4 & {$[\mathrm{P}](\mathrm{U})$} & Yahoo Sites & 3,564 & 52.2 & 93.1 & 99 & 105 & 308 & 145 & 101 & 15,059 & 9.6 & 4.2 \\
\hline 5 & {$[\mathrm{P}](\mathrm{U})$} & Grupo El Comercio & 3,546 & 51.9 & 95.0 & 101 & 105 & 443 & 105 & 105 & 19,283 & 5.4 & 5.4 \\
\hline & {$[\mathrm{M}](\mathrm{U})$} & ELCOMERCIO.PE & 2,567 & 37.6 & 95.3 & 102 & 105 & 328 & 66 & 42 & 14,018 & 4.7 & 5.5 \\
\hline & {$[\mathrm{M}](\mathrm{u})$} & GESTION.PE & \begin{tabular}{|l|l}
583 \\
\end{tabular} & 8.5 & 96.3 & 103 & 104 & 32 & 4 & 5 & 1,212 & 3.2 & 2.1 \\
\hline 6 & {$[\mathrm{P}](\mathrm{U})$} & Linkedin & 2,452 & 35.9 & 94.1 & 100 & 104 & 251 & 29 & 23 & 9,565 & 3.0 & 3.9 \\
\hline 7 & {$[\mathrm{P}](\mathrm{U})$} & Grupo RPP & 2,235 & 32.7 & 94.1 & 100 & 103 & 293 & 10 & 27 & 11,905 & 0.8 & 5.3 \\
\hline & {$[\mathrm{M}](\mathrm{U})$} & RPP.PE & 1,503 & 22.0 & 94.6 & 101 & 104 & 136 & 6 & 14 & 5,251 & 1.1 & 3.5 \\
\hline & {$[\mathrm{M}](\mathrm{U})$} & LAZONA.COM.PE & \begin{tabular}{l|l|}
546 \\
\end{tabular} & 8.0 & 91.2 & 97 & 96 & 35 & 0 & 2 & 1,174 & 0.3 & 2.1 \\
\hline & {$[\mathrm{M}](\mathrm{U})$} & CAPITAL.COM.PE & \begin{tabular}{l|l}
455 \\
\end{tabular} & 6.7 & 95.3 & 102 & 102 & 27 & 0 & 1 & 932 & 0.5 & 2.0 \\
\hline & {$[\mathrm{M}](\mathrm{U})$} & STUDIO92.COM & 447 & 6.6 & 90.9 & 97 & 96 & 30 & 0 & 1 & 980 & 0.3 & 2.2 \\
\hline & {$[\mathrm{M}](\mathrm{U})$} & LA10.PE & 434 & 6.4 & 93.4 & 100 & 100 & 130 & 2 & 7 & 4,785 & 0.3 & 11.0 \\
\hline & {$[\mathrm{M}](\mathrm{U})$} & CORAZON.PE & 280 & 4.1 & 94.1 & 100 & 102 & 37 & 0 & 2 & 1,295 & 0.3 & 4.6 \\
\hline & {$[\mathrm{M}](\mathrm{U})$} & OXIGENO.COM.PE & 98 & 1.4 & 94.0 & 100 & 103 & 7 & 0 & 0 & 223 & 0.3 & 2.3 \\
\hline & {$[\mathrm{M}]$} & RPP.COM.PE & 11 & 0.2 & 94.6 & 101 & 101 & 0 & 0 & 0 & 11 & 1.2 & 1.1 \\
\hline & {$[\mathrm{M}]$} & FELICIDAD COM.PE & 5 & 0.1 & 98.7 & 105 & 106 & 0 & 0 & 0 & 5 & 1.7 & 1.1 \\
\hline
\end{tabular}

Figura 54. Promedio de visitas en los medios. Información interna de ComScore.com

La campaña de lanzamiento se realizará a inicios de año en los meses de Enero y Febrero ya que, las fiestas patronales como la Fiesta de la Candelaria atraen a una gran cantidad de público de todo Puno y a nivel nacional. Esos meses son la mejor oportunidad para promocionar el lanzamiento de los servicios.

A lo largo de la ejecución del proyecto se tendrá como meta captar 40 clientes diarios y 1200 clientes de forma mensual para poder alcanzar la participación de mercado deseada.

Asimismo para poder cubrir la meta se requerirá de al menos 80,000 impactos para generar 1200 clientes interesados. Los clientes interesados podrían optar o no por el servicio una vez se contacten con la empresa. El porcentaje de captura de dicho público se estima en un mínimo de $22.50 \%$ hasta llegar a un $42.50 \%$ al quinto año. 
Tabla 87

Meta Propuesta

\begin{tabular}{lr}
\hline Clientes & Cantidad \\
\hline Clientes deseados por mes & 1,200 \\
Clientes deseados por día & 40 \\
\hline
\end{tabular}

Nota: Clientes deseados por día según Esferacom.SAC

Tabla 88

Publicidad Necesaria Para Lograr Meta

Detalle

Impactos necesarios por mes

80,000

Tasa de compra por publicidad escuchada (1.5\%)

1200

Nota: Tasa promedio referencial según Esferacom.SAC

Campaña de lanzamiento:

Se realizará en el mes de febrero para aprovechar afluencia local y nacional. Se consideran dos medios: radio, medios digitales y vallas móviles.

La campaña radial se realizará con las emisoras Pachamama y Radio Onda Azul, de las cuales se tendrán spots de lunes a viernes con una frecuencia diaria de seis veces. No se consideran fines de semana ya que, mayor cantidad de oyentes es de lunes a viernes. 


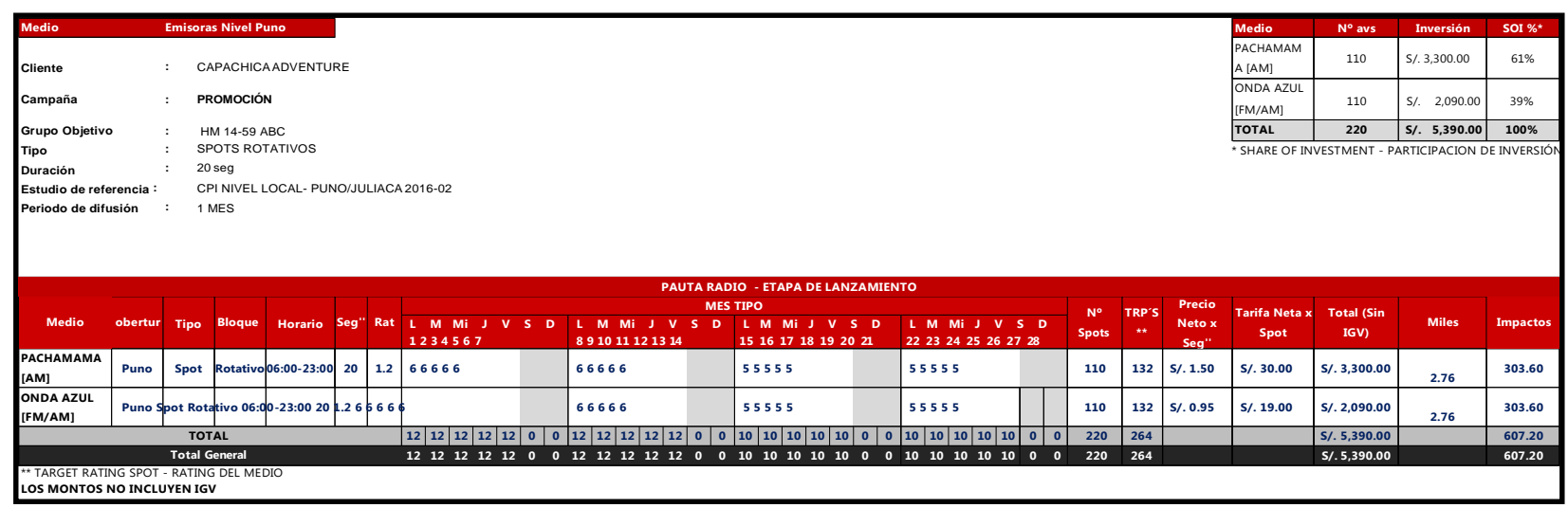

Figura 55. Presupuesto de publicidad en medios radiales. Presupuesto brindado por esferacom SAC

En cuanto a los medios digitales se usarán Facebook, Google Search y Google Display.

Para Facebook se promocionará a través del Fan Page de la empresa donde se ofertarán los servicios. En "Post Ads" se toma un costo por click y el mensaje publicados por la página de la empresa llegará tanto a seguidores como personas que se encuentren viviendo en las ciudades de Puno, Cusco, Arequipa y Lima. Los "Post Video" también se promocionaran con seguidores de la página y público que viva en las ciudades de antes mencionadas. Se transmitirá videos en vivo y promocionales. En este caso el costo por vista se hace efectivo si llegan a ver el video completo. Por otro lado, en Youtube se presentará un video promocional que mostrará imágenes de la zona, las actividades y tomas realizadas con las cámaras Go pro. La tasa de efectividad es más alta por ser un medio más especializado. En cuanto a Google Search, el costo se hace efectivo por click realizado, se utilizaran palabras claves para generar un buen alcance en las búsquedas realizadas en el google.com, asimismo se delimitará geográficamente en las ciudades de Puno, Lima, Arequipa y Cusco. Para poder generar un control y mayor efectividad por los clipk realizados que son orientados a la página web de la empresa, saldrá un pantalla con un formulario simple para poder hacer llegar ofertas especiales. En cuanto a Google Display, se optará con banner digitales en las principales páginas web de aventura, búsquedas, blog 
deportivos y canales de Youtube. Todo ello permitirá una mejor presencia en las redes sociales realizando campañas dirigidas y obteniendo mejor presencia como empresa.

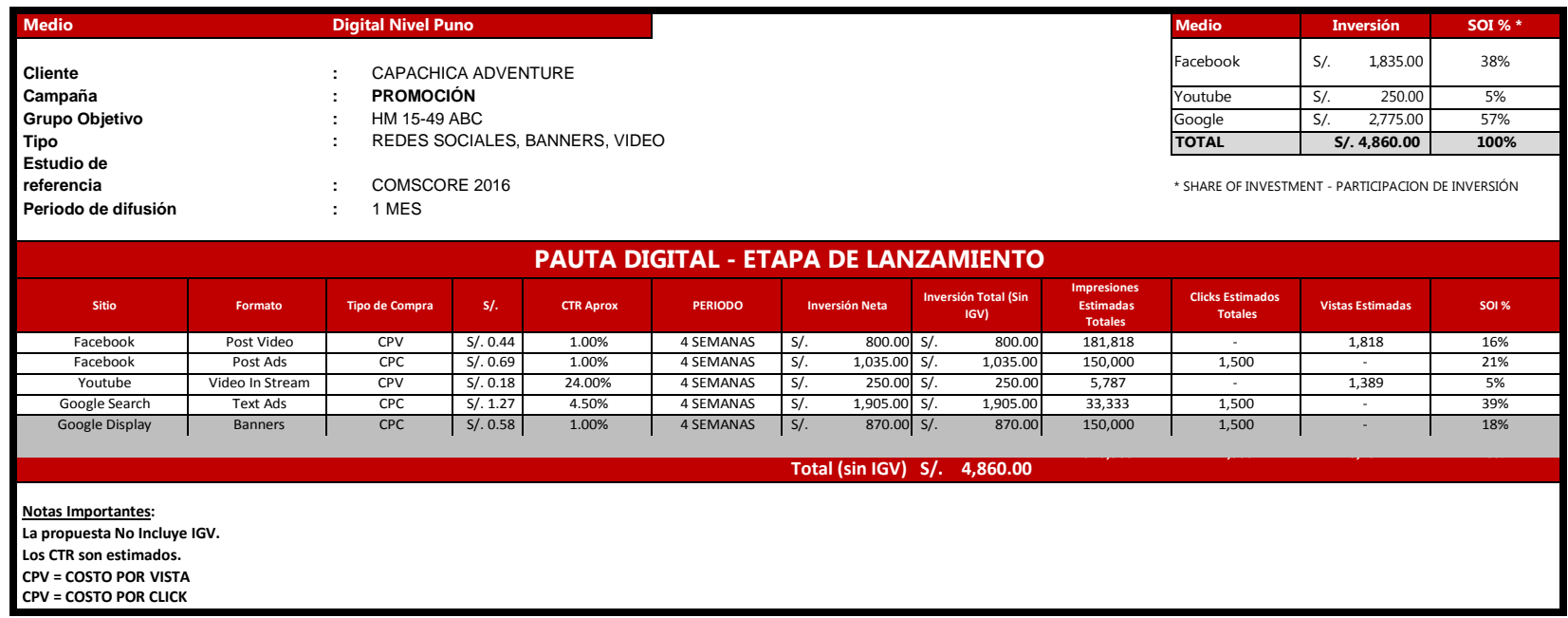

Figura 56. Presupuesto de publicidad en medios digitales. Presupuesto brindado por Comscore SAC

Asimismo, para la campaña de lanzamiento se considerará contratar vallas móviles, los cuáles transitarán por las principales avenidas de la ciudad. La ventaja frente a una valla estática es que las vallas móviles tienen un mayor alcance y uno puede cambiar la ruta hacia otras zonas. Con vallas estáticas no tienen ese soporte, y el alcance no será efectivo. La publicidad mediante este medio es mucho más masiva, simple y específica. 


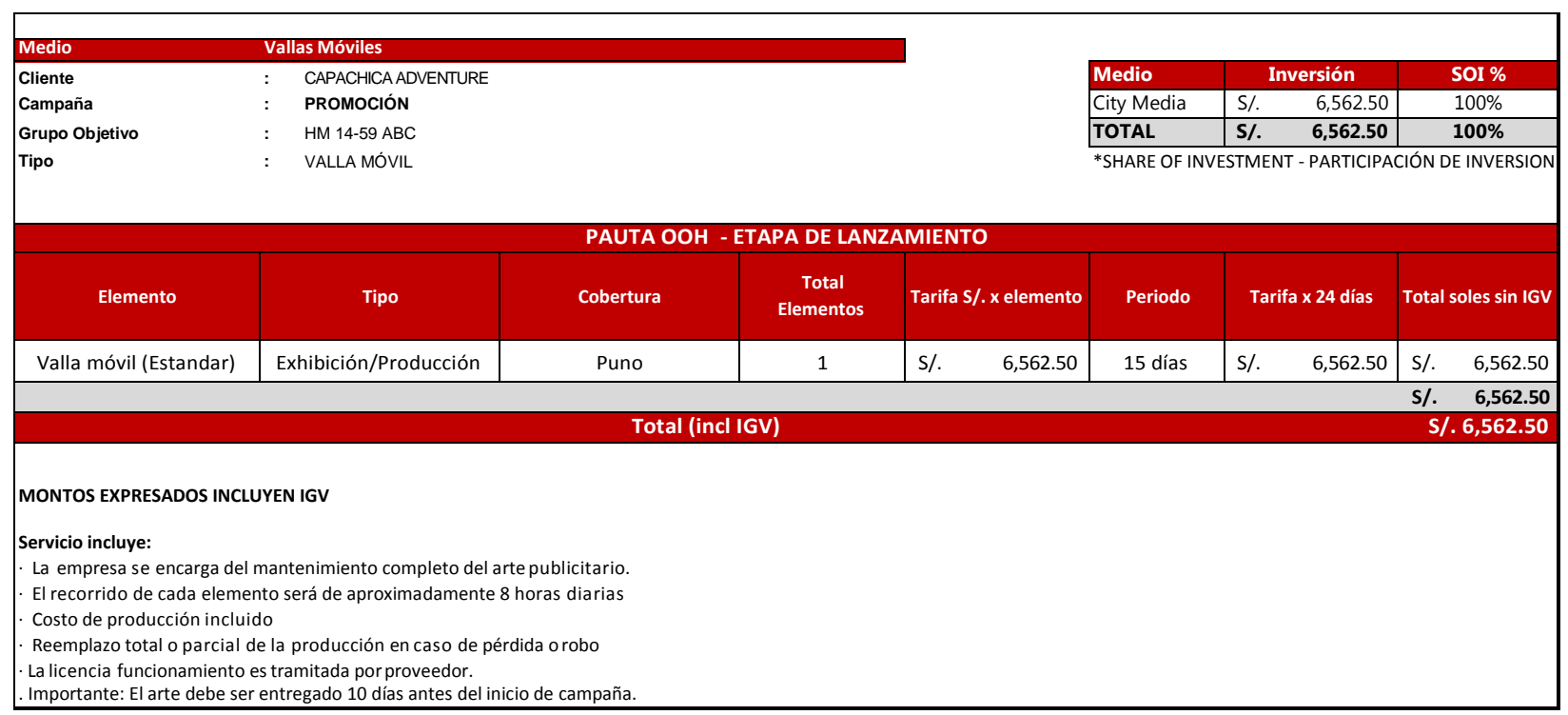

Figura 57. Presupuesto de publicidad valla móvil. Presupuesto brindado por esferacom SAC

a. Campaña de mantenimiento:

Se realizará los demás meses del año teniendo descansos en los meses de junio, noviembre, diciembre y enero. Dicha campaña tendrá como objetivo mantener en la mente del consumidor el nombre de la empresa y obtener nuevos clientes. El objetivo de la campaña de mantenimiento es poder garantizar una correcta afluencia de clientes para poder llegar a la participación de mercado deseada.

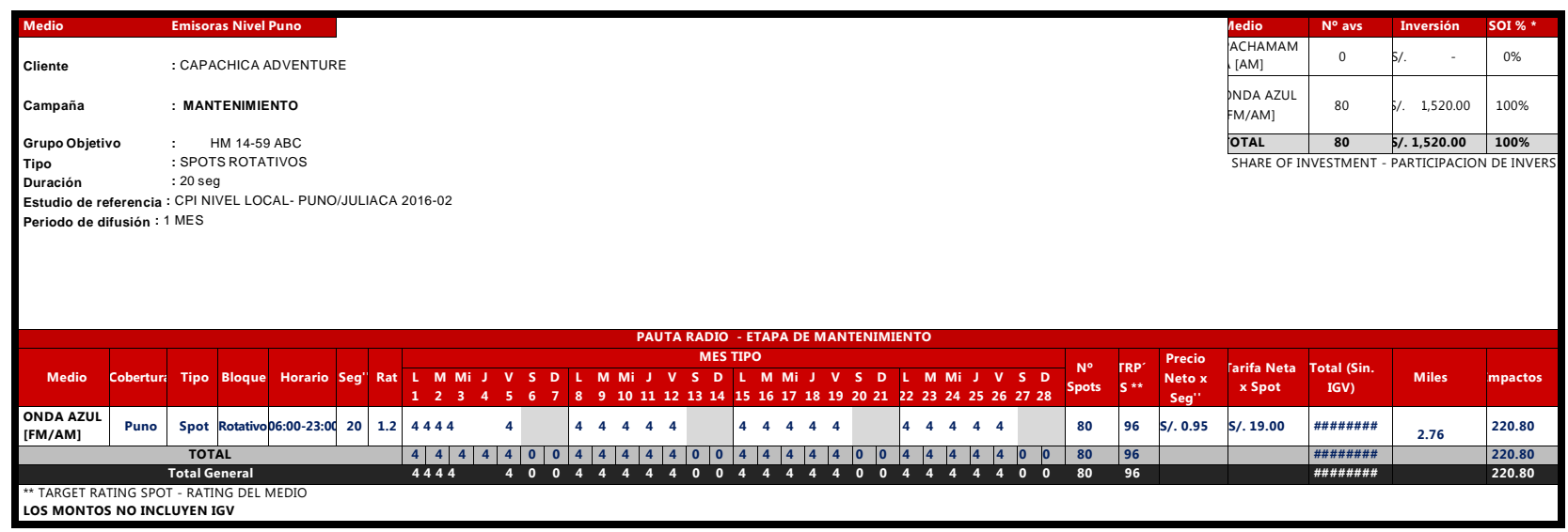

Figura 58. Presupuesto de mantenimiento de los medios radiales. Presupuesto brindado por esferacom SAC 
Solamente en radio, se invertirá en una sola emisora (radio onda azul) el cual tiene una audiencia 2.76 miles de personas por hora. Se realizarán 4 avisos diarios de lunes a viernes para poder tener un alcance de 220.8 miles de impactos mensuales.

\begin{tabular}{|c|c|c|c|c|c|c|c|c|c|c|c|}
\hline \multirow{2}{*}{\begin{tabular}{|l} 
Medio \\
\end{tabular}} & & & & & & & & & Medio & Inversión & SOI \% * \\
\hline & & \multicolumn{7}{|c|}{ Digital Nivel Puno } & Facebook & $1,190.00$ & $39 \%$ \\
\hline \multirow{2}{*}{\multicolumn{2}{|c|}{$\begin{array}{l}\text { Cliente } \\
\text { Campaña }\end{array}$}} & \multirow{2}{*}{\multicolumn{7}{|c|}{$\begin{array}{ll}: & \text { CAPACHICA ADVENTURE } \\
: & \text { MANTENIMIENTO }\end{array}$}} & Google & S/. $\quad 1,850.00$ & $61 \%$ \\
\hline & & & & & & & & & TOTAL & $5 / .3,040.00$ & $100 \%$ \\
\hline Grupo Objetivo & & \multicolumn{7}{|c|}{ : $\quad H M 14-59 A B C D$} & \multirow{2}{*}{\multicolumn{3}{|c|}{ *SHAREOFINVESTMENT - PARTICIPACIONDEINVERSIÓN }} \\
\hline \multicolumn{2}{|l|}{$\begin{array}{l}\text { Grupo Uojetivo } \\
\text { Tipo }\end{array}$} & \multicolumn{7}{|c|}{ REDES SOCIALES, BANNERS, VIDEO } & & & \\
\hline \multicolumn{2}{|l|}{ Estudio de referencia } & \multicolumn{7}{|c|}{ COMSCORE 2016} & & & \\
\hline \multicolumn{2}{|l|}{ Periododedifusión } & \multicolumn{7}{|c|}{$\begin{array}{l}: \quad \text { COMSCORE } 2016 \\
: \quad 1 \text { MES }\end{array}$} & & & \\
\hline \multicolumn{12}{|c|}{ PAUTA DIGITAL - ETAPA DE MANTENIMIENTO } \\
\hline Sitio & Formato & Tipo de Compra & s/. & CTR Aprox & PERIODO SUGERIDO & Inversión Neta & $\begin{array}{l}\text { Inversión Total (SIN } \\
\text { IGV) }\end{array}$ & $\begin{array}{c}\text { Impresiones } \\
\text { Estimadas }\end{array}$ & $\begin{array}{l}\text { Clicks Estimados } \\
\text { Totales }\end{array}$ & Vistas Estimadas & sol\% \\
\hline Facebook & Post Video & CPV & S/. 0.44 & $1.00 \%$ & 4 SEMANAS & 500.00 & 500.00 & 113,636 & - & 1,136 & $16 \%$ \\
\hline Facebook & Post Ads & CPC & $5 / .0 .69$ & $1.00 \%$ & 4 SEMANAS & 690.00 & 690.00 & 100,000 & 1,000 & - & $23 \%$ \\
\hline Google Search & Text Ads & CPC & S/. 1.27 & $4.50 \%$ & 4 SEMANAS & $1,270.00$ & $1,270.00$ & 22,222 & 1,000 & - & $42 \%$ \\
\hline Google Display & Banners & CPC & S/. 0.58 & $1.00 \%$ & 4 SEMANAS & 580.00 & 580.00 & 100,000 & 1,000 & - & $19 \%$ \\
\hline \multirow{2}{*}{\multicolumn{12}{|c|}{ 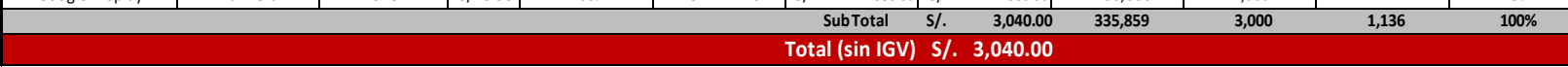 }} \\
\hline & & & & & & & & & & & \\
\hline \multicolumn{12}{|l|}{ Notas Importantes: } \\
\hline \multicolumn{12}{|l|}{ La propuesta Incluye IGV. } \\
\hline \multicolumn{12}{|l|}{ LosCTRsonestimados. } \\
\hline \multicolumn{12}{|l|}{ CPV $=$ COSTO POR VISTA } \\
\hline CPV $=$ COSTO POR CLICK & & & & & & & & & & & \\
\hline
\end{tabular}

Figura 59. Presupuesto de mantenimiento de medios digitales. Presupuesto brindado por Comscore SAC

En el caso de los medios digitales, solo se utilizaran Facebook, Google Search y Google Display. Con ello se pretenderá alcanzar 335 mil impresiones utilizando diversos métodos publicitarios disponibles con la herramienta.

Se descansan en el mes de enero, junio, noviembre y diciembre para optimizar los gastos publicitarios. Se cuenta tanto de los medios de radio como digitales la suficiente cantidad de impresiones para poder generar la demanda adecuada para la empresa. 


\begin{tabular}{|c|c|c|c|c|c|c|c|c|c|c|c|c|c|}
\hline $\begin{array}{l}\text { Cliente } \\
\text { Campaña } \\
\text { Grupo Objetivo }\end{array}$ & & \multicolumn{2}{|c|}{$\begin{array}{l}\text { :CAPACHICAADVENTURE } \\
: \quad \text { PROMOCIÓN }\end{array}$} & & & & & & & & & & \\
\hline \multirow{2}{*}{ Medio } & \multicolumn{2}{|c|}{ LANZAMIENTO } & \multicolumn{10}{|c|}{ MANTENIMIENTO } & \multirow{2}{*}{$\begin{array}{c}\text { TOTAL } \\
\text { (SIN IGV) }\end{array}$} \\
\hline & Enero & Febrero & Marzo & Abril & Mayo & Junio & Julio & Agosto & Septiembre & Octubre & Noviembre & Diciembre & \\
\hline Radio Nivel Local & & S/. 5,390 & S/. 1,520 & S/. 1,520 & S/. 1,520 & & S/. 1,520 & S/. 1,520 & S/. 1,520 & S/. 1,520 & & & S/. 16,030.00 \\
\hline Digital & & S/. 4,860 & & & & & S/. 3,040 & & & S/. 3,040 & & & S/. $10,940.00$ \\
\hline Vallas Móviles & & S/. 6,563 & & & & & & & & & & & S/. 6,562.50 \\
\hline Total General & $5 / .0$ & $S / .16,813$ & $S / .1,520$ & $5 / .1,520$ & $S / .1,520$ & $S / .0$ & $S / .4,560$ & $S / .1,520$ & $5 / 1,520$ & $S / .4,560$ & $5 / .0$ & $5 / .0$ & S/. 33,533 \\
\hline
\end{tabular}

Figura 60. Flujo anual de gastos publicitarios

Tabla 89

\begin{tabular}{lcc}
\hline $\begin{array}{l}\text { Plan de Medios Capachica Adventure } \\
\text { Medio }\end{array}$ & Inversion total Sin IGV & $\%$ \\
\hline Radio nivel local & 16,030 & $48 \%$ \\
Digital & 10,940 & $33 \%$ \\
Vallas móviles & 6,563 & $20 \%$ \\
Total general & 33,533 & $100 \%$ \\
\hline
\end{tabular}

Nota: Plan de medios Capachica Adventure

\subsection{Estrategia de Ventas}

Las ventas se realizaran de la siguiente forma:

a. Ventas personales, a través del equipo comercial se realizará la venta del servicio tanto en el local comercial, zonas aledañas y visitas personales a instituciones público y privadas.

b. Venta en eventos y ferias, se ubicará un módulo de ventas en los eventos deportivos que auspiciará la empresa. Ello permitirá captar un público especializado que gusta de deportes de aventura.

c. Ventas online, se realizarán a través de la página Web y en gran parte por las redes sociales como Facebook. Se aprovechará aplicaciones de comunicación como Whatapp para consultas en tiempo real. 
d. Ventas telefónicas, se usaran con cartera de clientes para poder dar uso a un programa de referidos donde clientes puedan en obtener un descuento especial en su próxima visita.

e. Ventas por hoteles, se tendrá convenios con los principales hoteles de la ciudad para poder dejar material publicitario en la recepción. Asimismo se otorgará un valor de venta especial al hotel para que ellos puedan discriminar el valor de venta del servicio y ganar una comisión por los referidos.

f. Venta a través de agencia de viaje, se otorgará al igual que el hotel un valor de venta especial para que generen mayores ganancias y como empresa se le garantiza una buena calidad de servicio y un soporte adecuado. Una buena imagen con agencias de viaje permitirá captar grupos de turistas durante el año. Este canal es el menos utilizado por el público objetivo solo un $4.20 \%$ de los utilizó agencias de viaje. Sin embargo, es un canal a explotar más adelante para público extranjero.

\subsubsection{Plan de ventas.}

El plan de ventas está de acuerdo a la estacionalidad del clima y fechas festivas. Los meses de febrero y julio son los de mayor afluencia por las fiestas patrias y la fiesta de la Virgen de la Candelaria. Los meses más bajos del año son junio, por el frío de invierno, y enero, porque la gente suele tener vacaciones. Los demás meses se toman como meses de afluencia media ya que, no hay una festividad que traslade grandes grupos de personas hacia la ciudad de Puno. 
Tabla 90

Plan de Ventas Anuales

\begin{tabular}{|c|c|c|c|c|c|c|c|c|c|c|c|c|c|}
\hline & Enero & Febrero & Marzo & Abril & Mayo & Junio & Julio & Agosto & Septiembre & Octubre & Noviembre & Diciembre & Total \\
\hline $\begin{array}{l}\text { Nro de pasajeros } \\
\text { atendidos }\end{array}$ & 0 & 0 & 0 & 310 & 310 & 279 & 403 & 310 & 310 & 310 & 279 & 280 & 2,791 \\
\hline \multirow[t]{2}{*}{ Estacionalidad } & BAJO & $\begin{array}{l}\text { MUY } \\
\text { ALTO }\end{array}$ & MEDIO & MEDIO & MEDIO & BAJO & ALTO & MEDIO & MEDIO & MEDIO & BAJO & BAJO & \\
\hline & $90 \%$ & $130 \%$ & $100 \%$ & $100 \%$ & $100 \%$ & $90 \%$ & $130 \%$ & $100 \%$ & $100 \%$ & $100 \%$ & $90 \%$ & $90 \%$ & \\
\hline
\end{tabular}

\subsubsection{Políticas de servicios y garantías.}

Para satisfacer las necesidades de los clientes (turistas locales y nacionales) en el servicio del circuito turístico, la empresa cuenta con personal capacitado y con experiencia en el sector de turismo es así que se han determinado las siguientes políticas:

a. Política de servicios:

1. Política de Fidelización :

Se enviará un correo de agradecimiento por elegir a la empresa, así también como correo de felicitaciones por cumpleaños a los clientes. Se tendrá que responder a la brevedad posible los comentarios positivos y negativos de nuestros clientes. Se ofrecerá promociones vigentes mediante mensajes a correos o Facebook. Mantener un trato cordial y buena relación al momento de asesorar al cliente sobre el servicio que se le brindará. Se realizarán encuestas de satisfacción personal o por medios como correo electrónico o Facebook

2. Política de ventas

Se realizará un protocolo de ventas por parte del personal encargado, dicho protocolo estará definido en los procedimientos de Atención al Cliente. Se informará al cliente sobre todos 
los detalles del circuito turístico, así como los equipos a usar en el circuito (bicicletas y motos acuáticas), rutas del circuito, horarios, servicios adicionales. El seguimiento de post venta se hará mediante una evaluación que se le hará al cliente después de haber regresado del circuito brindado.

3. Política de seguridad

El personal guía inicialmente dará las recomendaciones y cuidados que los turistas tendrán que tener durante el circuito. El personal dará instrucciones de uso de los equipos (bicicleta, rutas de caminata) en el caso de las motos acuáticas se tendrá una inducción antes de realizar este momento del recorrido. Clientes estarán obligados a usar los implementos de seguridad durante el circuito turístico. La empresa no permitirá el recorrido en las bicicletas y motos acuáticas si los turistas muestran estados de ebriedad y/o estupefacientes. El servicio del circuito turístico estará siendo acompañado durante todo el recorrido por una enfermera que de darse el caso brindará el apoyo de primero auxilio a los turistas. Asimismo se contará con dos seguros: uno de responsabilidad civil durante el trayecto y otro seguro contra todo riesgo para las motos acuática que en caso de accidentes se activarán los dos seguros para cubrir cualquier contingencia, accidente o muerte accidental.

\section{Política de pago}

Los pagos del servicio del circuito turístico se realizarán antes de iniciar el respectivo recorrido. Pagos en efectivo (moneda nacional o extranjera), sólo el vendedor estará autorizado para recibir dichos pagos. Pago con tarjetas de crédito/debito (Visa y Mastercard), previa identificación del usuario. 
5. Política de garantía

a. cancelación del circuito por factores climáticos.- Dada las circunstancias climatológicas del departamento de Puno, la empresa cancelará el circuito garantizando el cambio de día u horario para llevar acabo el circuito, esto será según disposición del turista local. Dada la situación del turista nacional la empresa realizará la devolución de lo desembolsado por el pago del circuito, siempre y cuando éste lo solicite de ser el caso se le reprogramará el día y hora del circuito.

b. Los cambios de horarios solicitados por los turistas estarán sujetos a pago de penalidades y de supeditados a esperar la disponibilidad o cupos en nuevos grupos.

c. Los cambios de horarios solicitados por los turistas estarán sujetos a pago de penalidades y de supeditados a esperar la disponibilidad o cupos en nuevos grupos.

d. Cancelación: Las cancelaciones por parte de los clientes (turistas) a dos horas de iniciar el circuito turístico la empresa no garantiza la devolución de los pagos realizados. 


\section{Capítulo VIII: Planificación Financiera.}

La planificación financiera es un proceso en virtud del cual se proyecta y se fijan las bases de las actividades financieras, con el objeto de minimizar el riesgo, aprovechar las oportunidades y los recursos.

El presente capitulo tiene por finalidad identificar todas las inversiones que se realicen para el funcionamiento del proyecto, el capital de trabajo necesario que se necesitará para funcionar, así como también mostrar el financiamiento del proyecto, el costo del accionista, el costo de oportunidad de invertir en dicho proyecto, del mismo modo se presentará los presupuesto de cada área y los resultados al final de cada año para poder medir nuestra rentabilidad y la proyección de cada año por un tiempo de cinco años, los que son estimados para dicho proyecto.

\subsection{La Inversión.}

De acuerdo con Sapag (2011), “la primera inversión que se debe calcular incluye a todos los activos físicos necesarios para asegurar el correcto funcionamiento del proyecto“* (p.125).

Para el presente proyecto, la principal inversión será destinada en la adquisición de activo fijo que son las motos acuáticas, seguido por la compra de bicicletas montañeras, así como también cámaras Go pro y complementos a las actividades del circuito turístico.

\subsubsection{Inversión pre-operativa.}

Antes que el presente proyecto comience a funcionar, se incurrirán en gastos necesarios para en funcionamiento del proyecto los cuales se detallan a continuación: 
Los activos fijos se encuentran dividido en tres partes los cuales son los activos relacionados esencialmente con el funcionamiento del negocio, los activos relacionados al mobiliario de las oficinas y el gasto operativo.

Tabla 91

Inversión de equipos para el servicio

Inversión de equipos para el servicio

\begin{tabular}{|c|c|c|c|c|}
\hline Item & cantidad & sto unitario & $\begin{array}{c}\text { costo total sin } \\
\text { IGV }\end{array}$ & $\begin{array}{c}\text { costo total } \\
\text { incluido IGV }\end{array}$ \\
\hline bicicleta montaña con suspensión delantera & 10 & 5,599 & 47,449 & 55,990 \\
\hline go pro & 8 & 1,799 & 12,197 & 14,392 \\
\hline dron & 1 & 6,599 & 5,592 & 6,599 \\
\hline equipo de seguridad & 8 & 200 & 1,356 & 1,600 \\
\hline chaleco salvavida & 8 & 299 & 2,028 & 2,393 \\
\hline guantes & 10 & 33 & 280 & 330 \\
\hline motos acuaticas Kawasaky STX-15F 2015 & 8 & 28,586 & 193,800 & 228,684 \\
\hline total & & & 262,702 & 309,988 \\
\hline
\end{tabular}

Como se observa en la tabla superior, la inversión en activo relacionado con el servicio directamente ascienden a S/.309,998 sin incluir el IGV, la inversión más relevante es la inversión hecha en las motos acuáticas, con un total de inversión de S/.228,684.00, seguidos por el requerimiento de bicicletas montañeras y las cámaras Go pro.

Las motos que se adquirirán son ocho, los cuales están destinados a realizar el servicio turístico, los precios de la motos acuáticas son en dólares transformados a soles con el tipo de cambio de Enero 2016, el cual es S/.3.306 dato obtenido de la superintendencia de banca y seguros y Afp`s (SBS) al 27/01/2017. 
Tabla 92

Concepto motos acuáticas

Concepto Motos Acuaticas

\begin{tabular}{lccccc}
\hline & Cantidad & $\begin{array}{c}\text { Costo } \\
\text { Unitario } \\
\text { Dolarés }\end{array}$ & Total USD & $\begin{array}{c}\text { Total S/. } \\
\text { (sin IGV) }\end{array}$ & $\begin{array}{c}\text { Total S/. } \\
\text { (con IGV) }\end{array}$ \\
Item & 8 & 8,500 & 68,000 & 193,800 & 228,684 \\
Kawasaky STX-15F 2015 & & & 68,000 & 193,800 & 228,684 \\
Total & & &
\end{tabular}

Para el funcionamiento de los locales que van atender al público tanto en la ciudad de Puno, como en el lugar de operaciones (Playa Capachica), se detallan a continuación en el siguiente cuadro:

Tabla 93

Inversión de mobiliario para locales

$\underline{\text { Inversion de mobiliario para locales }}$

\begin{tabular}{|c|c|c|c|c|}
\hline Item & cantidad & costo unitario & $(\sin I G V)$ & $\begin{array}{c}\text { costo total } \\
\text { (incluido IGV) }\end{array}$ \\
\hline Mueble de recepción & 2 & 300 & 508 & 600 \\
\hline Sillas de madera tornillo & 12 & 50 & 508 & 600 \\
\hline Computadora marca toshiba & 2 & 1,750 & 2,966 & 3,500 \\
\hline Juego de sillones de cuero & 1 & 1,800 & 1,525 & 1,800 \\
\hline Impresora multifuncional epson & 1 & 600 & 508 & 600 \\
\hline Escritorio de madera tornillo & 2 & 800 & 1,356 & 1,600 \\
\hline Teléfono marca Samsung & 2 & 215 & 364 & 430 \\
\hline Televisor 43" marca samsung & 1 & 1,650 & 1,398 & 1,650 \\
\hline Útiles de escritorio(papel, lapiceros) & 2 & 215 & 364 & 430 \\
\hline Total & & & 9,500 & 11,210 \\
\hline
\end{tabular}

Como se aprecia en la tabla de la parte superior, la inversión más fuerte se realiza en la compra de dos computadoras marca Toshiba con una inversión de S/. 2,966 soles sin incluir el IGV correspondiente. 
Para que empiece el funcionamiento del proyecto se requiere la compra de insumos y

pago de gastos necesarios para el inicio de la actividad los cuales se detallan en la tabla número

94, que a continuación se detalla.

Tabla 94

Detalle de gastos pre-operativos

Detalle de gastos de Pre -operativos

\begin{tabular}{|c|c|c|c|c|}
\hline Item & cantidad & costo unitario & $(\sin I G V)$ & $\begin{array}{c}\text { costo total } \\
\text { (incluido IGV) }\end{array}$ \\
\hline \multicolumn{5}{|l|}{ Constitución de empresa } \\
\hline - reserva de nombre SUNARP & 1 & 9 & 9 & 11 \\
\hline - constitución de Persona Juridica & 1 & 23 & 23 & 27 \\
\hline - licencia de funcionamiento & 1 & 279 & 279 & 329 \\
\hline - minuta y escritura pública de constitución de empresa & 1 & 800 & 800 & 944 \\
\hline Asesorias externas & & & & 0 \\
\hline - asesoria legal & 1 & 100 & 100 & 118 \\
\hline - asesoria contable & 1 & 300 & 300 & 354 \\
\hline Insumos y suministros & & & & 0 \\
\hline - productos de limpieza & 1 & 100 & 100 & 118 \\
\hline - señales de seguridad & 1 & 500 & 500 & 590 \\
\hline - impresión de boletas de venta y facturas & 1 & 300 & 300 & 354 \\
\hline Personal & & & & 0 \\
\hline - capacitacion al personal & 7 & 200 & 1,400 & 1,652 \\
\hline - uniformes & 7 & 95 & 665 & 785 \\
\hline Marketing & & & & 0 \\
\hline - banner $1.40 \times 2.00 \mathrm{~m}$ & 2 & 39 & 78 & 93 \\
\hline - pagina Web (pagina + dominio y correos) & 1 & 800 & 800 & 944 \\
\hline - folleteria (5 millares de tripticos en A4) & 1 & 500 & 500 & 590 \\
\hline - radio nivel local & 1 & 5,390 & 5,390 & 6,360 \\
\hline - campaña medios digitales & 1 & 4,860 & 4,860 & 5,735 \\
\hline - vallas móviles & 1 & 6,563 & 6,563 & 7,744 \\
\hline cascos y guantes equipos de seguridad & 22 & 400 & 8,800 & 10,384 \\
\hline uniformes termicos & 22 & 615 & 13,530 & 15,965 \\
\hline Total Gastos & & & 44,997 & 53,096 \\
\hline
\end{tabular}

Además, el proyecto incurrirá en gastos operativos mensual que son: servicios, personal, insumos y suministros, artículos de limpieza y botiquín, gastos financieros, asesorías externas, útiles de escritorio y alquiler de locales los cuales formaran nuestro capital de trabajo mensual. 
Tabla 95

Detalle de capital de trabajo mensual

Detalle de capital de trabajo mensual

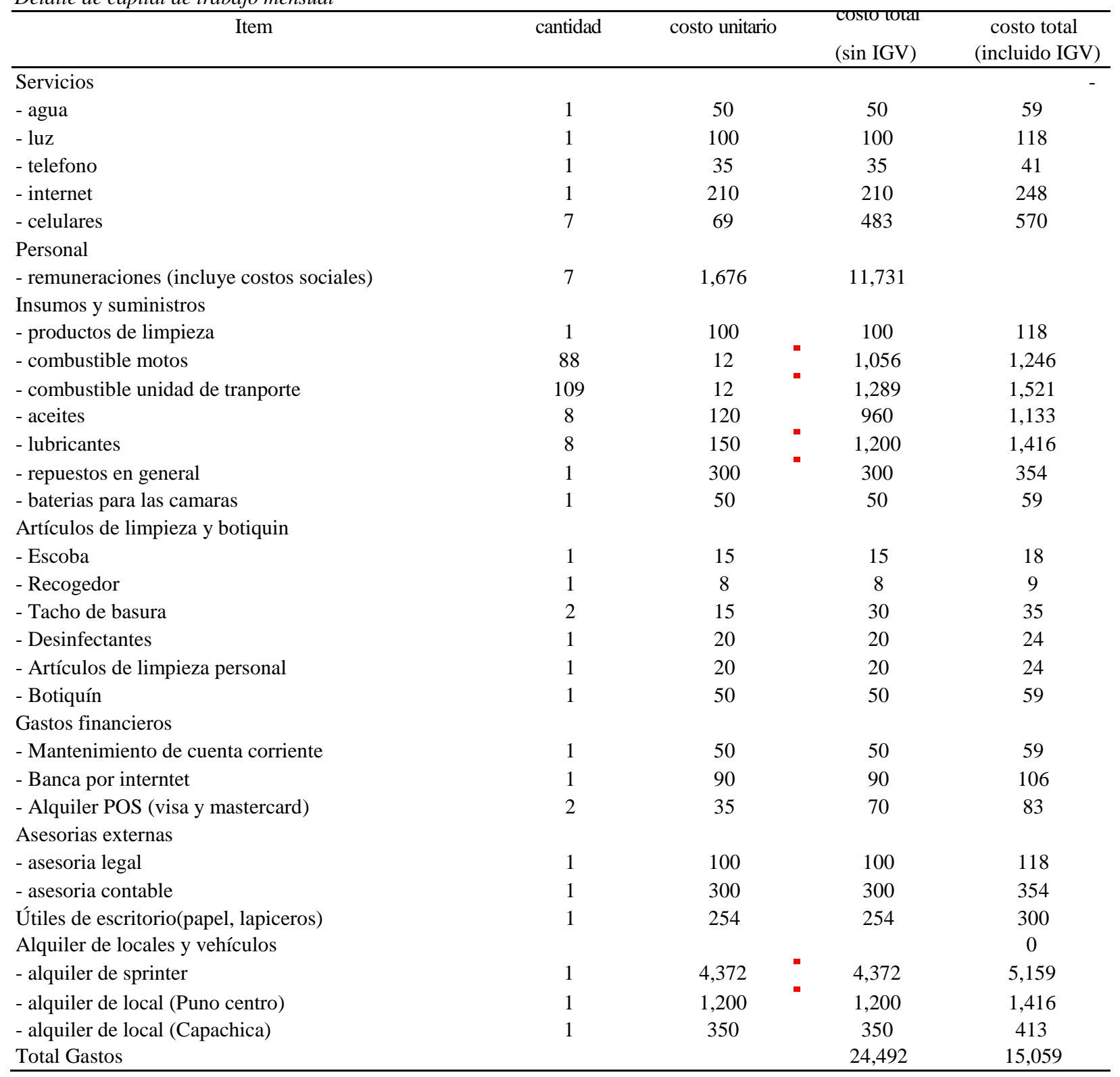

\subsubsection{Inversión en capital de trabajo.}

Para poder determinar el capital de trabajo, lo primero que se hace es hallar el flujo de caja del primer año, se realizó el cálculo mediante el método máximo déficit acumulado 
mensual, tal como se aprecia, se en la tabla 96 pudo identificar que el aporte mayor es en el mes de marzo, además que se consideró un mínimo de caja. 
Tabla 96

\section{Inversión en capital de trabajo}

Inversión en capital de trabajo

\begin{tabular}{|c|c|c|c|c|c|c|c|c|c|c|c|c|}
\hline Meses & Enero & Febrero & Marzo & Abril & Mayo & Junio & Julio & Agosto & Septiembre & Octubre & Noviembre & Diciembre \\
\hline Ingresos & 0 & 0 & 0 & 45,758 & 45,758 & 41,183 & 59,486 & 45,758 & 45,758 & 45,758 & 41,183 & 41,273 \\
\hline Total ingresos & 0 & 0 & 0 & 45,758 & 45,758 & 41,183 & 59,486 & 45,758 & 45,758 & 45,758 & 41,183 & 41,273 \\
\hline \multicolumn{13}{|l|}{ EGRESOS } \\
\hline CostodeServiciosdirectos-Manodeobra & 1,782 & 1,782 & 1,782 & 1,782 & 1,782 & 1,782 & 1,782 & 1,782 & 1,782 & 1,782 & 1,782 & 1,782 \\
\hline Costo de Servicios Indirectos - Mano de obra & 4,306 & 4,306 & 4,306 & 4,306 & 4,306 & 4,306 & 4,306 & 4,306 & 4,306 & 4,306 & 4,306 & 4,306 \\
\hline Compra Suministros y/o Insumos & 7,536 & 7,536 & 7,536 & 7,536 & 7,536 & 7,536 & 7,536 & 7,536 & 7,536 & 7,536 & 7,536 & 7,536 \\
\hline Gastos Administrativos & 5,134 & 5,134 & 5,134 & 5,134 & 5,134 & 5,134 & 5,134 & 5,134 & 5,134 & 5,134 & 5,134 & 5,134 \\
\hline Gastos ventas & 3,500 & 20,645 & 5,852 & 5,352 & 5,852 & 3,832 & 8,392 & 5,852 & 8,392 & 5,852 & 3,832 & 4,332 \\
\hline Gastos Financieros & 3,182 & 3,151 & 3,120 & 3,501 & 3,470 & 3,397 & 3,530 & 3,374 & 3,341 & 3,308 & 3,233 & 3,199 \\
\hline TOTALEGRESOS & 25,441 & 42,555 & 27,732 & 27,612 & 28,081 & 25,988 & 30,681 & 27,985 & 30,492 & 27,919 & 25,824 & 26,290 \\
\hline Saldo del mes & $-25,441$ & $-42,555$ & $-27,732$ & 18,146 & 17,677 & 15,194 & 28,805 & 17,774 & 15,266 & 17,840 & 15,358 & 14,982 \\
\hline Saldo Acumulado & $-25,441$ & $-67,996$ & $-95,727$ & $-77,581$ & $-59,904$ & $-44,709$ & $-15,904$ & 1,869 & 17,136 & 34,975 & 50,334 & 65,316 \\
\hline
\end{tabular}




\subsubsection{Costo del proyecto.}

El costo total del presente negocio está compuesto por el activo fijo y el capital de trabajo, tal como se muestra en la tabla de abajo.

Tabla 97

Inversión total equipo y mobiliario

Inversión total equipo y mobiliario

\begin{tabular}{lc}
\hline Item & costo total \\
\hline Equipamiento & 262,702 \\
Mobiliario & 9,500 \\
Gastos pre operativos & 44,997 \\
Inversión capital de trabajo & 95,727 \\
total costo de inversión del proyecto & 412,926 \\
\hline
\end{tabular}

\subsubsection{Inversiones futuras.}

En el periodo de funcionamiento de nuestro negocio, se prevé que no se va a realizar inversiones futuras durante los primeros cinco años, se considera que con la inversión inicial se alcanzará todos los objetivos planteados en el proyecto.

\subsection{Financiamiento.}

\subsubsection{Endeudamiento y condiciones.}

Según Sapag (2011), “Al incurrir a un préstamo bancario para financiar el proyecto, la empresa debe de asumir el costo financiero que está asociado a todo proceso de otorgamiento de créditos, el cual tiene un efecto negativo sobre las utilidades“" (p.257).

Conociendo el concepto de endeudamiento se tomó la decisión de financiar una parte del total activo con aporte propio el cual corresponde a (70.43\%), el cual nos da la cifra de 
S/.290,832 dicho monto dividido en partes iguales entre los cuatro socios nos da un monto de S/.72,708, el cual cada socio de la empresa tendrá que aportar.

Por otra parte se financiera el monto de S/.174, 420 lo cual comprende compra de activo fijos, inversión de equipos para servicios y otros activos, según las políticas del banco solo se financia el $70 \%$ del préstamo que corresponde a 122,094 y que corresponde a $(29.57 \%)$ del total de la inversión de nuestro proyecto, para lo cual los activos fijos a financiar serán objeto de un contrato de activo fijo entre el banco y la empresa. Lo cual indica que el banco va tener la posesión de los activos en garantía hasta el fin del contrato, el banco solo está financiando motos acuáticas, que son activos fijos aceptantes por la entidad financiera consultada.

Tabla 98

Estructura de financiamiento

\begin{tabular}{lcc}
\hline Estructura de Financiamiento & & \\
\hline Estructura de Financiamiento & Monto (S/) & Porcentaje \\
\hline Aporte Accionistas & 290,832 & $70.43 \%$ \\
Inversión de equipos para servicios & & \\
$\quad$ Equipos diversos & 3,663 & \\
$\quad$ Inicial (bicicletas montaña, cámaras y motos acuaticos) & 25,904 & \\
Inversión mobiliario para locales & 9,500 & \\
Gastos Pre-operativos & 44,997 & \\
Inversión capital de trabajo & 95,727 & \\
bicicleta montafia con suspensión delantera & 42,704 & \\
cámaras go pro & 10,977 & \\
dron & 5,033 & \\
motos acuaticas Seadoo Gti 90 HP & 174,420 & \\
Prestamo Bancario & 122,094 & \\
inicial de préstamo & 52,326 & \\
Total & 412,926 & \\
\hline
\end{tabular}


Después de haber decidido el monto al cual se va financiar y habiendo evaluado varias alternativas de financiamiento con distintos bancos y financieras y también de acuerdo al tamaño de nuestra empresa se ha decidido financiar el préstamo con el banco BBVA Continental mediante un préstamo comercial, lo que se va financiar es parte del activo total sin incluir el capital de trabajo, dicho monto a financiar es en activo fijo, cumpliendo las políticas del banco en función a créditos y aportando un 30\% de inicial reduciendo el riesgo del banco y mediante un contrato de hipoteca por los activos financiados.

Tabla 99

Simulador préstamo a financiar

\begin{tabular}{lc}
\hline Simulador préstamo a financiar & \\
\hline Entidad & BBVA Continental \\
Monto inicial & $174,420.00$ soles \\
inicial $30 \%$ & $52,326.00$ \\
Monto solicitado & $122,094.00$ \\
Plazo de crédito & 60 meses \\
Tasa de interés & $14 \%$ TEA \\
\hline
\end{tabular}

Como se puede apreciar en la tabla de la parte superior se va a financiar el préstamo a 60 meses con una tasa de costo efectiva de 14\%, a continuación se muestra el cronograma de pagos para los próximos cinco años. 


\section{Tabla 100}

\section{Simulador de cronograma de pagos}

\begin{tabular}{|c|c|c|c|c|c|}
\hline S̈imulador cuotas & & & & & \\
\hline Nro & Saldo inicial & Interés & Capital & Cuota & Saldo final \\
\hline 1 & $122,094.00$ & $1,340.45$ & $1,448.49$ & $2,788.94$ & $120,645.51$ \\
\hline 2 & $120,645.51$ & $1,324.55$ & $1,464.39$ & $2,788.94$ & $119,181.12$ \\
\hline 3 & $119,181.12$ & $1,308.47$ & $1,480.47$ & $2,788.94$ & $117,700.65$ \\
\hline 4 & $117,700.65$ & $1,292.22$ & $1,496.72$ & $2,788.94$ & $116,203.93$ \\
\hline 5 & $116,203.93$ & $1,275.79$ & $1,513.15$ & $2,788.94$ & $114,690.78$ \\
\hline 6 & $114,690.78$ & $1,259.17$ & $1,529.77$ & $2,788.94$ & $113,161.01$ \\
\hline 7 & $113,161.01$ & $1,242.38$ & $1,546.56$ & $2,788.94$ & $111,614.45$ \\
\hline 8 & $111,614.45$ & $1,225.40$ & $1,563.54$ & $2,788.94$ & $110,050.91$ \\
\hline 9 & $110,050.91$ & $1,208.23$ & $1,580.71$ & $2,788.94$ & $108,470.20$ \\
\hline 10 & $108,470.20$ & $1,190.88$ & $1,598.06$ & $2,788.94$ & $106,872.14$ \\
\hline 11 & $106,872.14$ & $1,173.33$ & $1,615.61$ & $2,788.94$ & $105,256.53$ \\
\hline 12 & $105,256.53$ & $1,155.60$ & $1,633.34$ & $2,788.94$ & $103,623.19$ \\
\hline 13 & $103,623.19$ & $1,137.66$ & $1,651.28$ & $2,788.94$ & $101,971.91$ \\
\hline 14 & $101,971.91$ & $1,119.53$ & $1,669.41$ & $2,788.94$ & $100,302.50$ \\
\hline 15 & $100,302.50$ & $1,101.21$ & $1,687.73$ & $2,788.94$ & $98,614.77$ \\
\hline 16 & $98,614.77$ & $1,082.68$ & $1,706.26$ & $2,788.94$ & $96,908.51$ \\
\hline 17 & $96,908.51$ & $1,063.94$ & $1,725.00$ & $2,788.94$ & $95,183.51$ \\
\hline 18 & $95,183.51$ & $1,045.01$ & $1,743.93$ & $2,788.94$ & $93,439.58$ \\
\hline 19 & $93,439.58$ & $1,025.86$ & $1,763.08$ & $2,788.94$ & $91,676.50$ \\
\hline 20 & $91,676.50$ & $1,006.50$ & $1,782.44$ & $2,788.94$ & $89,894.06$ \\
\hline 21 & $89,894.06$ & 986.93 & $1,802.01$ & $2,788.94$ & $88,092.05$ \\
\hline 22 & 88.092 .05 & 967.15 & 1.821 .79 & 2.788 .94 & 86.270 .26 \\
\hline 23 & $86,270.26$ & 947.15 & $1,841.79$ & $2,788.94$ & $84,428.47$ \\
\hline 24 & $84,428.47$ & 926.93 & $1,862.01$ & $2,788.94$ & $82,566.46$ \\
\hline 25 & 82.566 .46 & 906.48 & 1.882 .46 & 2.788 .94 & $80,684.00$ \\
\hline 26 & $80,684.00$ & 885.82 & $1,903.12$ & $2,788.94$ & $78,780.88$ \\
\hline 27 & $78,780.88$ & 864.92 & $1,924.02$ & $2,788.94$ & $76,856.87$ \\
\hline 28 & $76,856.87$ & 843.80 & $1,945.14$ & $2,788.94$ & $74,911.73$ \\
\hline 29 & $74,911.73$ & 822.44 & $1,966.50$ & $2,788.94$ & $72,945.23$ \\
\hline 30 & 72.945 .23 & 800.85 & 1.988 .09 & 2.788 .94 & 70.957 .15 \\
\hline 31 & $70,957.15$ & 779.03 & $2,009.91$ & $2,788.94$ & $68,947.23$ \\
\hline 32 & $68,947.23$ & 756.96 & $2,031.98$ & $2,788.94$ & $66,915.26$ \\
\hline 33 & $66,915.26$ & 734.65 & $2,054.29$ & $2,788.94$ & $64,860.97$ \\
\hline 34 & $64,860.97$ & 712.10 & $2,076.84$ & $2,788.94$ & $62,784.13$ \\
\hline 35 & 62.784 .13 & 689.30 & 2.099 .64 & 2.788 .94 & 60.684 .48 \\
\hline 36 & $60,684.48$ & 666.25 & $2,122.69$ & $2,788.94$ & $58,561.79$ \\
\hline 37 & $58,561.79$ & 642.94 & $2,146.00$ & $2,788.94$ & $56,415.79$ \\
\hline 38 & 56.415 .79 & 619.38 & 2.169 .56 & 2.788 .94 & 54.246 .23 \\
\hline 39 & $54,246.23$ & 595.56 & $2,193.38$ & $2,788.94$ & $52,052.85$ \\
\hline 40 & $52,052.85$ & 571.48 & $2,217.46$ & $2,788.94$ & $49,835.39$ \\
\hline 41 & $49,835.39$ & 547.14 & $2,241.80$ & $2,788.94$ & $47,593.59$ \\
\hline 42 & $47,593.59$ & 522.52 & $2,266.42$ & $2,788.94$ & $45,327.17$ \\
\hline 43 & 45.327 .17 & 497.64 & 2.291 .30 & 2.788 .94 & 43.035 .87 \\
\hline 44 & $43,035.87$ & 472.48 & $2,316.46$ & $2,788.94$ & $40,719.42$ \\
\hline 45 & $40,719.42$ & 447.05 & $2,341.89$ & $2,788.94$ & $38,377.53$ \\
\hline 46 & $38,377.53$ & 421.34 & $2,367.60$ & $2,788.94$ & $36,009.93$ \\
\hline 47 & $36,009.93$ & 395.35 & $2,393.59$ & $2,788.94$ & $33,616.34$ \\
\hline 48 & 33.616 .34 & 369.07 & 2.419 .87 & 2.788 .94 & 31.196 .47 \\
\hline 49 & $31,196.47$ & 342.50 & $2,446.44$ & $2,788.94$ & $28,750.03$ \\
\hline 50 & $28,750.03$ & 315.64 & $2,473.30$ & $2,788.94$ & $26,276.73$ \\
\hline 51 & 26.276 .73 & 288.49 & 2.500 .45 & 2.788 .94 & 23.776 .28 \\
\hline 52 & $23,776.28$ & 261.04 & $2,527.90$ & $2,788.94$ & $21,248.38$ \\
\hline 53 & $21,248.38$ & 233.28 & $2,555.66$ & $2,788.94$ & $18,692.72$ \\
\hline 54 & $18,692.72$ & 205.22 & $2,583.72$ & $2,788.94$ & $16,109.00$ \\
\hline 55 & $16,109.00$ & 176.86 & $2,612.08$ & $2,788.94$ & $13,496.92$ \\
\hline 56 & 13.496 .92 & 148.18 & 2.640 .76 & 2.788 .94 & 10.856 .16 \\
\hline 57 & $10,856.16$ & 119.19 & $2,669.75$ & $2,788.94$ & $8,186.41$ \\
\hline 58 & $8,186.41$ & 89.88 & $2,699.06$ & $2,788.94$ & $5,487.35$ \\
\hline 59 & $5,487.35$ & 60.24 & $2,728.70$ & $2,788.94$ & $2,758.65$ \\
\hline 60 & $2,758.65$ & 30.29 & $2,758.65$ & $2,788.94$ & 0.00 \\
\hline
\end{tabular}




\subsubsection{Capital y costo de oportunidad.}

De acuerdo con Sapag (2011), "el costo de oportunidad es la rentabilidad que obtendría el inversionista en otras inversiones posibles que dejaría de hacer para destinarlas al proyecto“ (p.372).

El presente proyecto de servicio turístico de aventura en la ciudad de Puno, debe ser sostenido y rentable en el tiempo, por tal motivo se puede medir mediante el COK (costo de oportunidad).

De acuerdo a lo estudiado en clases y en libros, el mejor modelo para determinar el costo de oportunidad de una inversión es el CAPM (Capital Asset Princing Model), el cual traducido al castellano es el modelo de valoración de activos.

Según Sapag (2011), "La rentabilidad esperada para la empresa se puede calcular mediante el modelo para la valoración de los activos de capital (CAPM), que señala que la tasa exigida de rentabilidad es igual a la tasa libre de riesgo más un prima por riesgo “ (p.373).

$$
\mathrm{Ku}=\mathrm{Rf}+\beta \mathrm{u}(\mathrm{Rm}-\mathrm{Rf})
$$

Para la inversión libre de riesgo (Rf), se ha utilizado el bono americano, el cual se puede observar en la siguiente tabla:

Tabla 101

Rendimiento histórico bonos EEUU

Rendimiento histórico Bonos EEUU

\begin{tabular}{lrrr}
\hline Arithmetic Average & \multicolumn{1}{c}{ Stocks } & Stocks - T.Bill & ocks - T.Bon \\
\hline $1928-2016$ & $11.42 \%$ & $3.46 \%$ & $5.18 \%$ \\
$1967-2016$ & $11.45 \%$ & $4.88 \%$ & $7.08 \%$ \\
$2007-2016$ & $8.65 \%$ & $0.74 \%$ & $5.03 \%$ \\
\hline
\end{tabular}

Nota: Adaptado de Damodaran Online (2017) 
Según Sapag (2011), “El riesgo asociado con una inversión se define por su beta $(\beta)$, el cual corresponde al factor que representa en cuanto afectan las fluctuaciones observadas en la rentabilidad de todo el mercado a la rentabilidad de una empresa similar a la del proyecto. En otras palabras, el coeficiente beta es el factor de medida de riesgo sistemático de invertir en la industria“" (p.373).

En cuanto al beta, se consultó a la página de Damodaran en línea, se buscó un beta del sector, en el presente proyecto el beta del sector se ha ubicado en recreación, tal como se puede apreciar en la tabla inferior.

Tabla 102

Beta del sector

Beta del sector

\begin{tabular}{lccccc}
\hline Sector & No de firmas & Beta & DER Ratio & Tax rate & $\begin{array}{c}\text { Unlevered } \\
\text { Beta }\end{array}$ \\
\hline Recreation & 66 & 0.92 & $31.12 \%$ & $13.21 \%$ & 0.73 \\
\hline
\end{tabular}

Nota: Adaptado de Damodaran Online (2017)

Del mismo modo se han hallado los datos de riesgo país Perú, también se considera que los riesgos de los países más desarrollados no son iguales a los de los países emergentes, por tal motivo es necesario realizar un ajuste adicional por el mayor riesgo de invertir en un país emergente, la forma más adecuada es aumentar el riesgo país como se puede ver en la siguiente formula.

$$
K u=R f+\beta u(R m-R f)+R p
$$

A continuación se muestran los resutados obtenidos: 
Tabla 103

Tasa de descuento del accionista

\begin{tabular}{lr}
\hline Tasa de Descuento del proyecto & \\
\hline Datos & Valores \\
Beta Sector EEUU (Recreation) & 0.92 \\
Beta Proyecto = Bu (desapalancado) & 0.73 \\
Beta Apalancado & 1.68 \\
Rf (tasa de libre riesgo) & $5.03 \%$ \\
Rm (rentabilidad esperada del mercado) & $8.45 \%$ \\
Riesgo Pais Perú (Moody's Rating - A3) & $1.66 \%$ \\
Tasa Descuento Accionista (Re) & $20.90 \%$ \\
\hline
\end{tabular}

La rentabilidad esperada del mercado es de $8.45 \%$ lo cual se da con el índice de rentabilidad de las empresas del sector y la teoría se comprueba con el libro finanzas corporativas, person 2008.

La tasa de descuento se ajusta a la inflación esperada para los siguiente años, el cual estaría en 2.7\% al 2019. Se toma esta referencia para ajuste de inflación del COK.

\begin{tabular}{|c|c|c|c|c|c|c|c|c|}
\hline \multicolumn{9}{|c|}{ RESUMEN DE LAS PROYECCIONES } \\
\hline & & \multirow{2}{*}{2015} & \multirow{2}{*}{2016} & \multicolumn{2}{|c|}{$2017^{*}$} & \multicolumn{2}{|c|}{2018} & \multirow{2}{*}{$\frac{2015^{\prime \prime}}{\text { RI Set.17 }}$} \\
\hline & & & & Fi Jun.17 & Risat17 & Ri Jun.17 & Fisot 17 & \\
\hline \multicolumn{9}{|c|}{ Var, $\%$ real } \\
\hline 1. & Producto bristo interne & 3,3 & 4,0 & 2,8 & 2,8 & 4,2 & 4,2 & 4,2 \\
\hline 2. & Dernarda interna & 2,9 & 1,0 & 1,9 & 2,3 & 4,0 & 4,2 & 4,2 \\
\hline & ョ. Corsumo prinado & 3,4 & 3.4 & 2,5 & 2,6 & 3,0 & 3.3 & 3,8 \\
\hline & b. Consumo püblico & 9,8 & $-0,5$ & 2,3 & 2,3 & 3,0 & 3,6 & 2,0 \\
\hline & c. Inversón privada fija & $-4,3$ & $-5,9$ & $-1,8$ & $-1,0$ & 5,3 & 5,3 & 7,5 \\
\hline & d. Inversion pública & $-9,5$ & 0,6 & 7,0 & 7,0 & 15,0 & 15.0 & 4,0 \\
\hline 3. & Exportaciones de tienes y senvicios & 4,0 & 9,5 & 5,9 & 5,0 & 4.4 & 3.8 & 4,4 \\
\hline 4. & Impcriaciones de tiener y servitios & 2,4 & $-2,2$ & 2,9 & 3,3 & 3.5 & 4,1 & 4.6 \\
\hline 5. & Crecimiento de nuestros socios comeroales & 3,2 & 2,8 & 3,2 & 3,3 & 3,3 & 3,3 & 3,2 \\
\hline \multicolumn{9}{|c|}{ Nota: } \\
\hline & echa del producto" (\%) & $-1,0 ; 0,0$ & $-1,0,0,1$ & $-1,7,0,0$ & $-1,5 ;-0,5$ & $-1,2,0,0$ & $-1,0 ; 0,0$ & $-0,5,0,0$ \\
\hline \multicolumn{9}{|c|}{ Var. $\%$} \\
\hline 6. & Inflaciton & 4,4 & 3,2 & $2,0.2,5$ & $2,0-2,5$ & $2,0-2,2$ & 2,0 & 2,0 \\
\hline 7: & Inflacićn esperaday" & - & $\therefore$ & 3,0 & 2,8 & 2,8 & 2,7 & 2,7 \\
\hline 8. & Depreciación esperads" & - & 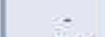 & $-2,7$ & $-2,5$ & 1.5 & 1,6 & 1,3 \\
\hline \multirow[t]{3}{*}{ 9. } & Términos de intercamaibu" & $-6,4$ & $-0,7$ & 5,5 & 7,0 & 0,0 & 2,0 & 0,0 \\
\hline & a. Precios de exportación & $-15,0$ & $-3,6$ & 10,2 & 12,0 & 0,6 & 2,2 & 1,0 \\
\hline & b. Precias de importadion & $-9,2$ & $-3,0$ & 4,5 & 4,7 & 0,6 & 0,1 & 1,0 \\
\hline
\end{tabular}


Figura 61. Proyección reporte de inflación setiembre 2017. Tomado de http://www.bcrp.gob.pe/docs/Publicaciones/Reporte-Inflacion/2017/setiembre/reporte-deinflacion-setiembre-2017.pdf

Tabla 104

Tasa de descuento del accionista ajustado

\begin{tabular}{lr}
\hline Tasa de Descuento del proyecto & \\
\hline Datos & Valores \\
Beta Sector EEUU (Recreation) & 0.92 \\
Beta Proyecto = Bu (desapalancado) & 0.73 \\
Beta Apalancado & 1.68 \\
Rf (tasa de libre riesgo) & $5.03 \%$ \\
Rm (rentabilidad esperada del mercado) & $8.45 \%$ \\
Riesgo Pais Perú (Moody's Rating - A3) & $1.66 \%$ \\
Tasa Descuento Accionista ( $\mathrm{Ke})$ & $20.90 \%$ \\
Inflación Esperada 2017- 2019 & $2.70 \%$ \\
Ke Real & $24.72 \%$ \\
\hline
\end{tabular}

Se realiza el ajuste de la inflación mediante la fórmula

$$
C O K_{\gamma}=\frac{1+C O K_{n}}{1+\pi}-1
$$

Además se realiza el tipo de cambio para tener datos más exactos así como también se le suma 7 puntos adicionales por ser un proyecto nuevo y tiene un riesgo inherente el cual no se puede reducir.

\subsubsection{Costo de capital promedio ponderado.}

El costo de capital promedio ponderado (WACC) es la combinación del costo de oportunidad (COK) y se le agrega el costo de la deuda del proyecto, en caso de que el proyecto 
no tuviera financiamiento solo se tendría que hallar el (COK), el actual proyecto si cuenta con financiamiento a lo que se procederá hallar el (WACC):

\section{WACC=Ke $E(E+D)+\operatorname{Kd}(1-\mathrm{T}) \mathrm{D}(\mathrm{E}+\mathrm{D})$}

A continuación se calcula la fórmula del (WACC):

Tabla 105

Tasa de descuento del proyecto

Tasa de Descuento del proyecto

Datos

Valores

Beta Sector EEUU (Recreation)

0.92

Beta Proyecto $=\mathrm{Bu}$ (desapalancado)

0.73

Beta Apalancado

1.22

Rf (tasa de libre riesgo)

$5.03 \%$

Rm (rentabilidad esperada del mercado)

$6.42 \%$

Riesgo Pais Perú (Moody's Rating - A3)

$1.66 \%$

Tasa Descuento Accionista ( $\mathrm{Ke})$

$14.53 \%$

Inflación Esperada 2017- 2019

$2.70 \%$

Inflacción peru eeuu

$2.80 \%$

Ke Real

$11.41 \%$

E

0.70

D

0.30

D/E

0.42

$\mathrm{T}$ (Impuesto Renta)

0.28

$\mathrm{Kd}$ (Tasa bancos)

$14.00 \%$

WACC

$11.01 \%$

Nota: Adaptado de Damodaran Online (2017). 
Como se puede apreciar en el cuadro de la parte superior tenemos el beta desapalancado el cual se ha hallado de la página de Damodaran online para después hallar el beta apalancado el cual se incluye la estructura de deuda más la tasa impositiva de Perú .

\subsection{Presupuestos Base.}

La formulación y evaluación de los siguientes presupuestos que se mostraran a continuación están sustentados y soportados por el análisis y evaluación de los capítulos anteriores, respecto a definiciones de valor de venta, como los sustentos de los presupuestos de ventas, del costo de ventas, los gastos administrativos como también de los gastos de ventas y marketing

\subsubsection{Presupuesto de ventas.}

El servicio de turismo de aventura genera ingresos por la misma prestación de los servicios, el precio de venta estimado para el servicio es de $\mathrm{S} / .201$ soles por persona, el precio de venta al cual se halló, en el capítulo tres mediante un estudio de mercado que arrojo el precio de venta estimado el cual cubre un circuito que permite la utilización de las motos montañeras, el tracking y el servicio de las motos acuáticas, no se está considerando el IGV, según pronósticos y estimaciones se cree por conveniente sensibilizar el proyecto los tres primeros meses, considerando como cero el total de ventas en estos primeros meses, como se muestra a continuación en la tabla 106. 
Tabla 106

Presupuesto de ventas - primer año

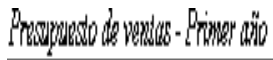

\begin{tabular}{|c|c|c|c|c|c|c|c|c|c|c|c|c|}
\hline & Enese & Teterero & Maraz) & abd & Mayo & Junio & Who & Segosto Seppenture & Octalye & Noveredere & Dinembere & Total \\
\hline 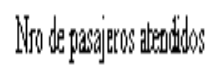 & 0 & 0 & 0 & 310 & 310 & 279 & 413 & 310 & 30 & 279 & 279 & 2,90 \\
\hline Walo deredta & 21 & W1 & $\mathbb{2 1}$ & 201 & 201 & 201 & 201 & 201 & 201 & 201 & 201 & \\
\hline Total Yedures & 1 & 1 & 1 & 62,303 & 62,3103 & 56,013 & 80,99 & $0,3,03 \quad 60,303$ & $62,0,3$ & 56,073 & $56,1,13$ & 50,731 \\
\hline
\end{tabular}

Tomando como base el mercado objetivo y el pronóstico de ventas, se muestra el presupuesto de ingresos del primer año y la proyección hasta el quinto año, se estima un crecimiento promedio de $4 \%$ para los siguientes años:

Tabla 107

Presupuesto de ventas anual

\section{Presupuesto de ventas Anual}

\begin{tabular}{lccccc}
\hline Afio & 1 & 2 & 3 & 4 & 5 \\
\hline Nro de pasajeros atendidos & 2,036 & 2,168 & 2,309 & 2,458 & 2,617 \\
Valor de venta & 201 & 201 & 201 & 201 & 201 \\
Tasa de Crecimiento & & $6.48 \%$ & $6.48 \%$ & $6.48 \%$ & $6.48 \%$ \\
Total Ventas & 409,299 & 435,801 & 464,019 & 494,064 & 526,055 \\
\hline
\end{tabular}

\subsubsection{Presupuesto de costos de producción.}

Siendo el presente proyecto, una empresa de servicio no se incurre en costos de producción, por el motivo que no producimos ningún bien y el mayor costo de operación son los trabajadores con los que cuenta la empresa.

\subsubsection{Presupuesto de compras.}

Las compras están compuesta por artículos consumibles y considerados en los gastos directos e indirectos para la prestación del servicio, como se detalla en el cuadro la frecuencia de 
compra varia en compras mensuales y trimestrales, las cantidades y los valores considerados en las compras se han estimado de acuerdo a cotizaciones y opinión de personas conocedoras en el sector.

Tabla 108

Presupuesto de compras de Suministros y/oInsumos

\begin{tabular}{|c|c|c|c|c|c|}
\hline Detalle & $\begin{array}{c}\text { importe } \\
\text { total } \\
\text { soles }\end{array}$ & $\begin{array}{c}\text { clasificació } \\
\text { del } \\
\text { gasto }\end{array}$ & $\begin{array}{l}\text { frecuencia } \\
\text { de } \\
\text { compra }\end{array}$ & $\begin{array}{c}\text { gasto } \\
\text { total } \\
\text { mensual }\end{array}$ & $\begin{array}{c}\text { gasto } \\
\text { total } \\
\text { anual }\end{array}$ \\
\hline - productos de limpieza & 100 & fijo & mensual & 100 & 1,200 \\
\hline - combustible motos & 1,056 & variable & mensual & 1,056 & 12,672 \\
\hline - combustible unidad de tran & 1,289 & fijo & mensual & 1,289 & 15,463 \\
\hline - aceites & 960 & variable & trimestral & 320 & 3,840 \\
\hline - lubricantes & 150 & variable & trimestral & 50 & 600 \\
\hline - repuestos en general & 300 & fijo & mensual & 300 & 3,600 \\
\hline - baterias para las camaras & 50 & fijo & mensual & 50 & 600 \\
\hline \multirow{2}{*}{$\begin{array}{l}\text {-alquiler de las sprinters } \\
\text { total }\end{array}$} & 4,372 & fijo & mensual & 4,372 & 52,463 \\
\hline & & & & 7,536 & 90,438 \\
\hline
\end{tabular}

Presupuesto de compras suministros y/o insumos

\subsubsection{Presupuesto de costo de ventas.}

El presente proyecto es una empresa de servicio, por tal motivo los cálculos de costo de ventas no pueden ser igual a una empresa de producción por tal motivo se ha optado por otra metodología en la cual el costo de ventas se ha dividido en tres partes:

a) Servicios directos. Consideramos todos los servicios que están directamente en nuestro costo, para el proyecto que se desarrolla se cree conveniente que el costo directo son los trabajadores que están directamente en la parte operativa del negocio, tal como se puede apreciar la tabla de abajo, la cual se ha divido en dos para una mejor apreciación. 
Tabla 109

Costo de servicios directos - Mano de obra

Costo de Servicios directos - Mano de obra

\begin{tabular}{|c|c|c|c|c|c|c|c|c|c|c|c|c|c|}
\hline & Remuneraci & enero & febrero & marzo & abril & mayo & junio & julio & \multicolumn{5}{|c|}{ agosto septiembre octubre noviembre diciembre } \\
\hline Guía & 1,782 & 1,782 & 1,782 & 1,782 & 1,782 & 1,782 & 1,782 & 1,782 & 1,782 & 1,782 & 1,782 & 1,782 & 1,782 \\
\hline Depreciación de equipos financiados & & 3,886 & 3,88 & 3,886 & 3,88 & 3,886 & 3,886 & 3,886 & 3,886 & 3,886 & 3,886 & 3,886 & 3,886 \\
\hline Depr & & 55 & 55 & 55 & 55 & 5 & 55 & 0 & 5 & 55 & 55 & 55 & 55 \\
\hline Total Costo de servicios directos & & 5,722 & 5,722 & 5,722 & 5,722 & 5,722 & 5,722 & 5,722 & 5,722 & 5,722 & 5,722 & 5,722 & 5,722 \\
\hline
\end{tabular}

Según los datos obtenidos se ha realizado la proyección por un periodo de cinco años, teniendo como una constante el pago del guía, sin ningún incremento por año debido a que es un costo fijo, el cual se va a pagar así todos los meses y años, a continuación se muestra en la siguiente tabla la proyección para cinco años.

Tabla 110

Costo de servicios directos - Mano de obra por año

Costo de Servicios directos - Mano de obra por año

\begin{tabular}{lccccc}
\hline \multicolumn{1}{c}{ detalle / año } & 1 & 2 & 3 & 4 & 5 \\
\hline Guía & 21,383 & 21,597 & 21,813 & 22,031 & 22,251 \\
Depreciación de equipos financiados & 46,627 & 46,627 & 46,627 & 46,627 & 46,627 \\
Depreciación demas equipos & 659 & 659 & 659 & 659 & 659 \\
Total costo de servicios directos & 68,669 & 68,883 & 69,099 & 69,317 & 69,538 \\
\hline
\end{tabular}

b) Servicios Indirectos. Se considera en los servicios indirectos todos los costos en los cuales participan trabajadores para que continúe el funcionamiento del negocio, pero que no están involucrados en área operativa, como se detalla a continuación: 


\section{Tabla 111}

Costo de servicios indirectos - Mano de obra

Costo de Servicios Indirectos - Mano de obra

\begin{tabular}{|c|c|c|c|c|c|c|c|c|c|c|c|c|c|}
\hline \multirow{2}{*}{$\frac{\text { Detalle }}{\text { Mantenimiento }}$} & \multirow{2}{*}{$\begin{array}{r}\begin{array}{r}\text { Remuneraci } \\
\text { on Costo }\end{array} \\
1,485\end{array}$} & \multirow{2}{*}{$\begin{array}{c}\text { enero } \\
1,485\end{array}$} & \multirow{2}{*}{$\begin{array}{l}\text { febrero } \\
1,485\end{array}$} & \multirow{2}{*}{$\frac{\text { marzo }}{1,485}$} & \multirow{2}{*}{$\frac{\text { abril }}{1,485}$} & \multirow{2}{*}{$\begin{array}{r}\text { mayo } \\
1,485\end{array}$} & \multirow{2}{*}{$\begin{array}{l}\text { junio } \\
1,485\end{array}$} & \multirow{2}{*}{$\frac{\text { julio }}{1,485}$} & \multicolumn{5}{|c|}{ agosto septiembre octubre noviembre diciembre } \\
\hline & & & & & & & & & & & 1,485 & 14 & 1,485 \\
\hline Chofer & 1,485 & 1,485 & 1,485 & 1,485 & 1185 & 1185 & 140 & 1485 & & & 1,4 & 1 , & 1,485 \\
\hline Enferme & 1,336 & 1,336 & 1,336 & 1,336 & 1,33 & 1,3 & 3 & 1,3 & 1,3 & 1,3 & 1,336 & 1,3 & 36 \\
\hline Total costo de servicio indirecto & & 4,306 & 4,306 & 4,306 & 4,306 & 4,306 & 4,306 & 4,306 & 4,306 & 4,306 & 4,306 & 4,306 & 4,306 \\
\hline
\end{tabular}

También se detalla los costos de servicios indirectos, la proyección por cinco años manteniendo fijo los costos sin ningún crecimiento por el motivo que son costos fijos.

Tabla 112

Costo de servicios indirectos - Mano de obra por año

Costo de Servicios indirectos - Mano de obra por año

\begin{tabular}{cccccc}
\hline detalle / año & 1 & 2 & 3 & 4 & 5 \\
\hline Total costo de servicios indirectos & 51,676 & 52,192 & 52,714 & 53,241 & 54,306 \\
\hline
\end{tabular}

c) Suministros consumibles. En este puesto se considera todos los suministros que necesita el proyecto para su financiamiento, como son: gasolina para las motos acuáticas, como también para la movilidad, se detalla todos los suministros en el siguiente cuadro y los gastos mensuales que generan. 
Tabla 113

Presupuesto de compras de suministros y/o Insumos

Presupuesto de compras de Suministros y/o Insumos

\begin{tabular}{|c|c|c|c|c|c|}
\hline Detalle & $\begin{array}{c}\text { importe } \\
\text { total } \\
\text { soles }\end{array}$ & $\begin{array}{c}\text { clasificación } \\
\text { del } \\
\text { gasto }\end{array}$ & $\begin{array}{l}\text { frecuencia } \\
\text { de } \\
\text { compra }\end{array}$ & $\begin{array}{c}\text { gasto } \\
\text { total } \\
\text { mensual }\end{array}$ & $\begin{array}{l}\text { gasto } \\
\text { total } \\
\text { anual }\end{array}$ \\
\hline - productos de limpieza & 100 & fijo & mensual & 100 & 1,200 \\
\hline - combustible motos & 1,056 & variable & mensual & 1,056 & 12,672 \\
\hline - combustible unidad de transporte & 1,289 & fijo & mensual & 1,289 & 15,463 \\
\hline - aceites & 960 & variable & trimestral & 320 & 3,840 \\
\hline - lubricantes & 150 & variable & trimestral & 50 & 600 \\
\hline - repuestos en general & 300 & fijo & mensual & 300 & 3,600 \\
\hline - baterias para las camaras & 50 & fijo & mensual & 50 & 600 \\
\hline \multirow{2}{*}{$\begin{array}{l}\text {-alquiler de las sprinters } \\
\text { total }\end{array}$} & \multirow[t]{2}{*}{4,372} & \multirow[t]{2}{*}{ fijo } & \multirow[t]{2}{*}{ mensual } & 4,372 & 52,463 \\
\hline & & & & 7,536 & 90,438 \\
\hline
\end{tabular}

Tabla 114

Costo de suministros y/o insumos

Compra Suministros y/o Insumos

\begin{tabular}{|c|c|c|c|c|c|c|c|c|c|c|c|c|}
\hline Detalle & Enero & Febrero & Marzo & Abril & Mayo & Junio & Julio & Agosto & Septiembre & Octubre & Noviembre & Diciembre \\
\hline - productos de limpieza & 100 & 100 & 100 & 100 & 100 & 100 & 100 & 100 & 100 & 100 & 100 & 100 \\
\hline - combustible motos & 1,056 & 1,056 & 1,056 & 1,056 & 1,056 & 1,056 & 1,056 & 1,056 & 1,056 & 1,056 & 1,056 & 1,056 \\
\hline - combustible unidad de transporte & 1,289 & 1,289 & 1,289 & 1,289 & 1,289 & 1,289 & 1,289 & 1,289 & 1,289 & 1,289 & 1,289 & 1,289 \\
\hline - aceites & 320 & 320 & 320 & 320 & 320 & 320 & 320 & 320 & 320 & 320 & 320 & 320 \\
\hline - lubricantes & 50 & 50 & 50 & 50 & 50 & 50 & 50 & 50 & 50 & 50 & 50 & 50 \\
\hline - repuestos en general & 300 & 300 & 300 & 300 & 300 & 300 & 300 & 300 & 300 & 300 & 300 & 300 \\
\hline - baterias para las camaras & 50 & 50 & 50 & 50 & 50 & 50 & 50 & 50 & 50 & 50 & 50 & 50 \\
\hline -alquiler de las sprinters & 4,372 & 4,372 & 4,372 & 4,372 & 4,372 & 4,372 & 4,372 & 4,372 & 4,372 & 4,372 & 4,372 & 4,372 \\
\hline total & 7,536 & 7,536 & 7,536 & 7,536 & 7,536 & 7,536 & 7,536 & 7,536 & 7,536 & 7,536 & 7,536 & 7,536 \\
\hline
\end{tabular}

Como se apreciado en las tablas de la parte superior el detalle mes a mes, se procede a proyectarlo por los cinco años del proyecto, cabe recalcar que los suministros y/o insumos tienen un incremento año a año, que es proporcional con el incremento de las ventas. 
Tabla 115

Presupuesto total de compras de suministros y/o insumos

Presupuesto Total de compras de Suministros y/o Insumos

\begin{tabular}{|c|c|c|c|c|c|}
\hline detalle / año & 1 & 2 & 3 & 4 & 5 \\
\hline Insumos & 90,438 & 91,342 & 92,255 & 93,178 & 94,110 \\
\hline total & 90,438 & 91,342 & 92,255 & 93,178 & 94,110 \\
\hline
\end{tabular}

Lo que se procede es acoplar todos los cuadros hallados en uno solo, para hallar nuestro costo de ventas final y proyectarlo año a año.

Tabla 116

Presupuesto total de costo de ventas

Presupuesto Total de Costo de Ventas

\begin{tabular}{lccccc}
\hline \multicolumn{1}{c}{ detalle / año } & 1 & 2 & 3 & 4 & 5 \\
\hline Presupuesto de costo de servicio directo & 68,669 & 68,883 & 69,099 & 69,317 & 69,538 \\
Presupuesto de costo de servicio indirecto & 51,676 & 52,192 & 52,714 & 53,241 & 54,306 \\
Presupuesto de suministros e insumos & 90,438 & 91,342 & 92,255 & 93,178 & 94,110 \\
Total costo de ventas & 210,782 & 212,417 & 214,069 & 215,737 & 217,954 \\
\hline
\end{tabular}

\subsubsection{Presupuesto de gastos administrativos.}

Para formulación de nuestros gastos administrativos, se ha clasificado los gastos generales y se consideran los gastos que por su naturaleza no se vinculan directamente con la prestación del servicio.

La distribución de estos gastos se ha subdividido en servicios, asesorías externas, útiles de escritorio, artículos de limpieza, remuneraciones del personal administrativo y alquiler de oficinas, los cuales se detallan en la siguiente tabla. 
Tabla 117

Presupuesto de gasto administrativo

Presupuesto de Gastos Administrativos

\begin{tabular}{|c|c|c|c|c|c|}
\hline Detalle & $\begin{array}{c}\text { importe } \\
\text { total } \\
\text { soles }\end{array}$ & $\begin{array}{c}\text { clasificación } \\
\text { del } \\
\text { gasto } \\
\end{array}$ & $\begin{array}{c}\text { frecuencia } \\
\text { de } \\
\text { compra }\end{array}$ & $\begin{array}{c}\text { Gasto } \\
\text { total } \\
\text { mensual }\end{array}$ & $\begin{array}{c}\text { Gasto } \\
\text { total } \\
\text { anual }\end{array}$ \\
\hline \multicolumn{6}{|l|}{ Servicios } \\
\hline - agua & 50 & fijo & mensual & 50 & 600 \\
\hline - luz & 100 & fijo & mensual & 100 & 1,200 \\
\hline - telefono & 35 & fijo & mensual & 35 & 420 \\
\hline - internet & 210 & fijo & mensual & 210 & 2,520 \\
\hline - celulares & 483 & fijo & mensual & 483 & 5,796 \\
\hline \multicolumn{6}{|l|}{ Asesorias externas } \\
\hline - asesoria legal & 100 & fijo & trimestral & 33 & 400 \\
\hline - asesoria contable & 300 & fijo & mensual & 300 & 3,600 \\
\hline Útiles de escritorio(papel, lapiceros) & 254 & fijo & trimestral & 85 & 1,016 \\
\hline \multicolumn{6}{|l|}{ Artículos de limpieza y botiquin } \\
\hline - Escoba & 15 & fijo & anual & 1 & 15 \\
\hline - Recogedor & 8 & fijo & anual & 1 & 8 \\
\hline - Tacho de basura & 30 & fijo & anual & 3 & 30 \\
\hline - Desinfectantes & 20 & fijo & mensual & 20 & 240 \\
\hline - Artículos de limpieza personal & 20 & fijo & mensual & 20 & 240 \\
\hline - Botiquín & 50 & fijo & trimestral & 17 & 200 \\
\hline \multicolumn{6}{|l|}{ Remuneraciones } \\
\hline - Administrador & 2,227 & fijo & mensual & 2,227 & 26,729 \\
\hline \multicolumn{6}{|l|}{ Alquiler de Oficinas } \\
\hline - alquiler de local (Puno centro) & 1,200 & fijo & mensual & 1,200 & 14,400 \\
\hline - alquiler de local (Capachica) & 350 & fijo & mensual & 350 & 4,200 \\
\hline
\end{tabular}




\section{Tabla 118}

Presupuesto de gasto administrativos - primer año

Presupuesto de gasto administrativos - Primer año

\begin{tabular}{|c|c|c|c|c|c|c|c|c|c|c|c|c|}
\hline Detalle & enero & febrero & marzo & abril & mayo & junio & julio & agosto & septiembre & octubre & noviembre & diciembre \\
\hline Servicios & 878 & 878 & 878 & 878 & 878 & 878 & 878 & 878 & 878 & 878 & 878 & 878 \\
\hline Asesorías externas & 333 & 333 & 333 & 333 & 333 & 333 & 333 & 333 & 333 & 333 & 333 & 333 \\
\hline Útiles de escritorio(papel, lapiceros) & 85 & 85 & 85 & 85 & 85 & 85 & 85 & 85 & 85 & 85 & 85 & 85 \\
\hline Articulos de limpieza y botiquin & 61 & 61 & 61 & 61 & 61 & 61 & 61 & 61 & 61 & 61 & 61 & 61 \\
\hline Remuneraciones & 2,227 & 2,227 & 2,227 & 2,227 & 2,227 & 2,227 & 2,227 & 2,227 & 2,227 & 2,227 & 2,227 & 2,227 \\
\hline Alquiler de Oficinas & 1,550 & 1,550 & 1,550 & 1,550 & 1,550 & 1,550 & 1,550 & 1,550 & 1,550 & 1,550 & 1,550 & 1,550 \\
\hline Depreciación otro equipos & 143 & 143 & 143 & 143 & 143 & 143 & 143 & 143 & 143 & 143 & 143 & 143 \\
\hline Total & 5,277 & 5,277 & 5,277 & 5,277 & 5,277 & 5,277 & 5,277 & 5,277 & 5,277 & 5,277 & 5,277 & 5,277 \\
\hline
\end{tabular}

Se proyecta los gastos administrativos por los siguientes cinco años del proyecto, y como se

puede observar en el cuadro de la parte inferior el crecimiento en los gastos administrativos es de $1 \%$, el mismo comportamiento se da en todos los años.

Tabla 119

Total de presupuesto gasto administrativo

Total de presupuesto gasto administrativo

\begin{tabular}{lccccc}
\hline \multicolumn{1}{c}{ detalle / año } & 1 & 2 & 3 & 4 & 5 \\
\hline Servicios & 10,536 & 10,641 & 10,748 & 10,855 & 10,964 \\
Asesorias extemas & 4,000 & 4,040 & 4,080 & 4,121 & 4,162 \\
Artículos de limpieza y botiquin & 1,016 & 1,026 & 1,036 & 1,047 & 1,057 \\
Útiles de escritorio(papel, lapiceros) & 733 & 740 & 748 & 755 & 763 \\
Remuneraciones & 26,729 & 26,996 & 27,266 & 27,539 & 27,814 \\
Alquiler de Oficinas & 18,600 & 18,786 & 18,974 & 19,164 & 19,355 \\
Depreciación otro equipos & 1,710 & 1,710 & 1,710 & 1,710 & 1,710 \\
Total & 63,324 & 63,940 & 64,562 & 65,191 & 65,826 \\
\hline
\end{tabular}




\subsubsection{Presupuesto de marketing y ventas.}

Los gastos de marketing y ventas se han relacionado con los gastos realizados en publicidad, como también los gastos de personal de marketing y ventas, que en el caso de dicho proyecto son los vendedores y los encargados de marketing.

Tabla 120

Presupuesto de marketing y ventas

Presupuesto de marketing y ventas

\begin{tabular}{|c|c|c|c|c|c|c|c|}
\hline Detalle & $\begin{array}{c}\text { importe } \\
\text { unitario } \\
\text { soles } \\
\end{array}$ & cantidad & $\begin{array}{c}\text { importe } \\
\text { total } \\
\text { soles } \\
\end{array}$ & $\begin{array}{c}\text { clasificaci } \\
\text { del } \\
\text { gasto }\end{array}$ & $\begin{array}{c}\text { frecuencia } \\
\text { de } \\
\text { compra }\end{array}$ & $\begin{array}{c}\text { Gasto } \\
\text { total } \\
\text { mensual }\end{array}$ & $\begin{array}{c}\text { Gasto } \\
\text { total } \\
\text { anual }\end{array}$ \\
\hline - banner $1.40 \times 2.00 \mathrm{~m}$ & 39 & 2 & 78 & fijo & anual & 7 & 78 \\
\hline - pagina Web (pagina + dominio y correos) & 800 & 1 & 800 & fijo & anual & 67 & 800 \\
\hline - folleteria ( 5 millares de tripticos en A4) & 500 & 1 & 500 & fijo & bimensual " & 83 & 1,000 \\
\hline - radio nivel local & 16,030 & 1 & 16,030 & fijo & anual & 1,336 & 16,030 \\
\hline - campaña medios digitales & 10,940 & 1 & 10,940 & fijo & anual & 912 & 10,940 \\
\hline - vallas móviles & 6,563 & 1 & 6,563 & fijo & anual & 547 & 6,563 \\
\hline - participación de eventos y/o activaciones & 5,000 & 1 & 5,000 & fijo & anual & 417 & 5,000 \\
\hline - Vendedor & 1,930 & 1 & 1,930 & fijo & mensual & 1,930 & 23,165 \\
\hline - Marketing & 1,485 & 2 & 1,485 & fijo & mensual & 1,485 & 17,819 \\
\hline total & & & & & & 6,783 & 81,395 \\
\hline
\end{tabular}

Para el presupuesto del segundo, tercer,cuarto y quinto año se han tomado las cifras del primer año, y se han pryectado al quinto año, como se puede apreciar en la table número 122, incluyendo un incremento de $1 \%$, igual que el gasto administrativo.. 
Tabla 121

Total de presupuesto de marketing y ventas

\begin{tabular}{|c|c|c|c|c|c|}
\hline detalle / año & 1 & 2 & 3 & 4 & 5 \\
\hline Radio nivel Local & 16,030 & 16,190 & 16,352 & 16,516 & 16,681 \\
\hline Digital & 10,940 & 11,049 & 11,160 & 11,271 & 11,384 \\
\hline Vallas moviles & 6,563 & 6,628 & 6,694 & 6,761 & 6,829 \\
\hline Folleteria & 3.000 & 3.030 & 3.060 & 3.091 & 3.122 \\
\hline Pagina Web & 800 & 808 & 816 & 824 & 832 \\
\hline banner & 78 & 79 & 80 & 80 & 81 \\
\hline Participación de eventos y/o activaciones & 5,000 & 5,050 & 5,101 & 5,152 & 5,203 \\
\hline Vendedor & 23,165 & 23,397 & 23,631 & 23,867 & 24,106 \\
\hline Marketing & 17,819 & 17,997 & 18,177 & 18,359 & 18,543 \\
\hline Total & 83,395 & 84,229 & 85,071 & 85,922 & 86,781 \\
\hline
\end{tabular}

\subsubsection{Presupuesto de gastos financieros.}

Los gastos financieros corresponden a los gastos realizados en mantenimiento de cuenta corriente, banca por internet, alquiler del POS (visa y mastercard), como también la comisión del POS, seguido de las comisiones e interés que nos cobra el banco BBVA continental por el préstamo obtenido y por último, el seguro todo riesgo que es obligatorio para préstamos comerciales, como es el proyecto presente.

Tabla 122

Presupuesto de gastos financieros

\begin{tabular}{|c|c|c|c|c|c|c|c|c|c|c|c|c|c|}
\hline \multicolumn{14}{|l|}{ Preapuesto de Gastos Fivoxiceros } \\
\hline Detalle & entero & febrere & matros & $a b r i$ & mayo & jation & julio & agosto & septembre & octobre & noriententer & diciembre & Total \\
\hline Manteriminesto de cuetha concente & 50 & 50 & 50 & 50 & 50 & 50 & 50 & 50 & 50 & 50 & 50 & 50 & 600 \\
\hline Banca por interntet & 90 & 90 & 90 & 90 & 90 & 90 & 90 & 90 & 90 & 90 & 90 & 90 & 1,080 \\
\hline 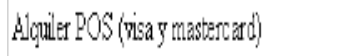 & 70 & 70 & 70 & 70 & 70 & 70 & 70 & 70 & 70 & 70 & 70 & 70 & 840 \\
\hline Comisión por renta POS (30\% de vestas) - & 0 & 0 & 0 & 408 & 409 & 368 & 532 & 408 & 409 & 409 & 368 & 368 & 3,684 \\
\hline Interésy courisiones & 1,340 & 1,325 & 1,308 & 1,202 & 1,276 & 1,259 & 1,242 & 1,225 & 1,208 & 1,191 & 1,173 & 1,173 & 15,014 \\
\hline Seguro todo nesso & 412 & 412 & 412 & 412 & 412 & 412 & 412 & 412 & 412 & 412 & 412 & 412 & 4,444 \\
\hline total gasto anual & 1,982 & 1,347 & 1,930 & 2,324 & $2,30 ?$ & 2,250 & 2,396 & 2,257 & 2,240 & 2,222 & 2,164 & 2,164 & 26,162 \\
\hline
\end{tabular}

Habiendo hallado los gastos financieros mensuales se procede a la proyección de lo gastos en los cinco años de proyecto como se muestra a continuación. 
Tabla 123

Presupuesto de gastos financieros

Presupuesto de Gastos Financieros

\begin{tabular}{lccccc}
\hline \multicolumn{1}{c}{ Detalle } & 1 & 2 & 3 & 4 & 5 \\
\hline Mantenimiento de cuenta corriente & 600 & 600 & 600 & 600 & 600 \\
Banca por interntet & 1,080 & 1,080 & 1,080 & 1,080 & 1,080 \\
Alquiler POS (visa y mastercard) & 840 & 840 & 840 & 840 & 840 \\
Comisión por venta POS (30\% de ventas) - : & 3,684 & 3,922 & 4,176 & 4,447 & 4,734 \\
Interés y comisiones & 15,014 & 12,411 & 9,463 & 11,659 & 4,371 \\
Seguro todo riesgo & 4,944 & 4,944 & 4,944 & 4,944 & 4,944 \\
total gasto anual & 26,162 & 23,797 & 21,103 & 23,569 & 16,570 \\
\hline
\end{tabular}

\subsection{Presupuestos de Resultados.}

Los estados de resultados del primer año, como los estimados para los siguientes años, nos van a dar a conocer la posición de la empresa, así como también la gestión que se ha realizado, y los flujos de caja necesarios para el funcionamiento de nuestro negocio.

\subsubsection{Estado de ganancias y pérdidas proyectado.}

El estado de resultados, nos permite visualizar los ingresos y gastos que se generaran el transcurso de estos cinco años de proyeccion, tanto gastos directos como indirectos, y nos permite ver los resultados que se obtendran de acuerdo a una buena gestión realizada, a continuación se muestra el estado de ganacias y pérdidas mes a mes, durante el primer año de funcionamiento.

Tabla 124

Estado de ganancias y pérdidas 
Estado de Ganancias y Perdidas Proyectado

\begin{tabular}{|c|c|c|c|c|c|c|c|c|c|c|c|c|c|}
\hline Detalle & enero & febrero & marzo & abril & mayo & junio & jullio & agosto & septiembre & octibre & notiembre & diciembre & Total \\
\hline Ventas totales & 0 & 0 & 0 & 62,303 & 62,303 & 56,073 & 80,994 & 62,303 & 62,303 & 62,303 & 56,073 & 56,073 & 560,731 \\
\hline Costo de Ventas & 17,565 & 17,565 & 17,565 & 17,565 & 17,565 & 17,565 & 17,565 & 17,565 & 17,565 & 17,565 & 17,565 & 17,565 & 210,782 \\
\hline Uttilidad Bruta & $-17,565$ & $-17,565$ & $-17,565$ & 44,738 & 44,738 & 38,508 & 63,429 & 44,738 & 44,738 & 44,738 & 38,508 & 38,508 & 349,948 \\
\hline G. Administrativos & 5,277 & 5,277 & 5,277 & 5,277 & 5,277 & 5,277 & 5,277 & 5,277 & 5,277 & 5,277 & 5,277 & 5,277 & 63,324 \\
\hline G. Ventas & 5,210 & 20,645 & 5,852 & 5,352 & 5,852 & 3,832 & 8,392 & 5,852 & 8,392 & 5,852 & 3,832 & 4,332 & 83,395 \\
\hline Utilidad Operativa & $-28,052$ & $-43,487$ & $-28,694$ & 34,109 & 33,609 & 29,399 & 49,760 & 33,609 & 31,069 & 33,609 & 29,399 & 28,899 & 203,230 \\
\hline G. Financieros & 3,182 & 3,151 & 3,120 & 3,650 & 3,619 & 3,531 & 3,723 & 3,523 & 3,490 & 3,457 & 3,367 & 3,333 & 41,146 \\
\hline $\begin{array}{l}\text { Utilidad antes de Impuest } \\
\text { Impuesto a la renta (28\%) }\end{array}$ & $-31,234$ & $-46,638$ & $-31,815$ & 30,459 & 29,990 & 25,868 & 46,037 & 30,087 & 27,579 & 30,153 & 26,032 & 25,566 & $\begin{array}{l}162,084 \\
45,384\end{array}$ \\
\hline Utilidad Neta & $-31,234$ & $-46,638$ & $-31,815$ & 30,459 & 29,990 & 25,868 & 46,037 & 30,087 & 27,579 & 30,153 & 26,032 & 25,566 & 116,701 \\
\hline
\end{tabular}

Podemos concluir que el presente proyecto tiene una utilidad positiva al término del primer año, a continuación en la siguiente tabla nos va permitir observar el crecimiento de esta utilidad en el transcurso de los siguientes años.

Tabla 125

Estado de ganancias y pérdidas proyectado

Estado de Ganancias y Perdidas Proyectado

\begin{tabular}{lccccc}
\hline Detalle & 1 & 2 & 3 & 4 & 5 \\
\hline Ventas totales & 560,731 & 597,038 & 635,696 & 676,858 & 720,684 \\
Costo de Ventas & 210,782 & 212,417 & 214,069 & 215,737 & 217,954 \\
$\quad$ Utilidad Bruta & 349,948 & 384,621 & 421,628 & 461,121 & 502,731 \\
G. Administrativos & 63,324 & 63,940 & 64,562 & 65,191 & 65,826 \\
G. Ventas & 83,395 & 84,229 & 85,071 & 85,922 & 86,781 \\
Utilidad Operativa & 203,230 & 236,452 & 271,995 & 310,009 & 350,124 \\
G. Financieros & 41,146 & 36,535 & 31,254 & 25,207 & 18,286 \\
Utilidad antes de Impuest. & 162,084 & 199,917 & 240,741 & 284,802 & 331,838 \\
Impuesto a la renta (28\%) & 45,384 & 55,977 & 67,407 & 79,744 & 92,915 \\
Utilidad Neta & 116,701 & 143,941 & 173,333 & 205,057 & 238,924 \\
\hline
\end{tabular}




\subsubsection{Balance proyectado.}

El balance general es la foto de la empresa a una fecha indicada, nos muestra los bienes, derechos y obligaciones, que tendrá la empresa al cabo de un periodo, que por lo general y como lo estamos trabajando es de un año para después proyectarlo por los cinco años de estudio.

La situación financiera, para el proyecto indica que el primer año la empresa tendrá activos por un monto de S/.575, 010 compuesto básicamente por el efectivo generado en el primer año, teniendo un capital social de S/.179,791 compuesto por el aporte de los socios de la empresa, a continuación se muestra el balance del primer año, como también del tiempo esperado para el proyecto. 
Tabla 126

Balance proyectado

Balance Proyectado

\begin{tabular}{|c|c|c|c|c|c|}
\hline & 1 & 2 & 3 & 4 & 5 \\
\hline \multicolumn{6}{|l|}{ Activo } \\
\hline Caja y bancos & 136,626 & 295,955 & 479,476 & 688,758 & $1,067,364$ \\
\hline \multicolumn{6}{|l|}{ Clientes } \\
\hline Existencias & 1,749 & 1,766 & 1,784 & 1,802 & 1,820 \\
\hline Activo Corriente & 138,375 & 297,722 & 481,260 & 690,560 & $1,069,184$ \\
\hline Inmueble, maquinaria y equipo & 372,202 & 372,202 & 372,202 & 372,202 & 372,202 \\
\hline - depreciación acumulada & $-37,996$ & $-75,993$ & $-113,989$ & $-151,985$ & $-300,981$ \\
\hline \multicolumn{6}{|l|}{ Intangibles } \\
\hline Activos diferidos & 102,430 & 100,343 & 99,359 & 99,612 & 69,826 \\
\hline Activo No Corriente & 436,635 & 396,552 & 357,571 & 319,828 & 141,046 \\
\hline Total Activo & 575,010 & 694,274 & 838,831 & $1,010,389$ & $1,210,230$ \\
\hline \multicolumn{6}{|l|}{ Pasivo } \\
\hline \multicolumn{6}{|l|}{ Proveedores } \\
\hline \multicolumn{6}{|l|}{ Deudas financieras } \\
\hline Tributos por pagar & 45,384 & 55,977 & 67,407 & 79,744 & 92,915 \\
\hline Pasivo Corriente & 45,384 & 55,977 & 67,407 & 79,744 & 92,915 \\
\hline Deudas financieras LP & 233,134 & 197,865 & 157,658 & 111,822 & 59,569 \\
\hline Pasivo No Corriente & 233,134 & 197,865 & 157,658 & 111,822 & 59,569 \\
\hline Total Pasivo & 278,518 & 253,842 & 225,065 & 191,566 & 152,483 \\
\hline Capital Social & 179,791 & 179,791 & 179,791 & 179,791 & 179,791 \\
\hline Resultados Acumulados & 0 & 116,701 & 260,641 & 433,975 & 639,032 \\
\hline Resultados del ejercicio & 116,701 & 143,941 & 173,333 & 205,057 & 238,924 \\
\hline Total Patrimonio & 296,492 & 440,433 & 613,766 & 818,823 & $1,057,747$ \\
\hline Total Pasivo y Patrimonio & 575,010 & 694,274 & 838,831 & $1,010,389$ & $1,210,230$ \\
\hline
\end{tabular}

\subsubsection{Flujo de caja proyectado.}

De acuerdo con Sapag (2011), “Un flujo de caja se estructura en varias columnas que representan los momentos en que se generan los costos y beneficios de un proyecto. Cada momento refleja dos cosas: los movimientos de caja ocurridos durante un periodo, generalmente de un año, y los desembolsos que deben estar realizados para que los eventos del periodo siguiente puedan ocurrir“ (p.250). 
La tabla 127 muestra el flujo económico y financiero del primer año, estructurado en

meses.

Tabla 127

Flujo de caja mensual

\begin{tabular}{|c|c|c|c|c|c|c|c|c|c|c|c|c|c|}
\hline \multicolumn{14}{|l|}{ Fajo de raja menenal } \\
\hline Detalle & 0 & Enero & Febrere & Marzo & Abrol & Mayo & Jorio & JW Wio & Agosto & Septembotre & Octubse & Noniembre & Dicienubre \\
\hline Jotitdad Neta & & 46,638 & $-31,815$ & 30,459 & 29,900 & 25,868 & 46,137 & 30,007 & 27,579 & 30,153 & 26,032 & 25,566 & 116,701 \\
\hline (t) deppreciación & & 4,083 & 4,003 & 4,083 & 4,083 & 4,083 & 4,083 & 4,083 & 4,083 & 4,083 & 4,083 & 4,083 & 4,083 \\
\hline (-) aroutizacion & & 0 & 0 & 0 & 0 & 0 & 0 & 0 & 0 & 0 & 0 & 0 & 0 \\
\hline (-) Inversion Iricial & 412,926 & & & & & & & & & & & & \\
\hline (-) Varacion Capdala Trabajo & & 0 & 0 & 0 & 0 & 0 & 0 & 0 & 0 & 0 & 0 & 0 & 0 \\
\hline (t) Yalor residual & & 0 & 0 & 0 & 0 & 0 & 0 & 0 & 0 & 0 & 0 & 0 & 0 \\
\hline FCL & 412,226 & 42,555 & $-27,732$ & 34,542 & 34,073 & 29,951 & 50,120 & 34,170 & 31,662 & 34,236 & 30,115 & 29,649 & 120,784 \\
\hline (t)prestrano & 233,134 & & & & & & & & & & & & \\
\hline (-) Pago captat Deuda Bancaria & & $-2,766$ & $-2,796$ & $-2,827$ & $-2,858$ & $-2,889$ & $-2,2,21$ & $-2,953$ & $-2,986$ & $-3,018$ & $-3,051$ & $-3,085$ & $-3,119$ \\
\hline \multicolumn{14}{|l|}{ Alunesto (redecrion) } \\
\hline efectro onto & 0 & $-39,789$ & $-24,935$ & 33,369 & 36,931 & 32,840 & 53,141 & 33,123 & 34,648 & 37,254 & 33,166 & 32,734 & 123,002 \\
\hline Saldo inicial de efection & 0 & 0 & $-39,789$ & $-64,724$ & $-27,355$ & 9,576 & 42,416 & 95,457 & 132,500 & 167,228 & 204,482 & 237,648 & 270,382 \\
\hline Saldo frial de efectivo & 0 & $-39,789$ & $.64,724$ & $-27,355$ & 9,576 & 42,416 & 95,457 & 132,580 & 167,228 & 204,482 & 237,648 & 270,382 & 394,284 \\
\hline
\end{tabular}

Para el flujo de los siguientes cuatro años se tomó las mismas variables y condiciones, determinadas en el primer, tomando en consideración la variación de crecimiento de los presupuestos. 


\section{Tabla 128}

\section{Flujo de caja anual}

Flujo de caja anual

\begin{tabular}{|c|c|c|c|c|c|c|}
\hline Detalle & 0 & 1 & 2 & 3 & 4 & 5 \\
\hline Utilidad Neta & & 116,701 & 143,941 & 173,333 & 205,057 & 238,924 \\
\hline$(+)$ depreciación & & 48,996 & 48,996 & 48,996 & 48,996 & 48,996 \\
\hline (-) amortizacion & & 0 & 0 & 0 & 0 & 0 \\
\hline (-) Inversion Inicial & $-412,926$ & & & & & \\
\hline (-) Variacion Capital Trabajo & & $-6,198$ & $-6,600$ & $-7,027$ & $-7,482$ & 123,034 \\
\hline ( + ) Valor residual & & & & & & 27,220 \\
\hline Flujo de Caja & $-412,926$ & 171,895 & 199,536 & 229,357 & 261,536 & 438,174 \\
\hline$(+)$ prestamo & 233,134 & & & & & \\
\hline $\begin{array}{l}\text { (-) Pago capital Deuda } \\
\text { Bancaria }\end{array}$ & & $-35,269$ & $-40,207$ & $-45,836$ & $-52,253$ & $-59,569$ \\
\hline Flujo de Caja libre & $-179,791$ & 136,626 & 159,329 & 183,521 & 209,282 & 378,606 \\
\hline Saldo inicial de efectivo & & 136,626 & 136,626 & 295,955 & 479,476 & 688,758 \\
\hline Saldo final de efectivo & & 136,626 & 295,955 & 479,476 & 688,758 & $1,067,364$ \\
\hline
\end{tabular}




\section{Capítulo IX: Evaluación Económico Financiera}

\subsection{Evaluación Financiera.}

En el presente capítulo se demostrará la rentabilidad del proyecto, desde un punto básicamente financiero, el cual tiene como objetivo cubrir las expectativas del inversionista en la rentabilidad como en su funcionamiento.

\subsubsection{Tasa interna de retorno.}

Según Baca (2012) “Se le llama tasa interna de rendimiento porque supone que el dinero que se gana año con año se reinvierte en su totalidad, es decir, se trata de la tasa de rendimiento generada en su totalidad en el interior de la empresa por medio de la reinversión“ (p.222).

Es la tasa de descuento que hace que el valor actual de los beneficios futuros sea igual a la inversión actual.

a) TIR Financiero

Tabla 129

Tasa interna de retorno

Tasa interna de retorno

\begin{tabular}{lcccccc}
\hline Detalle & 0 & 1 & 2 & 3 & 4 & 5 \\
\hline Flujo de Caja libre & $-179,791$ & 136,626 & 159,329 & 183,521 & 209,282 & 378,606 \\
TIR & $87 \%$ & & & & & \\
\hline
\end{tabular}

El resultado obtenido nos indica que el inversionista puede exigir un mayor rendimiento en el proyecto, se tendría que pedir una tasa de $87 \%$, el TIR nos indica que el proyecto es rentable. 
b) TIR Económico

Sin incluir el préstamo comercial del banco la TIR económica sale menor, esto indica que para el presente proyecto es una buena opción el financiamiento debido a que eleva nuestra tasa de retorno.

Tabla 130

Tasa interna de retorno económico

\begin{tabular}{|c|c|c|c|c|c|c|}
\hline Detalle & 0 & 1 & 2 & 3 & 4 & 5 \\
\hline Flujo de Caja & $-412,926$ & 171,895 & 199,536 & 229,357 & 261,536 & 438,174 \\
\hline TIR & $45 \%$ & & & & & \\
\hline
\end{tabular}

\subsubsection{Valor actual neto.}

De acuerdo con Stephen (2014) "si una inversión genera valor para sus propietarios, vale la pena efectuarla. En el sentido más general, se crea valor al identificar una inversión cuyo valor en el mercado es mayor que los costos de su adquisición” (p. 237).

Es un método de evaluación para medir el valor presente neto del proyecto a través de la actualización de los beneficios o flujos netos, el factor de la actualización está dado por el costo de capital de la empresa.

a) Valor actual neto Financiero

Tabla 131

Valor actual neto financiero

Valor actual neto

\begin{tabular}{lcccccc}
\hline Detalle & 0 & 1 & 2 & 3 & 4 & 5 \\
\hline Flujo de Caja libre & $-179,791$ & 136,626 & 159,329 & 183,521 & 209,282 & 378,606 \\
VAN & 461,775 & & & & & \\
\hline
\end{tabular}


Es importante determinar el valor actual neto en términos monetarios, y si el VAN es mayor a cero, nos muestra la ganancia del proyecto, después de recuperar la inversión, por sobre la tasa de retorno que se exigía al proyecto.

b) Valor actual neto Económico

Tabla 132

Valor actual neto económico

Valor actual neto económico

\begin{tabular}{lcccccc}
\hline Detalle & 0 & 1 & 2 & 3 & 4 & 5 \\
\hline Flujo de Caja & $-412,926$ & 171,895 & 199,536 & 229,357 & 261,536 & 438,174 \\
VAN & 887,572 & & & & & \\
\hline
\end{tabular}

El valor actual neto es mayor si no se incurre en financiamiento, ya que la ganancia es mayor a cero, se cree conveniente invertir en el proyecto, ya sea el VAN financiero o el VAN económico.

\subsubsection{Roe.}

Según Sapag (2011) “el periodo de recuperación de la inversión, es el tercer criterio más usado para evaluar un proyecto y tiene por objeto medir en cuanto tiempo se recupera la inversión, incluyendo el costo de capital involucrado” (p. 307).

\section{Tabla 133}

Periodo de recuperación de la inversión

Periodo de recuperacion

\begin{tabular}{lcccccc}
\hline Detalle & Inversión & 1 & 2 & 3 & 4 & 5 \\
\hline Flujo de Caja & $-179,791$ & 136,626 & 159,329 & 183,521 & 209,282 & 378,606 \\
Años de recuperación & 4 & años & & & & \\
\hline
\end{tabular}


El proyecto de recuperación de la inversión es de 4 años para recuperar la inversión, lo que significa que el tiempo recuperable es aceptable para el inversionista.

\subsubsection{Ratios.}

En la tabla número 134, mostramos todos los ratios financieros, desde el año uno hasta el año cinco, los cuales se obtienen de la evaluación de los estados financieros proyectados del periodo de estudio, el la presenta tabla se muestran los ratios más relevantes que son los ratios de liquidez, solvencia y rentabilidad.

a) Ratios de liquidez.- entre los ratios más importantes tenemos la razón corriente, que para el presente proyecto es de 3.05 para el primer año, es decir por cada sol de deuda que tenga la empresa, tiene ocho soles con cuarenta y cinco céntimos para afrontar la deuda.

b) Ratios de solvencia.- este ratio mide la capacidad en activos y recursos que tiene el negocio, para responder con sus acreedores uno de los ratios más importantes es cobertura de intereses, este punto nos permite saber hasta cuanto pueden disminuir la utilidad operativa que en el primer año es de 0.20 .

c) Ratios de rentabilidad. En este ratio podemos mencionar como uno de los ratios más importantes el ratio de rendimiento sobre la inversión, este ratio nos permite conocer la generación de utilidades que tiene el negocio a partir de los recursos con los que cuenta, para el primer año es de $39 \%$. y al finalizar el proyecto a $20 \%$. 
Tabla 134

Ratios financieros

Ratios financieros

\begin{tabular}{lccccc}
\hline Detalle & Año 1 & Año 2 & Año 3 & Año 4 & Año 5 \\
\hline Ratio de Liquidez & 3.05 & 5.32 & 7.14 & 8.66 & 11.51 \\
Prueba Acida & 3.01 & 5.29 & 7.11 & 8.64 & 11.49 \\
Capital de Trabajo & 92,991 & 241,745 & 413,853 & 610,816 & 976,269 \\
& & & & & \\
Dias Promedio Inventario & 0.00 & 0.00 & 0.00 & 0.00 & 0.00 \\
Dias Promedio de Cobro & 0.00 & 0.00 & 0.00 & 0.00 & 0.00 \\
Dias Promedio de Pago & 0.00 & 0.00 & 0.00 & 0.00 & 0.00 \\
Ciclo de Negocios & 0.00 & 0.00 & 0.00 & 0.00 & 0.00 \\
& & & & & \\
Cobertura de intereses & 9.82 & 14.80 & 10.20 & 8.34 & 8.29 \\
Apalacamiento & 0.48 & 0.37 & 0.27 & 0.19 & 0.13 \\
Rotación de Activo & 0.98 & 0.86 & 0.76 & 0.67 & 0.60 \\
Margen Neto & 0.21 & 0.24 & 0.27 & 0.30 & 0.33 \\
Multiplicador de Capital & 3.20 & 3.86 & 4.67 & 5.62 & 6.73 \\
ROA & $20 \%$ & $21 \%$ & $21 \%$ & $20 \%$ & $20 \%$ \\
ROE & $39 \%$ & $33 \%$ & $28 \%$ & $25 \%$ & $23 \%$ \\
\hline
\end{tabular}

\subsection{Análisis de Riesgo.}

Todo proyecto de inversión cuenta con ciertos riesgos, lo que nos lleva a analizarlos, en consecuencia lo que veremos a continuación en el presente trabajo, es el punto de equilibrio y análisis de sensibilidad.

\subsubsection{Análisis de punto de equilibrio.}

El punto de equilibrio nos muestra la situación en donde un proyecto no gana ni pierde, lo cual es importante para nuestro proyecto para poder determinar cuánto es el valor de venta más bajo al que se puede atender o el nivel de cliente mínimos que se tiene que atender, para el cálculo del punto de equilibrio lo primero que se tiene que 
hacer es calcular los costos fijos y los costos variables del proyecto, así como se muestra a continuación.

Tabla 135

Detalle de costos fijos y variables mensual

Detalle de costos fijos y variables mensual

\begin{tabular}{lcc}
\hline Detalle & Costos fijos & Costos Variables \\
\hline Costo de servicios directos & 5,722 & \\
Costo de servicio indirecto & 4,306 & \\
Suministros y/o Insumos Fijos & 6,110 & \\
Suministros y/o Insumos Variables & & 1,426 \\
Gastos administrativos & 5,277 & \\
Gastos marketing y ventas & 6,783 & \\
Gastos financieros fijos & 622 & 1,440 \\
Gastos financieros variables (promedio) & & 2,866 \\
Total & 28,821 & \\
\hline
\end{tabular}

Habiendo realizado el detalle de costos fijos y variables se procede a realizar el punto de equilibrio, tanto en precio, como en número de clientes a atender, lo cual se muestra en

Tabla 136

Punto de equilibrio

Punto de equilibrio

Costos fijos mensuales

28,821

Precio unitario

Promedio de clientes mensuales

265

Costo variable unitario

10.83

PE mensual (pasajeros)

152

$\mathrm{PE}$ diario (pasajeros)

PE mensual (en soles)

$\mathrm{PE}$ diario (en soles)

Si. 30,463

S/. 1,172 


\subsubsection{Análisis de sensibilidad.}

Para determinar el análisis de sensibilidad el presente proyecto lo está enfocando en tres puntos que son el valor de venta, los costos variables y el gasto administrativo, a continuación vamos a observar que pasa cuando hay un cambio en cada uno de ellos, se podrá observar el cambio el valor actual neto, como también el cambio en la tasa interna de retorno. A continuación se muestra en la tabla número 137, los cambios ocurridos.

Tabla 137

Análisis de sensibilidad

\begin{tabular}{lcc} 
Analisis de sensibilidad & & \\
\hline Detalle & VAN & TIR \\
\hline Precio +1 & 88,400 & $25 \%$ \\
Costo Variable Unitario +1 & 65,389 & $21 \%$ \\
Gasto Administrativo +8000 & 54,793 & $20 \%$ \\
\hline
\end{tabular}

Como se puede apreciar tenemos variaciones en el valor de venta un sol, es decir si antes nuestro valor de venta costaba S/201,00 soles ahora cuesta S/202,00 y se observa variación en el VAN y en la TIR, igualmente se puede apreciar con el costo de venta unitario y el gasto administrativo.

\subsubsection{Análisis de escenarios.}

Para el análisis de escenarios el presente proyecto trabaja con tres tipos de escenarios, un escenario positivo en donde nuestra ventas aumentan en un $10 \%$, un escenario normal, donde no existe variación de datos y un escenario negativo, que se puede dar por desastres, una baja en el mercado, etc., en donde nuestras ventas tienden a disminuir en un 10\%, a continuación en la tabla 139, se muestra 
las tres variaciones y como están aumentan o disminuyen el valor actual neto y la tasa interna de retorno.

Tabla 138

Análisis de escenarios

Analisis de escenarios

\begin{tabular}{lcc}
\hline Detalle & Ventas proyectada & VAN \\
\hline Optimista & $10.00 \%$ & 190,976 \\
Normal & $0.00 \%$ & 75,578 \\
Pesimista & $-10.00 \%$ & $-47,639$ \\
\hline
\end{tabular}




\section{Conclusiones y recomendaciones}

\section{Conclusiones.}

- Las agencias de viaje desarrollan un papel importante en los últimos años ya que el turismo en el Perú ha incrementado un $20 \%$ desde el año 2011, por lo que se debe innovar y explotar lugares turísticos poco conocidas por el turista nacional de acuerdo a estas cifras nace el proyecto para poder explotar las playas de Capachica mediante el circuito de turismo de aventura.

- El tamaño de mercado de agencias de viaje en Puno se ha estimado en S/36 millones de soles al año. No hay ninguna empresa que tenga más del $8 \%$ de participación de mercado lo cual indica que no hay monopolios, oligopolios, etc; presentes en el mercado.

- El mercado potencial está conformado por ciudadanos locales del departamento de Puno y turistas nacionales que arriban a Puno por año. El proyecto se enfoca en los NSE ABC dando lugar a un mercado disponible de 123,455 personas al año y un mercado efectivo que buscan servicios de aventura de 38,132 personas al año. De los mismos la investigación de mercado arroja que el 77\% tiene un gasto familiar de hasta S/200, y está dispuesto a pagar sólo por los servicios de alquiler de motos entre 15 a 30 minutos unos S/60. Por tanto, el valor de venta está acorde a lo que desea el público objetivo.

- La estrategia de marketing estará basada en la investigación realizada que indica que los clientes buscarán ante todo la "diversión” en los servicios brindados. Se fijan el valor de venta de acuerdo al promedio del mercado, al valor percibido, y 
se tendrá valor de venta diferenciados por canal y segmento de consumidor. Se contará con un precio tarifario de S/90.

- El plan de medios se realizará solo con tres tipos de canal: el digital, radio y vallas móviles ya que, demás medios no conseguirán los impactos deseados y su costo es mayor. Se eligen estos canales por su efectividad y costo.

- Se realizó la evaluación económica y financiera del proyecto, cuyos resultados fueron positivos y rentables para los inversionistas, determinado un TIR muy atractiva, con una tasa importante, se concluye que el proyecto es viable. 


\section{Recomendaciones.}

- Dada que la competencia es no directa, se debe aprovechar al máximo la difusión del circuito ya que es un servicio nuevo con paisajes no conocidos, por lo se contara con oficinas ubicadas estratégicamente para que así sea más fácil promocionar y vender este paquete turístico.

- El tamaño de mercado de agencias de viaje en Puno se ha estimado en S/36 millones de soles al año. No hay ninguna empresa que tenga más del $8 \%$ de participación de mercado lo cual indica que no hay monopolios, oligopolios, etc; presentes en el mercado. Sin embargo, se puede alcanzar participación más altas debido a que el nicho es nuevo y no explotado

- El mercado potencial está conformado por ciudadanos locales del departamento de Puno y turistas nacionales que arriban a Puno por año. El proyecto se enfoca en los NSE ABC dando lugar a un mercado disponible de 123,455 personas al año y un mercado efectivo que buscan servicios de aventura de 38,132 personas al año. De los mismos la investigación de mercado arroja que el $77 \%$ tiene un gasto familiar de hasta S/200, y está dispuesto a pagar sólo por los servicios de alquiler de motos entre 15 a 30 minutos unos S/60. Por tanto, los valores de venta están acordes a lo que desea el público objetivo.

- La estrategia de marketing estará basada en la investigación realizada que indica que los clientes buscarán ante todo la "diversión” en los servicios brindados. Se fijan los valores de venta de acuerdo al promedio del mercado, al valor percibido, y se tendrá valores de venta diferenciados por canal y segmento de consumidor. Se contará con un valor de venta tarifario de S/201. 
- El plan de medios se realizará solo con tres tipos de canal: el digital, radio y vallas móviles ya que, demás medios no conseguirán los impactos deseados y su costo es mayor. Se eligen estos canales por su efectividad y costo. 


\section{ANEXOS}

\section{Anexo 1}

\section{GUÍA DE PAUTA}

Entrevistas en Profundidad

\section{Saludo y presentación (3 min)}

- Gracias por venir y bienvenidos

Somos un grupo de alumnos de maestría ... (Presentación breve)

- No hay respuestas correctas o incorrectas; toda opinión es válida

- Informar sobre grabación de audio y video

- Informar tema principal de la sesión "Viabilidad para un proyecto sobre servicios turísticos de aventura de alquiler de motos acuáticas en el Lago Titicaca"

\section{Datos Personales (1 min)}

1. Indicarnos ¿Cuántos años tiene en el sector? ¿Su cargo en la empresa? ¿de qué profesión es?

\section{Sobre el sector (6 min)}

1. ¿Cómo ve la perspectiva de crecimiento para el sector turismo?

2. ¿Considera al Perú como un lugar potencial para desarrollar turismo de aventura?

3. ¿Considera que Puno es un lugar propicio para realizar turismo de aventura?

4. ¿Qué circuitos de aventura son ofrecidas por las agencias de viaje? ¿Cuáles son las más solicitadas?

5. ¿Considera que el turista local y nacional tiene interés en este tipo de circuitos?

IV. Sobre el proyecto $(10 \mathrm{~min})$

Se explica brevemente el proyecto de alquiler de motos acuáticas en el lago Titicaca

6. ¿Conoce de alguna alternativa similar al proyecto descrito? ¿cuáles?

7. ¿Sería atractivo para sus clientes optar por nuestro servicio? ¿por qué?

8. ¿Cuánto se podría pagar por el servicio? ¿por qué?

9. ¿Qué obstáculos podría observar para la ejecución del proyecto?

10. ¿Si ofreciera el servicio a sus clientes? ¿Cuál sería su principal expectativa y su principal preocupación?

11. ¿Cuál considera la mejor forma de publicitar el servicio?

\section{Cierre (5 min)}


- Agradecer la intervención del experto. Indicar que su opinión nos permite perfil el servicio brindado para estar acorde a las tendencias del mercado y gustos de los potenciales cliente. GRACIAS

Anexo 2

\section{GUÍA DE INDAGACIÓN}

Proyecto Motos Acuáticas en Chifron - Capachica

\section{Saludo y presentación ( 3 min)}

- Gracias por venir y bienvenidos

Somos una empresa de investigación de mercados... (Presentación breve)

- No hay respuestas correctas o incorrectas; toda opinión es válida

- Informar sobre grabación de audio y video

- Informar tema principal de la sesión "Aceptación sobre servicios turísticos de aventura de alquiler de motos acuáticas"

- Pasar bocaditos y bebidas

\section{Calentamiento (5 min)}

2. Me gustaría pedirles que cada uno se presente para que podamos conocer un poco más sobre los demás. Les pido que brevemente nos digan su nombre, a qué se dedican, de donde vienen

3. Dígame ¿qué suele hacer en su tiempo libre?

III. Estudio en profundidad $(60-120$ min)

\section{Acerca decisión de compra de un circuito turístico}

Explicar a que se llama "circuito turístico"

1. ¿Qué tipo de lugares turísticos les gustaría visitar en Puno? Breve descripción

2. ¿Antes de decidir por un circuito turístico como obtiene información del mismo?

3. ¿Qué medios utiliza para obtener información sobre un circuito turístico? Describir medios usados

4. ¿Qué tiempo considera usted necesario para un circuito turístico? Indicar en horas

5. ¿Cuánto estaba dispuesto a gastar para un circuito turístico? Indicar monto

6. ¿Qué lo anima por optar por un circuito turístico? Mencionar motivos

7. ¿Qué lo desanima por optar un circuito turístico'? Mencionar motivos

8. ¿Qué medidas de seguridad considera necesarios cuando opta por un circuito turístico?

9. ¿Qué establecimientos considera necesarios en una zona turística? 


\section{Acerca de Playas del Lago Titicaca}

1. ¿Conocen alguna playa en el lago Titicaca?

2. ¿Qué percepción tiene del Lago Titicaca? Respuesta Positiva/Negativa ¿Por qué?

3. ¿Con qué frecuencia visita las Playas de Puno? ¿cuáles?

4. ¿Cuáles son los factores influyentes para que visite las playa de Puno? ¿Por qué?

5. ¿Cuáles son las ventajas de ir a las Playas de Puno? ¿Por qué?

6. ¿Cuáles son las desventajas de ir a las Playas de Puno? ¿Por qué?

7. ¿Qué actividades ha realizado en las Playas de Puno? ¿Por qué?

8. ¿Qué lugares y festividades locales conoce de Puno? ¿cuál?

\section{Acerca del Proyecto}

1. ¿Consideras la ubicación del proyecto ideal? ¿por qué?

2. Después de haber comentado el proyecto, ¿lo consideras viable? ¿Por qué?

3. Después de la descripción del servicio, ¿usted lo considera seguro?

4. ¿Con que frecuencia utilizarías el servicio?

5. ¿Consideras adecuado el tiempo del servicio?

6. ¿El valor de venta es el adecuado para el servicio que ofrecemos?

7. ¿Qué tipos de promociones les gustaría?

8. De las siguientes alternativas complementarias al servicio por cual optarías ¿Por qué?

9. ¿Usted contrataría el servicio brindado?

10. ¿Recomendaría a otras personas el servicio? ¿Por qué?

\section{Cierre (5 min)}

- Agradezco a los participantes por brindarnos su tiempo y en especial su colaboración para responder a las preguntas. Asimismo, si tuvieran alguna otra sugerencia u opinión final respecto al proyecto servicio de turismo de aventura de motos acuáticas. Gracias por venir que tengan un buen día. (repartir un suvenir) 
Presentación: Buenos días, somos un grupo de alumnos de maestría que está realizando una breve encuesta para conocer su opinión con respecto a la contratación de circuitos turísticos. Sus respuestas nos

\section{Anexo 3}

a. Cuestionario

Buenos días, necesitamos tu apoyo para una breve encuesta servicios turísticos de aventura en Puno.

P1. GENERO

a) MASCULINO

b) FEMENINO

P2. EDAD

a) DE 14 A 29 AÑOS

b) $\mathrm{DE} 30 \mathrm{~A} 44 \mathrm{ANNOS}$

c) DE 45 A 59 AÑOS

P3. ESTADO CIVIL

a) $\operatorname{SOLTERO}(\mathrm{A})$

b) $\mathrm{CASADO}(\mathrm{A})$

c) DIVORCIADO $(\mathrm{A})$

d) CONVIVIENTE

P4. ¿CUAL ES GRADO DE INSTRUCCION

DE LA PERSONA QUE MÁS APORTA

ECONÓMICAMENTE EN TU HOGAR?

a) NINGUNO/ANALFABETO

b) PRIMARIA/SECUNDARIA

INCOMPLETA

c) SECUNDARIA/TECNICA

INCOMPLETA

d) TECNICA

COMPLETA/SUPERIOR

INCOMPLETA

e) SUPERIOR COMPLETA

f) POSTGRADO
P5. ¿CUANDO TIENE UNA CONSULTA

MEDICA EN QUE TIPO DE ESTABLECIMIENTO DE

SALUD SE ATIENDE?

a) POSTA

MÉDICA/FARMACIA/NATURIST

A

b) HOSPITAL DEL MINISTERIO DE SALUD/HOSPITAL DE LA

SOLIDARIDAD

c) SEGURO SOCIAL/ HOSPITAL FF.AA./ HOSPITAL DE POLICÍA

d) MÉDICO PARTICULAR EN CONSULTORIO

e) MÉDICO PARTICULAR EN CLÍNICA PRIVADA

P6. ¿CUAL DE LOS SIGUIENTES BIENE 0 SERVICIOS TIENE EN SU HOGAR? Marcar SI / NO

LAVADORA

$\mathrm{SI} / \mathrm{NO}$

REFRIGERADORA SI /NO

COCINA SI $/ \mathrm{NO}$

COMPUTADORA SI /NO

TELEFONO FIJO

$\mathrm{SI} / \mathrm{NO}$

P7. ¿CUANTAS PERSONAS VIVEN EN SU

HOGAR SIN INCLUIR A PERSONAL DE SERVICIO? 
P8. ¿CUANTOS DORMITORIOS TIENE EN

SU HOGAR?

P9. ¿QUÉ MATERIAL PREDOMINANTE

HAY EN LOS PISOS DE SU VIVIENDA?

a) TIERRA/ ARENA/ TABLONES SIN PULIR (SELVA)

b) CEMENTO SIN PULIR.

c) CEMENTO PULIDO/ TAPIZÓN/ TABLONES (COSTA Y SIERRA)

d) MAYÓLICA/ LOSETA/ MOSAICO/ VINÍLICO Y CERÁMICOS

e) PARQUET/ MADERA PULIDA/ ALFOMBRA/ LAMINADO TIPO MADERA/ MÁRMOL/ TERRAZO PUNO?

P10. ¿UD. VIVE EN EL DEPARTAMENTO DE

SI (PASAR A P.11) NO (PASAR A P.12)
a) $\mathrm{SI}$
b) $\mathrm{NO}$

P11. ¿DE QUÉ PROVINCIA PROVIENE?
a) PUNO (PUNO)
b) SAN ROMAN (JULIACA)
c) CHUCUITO (DESAGUADERO)
d) OTRO

P12. ¿DE QUÉ DEPARTAMENTO

PROVIENE?
a) LIMA
b) AREQUIPA
c) CUSCO
d) OTROS

P13. ¿CUÁNTOS DÍAS PERMANECERÁS EN LA PUNO?

Marcar más de 05 días si vive en la ciudad
a) 01 DÍA
b) 02 DÍAS
c) 03 DÍAS
d) MÁS DE 05 DÍAS

P14. ¿HA REALIZADO ALGUNA ACTIVIDAD DE TURISMO DE AVENTURA? Ejemplo: Caminatas, Ciclismo, Kayak, etc.

Si marca NO - Terminar encuesta
a) $\mathrm{SI}$
b) $\mathrm{NO}$

P15. ¿QUÉ TE MOTIVÓ HACER TURISMO

DE AVENTURA?
a) ADRENALINA
b) NUEVAS EXPERIENCIAS
c) DIVERSIÓN
d) RETO

P16. ¿DÓNDE OBTIENES INFORMACIÓN SOBRE TURISMO DE AVENTURA?

Seleccionar el medio más utilizado
a) AMIGOS
b) TELEVISIÓN
c) REDES SOCIALES
d) AGENCIA DE VIAJES
e) RADIO
f) PANELES PUBLICITARIOS
P17. ¿CUÁNDO REALIZASTE UNA

ACTIVIDAD DE TURISMO DE AVENTURA CUANTO

FUE EL GASTO REALIZADO?
a) MENOS DE $S / 100$
b) $\mathrm{S} / .101 \mathrm{~A} \mathrm{~S} / 200$
c) $\mathrm{S} / .201 \mathrm{~A} \mathrm{~S} / 300$
d) S/. $301 \mathrm{~A} \mathrm{~S} / 400$
e) S/. $401 \mathrm{~A}$ MÁS 
P18. ¿ESTAS INFORMADO DE LAS ALTERNATIVAS SOBRE TURISMO DE AVENTURA EN PUNO?

Pasar a P21

Si marca SI. Responder P19 Y P20 Si marca NO.
a) $\mathrm{SI}$
b) $\mathrm{NO}$

P19. MENCIONA LA AGENCIA Y/O EMPRESA QUE CONOCES QUE REALIZA TURISMO DE AVENTURA EN PUNO

Menciona la empresa o agencia que más recuerdes

P20. ¿QUÉ ACTIVIDAD DE AVENTURA

REALIZASTE?
a) TREEKING
b) CICLISMO
c) KAYAK
d) MOTO ACUÁTICA
e) CUATRIMOTOS
f) $\mathrm{OTR} \% \mathrm{OS}$

P21. ¿TE GUSTARÍA REALIZAR UN CIRCUITO DE CAMINATAS, CICLISMO Y MOTOS ACUÁTICAS EN CAPACHICA? (A CUARENTA MINUTOS DE PUNO)

Circuito consiste en traslado Puno-CapachicaPuno. Elección de Caminata o Ciclismo hasta el punto de embarque. Conducir Moto Acuática en el Lago Titicaca Si marca NO - Terminar encuesta
a) $\mathrm{SI}$
b) $\mathrm{NO}$
P.22 ¿QUÉ TIEMPO CONSIDERAS

ADECUADO QUE PODRÍA DURAR EL CIRCUITO? b) DE 01 HORA A 02 HORAS

c) MÁS DE 02 HORAS

P23. ¿CUÁNTO ESTARÍAS DISPUESTO A

PAGAR POR CIRCUITOS DESCRITO?
a) $\mathrm{DE} \mathrm{S} / .100 \mathrm{~A} \mathrm{~S} / 150$
b) $\mathrm{DE} \mathrm{S} / .151 \mathrm{~A} \mathrm{~S} / 200$
c) DE S/. $201 \mathrm{~A} \mathrm{~S} / 300$

P24. ¿CON QUE FRECUENCIA HARÍAS DEL

\section{CIRCUITO OFRECIDO?}
a) 01 VEZ AL AÑO
b) 02 VECES AL AÑO
c) MENSUAL
d) QUINCENAL

P25. ¿QUÉ SERVICIOS ADICIONALES TE GUSTARÍA ENCONTRAR EN CAPACHICA?

Si no conoce el lugar que servicio es el que como mínimo esperaría encontrar
a) HOSPEDAJE
b) MINIMARKET
c) RESTAURANTE
d) TIENDA DE ARTESANÍAS
e) OTROS

a) HASTA 01 HORA 
Focus 01

Qué es lo que les vamos a preguntar, les vamos a pedir que se presenten solamente digan su nombre, cuánto tiempo viven en Puno y qué profesión tienen.

Ahora si Uds. quieren viajar por Puno qué es lo que hacen, qué ventajas y desventajas tienen sobre las alternativas, qué hay en Puno, luego les vamos a hablar del proyecto que tenemos en mente más que todo queremos que nos digan qué es lo que piensan del proyecto, si va a resultar, si lo ven óptimo.

En resumen queremos que se presente cada uno de Uds. qué es lo que hacen en Puno, si quieren viajar y la última parte va ver una explicación del proyecto.

Les voy a pedir que cada uno se presente, su nombre, su edad

$\checkmark$ Mi nombre es Adrián vivo en Puno 10 años vengo de Macusani que pertenece al departamento de Puno vengo por estudiar y trabajar

$\checkmark$ Mi nombre es Calixto soy técnico en cenfotur mi especialidad es alimentos y bebidas he trabajado en varios hoteles a nivel nacional siempre en el área a y b alimentos y bebidas, me he quedado en Puno porque hay mucho turismo, tengo 33 años en turismo es muy bonito trabajar en turismo, también soy guía local pero lo que me gusta es la hotelería soy también profesor en la universidad en la UNA

$\checkmark$ Mi nombre es Sonia Virginia natural de Puno estoy en el octavo semestre en psicología, trabajó en el área de turismo soy técnica en turismo

$\checkmark$ Mi nombre el David soy técnico en turismo mi hobby es la fotografía me gustan los deportes extremos y turismo de aventura, pienso que no sólo se puede vender Taquile, Amantani, sino muchos otros lugares he viajado a varios lugares Lima, Arequipa y Puno el lugar que más me quedaría es en Puno

$\checkmark$ Mi nombre es Freddy no soy natural de Puno radicó en sandía por motivos familiares vine a Puno, he terminado en la universidad del altiplano la carrera de turismo, en Sandía hay atractivos turísticos yo les pediría qué visiten Sandía sólo hablamos de Taquile y Amantani, Puno Abarca también el café más rico del mundo como el café Tunki de Sandía 
$\checkmark$ Mi nombre es Frank no soy natural de Puno por motivos de estudio estoy en Puno y trabajo aquí para solventar mis estudios, vengo de un pueblo cerca a las Chulpas del Sillustani mi objetivo es ingresar a la universidad

$\checkmark$ Mi nombre es Yovanna soy natural de Puno, he estudiado la carrera de docencia Educación inicial no lo ejerce por motivos familiares, soy hija única no tuve hermanos que me apoyen, estoy trabajando acá para salir adelante

$\checkmark$ Mi nombre es Karina, sigo estudiando la carrera de guía oficial de turismo, escogí esta carrera porque me gusta viajar y conocer nuevos lugares y experimentar todos los tipos de turismo que hay en el Perú vivo en Puno 23 años.

Vamos a comenzar la actividad y quisiera que me digan en sus tiempos libres que les gusta y suelen hacer

$\checkmark$ En mis tiempos libres me gusta estar con los turistas tengo un pequeño hospedaje y les brindó un buen servicio

$\checkmark$ En Mis tiempos libres cómo estoy en el trabajo y en la tarde en la universidad es sagrado mi día libre, me viajó a cualquier lugar de Puno salgo en la mañana y regresó en la noche

$\checkmark$ Me dedico en Mis tiempos libres a la fotografía salgo a caminar por las noches por los cerros, más que todo la luna es lo que más me encanta, me gusta la puesta del sol y los paisajes

$\checkmark$ En mis días libres tengo un grupo de amigos en la universidad voy a jugar dota, paseamos por el malecón, fulbito también

$\checkmark$ En mis tiempos libres me gusta jugar fútbol es mi pasión

$\checkmark$ En mis tiempos libres me gusta viajar fuera de Puno, Chucuito hay varios lugares

$\checkmark$ Cuando tenemos tiempo libre salimos a viajar por ejemplo a Arequipa salir por la tarde y al día siguiente estás regresando ya que trabajar es estresante y tenemos que relajarnos

Por ejemplo a que lugares turísticos de Puno viajan muchos, me comentaron cerca a Puno por ejemplo a que sitios van. 
$\checkmark$ En lo personal ya conozco Chucuito, July, Pomata, Yunguyo por el lado Sur, por el lado Norte conozco Sillustani, Capachica, Ayaviri, Tinajani, me falta Moho y otros lugares que son muy cercanos un día temprano sales y por la noche estás regresando

$\checkmark$ Yo conozco July, Pomata todo el lado Aymara y un poco el lado quechua, en el lado Aymara aún es más fuerte la cultura

$\checkmark$ He paseado a los Urus con mis niños para que vayan conociendo

$\checkmark$ He ido a Taquile y Amantani

Antes de ir a esos sitios Cómo obtienen información de esos lugares, recurren a alguna agencia o cómo hacen para visitar esos sitios

$\checkmark$ En lo personal los lugares que he nombrado no están categorizados como lugares turísticos dentro de un mapa por ejemplo, lo más tradicional siempre te van a decir la isla, en el lago los Uros, Taquile, Amantani que es lo más tradicional, ahora por mi parte los lugares que yo he ido es: uno porque por grupos de amigos nos dicen yo conozco ese lugar y así hay tales cosas, para mi caso eso te crea una curiosidad y eso te motiva a viajar

Por ejemplo alguien más como es que busca información para viajar estos sitios, por ejemplo como ir a Sandia

$\checkmark$ Sandía por ejemplo, yo estudio en la universidad y tengo docentes de turismo nos dan folletos libros que nos venden los atractivos turísticos de Puno, nos basamos en los libros, en los folletos de los profesores que nos enseñan, la mayoría son guías, otros han trabajado en hoteles de cuatro a cinco estrellas entonces los docentes nos inculcan Por ejemplo cuando van a un lugar turístico consideran el tiempo como una variable importante para eso, si por ejemplo demora media hora o cuarenta minutos es algo decisivo para ir a ese sitio

$\checkmark \quad$ En lo particular para mí sí, el amanecer y el atardecer tiene que ser exacto no puedo perder el tiempo es cuestión de minutos 
Por ejemplo cuando suelen gastar cuando van a estos sitios turísticos en general

$\checkmark$ Con familia hasta $\$ 100$

$\checkmark$ Yo soy arriesgada, a veces me voy sola y no gastó más de 100 soles

$\checkmark$ Ante todo debemos ver las provisiones, voy a un lugar y averiguó qué lugares hay para visitar llegado a un pueblo y le dices a qué lugar puedo ir, para ver y observar algunos centros arqueológicos o algo la población misma te dicen

Pónganse en la situación que tienen un fin de semana libre y tienen dos opciones para viajar cuáles son los motivos que optan por viajar, para Uds. es importante que haya servicios de restaurantes que es lo más importante a la hora que toman un circuito turístico, la seguridad, precio cuales son esos factores

$\checkmark$ La seguridad si quieres pasar un momento con la familia hay que ver si hay la posibilidad de comer en un buen restaurante, porque para conocer, para saber, por ejemplo todos los sitios en Puno no cocinan lo mismo, igual en Arequipa tampoco en cualquier sitio tiene su especialidad entonces eso es lo que tenemos que ver nosotros para ofrecer a nuestros turistas

Por ejemplo ustedes chicas que cosas son importantes, por ejemplo tú me comentaste que viajas a los Uros, para ti que es lo más importante cuando tomas esa decisión de viajar, que tengas todos los servicios a la mano, más por un motivo de diversión

$\checkmark$ Pasarlo en familia tratar de conocer

Y digamos así el viaje te demore mucho, lo más importante es la familia, y si tomas la decisión solo tomas la decisión de ir por la mañana o pueden regresar en la tarde

$\checkmark$ Va a depender mucho del horario de los transportes, porque cuando esas zonas no son céntricas o alejadas a veces nos hay el transporte a toda hora, tú tienes que averiguar a que hora puedo regresar y a que hora salen los carros para cualquier lugar

Y por ejemplo dónde tú averiguas esa información

$\checkmark$ En el mismo paradero donde tú tomas la movilidad le preguntas y hasta que hora puedo regresar y ahí te dan la información 
Uds. más que todo van por iniciativa propia a estos sitios, no es que tomen una agencia de viajes guía de turismo

$\checkmark$ Como te decía no hay agencias que ofrezcan estos lugares y si lo hay te arman algo privado y te sale más caro

Y por ejemplo que medidas de seguridad optan cuando viajan, por ejemplo ven que el carro esté bien, tenga SOAT que aspectos ven respecto a seguridad cuando viajan a sitios cercanos

$\checkmark$ Generalmente por mi persona veo que pertenezcan a una buena empresa, presten un buen servicio en una empresa, te dan información del sitio, a que hora salen a que hora regresas

Digamos Uds. ve que a mayor información es más seguro

$\checkmark$ Si claro, es más seguro

Y por ejemplo cuando llegas a un sitio, que tipo de establecimientos sí o sí tiene que ver en ese sitio, farmacias, restaurantes

$\checkmark$ Generalmente que tipo de sitios puedes conocer, por ejemplo en Chucuito hay criadero de truchas, ves el reloj solar, ver las iglesias, entonces por ahí hay circuitos turísticos puedes conocer y haces conocer a tu familia

$\checkmark$ En lo personal creo que va a depender del tipo de viaje que tú estés haciendo, si es familiar o de forma individual, si es familiar siempre vas a buscar la seguridad de tus hijos y la alimentación que sea una buena alimentación y el tiempo que van a estar en el lugar, pero si vas sola o con un grupo de amigos siempre tratamos de ver la forma de economizar, encontrar lo más barato y si es posible desde que salimos ya llevarnos provisiones

Y díganme Qué playas del Lago Titicaca son las que conocen

$\checkmark$ Chiflón, Karina, Charcas y Suasi 
Que percepción tienen de las playas del lago, osea cuando van, hace frio, son limpias, cuál es su percepción de las playas que han visitado

$\checkmark$ Ccotos es la más limpia

$\checkmark$ Karina es la más tranquila

$\checkmark$ Para mi Suasi es una playa muy bonita

Por ejemplo con que frecuencia van a estas playas, en ciertas épocas del año, durante todo el año

$\checkmark$ En verano

$\checkmark$ Uno puede meterse al agua de nueve y media a diez hasta un aproximado de la una o dos, porque de ahí comienza a correr la brisa y es helada, tu sales del agua y estas así, porque adentro te atemperas tú vas entrando y todo normal

Cuáles son los meses en que ustedes van a la playa

$\checkmark$ Mes de Diciembre, Enero, Febrero y Marzo

$\checkmark$ Desde Noviembre que empieza el calor, porque ya termina el invierno

Y por ejemplo cuando van ustedes a estas playas qué buscan: tranquilidad, un momento agradable, relajarse

$\checkmark$ Lo que más queremos es relajarnos

$\checkmark$ Salir del estrés

$\checkmark$ Salir de lo común de la ciudad, por eso allá es campo casi solitario

$\checkmark$ A comparación de las playas, aquí de Puno con las del Norte, aquí si te relajas, si te tranquilizas, porque no hay un montón de gente haciendo todas sus cosas

O sea a comparación de una playa de la costa con unas playas de Puno cuáles prefieren

$\checkmark$ Las playas de Puno porque son más tranquilas

$\checkmark$ Depende también de las playas de la costa hay unas que son más escondidas

Y por ejemplo si les propusiera que ustedes van a vender un paquete turístico para esas playas cuáles son las mayores ventajas que resaltaría de este paquete 
$\checkmark$ Estas playas que hemos nombrado, más son visitadas en épocas de del día del estudiante o actividades escolares, son donde están más llenas, pero si piensas que en un fin de semana vas a encontrar 20, 30 ó 50 personas no es así es muy raro

$\checkmark$ Por ejemplo en Charcas hay como 4 playas una grande, una pequeñita, una pequeñita, una pequeñita, tú te aburres de acá te vas más allá, quieres más soledad como yo, te vas más allá

$\checkmark$ No es como para dirigir un grupo y decir aquí pongo mi empresa iba a resultar no es así, no hay cantidad suficiente para que te resulte a no ser que sea por temporadas como te digo, en las fiestas, que son viajes de promoción, viajes de estudio, desde Septiembre para adelante ahí más o menos hay gente

Cual seria las principales desventajas de ir a etas playas

$\checkmark$ Que ahí no vas a encontrar las comodidades, por ejemplo un restaurante a la orilla

$\checkmark$ La movilidad, porque ahí tienes que ver el tiempo, si vas a Charcas a partir de las 3 ya no hay carro tienes que estar caminando, la mayoría de playas siempre te va a pedir un tiempo porque son alejada del pueblo

$\checkmark$ El problema es que no hay servicio, por ejemplo si tú vas con tu ropa y quisiera alquilar acá no hay eso, no encuentras una sandalia, tienes que ir todo preparado y si hubiera una empresa tú vas por ejemplo miércoles te bañas y te vienes pero acá no vas solito y solo estás por ahí

$\checkmark$ Tienes que ir preparado: tu comidita, tu agua

$\checkmark$ Generalmente la gente va en pareja y se cocina, a lo mucho van a los mercados y compramos fruta gaseosa

$\checkmark$ Por ejemplo antes de ingresar a la playa pasas por un pueblo principal

Ahora como última parte del voy a explicar el proyecto y más o menos lo que queremos hacer.

Les voy a describir la mayor parte del servicio, nuestro servicio es brindar turismo de aventura justamente a zonas que no son conocidas en Puno, la primera zona que vamos atender es justamente las playas de Charcas sólo porque tiene un paisaje muy peculiar y muy tranquilo y 
otro porque hay la posibilidad de hacer otro tipo de servicio por ejemplo tracking, caminatas. Ahora cómo sería el servicio, definitivamente tendría que hacer con una empresa va a ser una movilidad propia de la empresa que los va a traer y llevar ahora, justamente dentro del recorrido se pueden ver varias opciones una de ellas es por ejemplo en Ácora hacer algunas cosas, los llevamos a Charcas y si es que ustedes quieren algún servicio adicional podríamos tercerizarlo un tema de hospedaje de repente, sí es que todo se anima un buffet que no sería tan caro, hacerles un servicio de camping, por ejemplo nosotros les prestaría por todo el tema de las tiendas las carpas el carbón y en la playa haríamos motos acuáticas.

Justamente si esta zona es muy tranquila no hay mucha gente como ustedes dicen, gente que quiere brindar un servicio de alquiler de motos acuáticas más o menos lo que estamos pensando son unos 15 ó 20 minutos por circuito.

Tal como ya le he comentado el proyecto lo verían ideal, del proyecto qué percepción tienen de lo que les he comentado

Podría resultar, no podría resultar

La moto acuática iría con un instructor porque la mayoría de nosotros nunca ha manejado una moto acuática

$\checkmark$ Tiene que ser un experto, hasta los marinos del Callao han tenido miedo cuando vinieron acá, porque las olas vienen de acá vienen acá, tener mucho cuidado con eso

Incluso cuando se haga este servicio de motos acuáticas irían con implementos de seguridad, por un tema del agua, digamos un traje térmico, un chaleco salvavidas el instructor un experto, tendríamos a la mano un paramédico, un enfermera y este un salvavidas, por el tema de que se caen y ahí tendría que acudir un salvavidas entonces más o menos Uds. Como lo ven el proyecto podría ser factible cuando podrían pagar por este servicio

$\checkmark$ En si el cajak cuanto te cuesta

$\checkmark$ Aquí cinco soles en cajak

$\checkmark$ Por cuanto tiempo seria el recorrido

Puede ser entre 15 a 20 minutos, 40 a una hora

$\checkmark$ Este servicio lo ofrecerían aquí en la ciudad o directamente Charcas 
Lo ofreceríamos acá en la ciudad, el punto donde captaríamos seria la plaza de armas y el puerto

$\checkmark$ Va haber algún numero para salir, por ejemplo si yo me animo para salir el sábado, voy compro el servicio y no va porque solamente estas tú y no hay más personas y me quedo con las ganas de ir

Lo ideal sería tener tres salidas permanentes por ejemplo a la 8,con horarios cosa que la gente ya sabría, seria con horarios específicos, si es a las 8 se trata de llenar con todos los que estén

$\checkmark$ Pero sale así haya uno o dos, pero sale

$\checkmark$ La gente así ya tiene confianza y compra

$\checkmark$ Para hacer una empresa yo creo que debe tener las reglas desde que comienza para marketearte hasta el final

Lo principal que se va ofrecer, es a muchos les preocupa el tiempo y eso no solo se da acá sino también en otra zona como Cuzco, no tiene que esperar; es por eso que se puede tener tres horarios de salida, si o si van a salir así sea una persona es para garantizar un poco la calidad del servicio y este como lo considerarían, seguro el servicio

$\checkmark$ Depende a la época, porque aquí en Puno como decía mi compañero por ejemplo en épocas de lluvia aunque el clima es más suave, no hace frio, es peligroso meterse al agua, algunas persona no saben escuchan lago a y piensan algo tranquilo pero aquí no es así

$\checkmark$ No se imaginan

$\checkmark$ Aquí han llegado hasta partirse las lanchas, cuando han ido a las rutas de Taquile

$\checkmark$ Ahí tenemos dos botes hundidos en Amantani

$\checkmark$ Esto es por el viento y el mismo agua ambos hacen la mezcla

Y esa temporada de vientos en que fecha se da

$\checkmark$ En Agosto, ahí es donde te digo que las olas vienen de todo lado y te golpea

$\checkmark$ El viento es problema a veces salen lanchas con turismo y no pueden regresar, te golpea, el viento es fuerte, entonces el piloto al que maneja la lancha no sale

$\checkmark$ De Agosto a Octubre son los vientos 
$\checkmark$ En si el clima esta medio raro hoy en día, eso también hay que ver

$\checkmark$ Por ejemplo antes de que venga la lluvia en esta temporada siempre hay viento y eso genera una tormenta y pienso que también es un mayor problema

Y por ejemplo en meses de Enero y Febrero que cae lluvia

$\checkmark$ Es tranquilo el lago

$\checkmark$ El problema es la lluvia, tienes que ponerlo su protector

$\checkmark$ El clima es impredecible

$\checkmark$ Uno es también vender esa información, tu empresa no va hacer todo el año, si no en ciertas épocas salimos y otras no

$\checkmark$ Que tal mañana tenemos un tour y que tal mañana está lloviendo y el clima se pone agreste, ayer antes de a ayer estaba lloviendo y mira el clima hoy está despejado

$\checkmark$ Y aparte si tu servicio va hacer en Charcas como está el clima allá

$\checkmark$ Aquí puede ser que hay un sol hermoso y si vamos y llegas y toda la lluvia

Entonces para Uds. Es importante saber cómo está el clima allá

$\checkmark$ Porque cuando tú vas hacer algo quieres divertirte al máximo

Por ejemplo que tiempo considerarían sin van hacer motos acuáticas, cual es el tiempo que Uds. consideran suficiente para viajar en motos

$\checkmark$ De 20 a 30 minutos

Y por ejemplo les pongo el papel que Uds. son los empresarios, en que meses Uds. ofertarían este servicio conociendo ya todo, Uds. mismo ya conocen como es el clima del lago durante todo el año en épocas de lluvia, viento frio, en que meses son los que ofrecerían más el servicio

$\checkmark$ En lo personal trataría de aprovechar las fiestas aquí en Puno, por ejemplo la Candelaria que empieza ya los últimos días de Enero y casi hasta la quincena de Febrero, no hay espacio para uno más, ahí es donde gente que viene a Puno a lo mucho están en la parada y el domingo y a veces ellos no saben qué cosas más hacer, poderles ofrecer estas alternativa seria grandioso

Entonces los meses más fuertes serian en los meses de la Candelaria 
$\checkmark \quad$ Y otro también en Noviembre

Y que meses definitivamente no ofrecerían el servicio ya sea por clima, frio

$\checkmark$ En tiempo de helada

De Mayo a Agosto más o menos

$\checkmark$ En Octubre los viento

$\checkmark$ En lo personal yo considero que si quieren vender este servicio tiene que ya ofertarlo ya desde Lima, porque como todos sabemos los pasajeros vienen ya con un plan de Puno, dos días, tres días y esto, porque de que tu vengas aquí y quieras ofrecerles algo más que ellos quisieran hacerlo te van a decir no puedo porque ya mis días están limitados solo puedo visitar las islas y no más

Una forma de promoción seria jalar el público desde Lima, ya ofrecerles el paquete completo

Y si quisiera promocionar eso para acá la población en Puno, cuál sería la mejor alternativa de promocionar, de repente la radio, televisión, periódicos

$\checkmark$ La televisión es lo mejor que puedes hacer

$\checkmark$ Utilizar todos los medios posibles, porque he visto que habido casos en que han tratado el mismo Municipio, Gobierno Regional de ofertar lo que es el turismo de aventura, hasta han sacado su publicidad por radio y han dicho tan fecha en la plaza de armas nos reunimos va haber un bus todos lo que quieran hacer tales cosas y no habido mucha acogida

Y por ejemplo acá cual es el canal de televisión que más ven

$\checkmark$ TV UNA, América

$\checkmark$ Pero para que salga más comerciable lo pasas por telecable y es barato

$\checkmark$ Yo creo que es más la radio que usan

Y que radio es la que más escuchan

$\checkmark$ Onda azul y pachamama y Mi radio, yo escucho siempre eso ahora mismo voy aprender

$\checkmark$ Pero eso no escucha el turismo extranjero en Lima no se escucha todo eso 
$\checkmark$ No pues para ya promocionar a los turistas nacionales utilizar la televisión

Y por ejemplo ya que les he descrito el servicio lo contratarían y cuanto pagarían por ello, cuanto estarían dispuestos a pagar

$\checkmark$ Pero que me ofreces solamente el paseo en motos acuáticas

Sería el transporte, de Puno a Charcas y el alquiler de las motos acuáticas y si quisieran un adicional por ejemplo comida podrían ser unos 20 soles más o si es que quieren camping o alojamiento puede ser entre 40 o 50 soles más fuera del precio del alquiler delas motos acuáticas. El servicio básico es tu transporte de Charcas a Puno ida y vuelta

$\checkmark$ Por ejemplo para irte a Amantani que te toca dormir allá te sale no más de 100 soles incluyendo que vas en una agencia, vas con un guía, te ponen el desayuno el almuerzo, la cena en la casa de la familia, luego regresas a Taquile y la visita a los Uros y todo con un guía, entonces yo me hago una idea de lo que podría pagarte

$\checkmark$ Yo pienso también eso pagaría 100 soles

$\checkmark$ Había hace tres meses que han lanzado para Sandia los lugares de esa zona se contactaron agencia de acá y una promoción para que puedan conocer un poco más ese lugar, ese servicio contaba dos noches de hospedaje claro tenía que llevar sus carpas todo pero te daban alimentación, desayuno, almuerzo, cena y habían también parapentes incluido dentro de ese paquete y movilidad desde Puno hasta Sandia ida y vuelta por ejemplo todo ese paquete estaba en promoción por primera vez 50 soles, como estaban sacando para conocer entonces conversaron con las universidades, con los docentes de turismos así, se contactaron con ellos como hay en la universidad más de 7000 estudiantes se contactaban también, estaban publicando por radio, televisión todo y habían un tope mínimo de 500 personas, máximo perdón hasta 500 personas, entonces habían gente aunque yo no he ido mis compañeros asistieron a eso entonces habían 500 persona que habían ido ahí, pero según nos comentaron los docentes no ha salido muy bien como ellos pensaban, ellos pensaban pasar maravillas no todos han disfrutado de eso, muchos han regresado desganados, pero todo este paquete estaba 50 soles

Como una especie de promoción

$\checkmark$ Claro 
Y tú por ejemplo me comentaste que eres de allá de Sandia, por ejemplo cuando viene paquetes ya desde Lima por ejemplo cuanto les cobran

$\checkmark$ Paquetes de Lima no, si lo que he visto persona que viene de Arequipa familiares no le sale más de 100, así porque el pasaje esta 20 soles y los productos así no cuesta tanto porque es zona de agricultura entonces frutas hay, papa todo en sí, un poco más familiar la gente bien acoge a los visitantes, también tiene agua termales Hajunputina le llaman, entonces pueden aprovechar los que quieren viajar no solo visitar lugares sino también montañas, cataratas, tal vez lo que dijo mi compañero tal vez no visitaron porque no conocían hay muchos, como vuelo de cóndores, luego hay es como un puente gigante que se llama Arcopunco le decimos pero creo que ni en Perú existe ese puente, creo que he escuchado hablar de Estados Unidos es grandazo 5 metros así, pura piedra, entonces cuenta la leyenda de que un puma pasaba y se ha convertido en piedra, tiene chulpa también y también hay una laguna que se bañan los cóndores, ahí puedes ver que los cóndores se bañan y también son aguas termales y andenes son como Huaruhuarus así encima de los andenes hay los incas tienen chulpas, dicen siempre en mes de Agosto los lugareños de ahí van y entonces y medianoche se sientan y dicen que vota fuego así los incas han enterrado oro, siempre hay esa excavaciones así.

Cuáles son los mejores meses para ir a sandia

Todo el año tiene diferentes calores, no es ni tan frio ni tan caliente es templado

$\checkmark$ Es ceja de selva en si

$\checkmark$ Los huaycos más bien por la carretera son desde Diciembre hasta Marzo, cuando llueve hasta buses se lo puede llevar fácilmente son cataratas en si

Y un servicio de parapente allá cuanto te cuesta

$\checkmark$ No hay ese servicio

$\checkmark$ Lo que estaba hablando es algo que lo había promocionado de forma extraordinaria

$\checkmark$ Turistas también han llegado yo he visto en el 2014, hay un docente de Sandia que trajo, hay llicllas así ven que el traje de las chicas te cuesta y en si a los turistas les gusta, en si tejido a base de mano, es original en sí, yo digo si pueden hacer una tesis así, Sandia yo 
les digo que en un mes así puede tener acogida de más, porque Puno promocionando ya conocen en si

$\checkmark$ Lo que no le ayuda a Sandia promocionarse es la carretera, porque tu vas en la carretera ya estás viendo un abismo, imagínate transportarte en época de lluvia sabiendo que hay huaycos, es muy arriesgado

$\checkmark$ Yo también tengo mi idea de hacer una tesis de turismo sostenible de Sandia, Cuyo Cuyo Por lo que me han estado comentando los profesores de la universidad promocionan mucho paquetes turísticos de lugares no muy visitado es cierto, entonces ellos podrían ayudarnos a que ellos nos promociones sería una buena idea

$\checkmark$ Igualmente a las agencia, las agencia son los que mueven eso la agencia lo vende

$\checkmark$ El docente mueve al alumnado que también no es muy poco, pero es un tiempo no, hasta que los conozcan, pero si ya lo vendes desde una agencia de viaje desde Lima, ya conocen y a quien se le llama la idea, la nueva experiencia, haber porque no conocerlo, porque no probarlo

De repente podríamos tener más acogida del proyecto si lo hacemos por agencia y traemos gente de otro lado, más que de la agencia de Puno

$\checkmark$ No tanto así, yo creo que primero tendríamos que trabajar en los medios, sobre las necesidades básicas, el transporte, la alimentación y el hospedaje si estas tres cosas, tú lo encuentras en el lugar que quieres promocionar te va ir bien, pero sino hay un buen medio de transporte no sabes ni cómo llegar tienes que esperar una hora para llegar al lugar turístico para ver solo una Chulpas entonces no es suficiente Bueno podríamos ya dar terminada la sesión, agradezco mucho su participación 
Focus 02

Soy estudiante de la maestría en la San Ignacio de Loyola, vamos hacer una pequeña entrevista de profundidad en este caso un focus group lo que le voy a pedir que cada uno se presente: diga su edad, su nombre, que está estudiando y más que todo después vamos a pasar a las preguntas.

$\checkmark$ Mi nombre es Guido estudio administración de empresas en la universidad andina de Puno

$\checkmark$ Mi nombre en Kenyo estudio administración y marketing en la andina también tengo 22 años

$\checkmark$ Mi nombre es Edel yo tengo 27 años también estudio administración y marketing

$\checkmark$ Mi nombre es Milton tengo 21 años y estudio contabilidad

$\checkmark$ Mi nombre es Geanpool tengo 21 años y estudio administración y marketing

$\checkmark$ Yo soy Jessica estudio también administración y marketing y tengo 23 años

$\checkmark$ Me llamo Edith soy estudiante de administración y marketing en andina tengo 22 años

$\checkmark$ Me llamo Katerine estudio administración y marketing y tengo 21 años

Bueno chicos la primera pregunta que quiero hacerle es que tipo de actividades hacen en sus ratos libres, puede empezar cualquiera

$\checkmark$ Hacemos escalada por la salida de Puno y también en las cataratas de Totorani

$\checkmark$ Yo paseo por los Uros, Taquile, por el puerto, las playas de Charcas, Chiflón, Ccotos, que se encuentra en la provincia de Ácora

$\checkmark$ También se pude decir dos islas hermosas que se encuentran en Taquile y Amantaní

$\checkmark$ En mis ratos libres también yo juego deporte y practico la natación en las piscinas de Puno y de la universidad

Cuando Uds. Suelen contratar un servicio turístico o van a un lugar cercano a los alrededores de Puno ósea de repente Charcas, Chucuito que factores son determinantes para Uds. Para ir a esos sitios digamos el presupuesto, el tiempo, que haya de repente servicios básicos en la zona de repente un restaurante, alojamiento. Osea antes de viajar que es lo que se ponen a pensar de lo que pueda ver ahí y hace que Uds. se decidan a viajar de repente por un tema de aventura o Uds. simplemente viajan, quisiera que nos expliquen un poco eso 
$\checkmark$ Yo principalmente veo la atención de la agencia y los servicios que vayan a ver en el lugar que vamos a ir

$\checkmark$ También puede ser para compartir con la familia los días domingos o también servirnos los alimentos en esos lugares alejados

$\checkmark$ Puede ser las costumbres que tiene cada pueblo, cada distrito, sus fiestas sus comidas, sus deportes que también se hacen ahí, cakay, campamento.

Y por ejemplo que lugares turísticos son a los que normalmente van

$\checkmark$ En grupo o con personas

Puede ser en grupo, individual

$\checkmark$ Lo más bonito y creo que todos coinciden en July, es lo más bonito para pasear, tiene arqueología, tiene su lado de playa, es una zona muy divertida

$\checkmark$ También Chucuito no está muy lejos y hay lugares muy bonitos para ver, como la piscigranja, el Templo de la Fertilidad, también que es muy conocido y también se puede comer rico allá

$\checkmark$ Yo comparto con mi compañero de July porque es una ciudad pequeña, tiene como cuatro iglesias y sobre todo la playa es muy limpia

$\checkmark$ Las islas flotantes de acá de los Uros, Taquile, Amantaní ahí más que todo se puede ver las costumbres, la comida la forma de vivencia de ese lugar

Chicos por ejemplo cuando van a esos sitios por cuánto tiempo se quedan, es solo por el día es medio día o se quedan de una noche a otra, por cuanto tiempo van

$\checkmark$ Los fines de semana, sábados y domingos

$\checkmark$ puede ser también un día feriado y se aprovecha en salir

$\checkmark$ En grupo y con familia

Y por ejemplo si contratan a una empresa para que les brinde un tour que es lo principal como medida de seguridad que Uds. Ven antes de decidirse por una agencia o esta empresa para poder realizar el viaje

$\checkmark$ Creo que es dependiendo si vamos a viajar por tierra obviamente la seguridad del carro, si vamos a ir por vía lacustre creo que es mayormente ver la seguridad de la embarcación y 
que agencias casi la gran mayoría de los chicos de acá no tomamos agencia, nos aventuramos no mas

$\checkmark$ Nos aventuramos a ver lo que salga

$\checkmark$ Se van a la aventura

$\checkmark$ Cuando tú vas, bueno si no es por agencia, tú vas al puerto y ahí mismo te ofrecen paquetes ahí mismo hay oficinas o simplemente hay lanchas, o los dueños de las lanchas que te ofrecen los paquetes en los terminales no, en el terminal provincial o departamental hay carros igual que te llevan los minivan, tomas y te llevan al lugar que quieras dependiendo del grupo que tienes ahora si es una sola persona de hecho es agarrar no mas

$\checkmark$ Lo mejor es ir en grupo porque tiene la ventaja de tener menos precio te ofrecen menos Les ofrecen mejores paquetes Y una consulta cuanto suelen gastar así en general cuando van a esos lugares

$\checkmark 150$ soles a los mucho, por estudiante algo leve

$\checkmark$ Eso fue dos noches creo, dos días y una noche más o menos salió ese costo de 150 soles

$\checkmark$ Pero fue un día entero en lancha al lugar que fuimos, también eso fue en los estudios de la carrera y viaje de estudio y del curso

Y cuales son las playas que más conocen del lago Titicaca cuales son las que más frecuentas

$\checkmark$ Chacas, Chiflón, Ccotos, Capachica, playa de Chatuma, July

$\checkmark$ Pero el lugar más amplio es Charcas y más limpio

Y si les dijera cuales son las tres mejores playas del lago Titicaca cuales serían

$\checkmark$ Charcas, la de Capachica y la de July son las más limpias y las más cómodas también En esas tres playas hay alguna desventaja en esas playas cuando viajan, digamos no hay algo que Uds. si necesitan

$\checkmark$ Comida, lo primordial, no hay mucha comida

$\checkmark$ Hay que llevarse la comida 
$\checkmark$ Lo que es de Charcas no hay restaurantes, son lugares alejados del pueblo, lo que pasa es que la gente del pueblo baja allá a vender y ahí se las arreglan para llevar alimentos, ahora lo que es July ahí hay pequeños kioscos en la misma playa

Si es por ejemplo por un tema de comidas es más a July que a Charcas, pero digamos que Charcas sería la más limpia ahora

$\checkmark \quad$ La de July también es limpia

Y por ejemplo en que mese Uds. van a esas playas

$\checkmark$ Día del estudiante, en Setiembre, en Agosto y Setiembre

$\checkmark$ Por día del estudiante más que todo, van las universidades, colegios

Y una consulta durante todo el año Uds. van a esas playas o hay meses en que para nada van a esas playas

$\checkmark$ Por temporadas

$\checkmark$ No se puede ir en Junio en Diciembre porque hace frío y la lluvia, pero los demás normal en cualquier momento

$\checkmark$ En cualquier momento a modo de pasear, distraerte un rato

Y por lo general en esas playas que tipo de actividades hacen, solamente van a bañarse a hacer campamento, van a juerguear, que es lo que realizan en ese tipo de playas

$\checkmark$ En July hay motocross, hay cajak y también hay parapente esas tres cosas

$\checkmark$ Esas cosas que se lanzan

Y esos servicios por ejemplo cuanto están en promedio

$\checkmark$ Está cinco soles creo dos vueltas y el cajak está igual cinco soles por persona

Y en estas zonas de las playas hay alguna festividad o no hay festividades

$\checkmark$ Sí que yo sepa en Capachica hay la fiesta mis Chiflón

$\checkmark$ Que es su aniversario de esa población y lo hacen junto con eso en la misma playa

$\checkmark$ Ahora en July hacen la elección de la señorita carnaval pero en la playa 
Bueno ahora les voy a explicar un poco de que consiste el proyecto que estamos evaluando, nuestro proyecto va hacer brindar servicios de motos acuáticas para el lago Titicaca la zona donde sería el circuito sería en las playas de Charcas por un tema de paisaje, tranquilidad y el lugar es bastante amplio la verdad y les voy a explicar un poco del servicio.

Nosotros los contactaríamos acá en la ciudad de Puno, el servicio incluiría en servicio de transporte de Puno a Charcas ida y vuelta, una vez llegando a Charcas se hace el circuito de moto que puede ser entre quince a media hora se le hace una servicio especial si ya tiene una experiencia con este tipo de artefactos una especie de rampas especiales donde tú puedas saltar y durante tu paseo se va a ofrecer un servicio de filmación que va hacer con unas cámaras gopro y mientras tu manejas tu moto la cámara te va estar filmando y ese video se les pasaríamos más adelante mediante faceebook, youtube o mediante un correo, ahora otro servicio adicional que podríamos brindar acá es un tema de alojamiento, comida o camping, entonces lo que yo quiero que me digan es como ven el proyecto que se pongan un poco en los zapatos del empresario y digan sabes que en estos meses puede que funcione este mes va hacer muy bajo, la idea esta buena pero falta algo más quiero que sean muy libres en expresar lo que piensan más o menos ese sería el proyecto que se está haciendo

$\checkmark$ A mi parecer no creo que funcione porque principalmente la distancia, está un poquito lejos Charcas, no es tan accesible, no es tan visita por temporadas que no sean en mes de Setiembre, lo que yo te sugiero es cambiar otro lugar, por ejemplo otro lugar es July porque allá todo el año es visitable al menos los meses de Enero, Febrero y Marzo que son de vacaciones, empiezan carnavales, y toda la gente es netamente de July regresan de Lima del extranjero, en carnavales es donde hay más movimiento allá en July

$\checkmark$ La otra opción sería la de Capachica, la de Chiflón porque también por ahí hacen turismo vivencial y hay turistas que van hacer bicicleteada, tracking, canotaje, como le dije hacen turismo vivencial esa es una no, Charcas como dice mi compañera es un mercado no muy abierto porque es temporal nada más, solo se va en Setiembre y el día del estudiante, son los únicos días, en Capachica como le vuelvo a reiterar ahí hay turismo casi todo el año y en July igual casi todo el año no hay para, esos son mercados potenciales creo yo

Sería más viable poner un proyecto en esa zona

$\checkmark$ Es muy accesible el lugar, hay carreteras que se pude ver 
Por ejemplo en tema de tiempo de viaje es más cerca ir a estas playas, es más fácil que llegar a Charcas, hay más afluencia, más transporte

$\checkmark$ Lo malo es que para Charcas tienes que llevar tu propia movilidad, pero si hay un carro particular que te deja ahí y luego no hay como poder regresar, no hay forma de regresar

$\checkmark$ En July por ejemplo hay carro hasta muy tarde, todos los días de Capachica igual hay carro todos los días, la movilidad es muy indispensable creo yo

Por ejemplo en estas playas que me mencionan los meses de más frio son Mayo, Junio y Diciembre, esos meses nadie va

$\checkmark$ Diciembre por la lluvia, mayormente por la lluvia nada más, agosto por la helada nadie va

$\checkmark$ Después es solecito

Por ejemplo si el proyecto fuera en estas playas cada cuanto tiempo irían hacer motos acuáticas

$\checkmark$ Yo iría cada 15 días creo

$\checkmark$ Claro depende no, si es para desestresarte ahí por ejemplo Capachica es por ejemplo una población de dos ejes comerciales tanto Juliaca como Puno, si es que haces tu publicidad los de Juliaca pueden venir a Capachica que van, porque dos movilidades van tanto de Capachica como para Juliaca y de Capachica para Puno

Osea en las dos ciudades el punto medio sería Capachica

$\checkmark$ Exacto

$\checkmark$ Entonces es una zona comercial

$\checkmark$ Mayor afluencia

$\checkmark$ July también porque esta Puno, esta Ilave, desagüadero, Yunguyo y hay mucha población también por ahí

Por ejemplo que precio Uds. Le podrían a este servicio si les incluimos el transporte, cuanto Uds. Estarían dispuestos a pagar

$\checkmark$ De acuerdo al tiempo, por ejemplo 10 minutos 15 minutos 
El tiempo suficiente sería 15 minutos a 30 minutos, y si les dijera también que van a tener ropa térmica, salvavidas, cuanto estarían dispuestos a pagar por eso

$\checkmark \quad 10$ soles a 15 soles

$\checkmark 10$ soles

$\checkmark \quad 10$ soles a 8 soles

Si se les incluye el servicio de transporte aumentarían algo más o sería lo mismo, cuanto más aumentarían

$\checkmark$ Por acá lo han intentado el Libertador ha traído y se atoraban

$\checkmark$ Decíamos que el Hotel Libertador hacia una promoción de motos acuáticas, traían de Lima sus competidores y habían un problema como esa parte está un poco contaminada entonces las algas del lago se pegaban al motor de las motos, al hélice y se atoraban y no funcionaba, pero las playas que les dijimos no hay esas algas está limpio

Y Uds. no me dijeron cuanto pagarían

$\checkmark$ Creo que en Lima el costo es de 10 soles y es media hora

Y si Uds. fuesen los empresarios y les cobraran eso a un turista nacional o extranjero, cuanto les cobraría

$\checkmark$ Normalmente como administradores categorizamos por escalas, por status, acá normalmente como es Cuzco cobran a los nacionales menos y a los extranjeros un poco más, por la calidad de servicio me imagino que debe haber, deberían ser iguales en calidad

Y si por ejemplo fuese en esas playas donde Uds. me dicen recomendarían el servicio, lo contratarían

$\checkmark$ Sí

$\checkmark$ Sí

$\checkmark$ Sí 
Y ven alguna desventaja si fuese en esos sitios, de esas dos playas que Uds. me han dicho, ponte en el caso que ahí estuviesen las motos acuáticas le ven alguna desventaja a alguna de esa zonas para implementar el servicio

$\checkmark$ No hay una desventaja creo yo

Hay más condiciones favorables que Charcas

$\checkmark$ Claro mucho mejor

$\checkmark$ Claro depende del público que quieras captar, Charcas como dijo tienes que ir con tu movilidad, nuestro grupo por ejemplo tendríamos que tomar un carro particular y estaríamos gastando parte del dinero, por ejemplo si vas allá, Capachica, el pasaje esta 3.5 soles y ya te regresas

Bueno chicos gracias por su opinión han sido muy sinceros y damos por terminada la sesión muchas gracias 
Focus 03

Vamos a tenerlo firmado para tener una mejor evaluación del proyecto, vamos hacer una serie de preguntas muy sencillas, para esto vamos a empezar con presentarnos quienes somos y a que nos dedicamos, comenzamos por aquí por favor digan sus nombres y que hacen en el tiempo libre

$\checkmark$ Mi nombre es Eguiluz en las tardes estudio

$\checkmark$ Mi nombre es Karina yo trabajo en la agencia casona tours en mis tiempos libres leo

$\checkmark$ Mi nombre es Karen trabajo en la casona plaza en mis ratos libres me dedico hacer la tesis

$\checkmark$ Mi nombre es Marcos y casi no dispongo mucho de ratos libres, paso todo el día trabajando

$\checkmark$ Mi nombre es Sonia trabajo en casona plaza, en mis tiempos libres me dedico hacer otros quehaceres de la casa y también con mis hijos me gusta pasar el tiempo con mis hijos

$\checkmark$ Mi nombre es Maria Luisa yo estudio por las tardes

$\checkmark$ Mi nombre es Sandra yo trabajo en la casona plaza en mis tiempos libres, la gran parte estoy en la universidad y en la empresa

$\checkmark$ Mi nombre es Jennifer trabajo independiente en mis tiempos libres estoy con mi hija

Ahora vamos a pasar a explicarles un poco que es un circuito turístico como todos saben más que todo es un recorrido por lugares que son conocidos en cualquier ciudad o país los cuales se realizan tomando puede ser un bus, pueden ir en bicicleta, pueden hacer tracking, escalar, muchas formas para que Uds. hagan circuitos turísticos

Empezamos con una pregunta que es para cada persona, si ustedes conocen lugares turísticos de Puno y cuales lugares turísticos

$\checkmark$ Conozco Sillustani, Pucara, Tinajani, Chucuito y muchos lugares más

$\checkmark$ Los lugares turísticos que yo conozco son las más conocidos las islas del lago Titicaca los Uros, Amantaní, Taquile, Sillustani, la ruta Aymara que es July, Chucuito y Pomata y también el corredor quechua, otros lugares que son muy conocidos como Cutimbo solo eso

$\checkmark$ Bueno como todos también yo diría las islas, Sillustani, Chucuito 
$\checkmark$ Yo conozco Taquile, Amantaní, Pukará casi los lugares que la mayoría conoce

$\checkmark$ Lo lugares turísticos que yo conozco es la isla de Taquile, Amantaní, Cutimbom, Sillustani, Pukará, Chucuito, los más frecuentes son la isla de los Uros también

$\checkmark$ Yo conozco las islas de Taquile, Amantaní, Sillustani

$\checkmark$ Bueno como ya han mencionado la gran mayoría de nosotros conoce el lago, Amantaní, los Uros, Pukará, Chucuito y July.

$\checkmark$ Bueno yo soy de Arequipa estoy viniendo por segunda vez a Puno y solo conozco lo que es el lago Titicaca, he ido a otros sitios no sé cómo se llamaran donde estaba el cóndor

Ahora donde creen que Uds. Pueden obtener información necesaria para estos circuitos turísticos

$\checkmark$ En agencias, con amigos

$\checkmark$ Creo que la información más completa la podremos obtener en agencia de viajes como su nombre lo indica en una agencia se dedica hacer circuitos turísticos, viajes, paquetes donde ellos te pueden dar mejor información, pero ahora como todos hemos visto en los turistas también ya más buscan en internet, también ya ahora existen paquetes y destinos para comprar ya directamente sin intermediarios de las agencias sino ya directamente también

$\checkmark$ Yo creo que el mayor medio de información es el internet

$\checkmark$ Muy aparte del internet, también las agencia de viaje, también personas por ejemplo la policía de turismo porque se han capacitado y te dan información

$\checkmark$ Ya lo han mencionado más que todo por internet

$\checkmark$ Yo también creo que es por el internet

$\checkmark$ La ventaja es que las agencias de viajes nos dan los lugares que podamos visitar, pero también por el medio del internet

$\checkmark$ Por agencias, por internet, quizás alguna amistades que te recomienden Cuanto gastarían, cuanto creen que podrían gastar por un circuito turístico

$\checkmark$ De unos 200 a 300 soles, también depende del circuito también Cuanto gastarían, cuanto tiempo Uds. Creen un día dos días

$\checkmark$ Cuatro a cinco días 
$\checkmark$ Yo pagaría por un circuito 350 soles aproximadamente, los tiempo sería tres días dos noches

$\checkmark$ Yo aproximadamente de 250 a 300 soles en un circuito de dos días

$\checkmark$ Yo un promedio de 250 soles, porque estuve dos noches con hotel

$\checkmark$ Por ahí yo un promedio de 250 a 300 soles por dos días

$\checkmark$ Tengo la experiencia de ir a las islas donde uno se gastó de 150 a 200 soles

$\checkmark$ De acuerdo al lugar que elijas me imagino de 200 a 300 soles, fuera de los objetos que tú puedas comprar en los lugares

$\checkmark$ Yo creo que sería recomendable de 250 a 350 soles, para que no te quedes con las ganas

Que les motivaría o desmotivaría en el momento de elegir un circuito turístico

$\checkmark$ Conocer nuevos lugares

Que desmotivaría

$\checkmark$ El clima

$\checkmark$ Me motivaría conocer nuevo lugares turísticos y si son de aventura mejor porque en Puno no hay ninguna agencia que te de este tipo de servicio y menos un servicio compartido si te ofrecen cajak o traking, es solo para servicio privado y es bastante caro si hay una agencia que preste esos servicios motivaría mucho, lo que me desmotivaría personalmente es que me pidan bastantes documentos

$\checkmark$ Yo creo que me motivaría hacer un tour así el hecho de conocer también lugares y sentir digamos la adrenalina o salir fuera de la ciudad y me desmotivaría algunos precios que son bien elevados

$\checkmark$ Me motiva el turismo místico muy aparte y me desmotiva la atención al cliente, otro sería la oferta la demanda a veces el costo que suele ser mucho y a veces no te alcanza, y por últimos el recibimiento la bienvenida que te dan la isla de Taquile por ejemplo

$\checkmark$ A mí me motivaría conocer más lugares turísticos el otro sería los precios que dan a veces son muy elevados

$\checkmark$ A mi motivaría tener nuevas experiencias, divertirme; lo que me desmotivaría que la gente no sea agradable

$\checkmark$ Me motivaría tener nuevas experiencia y conocer lugares y diversión 
Me motivaría conocer nuevos lugares, tener nuevas experiencia, la adrenalina; lo que me desmotivaría sería de repente que no pueda llevar a los niños.

Qué medidas de seguridad creen Uds. Que son necesarias

$\checkmark$ De las medidas de seguridad pienso que la gente que va adquirir el servicio tendría que tener un seguro, después la velocidad, el oxígeno todo el servicio que nos van a prestar cuente con todo lo que la entidad encargada de fiscalizar

$\checkmark$ Más que todo de acuerdo al servicio deberían contar con chalecos salvavidas

$\checkmark$ En las lanchas cuando van de viaje los turistas no tiene botiquín y si lo tienen no lo tienen muy completo, falta de chalecos salvavidas y muy aparte debería ver un personal que sea capacitado en caso que suceda un accidente, que tal los turistas se caen al agua, y si hablo de buses el traslado del hotel al puerto siempre es necesario que el chofer sea capacitado

$\checkmark$ Toda empresa debe tener chalecos salvavidas y que si deben tener capacitación

$\checkmark$ En cuanto a seguridad que tengan ante todo sus chalecos que es lo más importante y que haya persona capacitadas

$\checkmark$ Chalecos, que tengan un seguro en caso de un accidente

Ahora pasemos a lo que es el lago Titicaca, me imagino como Uds. viven aquí, conocen sobres las playas que hay alrededor de las playas que hay en el lago Titicaca, que playas conocen

$\checkmark$ Yo conozco Charcas, Chiflón solo esas playas conozco

$\checkmark$ Yo conozco las playas de Chiflón, de Charcas de July también allí sabemos que hay playas

$\checkmark$ Yo conozco Chiflón, Chatuma, Charcas, July, la otra que está en Capachica también

$\checkmark$ Yo conozco Charcas

$\checkmark$ Las playas más conocidas son Charcas, July

$\checkmark$ Yo conozco July, Charcas

$\checkmark$ Yo conozco las playas de Charcas

$\checkmark$ Como dije a las justas he llegado al lago Titicaca

Y que actividades han desarrollado ahí en el colegio, con la familia 
$\checkmark$ Yo tuve la oportunidad de ir con mis compañeros, fuimos a jugar y nadar

$\checkmark$ Igualmente en las oportunidades que yo he ido, hemos ido a jugar a bañarnos, además en esos lugares no hay otra cosa que se pueda realizar, si vas hay un pequeño barco que te puede llevar a realizar un paseo de 10 o 15 minutos y nada más

$\checkmark$ Claro usualmente la gente que visita esas playas son por paseo entre compañeros

$\checkmark$ Los motivos son por paseo, diversión

Que actividades has hecho, el frio no influye

$\checkmark$ Nadado, al medio día hace calorcito, pasada la tarde empieza el frío y ya no te da ganas de meterte al lago

$\checkmark$ Mayormente cuando vamos a divertirnos en familia, a conocer más, desestresarnos, y a veces también mucho trabajo también cansa más, que todo es por eso que vamos

$\checkmark$ Yo mayormente voy con mis compañeros vamos a divertirnos, a jugar, a nadar

$\checkmark$ Bueno si las playas que vamos nos organizamos entre amigos, nos organizamos por grupos para llevar de comer, beber, de los deportes por lo general el vóley y futbol, natación a modo de estar jugando y al que no quiere meter al agua igual lo obligamos

Ahora hablando del proyecto en sí, como ya conocen las playas de Charcas nosotros estamos pensado ubicar nuestro proyecto que es alquiler de motos acuáticas mediante un circuito en las playas de Charcas, que les parece la idea, no hay un orden, cualquiera puede opinar, lo creerían que es viable que iría el proyecto

$\checkmark$ Siempre y cuando como dijimos considerando las medidas de seguridad, y siempre preservado el cuidado del agua

$\checkmark$ Como les había comentado inicialmente no hay ninguna agencia en Puno que ofrezca servicio de turismo de aventura, entonces me gustaría saber en caso que se llegue hacer realidad el proyecto sería servicio privado, servicio compartido

La idea inicialmente es tener una agencia en Puno en donde cualquier persona que viva acá en Puno ya sea turista nacional vaya a la agencia y nosotros nos encargamos de llevarlo a las playas, cualquier persona puede utilizarlo no es privado 
$\checkmark$ No el servicio, porque cuando es privado es bastante caro si es un compartido ya es accesible

Claro es un compartido una minivan los lleva, los recoge y todo, no es algo exclusivamente que vayan a tener que pagar para ir, entonces es para todos, si igual alguno de Uds. Digamos quisiera ir con sus compañeros se alquilarían un bus, y nada más irían y alquilarían su paseo en motos y nada más, es algo que todos van a poder realizar.

La seguridad es lo que más les preocuparía en este caso, como es la primera vez que ustedes van a manejar una moto acuática en el lago es un poquito más complicado, es una nueva experiencia, es algo que disfrutarían bastante

Con que frecuencia más o menos irían, digamos una vez al mes, cada dos meses, cada semana

$\checkmark$ Depende del precio

Hablando de precios, un precio más o menos acorde al mercado, Uds. Cuanto pensarían que sea por ejemplo por 30 minutos un circuito en moto acuática, que precio le pondrían

$\checkmark$ Unos 80 soles a 100 soles

$\checkmark$ Unos 40 minutos a 80 soles pagaría

$\checkmark$ Unos 80 soles a 100 soles

$\checkmark$ Unos 50 soles

Dependiendo del tiempo verdad, si son 15 minutos, puede ser 30 soles, si subimos a media hora puede ser 60 soles

$\checkmark$ Para que la gente no se quede con las ganas

Finalmente a este servicio le agregaría otros servicios como almuerzo, camping, alojamiento o estaría solo bien el servicio de motos

$\checkmark$ No creo ya que Charcas está en el distrito de Ácora, entonces está en la ruta aymara, podrían aprovechar de hacer el circuito turístico hacer el turismo de aventura en la moto y retronamos a Puno, también hacer solo eso va hacer muy simple, para complementarlo creo que deberían agregar otros lugares que están en la ruta 
Y alojamiento, Uds. Quisieran alojamiento, alimentación, o quisieran camping, digamos que Uds. Nos digan vamos a ir con 20 amigos y queremos hacer un camping los 20 y hacerlo en las motos y es más comer ahí también

$\checkmark$ Serian bonito también camping para ir con todos los amigos ahí

$\checkmark$ Creo que deberían tener varias alternativas, porque los turistas van a querer llegar y conocer Chucuito otros lugares y también hacer eso, nosotros ya conocemos porque somos puneños vamos a querer ir y hacer el camping y nada mas

Y hacer eso nada más camping o las motos, Uds. ya conocen en realidad no es hacer turismo en cada lugar, solo hacer lo que quieren ver el funcionamiento y ya esta

Uds. Lo contratarían el servicio y lo recomendarían a otras personas

$\checkmark$ Si es seguro, hay muchas personas a los que les gusta la aventura, la adrenalina y van a querer ir muchas personas

Y más que Uds. las respuestas que nos han dado es que quieren calidad de servicio, que la seguridad que es lo principal, obviamente Uds. tienen miedo que les pase algo, no solamente Uds. si que pueden llevar a sus hijos, sus padres, por eso más que todo sería incluir lo que es el camping para que sea más familiar y puedan estar todos juntos y pasar un momento agradable

Bueno muchas gracias por su tiempo, nos ha servido mucho su apoyo y sus comentarios Gracias 
Focus 04

Buenas tardes somos alumnos de la Universidad San Ignacio de Loyola de Arequipa, de la maestría de ciencias empresariales, estamos haciendo un focus group de lo que es turismo de aventura en la ciudad de Puno

Para comenzar una breve mención de que opinan del turismo de aventura acá en Puno, como está desarrollando

$\checkmark$ No hay, y si hay muy poco lo difunden

Sobre lo que es ciclismo, cajak, canchas

$\checkmark$ Si hay pero, por ejemplo en la zona de Capachica, Llachón, algunos cajak pero no son muchos, pocos no más en ahí si hay bastante turismo en los meses de Julio y Agosto ahí viene los turistas

Que lugares tiene ahorita Puno así que son emblemáticos para hacer turismo

$\checkmark$ Los Uros, Amantaní, Taquile, Chucuito también

$\checkmark$ Camino a Juliaca el Sillustani

Y sobres las playas que tiene el lago conocen las playas conocidas

$\checkmark$ Charcas

$\checkmark$ Chiflón

Y que hacen en las playas Uds. Cuando van

$\checkmark$ Nadamos, es como nuestro mar

Y el frio no es impedimento para Uds.

$\checkmark$ Tiene sus momentos en el año, por temporadas

$\checkmark$ Por Junio frio es

Y más o menos a que hora Uds. Creen que se pueda ir para hacer un paseo en moto acuática en el lago Titicaca

$\checkmark$ Como que antes de las 3 de la tarde, porque después de ahí el viento 
$\checkmark$ Desde las 10 a 2 de la tarde, después ya hace frio

Y cuanto creen que Uds. podrían pagar por el alquiler de motos acuáticas en el lago, un promedio de cuanto creen

$\checkmark$ No hay motos acuáticas acá

Pero si implementaríamos un servicio de motos acuáticas cuanto pagarían, 40, 60, 80 soles

$\checkmark$ Por el tiempo sería

$\checkmark$ Depende del lugar y el tiempo

$\checkmark$ Depende del tiempo

$\checkmark \quad 10$ soles a 20 soles sería lo accesible porque después no van a querer pagar más

$\checkmark$ A pesar que los turistas si pagarían más

$\checkmark$ Claro sería un precio a las personas que viven y son de acá de Puno y otro para los turistas

De lo que se trata el proyecto es alquilar motos acuáticas mediante un circuito turístico, nosotros desde Puno los llevamos a Charcas en una minivan en un bus y de ahí les damos todo el servicio turístico que es las motos acuáticas, es un circuito de media hora, una hora, lo ven viable que sea así el proyecto

$\checkmark$ Podría ser

Les gustaría, estarían dispuestos a ir a pasear ahí en la moto acuática

$\checkmark$ Sí

$\checkmark$ Sí de acá lo haría para que vayan allá, allá por ejemplo en Charcas hay un hotel, se estacionan y si le ponen carros, pero llevarlo de ahí en carretera y traerlos de ahí a la ciudad no creo

Y adicionalmente a eso les gustaría que se añada servicios de alimentación, circuitos, hospedaje, quisieran un camping por ejemplo con sus amigos en Charcas

$\checkmark \quad$ Si eso si me gustaría

$\checkmark$ Alimentación puede ser 
$\checkmark$ Camping también

$\checkmark$ Como un paquete

Con que frecuencia más o menos utilizarían el servicio, una vez al mes, semanal

$\checkmark$ Quincenal puede ser

$\checkmark$ Una vez al mes

Como un viaje puede ser también de trabajo, tal vez

$\checkmark$ Si es feriado, como normalmente lo hacen

$\checkmark$ No van a salir todos los fines de semana

$\checkmark$ Una vez al mes

Gracias, muchas gracias por sus palabras 
Entrevista 01

Lugar: Cal. San Francisco 206 - Arequipa Hora: 11:00 am 18/01/2017

Gerente Ventas: Carmela Llerena Concha

Empresa: Colores Arequipa SAC (“C” - Entrevistado)

Richard Medrano ("R" - Entrevistador)

R: Hola que tal me llamo Richard Medrano, quisiera que primero te presentes. Digas tu cargo, años en el sector, etc.

C: Mi nombre es Carmela Llerena Concha, yo estudie en Lima en una escuela de turismo hace 35 años. Trabaje en Solmaltur, ese fue mi primer trampolín. Después inicie una empresa propia donde tenemos 25 años como empresa. La empresa tiene dos áreas la primera es el turismo receptivo la cual se encarga Natasha y el turismo internacional quien lo ve mi persona. Si hacemos muchos paquetes hacia salidas internacionales, como también para el mercado receptivo de Europa a Perú y está muy orientado al mercado francés.

R: ¿Cuál es la perspectiva de sector turismo?

C: El turismo en general en el Perú va en crecimiento a comparación de diez a quince años atrás. Mejora mucho ya que, el turismo no solamente es el turismo económico sino hoy en día la gente se proyecta, se organiza, con mucha anticipación lo cual le permite acceder a buenas ofertas y promociones en hotelería. El mercado europeo es muy bueno para Perú pero este año se proyecta a crecer entre un $5 \%$ a $10 \%$ más del año pasado. Siempre se crece un $10 \%$ guiándonos al ingreso de turistas que llegan a Cusco.

R: ¿Consideras a Perú como un lugar potencial para turismo de aventura? 
C: Definitivamente sí. Perú es un país muy rico en cultura no solo pensando en la parte de entrada en Machu Picchu sino también caminatas hacia Huayna Picchu, Choquequirao, que está en un valle entre el Apurimac y Cusco. Es precioso pero todavía no cuenta con la estructura necesaria. El tema es que se tienen que provisionar muchas cosas son unas horas en caminata, otras horas a caballo. Se tiene en Puno, en la Selva, en Cusco no solo es Machu Picchu, se tiene Maras, Tambomachay, cerro de colores. El Perú es muy rico en turismo capaz falta más apoyo del Gobierno para fomentar esto.

R: ¿Consideras a Puno una zona con potencial para turismo de aventura?

C: Si, en Puno se vende mucho el turismo vivencial como la isla de Los Uros. Eso atrae más a un turista extranjero, son pocos los peruanos que se atreven a realizar turismo vivencial. Eso está muy fuerte en el mercado pero al extranjero le gusta el turismo vivencial, la aventura, tener muchas caminatas, el compartir, etc. Uno es un destino precioso. No solo hay eso también hay Lampa que le dicen Roma chiquita. Cada pueblo que hay alrededor de Puno es espectacular.

R: ¿Hay algunas otras zonas en Puno?

C: Lo más fuerte es en Choquequirao, que es el valle entre Apurimac y Cusco. Cusco es lo más fuerte En Puno básicamente es el turismo vivencial. Sé que hay nuevas rutas pero no las tengo muy actualizada la oferta pero te la puede brindar.

R: ¿Considera que el turista local y nacional tiene interés en este tipo de circuitos? C: Si hay un grupo de gente mayor que les gusta el turismo de aventura y jóvenes también. Conozco un grupo de médicos entre 60 a 70 años que busca ese tipo de servicio. Que son gente dedicada al deporte, les gusta y como parte de ese deporte es la aventura. Toman la mochila y le dan. Lo que pasa que el turismo de aventura no nos arriesgamos con la misma facilidad porque 
sabemos que por conocimiento que la estructura no está en buenas condiciones. Hay que tomar muchas cosas, cuando llegas, cuanto tiempo es, si tienes agua, etc. Tienes que ir desde acá muy equipado y para eso tienes que promocionar con la gente. Pero si yo no tengo del otro lado la gente profesional para el tema no puede ser un viaje exitoso. Tú tienes que dar la seguridad del caso al cliente, tener la logística bien hecha, abastecimiento, etc.

\section{Explicación del Proyecto}

R: El proyecto consiste en explotar los paisajes relacionados al Lago Titicaca, se realizará el circuito en una zona entre Juliaca y Puno llamado Chifrón. Se realizara el traslado de la ciudad al sitio. Ni bien se llegue a la zona se realizara trecking o bicicleta de montaña y se complementará el servicios con el alquiler de motos acuáticas.

¿Conoces alguna alternativa similar a la mencionada?

C: No, pero te ayudo a pasarte la información de un especialista en esos paquetes.

$\mathrm{R}:$ ¿Consideras atractivo para tus clientes?

C: Yo creo que es algo muy simpático. Puno ha crecido bien en hotelería, que te garantice una estructura buena y puedas regresar a descansar también. Y cuidar, es trabajar mucho a nivel con las autoridades ya que, yo conozco la parte del lago hacia Bolivia y está muy bien cuidado por las autoridades. Todas esas cosas son para trabajar con cada autoridad del lugar para que haga mantenimiento a la zona. Si es una zona virgen y que recién se está empezando a promocionar hay que ver que las autoridades garanticen la seguridad y mantenimiento. La diferencia es que Bolivia tiene mejor cuidado el Lago. Si hay las autoridades locales trabajan en conjunto con las agencias locales quien son los que organizamos la parte de aventura y cuidamos como debe ser eso es un destino hermoso. Definitivamente lo recomendaría. 
R: ¿Por el servicio cuanto podrían pagar?

C: Depende del tiempo que tomes. El precio es de acuerdo a toda la infraestructura y logística que uses. No te puedo dar un precio porque tendría que revisarlo pero te puedo alcanzar alternativas parecidas para poder medir un costo.

R: ¿Qué obstáculo verías si se implementa el proyecto? Mencionaste a las autoridades ¿Por qué?

C: Las autoridades se sienten dueños de la zona. Si ellos no dan el pase no te dejan. Te cobran un ingreso ya que, tiene que dar un beneficio a la sociedad

R: ¿Si brindaras el servicio cual sería tu principal expectativa o preocupación?

C: Preocupación es el mejor servicio. Expectativa, si das un buen servicio y un precio competitivo para seguir promocionando

R: ¿Cuál sería un precio competitivo?

C: Para un turista un paquete sin boletos aéreos, y la categoría del hotel podría esta entre USD 140 a USD 180. Mucho depende de la categoría y servicios que brindes. Mayor servicio mejor precio. El mercado es para todos para económico y el caro.

R: ¿Cuál sería la mejor forma de publicitar el servicio?

C: La mejor forma ahora son los medios sociales y el boca a boca. El mejor de todos es el boca a boca, un periódico ó una nota periodística lo leen unos pocos pero es más eficiente que tus clientes te refieran.

R: En su experiencia en grupos de turistas nacionales que ha atendido. ¿Cuántas personas de un grupo de 10 turistas considera usted que le gusta realizar actividades al aire libre? 
C: Es muy variable no hay una promedio exacto pero por propia experiencia y debido a que la mayoría de turistas nacionales que atiendo proviene de Lima diría que entre 6 a 7 personas si disfrutan de un tour con actividades al aire libre. No te diría más ya que, un limeño es más citadino.

Entrevista 02

Lugar: Casona Hotel Fecha: 17 de Diciembre Hora: 11:00 am

William Bellido ("W" - Entrevistado)

Gianfranco Arana (“G” - Entrevistador)

G: Buenos Días nos encontramos haciendo la entrevista al Sr. William que es experto en turismo en la ciudad de Puno somos alumnos de la USIL de la Maestría de ciencias empresariales, coméntame que sitios turísticos tenemos en Puno para visitar

W: Los más visitados son las Islas los Uros, Amantani y Taquile y lo que es Sillustani, lo que no se conoce tanto o lo que no está muy promocionado es Tiahuanaco deberían ir por ahí.

G: Como circuitos turísticos siguiendo tres sitios también hay, coméntanos

W: Si lo básico para conocer en Puno como circuito turístico es la ciudad, las islas los Uros Amantani en un día, como también puede irse dos o tres días a Sillustani que es lo más conocido

G: Las persona que llegan a Puno o las que viven, como obtienen información acerca de estos circuitos mediante que organismos

W: Bueno uno tal como en el hotel todos son turismo receptivo directamente de la página web o captados por agencia de viajes y en tripadvisor todos ven ahí la información de Puno. 
G: un turista más o menos cuantos días se quedan en la ciudad de Puno

W: el promedio es uno, ahora se ha incrementado a 1 día y medio pero dos días es difícil porque Puno es una ciudad de paso.

G: la persona que vive en Puno o turista nacional cuanto está dispuesto a pagar por un circuito o ir a un lugar turístico

W: En realidad los precios varían y la información está por todo lado, antes normalmente llegaban directamente acá y se podría cobrar literalmente lo que uno pudiera y obtener una ganancia del 4050 hasta $60 \%$ de lo normal, pero ahora la información y competencia en turismo es tan variada que pueden pagar yo creo hasta un margen de ganancia de un $20 \%$ o inclusive si uno va al puerto directamente va encontrar a costos bajos de 10 o 15 soles.

G: el servicio turístico a las playas que tiene el Lago Titicaca hay o es muy poco solicitado

W: se está incrementando ahora bueno lo más conocido es charcas para nosotros, pero ahora todos se están yendo al lado de Capachica es una zona donde el lago es cálido y la arena blanca

G: ¿Cuáles son los factores influyentes para que una persona visite Puno o visite las playas del lago

W: realmente las playas promocionadas no están, y la información no es muy amplia, lo que ha incrementado el turismo nacional es gracias a Tu que planes y la página de Promperu pero no vienen exclusivamente a ver las islas de Puno, lo que sí es conocido es la Fiesta de la Candelaria.

G: los habitantes de Puno si hacen turismo o muy poco 
W: si lo que más hacen es los uros un solo día y bueno Chucuito.

G: hablando de nuestro proyecto, es alquiler de motos acuáticas mediante un circuito turístico, que te parece la idea del alquiler

W: mire en Charcas van regular personas porque estamos a 20 o 30 min y de Acora son 30 min, lo ideal sería estar en el puerto y de ahí partir, pero si es para turistas estaría perfecto porque en Charcas hay un hotel de lujo que se podría aprovechar

G: pero para el turista nacional o habitante de Puno si se les da la movilidad de llevarlos y recogerlo sería ideal

W: si es factible, esto va ligado al costo ya que el poder adquisitivo ha subido pero no tanto, pero si es factible hacer esto

G: y hablando del costo , un costo aproximado por un circuito de media hora en el lago en motos acuáticas cuanto seria para ti el costo ideal

W: mire no sabría decirle un costo especifico con motos ya que no se el costo de tener una ni las ganancias pero estaría entre 40 y 50 soles por media hora como mínimo.

G: que te parece la idea del turismo de aventura con motos acuáticas por ese lado.

W: en realidad en Puno no hay seria novedoso y muy atractivo porque lo único que hay es Kallac, las lanchas y canotaje que es lo más común

G: en tu experiencia de un grupo de 10 personas para un turista local ¿Cuántas consideras que les gusta realizar actividades al aire libre?

W: un turista regional o local de Puno si tiene mucha predisposición a realizar actividades al aire libre. Ello debido a que gran parte de los jóvenes al menos de la ciudad de Puno estudia o tiene amigos estudiando carreras relacionadas al turismo y parte de su esquema de estudio es 
realizar viajes internos y con mucha actividades al aire libre. Te diría con seguridad que 8 de cada 10 disfruta realizar actividades al aire libre.

G: esto sería todo, muchas gracias

W: Gracia a ti 
Entrevista 03

Lugar: Calle San José 207 - Arequipa Hora: 18:00 pm 02/05/2018

Gerente General: Carlos

Empresa: Casona Plaza ("C" - Entrevistado)

Ángel Jara (“A” - Entrevistador)

A : Buenas noches somos alumnos de la maestría de la San Ignacio de Loyola estamos siendo un proyecto de plan de negocios de servicios de motos acuáticas, quiera por favor de te des a conocer, quisiera saber cuánto tiempo tienes en este sector lógicamente de turismo, cual es tu cargo en la empresa y cuál es tu profesión.

C: Buenas noches, mi nombre es Carlos, tengo 10 años en el sector turismo en la agencia más o menos cinco años, mi profesión es ingeniero comercial y estoy abocado al sector turismo.

A: Puntualmente respecto al tema de turismo quisiéremos saber ¿Cómo ves la perspectiva del crecimiento de turismo?

C: Las perspectivas son muy buenas sabiendo que están más promocionando los destinos del Perú, tanto en las ferias nacionales como ferias internacionales, exclusivamente en la parte sur que son Cuzco, Arequipa y Puno, entonces hay una importante expectativa de crecimiento para los años que vienen.

A. ¿Hay algún porcentaje de crecimiento que más o menos que tú estimas i

C: Más o menos es un quince a veinte por ciento.

A: ¿Consideras al Perú como un lugar potencial para desarrollar turismo de aventura? 
C: Claro, falta mucho explotar a quien en el país, pero si hay mucho potencial y lugares como para hacer trekking, canotaje que no son explotados, tanto como en Arequipa, Cuzco, Puno incluso en Lima, es decir tiene mucho para explotar todavía.

A: Específicamente respecto a Puno, ¿consideras un lugar propicio para desarrollar turismo de aventura?

C: Sí claro, Puno es un lugar donde hay bastante por explotar en especial en el sector de aventura, teniendo el lago, las montañas se puede explotar mucho más.

A: ¿Qué circuitos de viajes son las que ofreces en tu agencia de viajes y cuáles son las más solicitadas?

C: Más que todo lo que se vende es para Puno en especial el canotaje, cajak en el lago, eso solicitan generalmente turistas jóvenes, hay un nuevo tour de sobre vuelo sobre el lago es algo nuevo que está creciendo poco a poco, luego son los tour convencionales que son los uros, las islas.

A: ¿Consideras que el turista nacional y local tienen interés en este tipo de circuitos?

C: $\mathrm{Si}$, yo creo que si más que todo los extranjeros, porque ellos buscan más la aventura, los nacionales son más convencionales, pero yo creo que en los extranjeros es un sector al que pueden avocarse porque les gusta más la aventura.

A: Ahora te paso a explicar brevemente el proyecto básicamente nuestro servicio consiste en captar a las personas interesadas, transportarlas en una minivan hasta la zona del circuito que es Capachica que es una zona muy comercial por estar entre Puno y Juliaca, definimos ese lugar porque consideramos que ahí se puede desarrollar altamente el turismo de aventura, llegamos a Capachica ahí se tiene dos opciones: caminar o ir en bicicleta el tiempo es de quince y veinte 
minutos respectivamente, llegar a un punto donde propiamente haremos el circuito de motos acuáticas entre media hora o cuarenta minutos y de ahí retornar a Puno ese es puntualmente el circuito que vamos a realizar y ahora ¿conoces algunas empresa que realizan este tipo de circuito o servicio de motos acuáticas en Puno?

C: En Puno, no nunca escuche sobre ese servicio.

A: ¿De alguna empresa que ofrece servicios similares?

C: Lo que he escuchado es cajak, pero de motos aún no.

A: ¿Crees que sería atractivo para tus clientes optar por este nuevo servicio y por qué?

C: Sería una buena opción ya que es algo nuevo, ya que aún no se ha visto en Puno y más que todo los turistas buscan siempre vivir esas nuevas experiencia que son únicas y se llevarían una nueva experiencia para ellos.

A: ¿Cuánto crees que pagarían por el servicio?

C: Uno cuarenta o cincuenta dólares en promedio.

A: ¿Que obstáculos crees que podría haber para desarrollar el proyecto?

C: Puede ser los permisos que hay que solicitar, la municipalidad el lugar de donde se desarrollara el circuito o algún tema de seguro para los turistas, se debería incluir un seguro porque eso es importante para los clientes.

A: Si nos ofrecemos como operadores de este servicio, ¿ofrecerías a tus clientes y cual sería tu principal expectativa y tu principal preocupación?

C: Si podría ofrecerlo, mi expectativa sería que los turista se puedan llevar una buena experiencia del servicio y sientan que valió lo que pagaron, la preocupación sería el tema de los 
accidentes es por eso que te comente brindarles un seguro para que ellos estén cubiertos en caso que suceda algo como un accidente en el trayecto o en el mismo lago.

A: ¿Cuál consideras que es la mejor forma de publicitar esos servicios de aventura?

C: Lo más importante sería publicitarlo en las agencias de viajes porque son los que más dan a conocer los servicios que se dan en Puno, también pueden promocionarlo por redes sociales, por ferias nacionales para así ser más conocido.

A: Gracias por tu tiempo y compartirnos tu experiencia. 
Entrevista 04

Lugar: Calle Alvarez Thomás 435- Arequipa Hora: 18:00 pm 04/05/2018

Jefa De Ventas: Paola

Empresa: Plaza Hotel Colonial ("P” - Entrevistado)

Ángel Jara ("A" - Entrevistador)

A: Buenas noches, somos alumnos de la universidad San Ignacio de Loyola estamos realizando un plan de negocios para nuestra maestría, quisiéramos saber cuál es tu nombre, tu cargo aquí en la empresa y tus años de experiencia en el rubro de turismo.

P: Mi nombre es Paola, trabajo unos diez años en el sector de turismo tengo el cargo de jefa de ventas, mi profesión es de turismo y hotelería.

A: Respecto al sector de turismo ¿cómo ves el crecimiento de este sector?

P: A nivel de Perú hay una demanda, quizás de un diez o quince por ciento por parte de turistas extranjeros y nacionales.

A: ¿Consideras al Perú como un lugar potencial para desarrollar turismo de aventura?

$\mathrm{P}$ : Si, considero que hay potencial porque los turistas van en busca de nuevos destinos donde puedan desarrollar ese tipo de turismo de aventura como trekking, cajak, canotaje y otros.

A: Respecto a Puno ¿crees que es un lugar propicio para hacer turismo de aventura?

P: No he visto o mucho en Puno que ofrezcan este tipo de servicios de aventura, sino sólo he escuchado del turismo convencional como las islas, Sillustani, turismo vivencial, pero propiamente de aventura no. 
A: ¿Que tipo de circuitos son los más solicitados por los turistas en la agencia de viaje?

P: Canotaje, trekking, etc.

A: ¿Consideras que el turista nacional y local tiene interés en este tipo de circuitos?

P: Sí, hay una demanda hay un sector que está interesado por este tipo de circuitos y este tipo de turismo de aventura.

A: Paso a explicarte el desarrollo de nuestro plan de negocios que consiste en un servicio de motos acuáticas en el lago Titicaca en Puno, puntualmente es en la zona de Capachica que es entre la zona de Puno y Juliaca es una zona altamente comercial y se ha visto que no hay mucha demanda de turismo por esa zona y nuestro objetivo es potencializarla y consideramos que el servicio es nuevo, puesto que lo más común en Puno son los Uros, el Sillustani , July, pero no hay nada de turismo de aventura. Nuestro servicio consiste en captar los turistas desde Puno transportarlos hasta Capachica llegado a un punto tendrá la opción de caminar o ser ruta con bicicleta luego ambos coinciden en un punto donde iniciará el circuito de motos acuáticas por media hora hora o cuarenta minutos, terminado el circuito volveremos a transportarlos hasta el centro de Puno.

Ahora ¿conoces alguna empresa que brinden estos servicio en Puno?

P: Jumbo Travel y Lancha veloz brindan servicios, pero más que todo de servicio de turismo convencional y circuitos de cajak.

A: ¿Conoces alguna empresa en Puno que ofrezca un similar servicio del proyecto descrito?

P: No, no he escuchado un servicio similar al que quieren ofrecer. 
A: ¿Crees que sería atractivo para tus clientes contar con este tipo de servicio y ofrecerlos?

P: Si es algo novedoso yo creo que sí, porque el turista busca circuitos novedosos donde pueda compartir nuevas experiencia.

A: ¿Alguna vez te han solicitado algún servicio de motos acuáticas?

P: Nunca lo han solicitado. Pero se les puede dar como alternativas puesto que es novedoso.

A: Según lo explicado servicio ¿cuánto crees que podrían pagar por el servicio brindado?

P: Quizás unos ochenta o setenta soles.

A: ¿Crees que en Puno habría alguna dificulta u obstáculo para ejecutar el proyecto que te describimos?

P: Se tendría que consultar a los pobladores, hacerles una encuesta para saber si están de acuerdo o no, y otro punto sería el tema de los permisos de las autoridades, pero mientras el poblador este de acuerdo no puede haber inconveniente, claro siempre y cuando ellos obtengan algún beneficio.

A: En el caso de ser operadores de este servicio ¿ofrecerías a tus clientes y cual sería tu principal expectativa y tu principal preocupación?

P: La expectativa sería que es un circuito novedoso y va hacer atractivo para los turistas y algo que obstaculice sería el tiempo que tiene los turistas para realizar el circuito, puesto que muchos vienen con tiempos ya programados para cada actividad.

A: ¿Cuál crees que sería la mejor forma de publicar este servicio? 
P: Seria por redes sociales, también podría ser por trifoliados, publicitarlos por medio de la municipalidad.

A: Gracias por tu tiempo. 


\section{REFERENCIAS}

Benassini, M (2014). Introducción a la Investigación de Mercados (3ra ed.) México, DF.:

Pearson Educación

Dessler, G. (2015). Administración de recursos humanos (14 Ed.). México: Editorial

Pearson

Koontz, H. (2013). Elementos de administración (8va Ed.). México DF: Ediciones McGraw-Hill Interamericana

Moran F, J. (2012) El desarrollo personal, clave del éxito en la actividad turística y hotelería (12 Ed.). Lima: Editorial Interamericana

Kotler, P. \& Keller, K. (2012). Dirección de Marketing (14va ed.). México, DF.: Pearson Educación

Kotler, P. \& Armstrong, G. (2012). Marketing (14va ed.) México, DF.: Pearson Educación

SAPAG. N .(2013). Preparación y evaluación de proyectos ( 2da Ed.). BogotáColombia: Editorial McGraw-Hill Interamericana

Sweeney A. \& Camm J, (2016). Estadística para Negocios y Economía (12va ed.) México, DF: Cengage Learning Editores

Talavera R. (2013). 30 años de turismo en el Perú: la crónica del turismo en el Perú narrada por sus propios protagonistas. CANATUR Lima-Perú.

Thompson, A. (2012). Administración estratégica teoría y casos (18 Ed.). México: Ediciones McGraw-Hill Interamericana 


\section{REFERENCIAS ELECTRÓNICAS}

ANDINA. (2016). Estiman que turismo en Puno crecerá en 6\% por Fiestas Patrias. Recuperado de: http://www.andina.com.pe/agencia/noticia-estiman-turismo-Puno-crecera-6fiestas-patrias-620014.aspx

American Marketing Association (2014). AMA: Definition of Marketing. Recuperado 05 de diciembre, 2016 de http://www.marketing-dictionary.org/Marketing+research

Arellano Markteting (2016.) Perfil del Turista de Aventura. Recuperado 05 de diciembre, 2016 de http://www.arellanomarketing.com/inicio/estilos-de-vida/

ATDI (2016). Adventure tourism development index:an adventure travel scorecard. Recuperado 05 de diciembre, 2016 de https://tia.org.nz/assets/Uploads/2016-adventure-tourismdevelopment-index.pdf

Banco Mundial (2016). PIB per cápita (US\$ a precios actuales). Recuperado 05 de diciembre, 2016 de http://datos.bancomundial.org/indicador/NY.GDP.PCAP.CD

Diario Gestión (2015). Perú es el tercer país de Sudamérica con más potencial en turismo de aventura. Recuperado 05 de diciembre, 2016 de http://gestion.pe/economia/perutercer-pais-sudamerica-mas-potencial-turismo-aventura-2128014

Diario Gestión (2015). Mincetur: Crecimiento del turismo en el Perú es tres veces el promedio mundial. Recuperado 05 de diciembre, 2016 de http://gestion.pe/economia/minceturcrecimiento-turismo-peru-tres-veces-promedio-mundial-2070967 
Diario La República (2016). Mincetur: número de turistas extranjeros se incrementó en el 2015. Recuperado 05 de diciembre, 2016 de http://larepublica.pe/turismo/rumbos-aldia/741811-mincetur-numero-de-turistas-extranjeros-se-incremento-en-el-2015

Ferrero, A (2015). Estabilidad política y económica en Perú. Revista América Economía. Recuperado 05 de diciembre, 2016 de http://www.americaeconomia.com/economiamercados/comercio/estabilidad-politica-y-economica-en-peru

INEI (2016). Estadísticas Población y Vivienda. Recuperado 05 de diciembre, 2016 de http://www.inei.gob.pe/estadisticas/indice-tematico/poblacion-y-vivienda/

Mercados\&Regiones (2016). PBI per cápita y preferencia electoral en la Macrorregión Sur. Recuperado 05 de diciembre, 2016 de http://mercadosyregiones.com/pbi-per-capita-ypreferencia-electoral-en-la-macrorregion-sur/

MINCETUR (2015). Turismo. Recuperado de: http://www.mincetur.gob.pe/turismo/ MINCETUR (2016). Visit Peru. . Recuperado 05 de diciembre, 2016 de https://issuu.com/visitperu/stacks

MINCETUR (2016). Centro de información Mincetur. . Recuperado 05 de diciembre, 2016 de http://datosturismo.mincetur.gob.pe/appdatosTurismo

PROMPERU (2008). Perfil del Turista de Aventura. Recuperado 05 de diciembre, 2016 de http://www.promperu.gob.pe/TurismoIN/Uploads/temp/Uploads_mercados_y_segmentos_segme ntos_1005_Publicacion-Perfil-del-Turista-de-Aventura.pdf

PROMPERU (2013). Turismos en cifras. Recuperado de: http://www.promperu.gob.pe/TurismoIN/Sitio/TurismoCifras 
PROMPERU (2015). Publicación Perfil del Vacacionista Nacional 2015. Recuperado 05 de diciembre, 2016 de http://www.promperu.gob.pe/TurismoIn/Sitio/VisorDocumentos?titulo=Tips\%20Perfil\%20Vaca cionista\%20Nacional\%202015\&url= /Uploads/perfiles_vacac_nac/1035/Tips\%20PVN2015\%20 Consolidado1.pdf\&nombObjeto=PerfVacacionistaNac\&back=/TurismoIN/Sitio/PerfVacacionist aNac\&issuuid=

Región Puno (2013). Plan estratégico regional de turismo Puno- PERTUR 2021. Recuperado 05 de diciembre, 2016 de http://www.regionPuno.gob.pe/descargas/planes/2013plan-estrategico-institucional-turismo-pertur-al-2021.pdf

Revista Semana Económica (2015). ¿Qué le espera a la economía peruana en el 2016 ? Recuperado 05 de diciembre, 2016 de http://semanaeconomica.com/article/economia/macroeconomia/175765-que-le-espera-a-laeconomia-peruana-en-el-2016/

Ugalda, N \& Balbastre, F (2013). Investigación cuantitativa e investigación cualitativa: buscando las ventajas de las diferentes metodologías de investigación. Recuperado 05 de diciembre, 2016 de http://revistas.ucr.ac.cr/index.php/economicas/article/viewFile/12730/11978

UNWTO (2016). El turismo internacional continúa creciendo por encima de la media en los cuatro primeros meses de 2016. Recuperado 05 de diciembre, 2016 de http://media.unwto.org/es/press-release/2016-07-19/el-turismo-internacional-continua-creciendopor-encima-de-la-media-en-los-c

UNWTO (2016). Tourism and Culture Partnership in Peru. Recuperado 05 de diciembre, 2016 de http://www.e-unwto.org/doi/pdf/10.18111/9789284417599 